February 1998

\title{
Qualitative Risk Assessment for an LNG Refueling Station and Review of Relevant Safety Issues
}

\section{RECEIVED \\ JUL $0^{9} 1998$ \\ OSTI}

Nathan Siu

J. Stephen Herring

Lee Cadwallader

Wendy Reece

James Byers

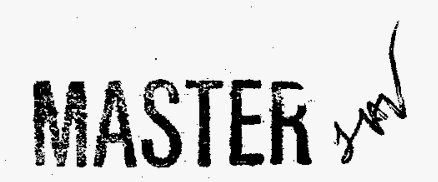

DISTAIBUTION OF THIS DOCUMENT IS UNLMTTED

LOCKHEED MARTIN 


\section{DISCLAIMER}

This report was prepared as an account of work sponsored by an agency of the United States Government. Neither the United States Government nor any agency thereof, nor any of their employees, make any warranty, express or implied, or assumes any legal liability or responsibility for the accuracy, completeness, or usefulness of any information, apparatus, product, or process disclosed, or represents that its use would not infringe privately owned rights. Reference herein to any specific commercial product, process, or service by trade name, trademark, manufacturer, or otherwise does not necessarily constitute or imply its endorsement, recommendation, or favoring by the United States Government or any agency thereof. The views and opinions of authors expressed herein do not necessarily state or reflect those of the United States Government or any agency thereof. 


\section{DISCLAIMER}

Portions of this document may be illegible in electronic image products. Images are produced from the best available original document. 
INEEL/EXT-97-00827 rev. 2

\title{
Qualitative Risk Assessment for an LNG Refueling Station and Review of Relevant Safety Issues
}

\author{
Nathan Siu \\ J. Stephen Herring \\ Lee Cadwallader \\ Wendy Reece \\ James Byers \\ Published February 1998 \\ Idaho National Engineering and Environmental Laboratory \\ Alternate Fuels Program \\ Lockheed Martin Idaho Technologies Company \\ Idaho Falls, Idaho 83415
}

Prepared for the

U.S. Department of Energy

Under DOE Idaho Operations Office

Contract DE-AC07-94ID13223 


\section{ABSTRACT}

This report is a qualitative assessment of the public and worker risk involved with the operation of a liquefied natural gas (LNG) vehicle refueling facility. This study includes facility maintenance and operations, tanker truck deliveries, and end-use vehicle fueling; it does not treat the risks of LNG vehicles on roadways. Accident initiating events are identified by using a Master Logic Diagram, a Failure Modes and Effects Analysis, and historical operating experiences. The event trees were drawn to depict possible sequences of mitigating events following the initiating events. The phenomenology of LNG and other vehicle fuels is discussed to characterize the hazard posed by LNG usage. Based on the risk modeling and analysis, recommendations are given to improve the safety of LNG refueling stations in the areas of procedures and training, station design, and the dissemination of "best practice" information throughout the LNG community. 


\section{SUMMARY}

This report is a qualitative assessment of the public and worker risk involved with the operation of a liquefied natural gas (LNG) vehicle refueling facility. A cryogenic fuel for vehicles is very different from the petroleum fuels presently in use. That is, LNG rapidly boils to a gas, it can cause cryogenic burns from skin contact, and exposure can cause brittleness in many engineering materials. This study includes facility maintenance and operations, tanker truck deliveries, and end-use vehicle fueling; it does not treat the risks of LNG vehicles on roadways. The qualitative risks have been outlined in Tables 1-2 and 1-3.

The report gives a description of refueling facilities visited and identifies the technologies involved for system familiarization. Then, accident initiating events are identified by using a Master Logic Diagram, a Failure Modes and Effects Analysis, and historical operating experiences. The event trees were drawn to depict possible sequences of mitigating events following the initiating events.

The phenomenology of LNG and other vehicle fuels is discussed to characterize the hazard posed by LNG usage. Physical parameters, methane flammability, and LNG issues such as weathering, rollover and geysering are discussed. Distinctions in phenomena between LNG peakshaving plants and refueling stations are explained and evaluated:

Based on the risk modeling and analysis, recommendations are given in the conclusions section. These recommendations to improve the safety of LNG refueling stations are in the areas of procedures and training, station design (especially leak pathway analysis), and fostering the dissemination of "best practice" information throughout the LNG community. 
FOREWORD

This risk assessment cites several past incidents in the use and handling of liquefied natural gas. We have relied on literature searches, the U.S. Department of Transportation database, and the memory of experts in the LNG field to gather information on these incidents. If any readers of this report know of incidents not cited and can provide information on such incidents, they are invited to contact Dr. Steve Herring, 208-526-9497, sth@inel.gov or Lee Cadwallader, 208-526-1232, lcc@inel.gov.

Furthermore, if any readers can suggest other members of the LNG community to whom this report should be sent, please notify us at the phone number or e-mail address listed above.

iv 


\section{ACKNOWLEDGMENTS}

The support of Robert Helton (U.S. Department of Energy), Richard Rice and Bruce Wilding (Lockheed-Martin Idaho Technologies Co.) are gratefully acknowledged. This report was prepared under the U.S. Department of Energy (DOE) Idaho Field Office Contract DE-AC07-94ID13223. The opinions, findings, conclusions, and recommendations expressed herein are those of the authors and do not necessarily reflect the views of the DOE. 


\section{ACRONYMS}

\begin{tabular}{ll} 
ACGIH & American Conference of Governmental Industrial Hygienists \\
ANS & American Nuclear Society \\
ASME & American Society of Mechanical Engineers \\
ATA & American Trucking Association \\
BLEVE & Boiling Liquid Expanding Vapor Explosion \\
CAI & LNG Release due to Construction Accident, Isolable \\
CAU & LNG Release due to Construction Accident, Unisolable \\
CFR & Code of Federal Regulations \\
CGA & Compressed Gas Association \\
CNG & Compressed Natural Gas \\
DBT & Ductile Brittle Transition \\
DMIM & Design, Manufacturing, Installation, or Maintenance \\
DOT & Department of Transportation (federal) \\
ED & Early Detection \\
EE & External Event \\
ER & Earty Recovery \\
EUV & End Use Vehicle \\
FCV & Flow Control Valve \\
FMEA & Failure Modes and Effects Analysis \\
GAO & Government Accounting Office \\
GF & Guaranteed Failure' \\
GRI & Gas Research Institute \\
HF & Hose Failure \\
IE & Initiating Event \\
LGFSTF & Liquefied Gaseous Fuel Spill Test Facility \\
LNG & Liquefied Natural Gas \\
LPG & Liquefied Petroleum Gas (usually propane) \\
LR & Late Recovery \\
MLD & Master Logic Diagram \\
NGV & Natural Gas Vehicle \\
OD & Driveaway (operational event) \\
OF & Filling Error (operational event) \\
OM & Maintenance Error (operational event) \\
PFI & Pipe Failure, Isolable \\
PFU & Pipe Failure, Unisolable \\
PPE & Personal Protective Equipment \\
PRA & Probabilistic Risk Assessment \\
PSV & Pressure Safety Valve \\
PT & Pressure Tank \\
RC & Release Containment (i.e. the release is contained in a secondary \\
RV FO & Relief Valve Fails Open \\
RV FTO & Relief Valve Fails to Open \\
SFI & Seal Failure, Isolable \\
SFU & Seal Failure, Unisolable \\
SI & Secondary Impact Prevention \\
ST & Storage Tank \\
& \\
\hline
\end{tabular}




$\begin{array}{ll}\text { STF } & \text { Storage Tank Failure } \\ \text { THRP } & \text { Tetrahydrothiophene } \\ \text { TLV } & \text { Threshold Limit Value } \\ \text { TTF } & \text { Truck Fuel Tank Failure } \\ \text { TIT } & \text { Tanker Truck Tank Failure } \\ \text { UVCE } & \text { Unconfined Vapor Cloud Explosion } \\ \text { USNRC } & \text { U.S. Nuclear Regulatory Commission } \\ \text { VA } & \text { LNG Release due to Vehicular Accident } \\ \text { VF } & \text { Valve Failure } \\ \text { VFI } & \text { Isolable Valve Failure } \\ \text { VFU } & \text { Unisolable Valve Failure }\end{array}$




\section{CONTENTS}

ABSTRACT

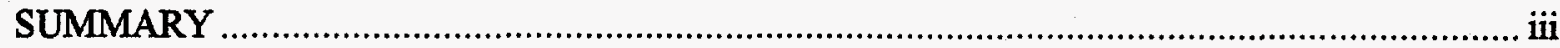

FOREWORD

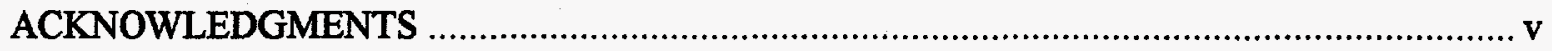

ACRONYMS

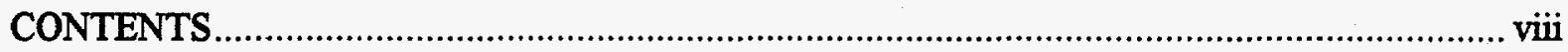

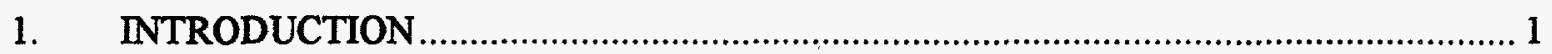

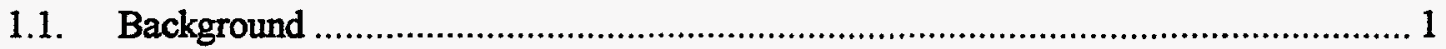

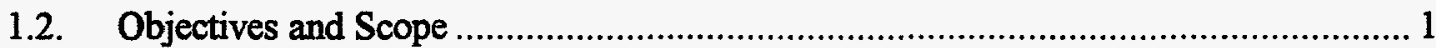

1.3. Summary of Technical Approach …………………........................................ 2

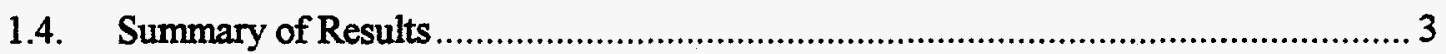

1.5. Overview of Report.................................................................................... 6

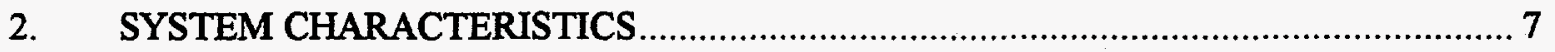

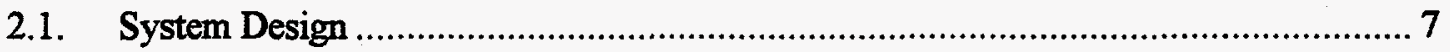

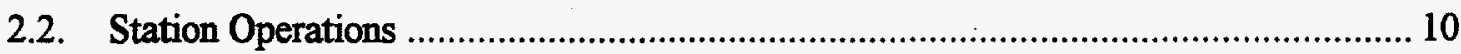

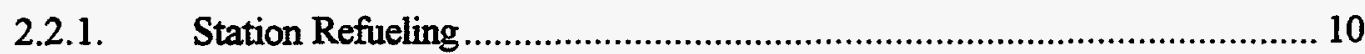

2.2.2. End User Vehicle Refueling ............................................................... 10

2.2.3. Other Activities ………………………………………...................... 12

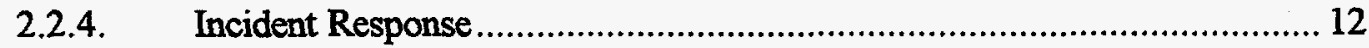

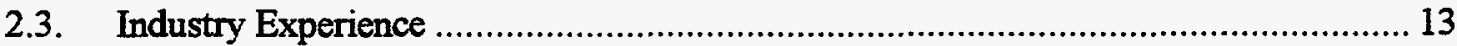

2.3.1. Experiences at Refueling/Maintenance Facilities ..................................... 13

2.3.2. LNG Truck Tankers .......................................................................... 15

2.3.3. Other LNG Experience ......................................................................... 18 


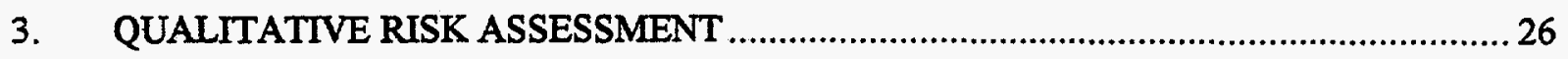

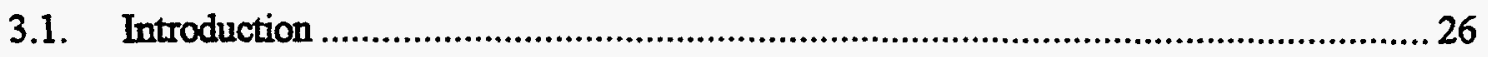

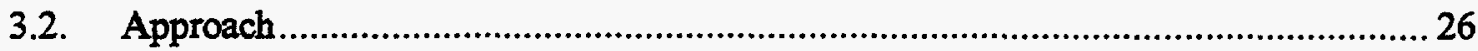

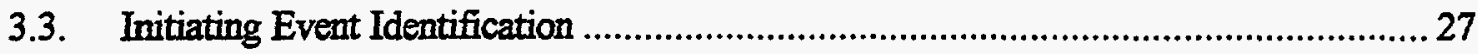

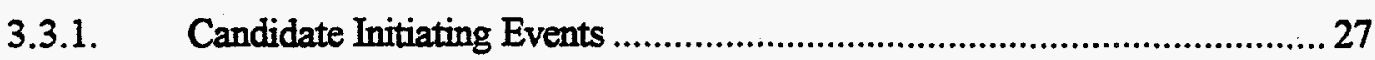

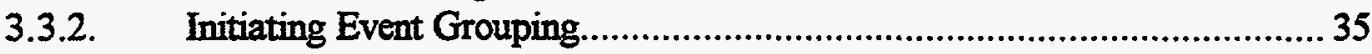

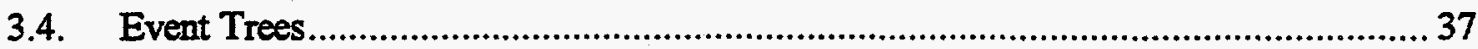

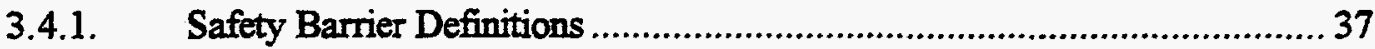

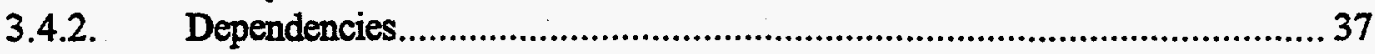

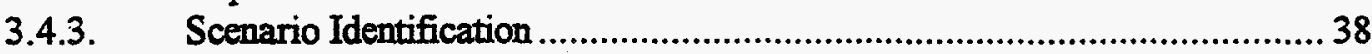

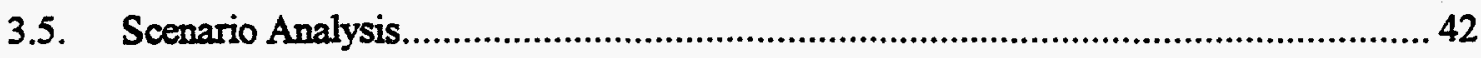

3.5.1. Scenarios with Severe Consequences............................................. 42

3.5.2. Potentially Dominant Scenarios.................................................... 42

3.5.3. Station Characteristics Affecting Dominant Scenarios ........................... 45

4. Phenomenology of Liquefied Natural Gas ............................................................56

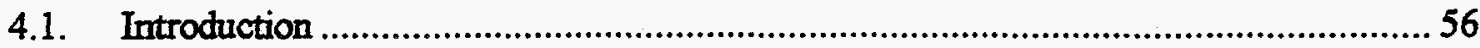

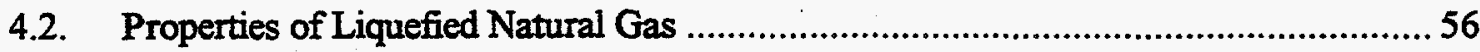

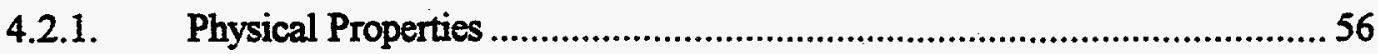

4.2.2. Combustion Properties..................................................................6 60

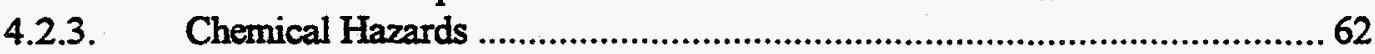

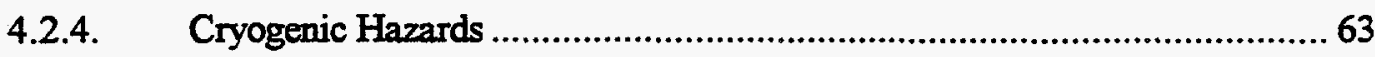

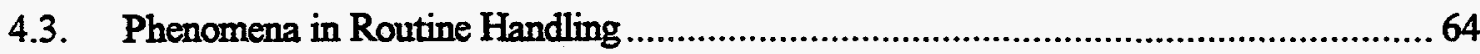

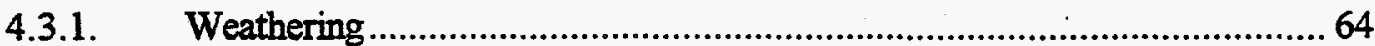

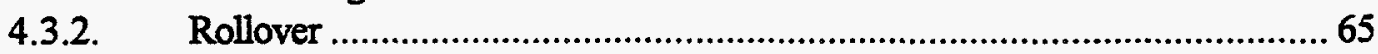

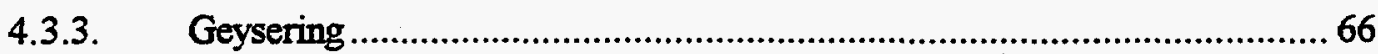

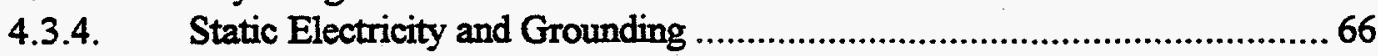

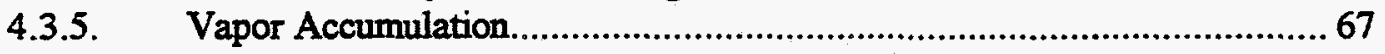


4.4. Phenomena Under Accident Conditions

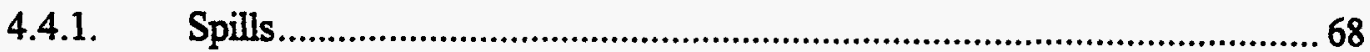

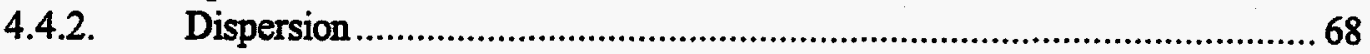

4.4.3. Boiling Liquid Expanding Vapor Explosions ..........................................6 68

4.4.4. Unconfined Vapor Cloud Explosions................................................6 69

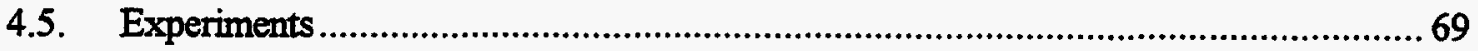

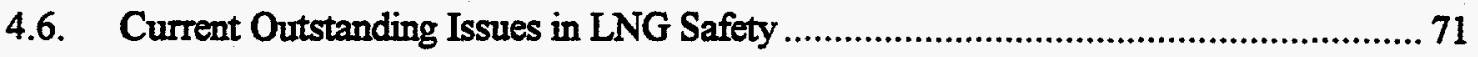

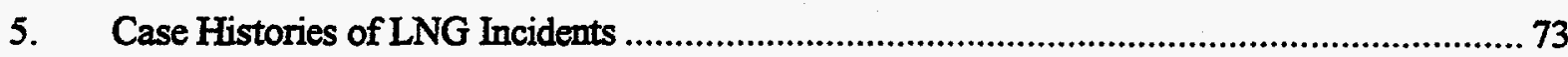

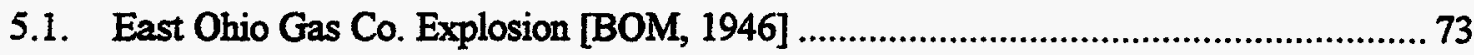

5.2: Raunheim, Germany explosion [CCPS, 1994] .................................................. 74

5.3. Portland, Oregon LNG tank explosion [ENR, 1968] .................................... 75

5.4. Quebec, Canada control room explosion [LNG, 1972] ......................................... 75

5.5. Staten Island LNG tank explosion [GPO, 1973] .............................................. 76

5.6. Cove Point, Maryland explosion at a peakshaving plant [NTSB, 1980; GPO, 1980]... 77

5.7. Liquefied Gaseous Fuels Spill Test Facility flash fire [NVO, 1987] ........................ 79

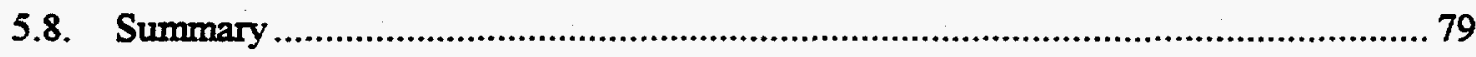

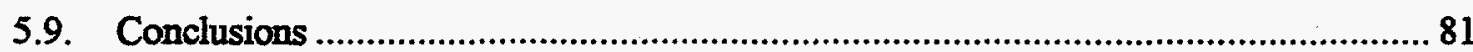

6. The Impact of Using Liquefied Natural Gas in the Context of Global Climate Change.......... 98

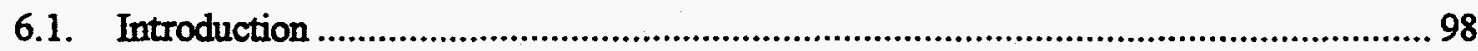

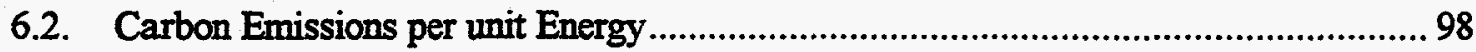

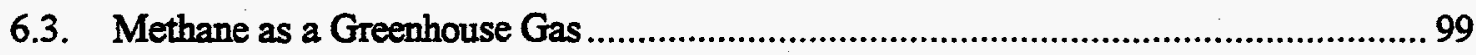

6.4. Means of Reducing the Amount of Methane Released ..........................................99

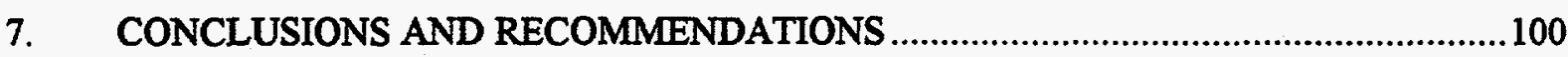

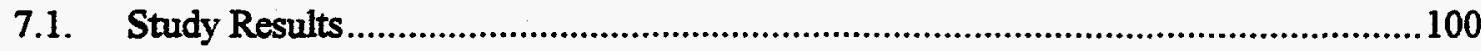

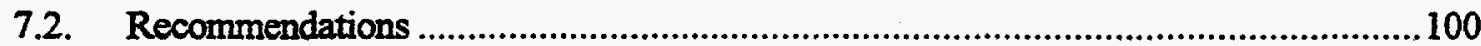

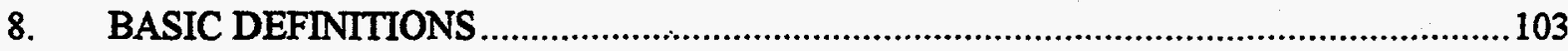


Appendix A-Failure Modes and Effects Analysis for Facility Number 1 ............................. A-1

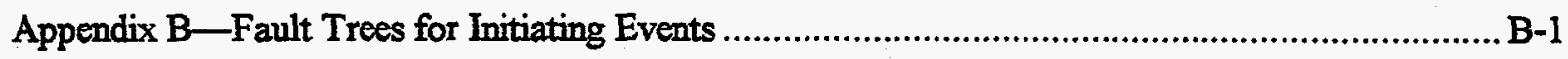

Appendix C—Event Trees for Refueling Station Qualitative Risk Assessment............................ C-1

Appendix D-Large Consequence Scenarios ....................................................

Appendix E_Bibliography on Liquefied Natural Gas .............................................. E-1

\section{FIGURES}

Figure 2-1. Example fueling system piping and instrumentation diagram. ..................................9

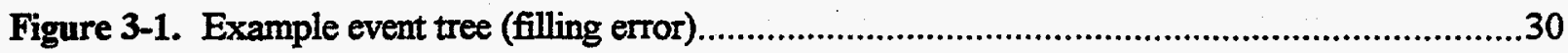

Figure 3-2. Master logic diagram: onsite serious injury or fatality............................................31

Figure 3-3. Master logic diagram: offsite serious injury or fatality.......................................32

Figure 3-4. Master logic diagram continuation: LNG release ...............................................33

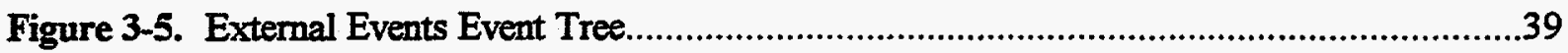

\section{TABLES}

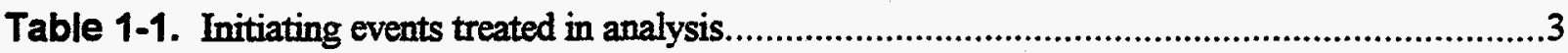

Table 1-2. Potentially dominant scenarios. large LNG release onsite. ....................................4

Table 1-3. Potentially dominant scenarios: large LNG release offsite........................................5

Table 2-1. Conditional probabilities of spills, given a track accident. ....................................16

Table 2-2. Conditional probabilities of immediate ignition, given a spill. ................................. 16

Table 2-3. Conditional probabilities of delayed ignition, given a spill. .......................................16

Table 2-4. Conditional probabilities of explosion, given ignition.............................................17

Table 2-5. Additional events involving transportation/handling of LNG...................................19

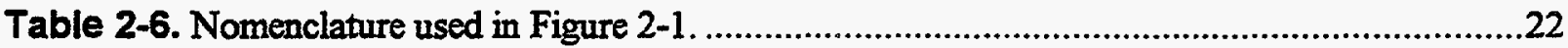

Table 3-1. Initiating events and mapping to MLD failure causes. ...........................................35 
Table 3-2. Initiating event-to-top event dependency matrix.

Table 3-3. Top event-to-top event dependency matrix.

Table 3-4. Potentially dominant scenarios: large LNG release and onsite ignition.

Table 3-5. Potentially dominant scenarios: large LNG release offsite. .44

Table 3-6. Noteworthy site-specific features affecting initiating event occurrence, Facilities 1,2 and $3 .^{2}$

Table 3-7. Noteworthy site-specific features affecting initiating event occurrence, Facilities 4, 5 and $6 .^{2}$.

Table 3-8. Noteworthy site-specific features affecting initiating event occurrence, Facilities 7,8 and $9 .^{2}$. .50

Table 3-9. Noteworthy site-specific features affecting top events, Facilities 1, 2 and 3.

Table 3-10. Noteworthy site-specific features affecting top events, Facilities 4, 5 and 6. .53

Table 3-11. Noteworthy site-specific features affecting top events, Facilities 7, 8 and 9. .54

Table 4-1. Comparison of LNG, diesel, and gasoline. 57

Table 4-2. Properties of hydrogen, methane and gasoline.

Table 4-3. Combustion properties of hydrogen, methane and gasoline.

Table 4-4. Temperature dependence of flammability limits for methane-air mixtures. 62

Table 4-5. Vapor pressures and heats of combustion for four energy gases. 65

Table 4-6. Parameters for Falcon experiments. 70

Table 5-1 Events and Causal Factors Table for the Cleveland Ohio Event. 83

Table 5-2 Events and Causal Factors Table for the Staten Island Event 87

Table 5-3 Events and Causal Factors Table for the Cove Point, Maryland Event. 94

Table 6-1 Carbon Emissions per unit Energy Output 98

Table 6-2 Global Warming Potentials. 99 


\section{Qualitative Risk Assessment for An LNG Refueling Station and Review of Relevant Safety Issues}

\section{INTRODUCTION}

\subsection{Background}

As part of the efforts currently under way to increase the use of natural gas in transportation applications, technology is being developed to enable the widespread use of liquefied natural gas (LNG) as a fuel. LNG, as a cryogenic liquid, has inherently different characteristics than the gasoline and diesel fuel we are accustomed to using. These differences include the rapid evolution of a gas that is lighter than air at room temperature, the potential for cryogenic burns, and changes in materials properties at low temperatures. The safe handling and use of LNG requires training and technology development. One of these technology development activities includes the performance of safety assessments for LNG systems. Such assessments can assist in the identification and prioritization of potential system weak points and associated improvements.

A failure modes and effects analysis (FMEA) has been performed for LNG-fueled trucks (ATA, 1995). This study documents a qualitative risk assessment for LNG refueling stations, part of the necessary infrastructure for an LNG-based trucking industry.

Risk assessment is a particular type of safety analysis aimed at: a) identifying accident scenarios of potential concern; and b) determining the probability and consequences of these scenarios (Kaplan and Garrick 1981). In a quantitative risk assessment, scenario probabilities and consequences are quantified and treated in a formal mathematical framework. In a qualitative risk assessment, scenarios are prioritized based on qualitative assessments of the absolute or relative probabilities and consequences. Qualitative risk assessments (of which FMEA is one form) is often a useful prelude to quantitative risk assessment, as it can identify scenarios where analysis resources should be focused. Both qualitative and quantitative risk assessment enable the prioritization of system design and operations alternatives based on an explicit consideration of accident likelihood and severity.

\subsection{Objectives and Scope}

The overall objective of this study is to generate safety lessons and insights useful to the development of LNG refueling stations. The specific objectives of this study are threefold:

- To identify and characterize public and worker risk and safety issues associated with the operation of LNG refueling stations for long-haul trucking

- To summarize the current state of knowledge regarding LNG safety

- To develop recommendations concerning:

- Improvements to current design and operational practices 


\section{- Areas requiring additional research and/or analysis.}

The study scope is limited to activities within the boundaries of refueling stations. However, it does include some issues generic to all LNG handling activities. It addresses issues not directly associated with the process of refueling trucks (e.g., fuel storage, station refueling, truck maintenance). The study also addresses current station designs and operational practices. Credit for improved practices since past accidents (e.g., the Cleveland tank failure in 1944) is taken as appropriate. Conversely, no credit is taken for potential future improvements in equipment or practices (e.g. in nozzles, instrumentation, or interlocks). Finally, it should be noted that the analysis is performed at a generic level; hazards (e.g., storms) and faults (e.g., refueling errors) believed to be relevant to most (if not all) stations are addressed, but system-specific detailed faults (e.g., failure of a particular piping segment or relief valve) are not treated. This generic approach provides common lessons and insights for the industry, but may not be detailed enough to support detailed system improvement studies.

\subsection{Summary of Technical Approach}

The approach employed in this study follows the general steps of most risk assessment studies. An example description of the risk assessment methodology can be found in ASME 1995. A detailed description of several of LNG stations can be found in GRI (1996).

In the system definition phase, data was gathered through site visits to three separate refueling facilities in addition to an extensive literature search. Information was collected on typical system design and operations, past events involving LNG, and LNG phenomenology relevant to accident occurrence and mitigation. Special attention was paid to the review of the phenomenological data (e.g., concerning LNG flammability and dispersion) in order to see if concerns raised in an earlier report (GAO 1978) and a recent memo reiterating these concerns (Hunt 1996) are still warranted.

In the model construction phase, event trees (ANS 1980) were constructed to represent possible scenarios following an initial fault (an "initiating event"). The event tree "top events," whose successes and failures define the different possible scenarios, are based on the generic safety functions defined in Siu et al 1995. The initiating events were identified using a variety of methods, including master logic diagrams, FMEA, review of past studies, and review of past events. The initiating events were grouped to keep the analysis tractable; grouping was performed based on considerations of accident magnitude and recoverability. The full set of initiating events considered is shown in Table 1-1. (Note that these initiators are defined in terms of LNG releases instead of the root causes of the releases.)

In the model analysis phase, accident scenarios leading to onsite ignition or offsite release were identified using the event trees constructed in the previous phase. Qualitative arguments concerning the likelihood of failure events and pairwise comparison of scenarios were then employed to identify the scenarios likely to dominate the risk from a given initiating event. Additional qualitative arguments based largely on accident phenomenology, event timing, and magnitude were then made to prioritize these potentially dominant scenarios. 


\subsection{Summary of Results}

The key results of this study are as follows.

- Sixteen potentially risk significant scenarios leading to an onsite fire or explosion and eight potentially risk significant scenarios leading to a large offsite release have been identified (see Tables 1-2 and 1-3). A number of differences in the operational practices and siting of the three facilities visited can affect the likelihood and consequences of these scenarios and need to be addressed (see below).

- Of the four safety issues raised in the Hunt memo, available data shows that two, the possibility of unconfined vapor cloud fires/explosions and the adverse effects of direct exposure to LNG vapor, are credible and of potential concern in this study. Additional study is needed to determine the quantitative risk significance of these issues. The other two issues, structural failure due to LNG exposure and the physical effects of a rapid phase transition of LNG in water, appear to be of lesser concern to the refueling station.

Table 1-1. Initiating events treated in analysis.

\begin{tabular}{ll}
\hline \multicolumn{1}{c}{ Description } & Identifier \\
\hline LNG release due to construction accident, isolable & CAI \\
LNG release due to construction accident, unisolable & CAU \\
LNG release due to external event & EE \\
Hose failure & HF \\
Driveaway & OD \\
Filling error & OF \\
LNG release due to maintenance error & OM \\
Pipe failure, isolable & PFI \\
Pipe failure, unisolable & PFU \\
Seal failure, isolable & SFI \\
Seal failure, unisolable & SFU \\
Storage tank failure & STF \\
Truck fuel tank failure & TTF \\
Tanker truck tank failure & TTT \\
LNG release due to vehicular accident & VA \\
Valve failure & VF \\
\hline
\end{tabular}


Table 1-2. Potentially dominant scenarios. large LNG release onsite.

Initiating

Event

Scenario Description

CAI Isolable release due to construction accident, guaranteed failure of early recovery efforts, ignition, failure of late recovery efforts

CAU Unisolable release due to construction accident, guaranteed failure of early and late recovery efforts, ignition

EE Release due to external event, failure of early detection, guaranteed failure of early and late recovery efforts, ignition

OD Driveaway, failure of early recovery efforts, ignition, failure of late recovery efforts

OF Release due to error during tank filling process, failure of early recovery efforts, ignition, failure of late recovery efforts

OM Release during maintenance due to error, failure of early recovery efforts, ignition, failure of late recovery efforts

OM Release during maintenance due to error, failure of early detection, guaranteed failure of early recovery efforts, ignition, failure of late recovery

SFI Isolable seal failure, failure of early detection, guaranteed failure of early recovery efforts, ignition, failure of late recovery efforts

SFU Unisolable seal failure, guaranteed failure of early and late recovery efforts, ignition

STF Storage tank failure, guaranteed failure of early and late recovery efforts, ignition

TTF Truck fuel tank failure, guaranteed failure of early and late recovery efforts, ignition

TTT Tanker truck tank failure, guaranteed failure of early and late recovery efforts, ignition

VA Release due to vehicular accident, guaranteed failure of early and late recovery efforts, ignition

VFI Isolable valve failure, failure of early recovery efforts, ignition, failure of late recovery efforts

VFI Isolable valve failure, failure of early detection, guaranteed failure of early recovery efforts, ignition, failure of late recovery efforts

VFU Unisolable valve failure, guaranteed failure of early and late recovery efforts, ignition 
Table 1-3. Potentially dominant scenarios: large LNG release offsite.

Initiating

Event

Scenario Description

EE Release due to external event, failure of early detection, guaranteed failure of early and late recovery efforts, failure of containment

OD Driveaway, failure of early recovery efforts, failure of late recovery efforts, failure of containment

OF Release due to error during tank filling process, failure of early recovery efforts, failure of late recovery efforts, failure of containment

OM Release during maintenance due to error, failure of early recovery efforts, failure of late recovery efforts, failure of containment

STF Storage tank failure, guaranteed failure of early and late recovery efforts, failure of containment

TTT Tanker truck tank failure, guaranteed failure of early and late recovery efforts, failure of containment

VA Release due to vehicular accident, guaranteed failure of early and late recovery efforts, failure of containment

VFU Unisolable valve failure, guaranteed failure of early and late recovery efforts, failure of containment

The recommendations stemming from this study concerning refueling station design and operational practices are as follows.

- Improvements should be made in procedures and training with respect to operational practices (e.g., tank venting, use of grounding wires, use of personal protective equipment), improper responses to alarms, and the performance of maintenance.

- Station designs should account for: a) the possibility of LNG leakage along unexpected pathways (e.g., past seals) to enclosed spaces; and b) the possibility of complete LNG inventory losses. For example, methane detectors should be provided in all enclosed spaces, facilities should be designed to prevent the buildup of methane in enclosed spaces (assuming a leak), and appropriately sized bund walls should completely surround the main LNG storage $\operatorname{tank}(\mathrm{s})$.

- The dissemination of best practices among stations should be strongly supported.

These recommendations are based on field observations at nine different LNG refueling stations and on information gathered from a number of papers and reports. To ensure that these recommendations are applicable to the range of refueling stations across the country, and to better define the degree of risk associated with the operation of these stations, the following studies are recommended.

- An in-depth review of LNG accident/event reports (case studies) should be performed to:

a) provide a stronger link between experiential data and the failure scenarios identified in the risk assessment; and b) identify historical failure mechanisms which are less likely or no 
longer relevant, due to advances in codes and standards, construction practices, operational practices, etc.

- A detailed review on post-1978 experimental data relevant to predicting LNG hazards should be performed to provide a more definitive picture of what is known concerning LNG dispersion and ignition under realistic accident conditions. This is needed to determine the risk significance of the two Hunt memo issues of potential concern (i.e., unconfined vapor cloud fires/explosions and direct exposure to LNG vapor).

Additional discussion on these insights and recommendations is provided in Section 5.

\subsection{Overview of Report}

Section 2 of this report describes typical LNG refueling station system design and operational characteristics, as observed during the nine site visits performed in conjunction with this study. Section 2 also discusses relevant industry experience and reports concerning LNG accidents. Section 3 discusses the qualitative risk assessment; it presents the methods and assumptions used to obtain the results shown in Tables 1-2 and 1-3. The section concludes with a summarization of station-specific features observed in the site visits which are relevant to the risk assessment results. Section 4 summarizes currently available information on LNG behavior under normal and accident conditions, and addresses issues identified in the GAO study and the Hunt memo. Section 5 provides a number of concluding remarks and recommendations. Details underlying the analysis (e.g., an FMEA for a refueling system, initiating event models, event trees, accident scenarios) are provided in Appendices A-D. 


\section{SYSTEM CHARACTERISTICS}

This section describes general design and operational characteristics of LNG refueling stations. This description is based on visits to nine separate facilities. Facility 1 is a temporary, restricted access, remotely sited refueling facility servicing a privately owned and operated fleet of buses and utility vehicles. Both LNG and compressed natural gas (CNG) fueled vehicles are serviced. The main LNG storage tank has a 13,000-gallon capacity. A permanent refueling station is being built nearby, but is not included in this analysis. Facility 2 is a publicly accessible self-service refueling station, which services both LNG and gasoline fueled vehicles. It used a 10,000 gallon parked trailer tank for the LNG at the time of our visit. The station is located in a semi-rural site (the nearest houses are about 200 feet away). Facility 3 is a restricted access combined LNG/CNG facility servicing a fleet of public transit vehicles. It has three 20,000-gallon storage tanks and has an urban location. Facility 4 is a permanent, restricted access. refueling facility serving baggage-handling vehicles at an airport. Facility 5 is a restricted access LNG facility servicing a metropolitan fleet of public transit busses. It has two 30,000-gallon storage tanks. Facility 6 is an older, permanent, restricted access LNG facility serving small transit vehicles. Facility 7 is a permanent, restricted-access LNG refueling facility serving shuttle busses at a major airport. Facility 8 is a restricted access LNG refueling facility serving a fleet of refuse-hauling trucks and a few outside customers. Facility 9 also serves a fleet of refuse-hauling trucks and is the only station having an underground storage tank.

During our visits at each of the stations, we agreed that the precise identity of the stations would not be included in this report. However, we have differentiated among the stations by their location, operational, and safety characteristics. We are free to say that Facility 1 is a temporary LNG/CNG station at the Central Facilities Area of the INEEL.

To provide a perspective on the safety characteristics of LNG and LNG handling, this section also discusses information on historical accidents involving $\mathrm{LNG}$.

\subsection{System Design}

This section describes a typical LNG refueling system. Many of the details (e.g., the parameter values) are derived from the system at Facility 1 (see Figure 2-1). Comments on variations in design are provided as appropriate within the text.

The basic system centers around a large storage tank, approximately 13,000-gallon capacity, held at an average pressure of 30 to $150 \mathrm{psig}$ (many storage tanks operate at the 40-psig range). The LNG is maintained at about $-260^{\circ} \mathrm{F}$ at atmospheric pressure and about $-128^{\circ} \mathrm{F}$ at $40 \mathrm{psig}$. The storage tank is mounted on steel supports rather than buried underground. (Most petroleum fuel tanks are buried, apparently to protect them from the heat of hot days, fires at the site, and vehicle collisions.) A berm or dike (constructed of metal, concrete, or earth) several feet in height is provided around the LNG storage tank as an impoundment area in case there is a tank leak (see 49CFR193.2149). In such a case, the berm is intended to confine the liquid while it vaporizes, and to ensure that the vapor rises in the immediate area of the tank.

The storage tank is double walled with a stainless steel inner tank that withstands cryogenic temperatures, and an outer wall of mild steel that cannot withstand cryogenic temperatures. Both the inner 
and outer vessels may use stiffening rings to give structural strength. The inner tank is supported or suspended inside the outer vessel using low thermal conductivity materials such as stainless steel. The tank annulus is evacuated to low pressure (on the order of $10^{-5}$ Torr) to reduce convective and conductive heat transfer from the ambient temperature outer vessel to the inner vessel. Some form of solid insulation, such as layers of foil sheeting (multilayer insulation) or perhaps granular pearlite (older technology), is used in the annulus to retard radiant heat transfer from the outer vessel to the inner vessel walls. The storage tank inner vessel is protected by pressure relief valves (usually set at $110 \%$ of design pressure) and rupture disks (usually set at $120 \%$ of design pressure) in case of overpressure. The annulus is also protected against overpressure by a rupture disk that opens at a pressure differential of 5 to $7 \mathrm{psig}$. This protection prevents inner vessel buckling if the annulus is pressurized.

A thermally insulated pipe from the storage tank connects to a smaller volume pressure tank ( 300 gallons in one facility; 500 gallons in another). The pressure tank is similar in design to the storage tank; it has a vacuum insulation annulus and pressure relief protection. The pressure tank houses a submerged centrifugal pump. The pump keeps the saturated LNG in the pressure tank at a high enough pressure (e.g., under 200 psig) to fill a vehicle fuel tank, which usually operates between 110 and 180 psig. (Note that the vehicle fuel tank relief valves at facility 1 are set at about 235 psig-vent to vehicle stackand 350 psig - vent to vehicle fuel tank compartment. If a high pressure pump is selected, scenarios where the pump pressurizes the pressure tank past the setpoint of the vehicle's first relief valve may be possible. Generally, the pressure pumps have only a 60 to 85 psi differential pressure.) Refueling flow rates are up to 50 gallons/minute. To refill a vehicle can require on the order of four minutes dispensing time. The vehicle LNG tanks at Facility 1 are kept over $10 \%$ full to keep the tanks at cryogenic temperatures. If a tank warms to room temperature, it is called a 'hot tank, and must be recooled to cryogenic temperature by refilling with LNG; much boiled LNG is vented in this cooldown process. Fortunately the time to warm an empty tank can be long (perhaps a day). If the refueling station also services CNG-fueled vehicles, the boiled LNG may be routed to the compressors of the CNG fueling system instead of venting to the atmosphere.

Pneumatic or solenoid operated flow control valves are used between the storage and pressure tanks. From the pressure tank, valves control flow to the vehicle fill line. There is also a reverse flow check valve in this section of piping to stop any flow from the vehicle tank to the pressure tank. The flexible metal fuel transfer hose has a special nozzle fitting with a two-handle positive locking clamp and a pintle-operated flapper valve so that the fill line must be connected to a vehicle before LNG can flow past the valve and into the vehicle fuel fill line. The vehicle fill line also has an anti-reverse flow valve. Operators can use a small diameter vent line to purge gas from the vehicle fuel tank ullage (the space above the liquid). This process reduces the tank pressure and can speed up the refueling process. The vented natural gas is routed up the small stack that protrudes on the top of the vehicle.

From the pressure tank, a pipe routes a small portion of LNG to a vaporizer that boils the LNG to saturated vapor conditions in a finned vaporizer attachment which uses heat from the ambient air. This type of vaporizer is called an ambient vaporizer. The boiled natural gas is returned to the ullage of the station's storage tank to maintain its pressure as the liquid level in the tank lowers during vehicle fueling operations.

Other valves are used for filling the storage tank, for isolating tank instrumentation, for taking LNG samples (to test for composition and purity), and for pressure relief protection of any pipe that could suffer LNG 'lock in.' ('Lock in' is a term that means the trapping of a cryogen in an enclosed volume such as a pipe section between two closed valves. If the liquid boils without pressure relief, the trapped volume of LNG will increase in pressure up to $9000 \mathrm{psig}$ in warming from $-260^{\circ} \mathrm{F}$ to $+70^{\circ} \mathrm{F}$.) 


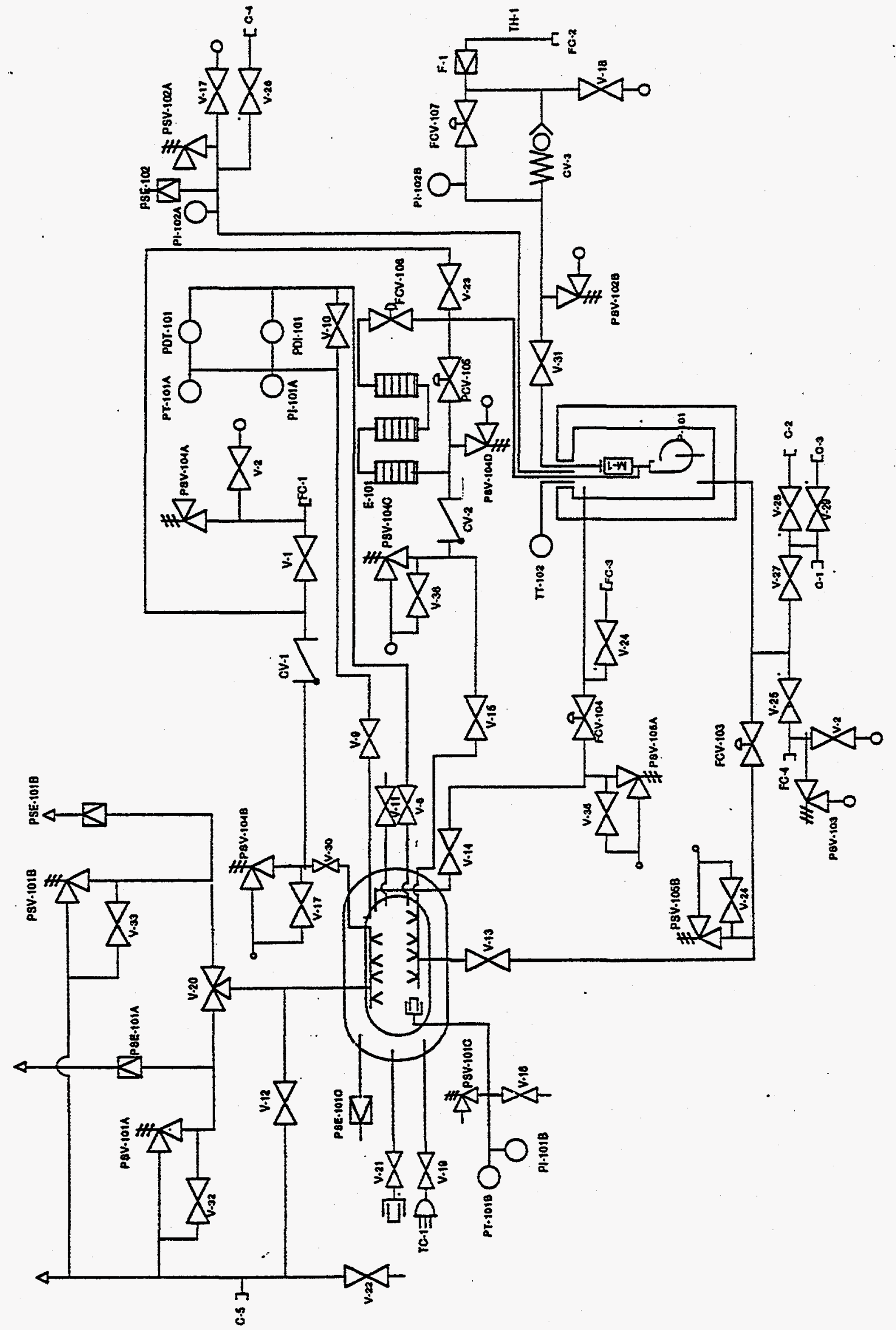

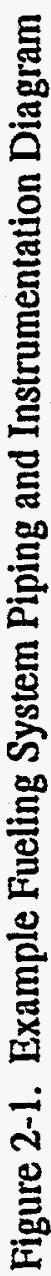




\subsection{Station Operations}

\subsubsection{Station Refueling}

Since none of the facilities visited have natural gas liquefaction facilities onsite, replenishing the LNG inventory in the storage tank is accomplished by deliveries from a tank truck. The rate of delivery naturally depends on the station usage. For the facilities visited, the delivery rates vary from once per day to once a month. The transfer process nominally proceeds as shown in Figure 2-1, which is based on discussions with Facility 1 personnel and a review of station design diagrams.

At Facility 1, the tank truck uses a flexible hose for the bottom fill operation, the liquid hose connected at connector FC-4. Valve V-25 must be opened. (Note that an alternative is to top fill the storage tank through connector FC-1.) The tank truck centrifugal pump is used to pump LNG into the system. The tank truck pressure is on the order of $40 \mathrm{psig}$, so pumping is needed to pressurize the LNG to system pressures. The transfer generally is performed using 4-inch diameter lines that can provide flow in the 400 to $500 \mathrm{gpm}$ range. Fuel transfer is metered when leaving the tank truck.

With proper flow velocity, there is adequate mixing of the new liquid emerging from the bottom sparger with the existing liquid in the storage tank, so LNG stratification by temperature (i.e., rollover) concerns are avoided. As the liquid level increases, the storage tank gas pressure increases and vapor collapse occurs.

Depending on the facility, fuel delivery is performed by the delivery truck driver or by a dedicated facility refueling technician. In either case, the fueler is supposed to wear personal protective equipment (PPE) consisting of cryogenic gloves, shield glasses/face shields, and, perhaps, a rubber apron. Remotely operated emergency shut off valves are provided to stop flow in case of a hose breach or loss of hose seal. Tank trucks are bonded to dissipate static electric charge buildup when fluid flows. A bonding wire to the system and a grounding wire to the earth may be provided to ensure proper dissipation of static electricity for the fuel transfer.

\subsubsection{End User Vehicle Refueling}

End use vehicle refueling requires both filling the fuel tank with liquid and venting of the tank ullage, as in station tank filling. Depending on the facility, refueling can be performed by the vehicle driver or by a dedicated technician. At Facility Number 2 (a self-service station), the nominal procedure is as follows:

The driver pulls his or her vehicle up next to the LNG island, turns off the engine, sets the parking brake, and gets out. The driver then authorizes the refueling at a keycard reader about 8 feet from the pump, dons personal protective equipment (gloves, safety glasses, apron), opens the fuel door on the vehicle, attaches the grounding wire, removes the nozzle from the pump and attaches it to the fill connection, and then stands back to wait while refueling occurs.

As part of the automatic refueling process, the Facility 2 system uses a single refueling hose to alternately vent and fill the vehicle fuel tank. It has a 30 to 45 second cycling time before starting to vent or fuel. In addition, the system automatically vents the nozzle and hose before and after use, so that no LNG is present during attachment and disattachment of the nozzle. The system will also automatically try to cool down a warm tank; that is, it will cycle through a vent, fill, vent pattern. The system will go through this cycle three times before it automatically turns off. Sometimes the 
system interprets the pressure spike when LNG enters a warm tank as an indication that the tank is full and thus a tank may not fill all the way. In such a situation, to finish refueling, the driver has to use the keycard to reauthorize fueling.

Upon completion of refueling, the driver detaches the nozzle and grounding wire, replaces these within the fuel pump barriers, closes the fuel door, takes off the PPE, gets in the vehicle, and drives away.

This same basic process is also used at Facilities 1 and 3, although there are some differences due to a) system design differences (e.g., Facility 1 does not require automatic venting); and b) the use of trained fueling technicians at Facility 3. The technicians typically work in shifts and are supervised. As compared with drivers who refuel their own vehicles, they might be expected to better adhere to procedures and safety regulations and avoid short-cuts (because of the nature of their training and supervision). We noted deviations from this expectation during sample site visits (e.g., involving the use of grounding wires).

Some safety-relevant variances from the nominal procedure observed by or related to the authors during this study's site visits are as follows: ${ }^{2}$

- Engines left ruming during refueling

- Parking brakes not set

- Lack of PPE use

- $\quad$ Lack of grounding wire use

- Manual operation of fuel tank vent valve to cool off the fuel tank and speed up refueling

- Failure to remove hose followed by driveaway. Note that hose breakaway sections are a routine component at the stations visited. These devices limited the amount of LNG lost in the driveaway events.

Regarding the use of grounding wires, it is not clear that these are necessary for safe operation of the system. (Some industry professionals question whether there is any risk since they have not seen static electricity buildup or arcing for non-grounded systems.) However, situations where grounding wires are administratively required but ignored by users may reflect a poor general attitude towards safety.

Manual operation of the fuel tank vent valve was observed at one of the facilities visited. This was done by drivers to avoid having to wait for the system to automatically cycle or to avoid having to reauthorize fueling (a lengthy process). No formal instructions or even encouragement had been given on the use of vent valves; the process had been spread by word of mouth. As a result, misuse occurred. Some drivers used the vent valve to excess just to make sure the system would not cycle to venting. Considerable quantities of LNG (condensed vapor clouds several feet in diameter) were observed coming out of the truck vent pipes. Some drivers used the vent valve at the wrong time resulting in no effect and no change in

a. The variances on this list are not necessarily common occurrences; however, they have been observed by this study's authors or by station personnel interviewed by the authors. 
system performance. They used it because they had heard it shortened refueling times, but they really did not understand what they were doing.

Driveaway events in which the vehicle is driven away with the fill line still connected and which are relatively common events at conventional fueling stations, have not yet been observed at Facility Numbers 1 or 2 . They have been observed at Facility Number 3. The hose is provided with a coupling designed to break if a driveaway occurs. Isolation valves are also provided to prevent significant fuel loss from the station or from the vehicle. Events involving vehicle driveaway with the grounding wire still attached have been observed at Facility Number 2. These have resulted in essentially no damage to the grounding wire clamp or the vehicle.

\subsubsection{Other Activities}

The variety of non-refueling activities taking place at the refueling station depends on the roles played by the station. For example, Facility Number 1 is essentially dedicated to LNG/CNG vehicle refueling; other vehicle activities (e.g., vehicle maintenance) occur well away from the refueling island. At Facility 2, the LNG station is co-located with a gasoline station/convenience store. However, the convenience store personnel do not operate the LNG station. The maintenance shop is located about five miles from the station. Facility Number 3 is a full service LNG/CNG refueling facility; the maintenance shops are onsite.

Maintenance of the station systems depends on the expertise and commitment of the station personnel. Station personnel were unaware of written procedures, checklists, or worksheets for operations or maintenance. Preventative activities can involve regular walkdowns of the system and regular examination of system parameters monitored by the computer. Other maintenance activities include dealing with valve stem packing leaks (tightening) and nozzle leaks (replacement). Lessons are often learned by trial and error; facilities with years of experience (e.g., Facility Number 3) may have smoother operations.

\subsubsection{Incident Response}

The LNG fueling facilities visited have methane detectors and manual emergency shutdown devices that trigger remote alerts to surveillance personnel (onsite or nearby). Designated staff affiliated with the fueling facility are trained to respond to alarms. Their responses may range from simply resetting the system following an erroneous shutdown, to using special fire extinguishers (e.g., Purple K-potassium bicarbonate) to put out small fires. For larger incidents, emergency response teams will need to be called in.

Fire departments local to LNG stations may have been specifically trained to contain a spill or fire. Since water and traditional extinguishers can exacerbate an LNG fire, response teams need to be properly prepared. Training programs for fire emergency management are provided by several organizations across the country. To aid firefighters, LNG stations must display a placard designed by the NFPA. The placard is required by U.S. DOT regulations. The placard is a four-part diamond showing the type of hazard being faced.

Responses to incidents will vary from facility to facility. Some potential concerns with incident response include:

- Manual overriding of alarms or emergency shutdown signals 
- Possibly delayed responses to emergencies

- Lack of training/procedures for a major leak.

Regarding the first issue, the emergency shutdown buttons have been accidentally actuated a number of times at one of the facilities visited, due to their poor location. (One such accidental actuation was observed during the site visit.) The station users have been informed that they may use the reset button once; if the system trips off again, they are to leave the station and call the designated response personnel. Such a response procedure, while understandable in motivation, may lead to an incorrect action in the event of a real emergency. (Operator neglect and/or override of alarms due to previous false alarms has been a prime contributor to a number of significant oil spill events, as described by Siu et al, 1995.)

Regarding the second issue, one of the sites visited is monitored remotely. However, the designated response personnel may be 5 to 20 miles away, depending on the time of day and the activities at the station. Clearly, delays in notifying the response personnel and in getting these personnel to the site may be long enough to preclude effective action in the event of a major incident. There have been times when an emergency shutdown occurred and the station alert signal (a flashing red light) was on, but the response personnel were not notified.

Regarding the third issue, two of the facilities visited appear to have no written procedures for emergency response and no equipment such as protective suits or self-contained breathing apparatus. The staff at one facility, when asked what they would do in response to a major leak, candidly replied, "Run."

\subsection{Industry Experience}

This section summarizes information collected on LNG refueling station events and on events potentially relevant to LNG refueling stations. It also discusses information collected from a number of safety studies relevant to this study.

\subsubsection{Experiences at Refueling/Maintenance Facilities}

Based on interviews conducted during the site visits, none of the facilities visited have experienced a major LNG accident. Discussions with industry representatives showed that there have not been any major LNG accidents at refueling stations. Some of the common events experienced include system leaks (e.g., valve stem packing leaks and fuel transfer nozzle leaks) and driveaways. One facility visited had experienced a spill of 200 gallons of LNG; this involved a vehicle fuel tank union coming loose. The spill pooled underneath the vehicle but eventually dissipated into the atmosphere without igniting. There was no collateral damage to the vehicle or its tires.

One disadvantage of LNG (as compared with CNG) is the current inability to odorize the fuel. Odorant may not be a benefit at a refueling site where small leaks will regularly occur, but odorant in a vehicle fuel system would be an advantage for detection by the operator or passengers. The LNG industry relies on methane detectors since odorant is not practical. Because the unodorized vapors are difficult for humans to detect, gas leaks in confined areas are particularly dangerous. In 1993, technicians performing maintenance on an LNG-fueled bus noticed a fuel leak. When they removed a floorboard to access the fuel system, a significant amount of gas from vaporizing LNG accumulated in the bus compartment. The onboard methane detection system was triggered, and shut down the bus as designed. The technicians, however, decided to override the system and attempt to drive the bus out of the maintenance garage. When 
the ignition switch was turned, a circuit breaker arc ignited the accumulated methane inside the bus, resulting in a small explosion. The technicians were not injured, but the bus windows were destroyed.

This event provides further illustration of the potential seriousness of the problem discussed in Section 2.2.4 and by Siu et al (1995): neglect and/or overriding of alarms, which may be habitual and even sanctioned, sometimes leads to serious consequences. It should be noted that following this event, several preventative measures were implemented by the company that owned the bus. Self-venting roof hatches were installed in all LNG buses. Vehicle equipment inspection and maintenance programs were formalized. Training and procedures were implemented for safe practices. These measures have been duplicated by other programs.

Other incidents reported by the industry (NGV 1996) have involved minor injuries due to cryogenic liquid burns from LNG during refueling and superficial burns from methane vapor flash fires during fuel system dismantling. In one case, an untrained worker received cryogenic burns to his hands while handling the LNG refueling components. Another instance resulted in a worker's beard being singed when methane was released from a dismantled LNG fuel system and was ignited.

A risk assessment was performed for indoor refueling of mass transit buses (SAIC 1990). Although the study deals with diesel and CNG rather than LNG, it is of interest because it addresses refueling issues. Note that CNG tanks are not insulated, whereas LNG tanks are double-walled steel cryogenic storage vessels. Normally the vacuum insulation has a temperature difference of about $200^{\circ} \mathrm{K}$ and maintains the fuel as a liquid for several days. During a fire, the temperature difference would be as much as $1200^{\circ} \mathrm{K}$, shortening the hold time by a factor of about six. Industry tests have shown that short-duration (10-15 minute) fires do not increase the fuel pressure.

The five postulated accident scenarios compared in the SAIC study were:

1. A CNG bus with one-quarter full tanks is brought in for maintenance and is exposed to a fire in the shop (careless disposal of smoking materials or an industrial fire).

2. A bus with full CNG tanks is brought in for maintenance and is exposed to the same fire postulated in scenario 1. This bus vents much more gas due to full tanks.

3. A bus is refueled inside a dual fuel shop (CNG and diesel fuel present). The bus leaks CNG and an ignition source is present.

4. A CNG bus is refueled inside a dual fuel shop (CNG and diesel fuel present). The bus is segregated from the diesel portions of the shop. The bus leaks CNG and an ignition source is present.

5. The same scenario as number four but with a dedicated indoor CNG refueling area.

Scenario 3 was found to be the most likely. The parameters most affecting the probability of this and the other scenarios were the human error and relief valve failure rates. (The analysis used generic failure rates from a variety of sources-apparently none of which include LNG or CNG industry experience-when quantifying the likelihood of the scenarios.) The study made the following recommendations:

- Develop redundant safety systems to keep refuelers from introducing ignition sources 
- Ensure that operators are regularly trained and tested

- Develop faster responding gas detection systems

- Ensure proper maintenance of redundant ventilation and exhaust fans

- Establish uniform indoor refueling standards and strictly enforce these standards.

Attempts to collect raw data on events at gasoline service stations and truck stops have been unsuccessful to date. 'No gasoline station operating experience reports or data compilations were found in the literature. Contact with the U.S. Department of Transportation (U.S. DOT) revealed that they do not collect these data. A detailed search for events (e.g., through reviewing data collected by fire departments or insurance companies, or through reviewing newspaper accounts) was judged to be beyond the scope of this study.

\subsubsection{LNG Truck Tankers}

One refueling station accident of potential concern involves LNG truck tankers, as these carry considerably more LNG (on the order of 10,000 gallons) than a typical LNG fuel tank (on the order of 200 gallons). While this study has not identified any information on significant truck tanker accidents at refueling stations (see the previous section), information is available on truck tanker highway accidents.

LNG truck tanker highway accidents are not common events, due to the relatively low amount of volume transported. The GAO report cites 11 accidents occurring over the time period 1971-1977 (GAO 1978). Of these accidents, one involved the release of about $20 \%$ of the truck tank inventory and another involved the release of about 5\%. The rest of the accidents apparently had little or no release. None of the 11 accidents involved ignition of the LNG (although one of the events involved a gasoline fire). The GAO report does report a number of propane tanker truck accidents that did lead to release and ignition.

A continuation of this risk assessment would be to investigate the transportation of other cryogenic fluids, such as nitrogen, oxygen, and hydrogen, to determine the safety of highway transport. Initial review of the U.S. DOT transportation incident log indicates that there have been few cryogen transport accidents.

A quantitative risk assessment was performed in 1991 on the transport of propane, gasoline, ethyl alcohol, and hydrogen on selected highway segments (Kazarians 1997). In that study, the overall truck accident frequencies range from $6 \times 10^{-7}$ per vehicle-mile-year to $1 \times 10^{-5}$ per vehicle-mile-year, based on route-specific data. The conditional probabilities of spills given an accident, of ignition (immediate and delayed) given a spill, and explosion given delayed ignition are shown in Tables 2-1 through 2-4. (These probabilities reflect an outdoor environment; different probabilities are used for accidents in tunnels.) The probabilities are based either on experiential data or engineering judgment; the study uses the results of earlier transportation risk studies on gasoline (Rhoads 1978) and propane (Geffen 1980) to provide some of the bases for its assumptions. 
Table 2-1. Conditional probabilities of spills, given a truck accident.

\begin{tabular}{lccc}
\multicolumn{1}{c}{ Fuel } & Small Spill $^{\mathrm{a}}$ & Large Spill $^{\mathrm{a}}$ & Total \\
\hline Propane & 0.075 & 0.025 & 0.10 \\
Gasoline & 0.09 & 0.07 & 0.16 \\
Ethyl alcohol & 0.09 & 0.06 & 0.15 \\
Hydrogen & 0.06 & 0.02 & 0.08
\end{tabular}

(Kazarians 1997)

a. "Small spills" involve $10 \%$ of tank inventory, "Large spills" involve $100 \%$ of tank inventory.

Table 2-2. Conditional probabilities of immediate ignition, given a spill.

\begin{tabular}{lcc}
\hline \multicolumn{1}{c}{ Fuel } & Small Spill $^{\mathrm{a}}$ & Large Spill $^{\mathrm{a}}$ \\
\hline Propane & 0.25 & 0.75 \\
Gasoline & 0.15 & 0.50 \\
Ethyl & 0.20 & 0.60 \\
alcohol & & \\
Hydrogen & 0.50 & 0.90
\end{tabular}

(Kazarians 1997)

a. "Small spills" involve $10 \%$ of tank inventory, "Large spills" involve $100 \%$ of tank inventory.

Table 2-3. Conditional probabilities of delayed ignition, given a spill.

\begin{tabular}{lcc}
\hline \multicolumn{1}{c}{ Fuel } & Small Spill $^{\mathrm{a}}$ & Large Spill $^{\mathrm{a}}$ \\
\hline Propane & $0.68^{\prime \prime}$ & $0.23^{\prime \prime}$ \\
Gasoline & 0.04 & 0.05 \\
Ethyl alcohol & 0.04 & 0.04 \\
Hydrogen & $0.45^{\prime \prime}$ & $0.09^{\prime \prime}$
\end{tabular}

(Kazarians 1997)

a. "Small spills" involve $10 \%$ of tank inventory, "Large spills" involve $100 \%$ of tank inventory.

b. Total contribution from scenarios involving: a) ignition when the vapor cloud edige is over the population edge, and b) ignition when the vapor cloud center is over the population center. 
Table 2-4. Conditional probabilities of explosion, given ignition.

\begin{tabular}{lc}
\multicolumn{1}{c}{ Fuel } & All Spills \\
\hline Propane & 0.33 \\
Gasoline & - \\
Ethyl alcohol & - \\
Hydrogen & 0.50
\end{tabular}

Kazarians, 1997

a. "Small spills" involve $10 \%$ of tank inventory, "Large spills" involve $100 \%$ of tank inventory.

This fuel transport risk assessment does not analyze LNG truck tanker accidents. The limited GAO data on LNG truck accidents discussed above indicate that the LNG spill probability may be less than or equal to the propane spill probability (where a release occurs in roughly $10 \%$ of all reportable tanker truck accidents and a large release occurs much less frequently). The physical characteristics of LNG tanks (low pressure, stainless steel, double walls ${ }^{b}$ also provide an argument that the LNG spill probabilities should be lower than those for propane. (A similar argument is used in the risk assessment to reduce the large spill probability for ethyl alcohol tank trucks.) However, this argument cannot as yet be supported by the data.

Regarding ignition, the fuel transport risk assessment does not strongly distinguish between the various fuels considered with respect to immediate ignition. (The ignition probabilities do not vary by orders of magnitude.) On the other hand, it states that gasoline and ethyl alcohol do not "demonstrate much vapor dispersion" and therefore employs order of magnitude lower delayed ignition probabilities for these fuels. It should be emphasized that since the report's ignition probabilities appear to rely heavily on engineering judgment; further investigation is needed to determine if these probabilities accurately reflect: a) current event experience, and b) the appropriate ignition probabilities for LNG.

More recently, GRI (1994) published a report on safety issues of LNG fueled vehicles. Areas with higher cryogenic leakage risk are differentially cooled sections, areas where hose or seal chafing can occur, areas where pipes or hoses could be stressed, sections that trap cryogens (cryogens boil and build pressure), and areas near relief valves. The report observes that LNG spills tend to occur in systems that are initially being cooled down, during fuel transfers, and during LNG sampling. LNG releases can lead to fires and vapor cloud deflagrations. The report also points out that breathing cold vapors from LNG evaporation or boiling can damage the lungs.

b. Note that the double wall design provides an additional defense against immediate releases due to impact. However, it does not provide complete rectundancy, if the outer wall fails, air will leak in and the LNG will heat up, boil, and eventually escape out of the tank relief valves. 


\subsubsection{Other LNG Experience}

This section discusses experiences with LNG and other cryogens used for automotive fuel. Since LNG has been used for a fuel gas (i.e., household use in stoves, water heaters, and furnaces; industrial use as a heat source), there is a breadth of experience in the literature. Two notable events involving LNG are the Cleveland tank failure and explosion in 1944 and the Cove Point leak and explosion in 1979.

In the Cleveland event (October 20, 1944), a cylindrical storage tank owned by the East Ohio Gas Company cracked and failed, releasing $144,000 \mathrm{ft}^{3}$ (10 gallons) of LNG. Most of the LNG vaporized and dispersed, but some LNG overflowed the bund wall and entered the surrounding storm sewers. (The wall had been designed assuming that the LNG release would be relatively slow, resulting in a slowly rising pool level and significant evaporation. Thus, it was not sized to contain the entire tank inventory, nor was it designed to prevent overflow by the LNG wave resulting from the rapid, catastrophic tank failure.) The dispersing gas ignited from multiple ignition sources and the flames ignited gas in the sewers. The fire caused failure of the supports of another tank, whose inventory was added to the fire. Flames over 2,800 feet high were reported, and there was destruction over a quarter mile radius from the cylindrical tank. 128 people died in this event and hundreds more were injured. Property damage was estimated to be over \$6.8M in 1944 dollars (\$62 million in 1997 dollars) (BOM 1946).

Lessons from this event include: a) the need to site large quantities of LNG more remotely; b) to not use $3.5 \%$ nickel steel for tanks; c) to build higher bund walls; and d) to preclude ignition source contact with flammable gas clouds (Zabetakis 1967).

In the Cove Point accident (October 6, 1979), a submerged pump for LNG transfer began leaking past an electrical power wire penetration. Natural gas vapors leaked into a conduit and accumulated in an electrical junction box located in a switchgear building some distance away from the leak. Although the site had methane detectors, there were none in the building. When plant persomnel performed a routine operating check in the switchgear room, they noted leaking vapor. Two operators decided to remove power from the pump so that it would not start and make the leak worse. The operators opened the motor starter and an electrical arc from the control circuit apparently ignited the methane gas, killing one man and injuring the second. There were no offsite consequences. As a corrective action, ventilated cabinets were installed to route any gas to a non-hazardous location and disperse any leaks to the atmosphere (NTSB 1980).

This event, while less severe than the Cleveland accident, is notable because the natural gas vapors propagated along an unanticipated pathway into a confined space. Another gas leakage event occurred in an LNG plant in Montreal in 1972. Here, the gas leaked through an air line into the plant control room and ignited (Van Horn and Wilson 1977). Design guidelines were revised after the Montreal and Cove Point accidents to preclude future occurrences.

A report on LNG plant operating experiences gives insights into the types of events and accidents that have occurred in peakshaving plants. These plants deliver natural gas fuel when needed to augment the natural gas supply to meet the peak usage demand for residential and commercial usage. Peakshaving plants store LNG during seasons of low demand and distribute gas to the pipeline distribution system during seasons of high demand. Some of the components used at these facilities are similar to those used in refueling stations. A major difference is that a peakshaving plant handles and vaporizes very large quantities (up to a billion cubic feet of gas per day) of LNG. Another difference is that pipeline quality gas stored at a peakshaving plant contained higher percentages of ethane and propane than the fuel used for LNG vehicles. 
Reviewing peakshaving plant experiences can give insights into component faults. The off-normal events that have occurred at peakshaving plants are: cold spots in storage tanks due to insulation settling, failure of tank foundation heating systems, vaporizer fires, small leaks from valve stems, piping gasket leaks, pump leaks, gas sensor false alarms (due to high winds, and sensor deterioration), false alarms of thermal radiation sensors, damaged thermal sensors during venting operations, fire protection system freeze-up due to cold weather, a few major leaks of gas (over 100,000 cubic feet of gas), electrical equipment fires not involving natural gas, and a few natural gas fires involving vaporizers (Welker and Schorr 1979). Due to the facility differences discussed above, some of the phenomena discussed for peakshaving plants, e.g. vaporizer fires or tank foundation heating system failures, are not pertinent to LNG refueling stations. However, these experiences do indicate a need for routine maintenance of gas sensors, seals, and the rest of the LNG confinement boundary.

It is important to note that some of these events are not directly relevant to refueling stations. For example, the refueling stations considered in this study do not use large foundation tanks for storage. Instead, they use pressure vessel tanks mounted above ground. As another example, the vaporizer used at peakshaving plants to quickly heat up LNG employs a combustion process and undergoes high thermal and pressurization stresses. The vaporizers for refueling stations are passive ambient-temperature vaporizers and deal with small quantities of LNG. The vaporizers in refueling stations are used to bring the liquid close to saturation, rather than to produce large quantities of room temperature vapor.

Finally, Table 2-5 lists a number of accidents involving the transportation and handling of LNG. This table includes the 11 LNG trucking accidents referred to in Section 2.3.2. Many of the other accidents in this table involve LNG tanker ships. They are included because: a) some of the failure modes (e.g., overfilling, isolation valve failures, lightning strikes, high winds) appear to be generally relevant to a refueling station; and b) they show that more often than not, the consequences of the accidents are limited in scope (e.g., some deck plate cracking).

Table 2-5. Additional events involving transportation/handling of LNG.

Methane Progress, December 25, 1964

Fire at the forward vent riser ignited by lightning during unloading at the receiving terminal resulted in a six-hour delay in unloading. Prompt crew reaction extinguished the flaring without damage. (Frondeville 1977)

Jules Verne, Voyage 2, 1965

During loading, LNG tank was overfilled, causing a liquid spill from vent riser. A foreign object jammed in the float track prevented proper indication of liquid level by liquid level gauge. The tank cover and a deck stringer plate fractured. (GAO 1978), (Frondeville 1977)

Methane Progress Voyage 14, May 1, 1965

At disconnection of loading arms, LNG spilled from ship's crossover line. Seating of the liquid leading valve was prevented by a piece of a failed Teflon valve facing that lodged between valve disc and seat. The drip pan overflowed due to water being projected onto it. A minor deck plating crack occurred. (GAO 1978) 
Table 2-5. (continued).

Polar Alaska, November 19, 1969

During LNG loading at Kenai, Alaska, gas leaking was detected at the No. 1 cargo tank primary barrier on the $71,500 \mathrm{~m}^{3}$ Gas Transport membrane LNG carrier. Invar strakes creased in numerous locations. Cable trays broke loose and caused damage. The vessel continued in service without using the No. 1 cargo tank and the damage was repaired at a later date. (Harris 1993)

Methane Princess, Voyage 182, May 30, 1971

Liquid nitrogen loading line relief valve opened and spilled liquid nitrogen through the combined vent line onto the foredeck. Some cracking in deck plating occurred. Relief valve had been improperly reset at annual survey to a lower than specified pressure setting. (Harris 1993)

Waterbury, Vermont June 25, 1971

A truck had a tire blowout, hit some rocks by the road, punctured a hole in the tank and spilled $20 \%$.

There was no fire and the remainder of the load was dumped. (GAO 1978)

Warner, New Hampshire August 28, 1971

The driver of a truck drove off the road due to driver fatigue. The truck overturned, cracking fittings on the truck. There was a small gas leak, but no fire. (GAO 1978)

North Whitehall, Wisconsin October 8, 1971

An LNG transport truck was in a head-on collision with another truck. There was a gasoline and tire fire, but no loss of the LNG cargo. (GAO 1978)

Methane Progress, Voyage 193. October 31, 1971

A liquid nitrogen storage tank was inadvertently overfilled, causing discharge through the tank vent valve and combined vent line onto the foredeck. Main and second deck plating were cracked. (Frondeville 1977)

Raynham, Massachusetts October 1973

An LNG truck sideswiped a parked car. The truck brakes locked and the trailer overturned. There was no LNG cargo on board and no fire occurred. (GAO 1978)

Junction of Interstates 80 and 95, Fort Lee, New Jersey 1973

A driver could not negotiate a turn off. The resulting rollover demolished the tractor and caused $\$ 40,000$ damage to the LNG trailer. No fire occurred. (GAO 1978)

Route 40, Hamilton Township, New Jersey February 18, 1974

Faulty brakes on a truck caused a wheel fire. A check valve cracked and $5 \%$ of the LNG load leaked out. The report is unclear whether the LNG ignited or not. (GAO 1978)

McKee City, New Jersey February 21, 1974

A loose valve on a truck leaked LNG during a transfer operation. (GAO 1978)

Massachusetts, July 16, 1974

A one-inch globe valve (nitrogen purge valve) was overpressured during cargo loading and spilled approximately 40 gallons of LNG. The sudden pressure rise occurred when the cargo loading valve closed because of a momentary electrical power interruption after generator switchover. The liquefied natural gas cracked the canopy deck. (GAO 1978) 
Table 2-5. (continued).

Chattanooga, Tennessee January 1976

A transport truck carrying LNG overturned due to an oil spill on an exit ramp. There was no fire. The truck was righted and continued delivery of its cargo. (GAO 1978)

Dalton, Georgia November 1975

The driver of a transport truck carrying LNG swerved to avoid a pedestrian, hit a guard rail and rolled over and down an 80-foot embankment. There was $\$ 18,000$ damage to the trailer, but apparently no fire.

(GAO 1978)

Pawtucket, Rhode Island September 16, 1976

A car hit an LNG trailer at the landing wheels, caused the trailer to overturn. There was no LNG loss or fire. (GAO 1978)

Connecticut Turnpike March or April 1977

An LNG truck was parked at the side of the turnpike with a blowout when it was hit in the rear by a tow truck. There was no leak or fire. (GAO 1978)

Arzew, Algeria March 30, 1977

An LNG spill of $1500 \mathrm{~m}^{3}$ occurred at the Camel plant, attributed to the rupture of a aluminum-cast valve body on a transfer line during the night. A plant operator was frozen to death, and the contingency plan was put into action. The LNG cloud had dissipated at dawn without further casualty. (Frondeville 1977)

Waterbury, Connecticut July 1977

A "single wall" LNG trailer was hit in the rear by a tractor-trailer, knocking the axle off. In this case the controls were under the tank. There was no loss of cargo. (GAO 1978)

El Paso Paul Kayser, June 29, 1979

After taking avoiding action to prevent a collision in fog at $22: 30$ hours the $125,000 \mathrm{~m}^{3} \mathrm{Gaz}$ Transport membrane LNG carrier ran on to rocks and grounded in the Straits of Gibraltar when loaded with $95,500 \mathrm{~m}^{3}$ of LNG. The bottom shell and double bottom were extensively damaged over almost the full length of the cargo spaces. The invar membrane was indented but remained liquid-tight. There was no cargo spillage. The vessel was refloated on July 4 and on July 11 the transfer of the cargo of LNG to sister ship El Paso Sanatrach was completed. The damaged ship was then gas-freed, inerted and towed to Lisbon for temporary repairs. Later the vessel proceeded under her own power to the ship's original building yard at Dunkerque for full repair work. (Harris 1993)

\section{LNG Taurus, December 12, 1980}

The $126,750 \mathrm{~m}^{3}$ Moss spherical tank LNG carrier grounded in strong winds at Mutsure anchorage, near the end of a loaded voyage from Bontang, Indonesia to Tobata, Japan. Approximately $40 \%$ of the double bottom was breached and open to the sea. Severe weather conditions with gale force winds and $3 \mathrm{~m}$ waves around the vessel hampered the salvage operations. Fuel from the bunkers was transferred to a barge and the damaged ballast spaces were pressurized. The vessel was refloated on December 16 and then towed to Tobata where the full cargo of LNG was discharged on December 18. (Harris 1993) 
Table 2-5. (continued).

Tenaga Satu, June 1983

Cargo pump defects caused damage to the No. 1 cargo tank on the $130,000 \mathrm{~m}^{3} \mathrm{Gaz}$ Transport membrane LNG carrier. Approximately $110 \mathrm{~m}^{2}$ of the invar primary barrier was renewed and patches fitted at Yokohama, Japan in June 1984. (Harris 1993)

Ramdane Abane, February 9, 1984

During the discharge of Algerian LNG at Montoir, France a cargo leak was noted through the No. 5 cargo tank membrane on the $126,190 \mathrm{~m}^{3}$ Gaz Transport membrane LNG carrier. The vessel was taken to the roads for gas-freeing and inspection. Several suction manifolds were also found to be cracked. Repairs were later carried out at St. Nazaire, France. (Harris 1993)

Isabella, June 14, 1985

A cargo valve failed on the $35,491 \mathrm{~m}^{3}$ Gaz Transport membrane LNG carrier at the beginning of the LNG discharge at Barcelona, Spain after a voyage from Skikda, Algeria. LNG from the No. 1 cargo tank overflowed onto the main deck, causing severe cracking to the steelwork. The tank was discharged without further incident. Extensive repairs were required resulting from the spill. (Harris 1993)

Tellier, February 15, 1989

Moorings broke on the $40,081 \mathrm{~m}^{3}$ Technigaz membrane LNG carrier, due to $160 \mathrm{~km} / \mathrm{hr}$ winds, during LNG loading at Skikda, Algeria. Four terminal loading arms were damaged and LNG leaked to the main deck causing extensive damage to the steelwork and upper primary and secondary barriers in the No. 3 cargo tank. The vessel delivered LNG to Fos, France on February 16. Steelwork repairs were carried out at Marseilles and the ship returned to service in June with one of the five cargo tanks out of commission. Permanent repairs to the containment system were completed at Marseilles in October 1990. (Harris 1993)

a. This event does not involve LNG, but provides a representative failure scenario involving a cryogenic liquid.

Table 2-6. Nomenclature used in Figure 2-1.

\begin{tabular}{lll}
\hline Component ID & Component Type & \multicolumn{1}{c}{ Notes } \\
\hline FCV-103 & Valve & Pump inlet \\
FCV-104 & Valve & Pump vent \\
FCV-105 & Valve & Recirculation \\
FCV-106 & Valve & Saturation coil feed \\
FCV-107 & Valve & Dispensing \\
V-1 & Valve & Top fill \\
V-2 & Valve & Hose drain \\
V-8 & Valve & Liquid phase \\
V-9 & Valve & Vapor phase \\
V-10 & Valve & LI-1 equalization
\end{tabular}


Table 2-6. (continued).

Component ID

Component Type

Notes

$\mathrm{V}-11$

V-12

V-13

V-14

$\mathrm{V}-15$

$\mathrm{V}-16$

$\mathrm{V}-17$

$\mathrm{V}-18$

V-19

$\mathrm{V}-20$

$\mathrm{V}-21$

$\mathrm{V}-22$

V-23

$\mathrm{V}-24$

V-25

$\mathrm{V}-26$

V-27

$\mathrm{V}-28$

V-29

$\mathrm{V}-30$

V-31

$\mathrm{V}-32$

V-33

V-34

$\mathrm{V}-35$

$\mathrm{V}-36$

V-37

CV-1

CV-2

CV-3

PSV-101A

PSV-101B
Valve

Valve

Valve

Valve

Valve

Valve

Valve

Valve

Valve

Valve

Valve

Valve

Valve

Valve

Valve

Valve

Valve

Valve

Valve

Valve

Valve

Valve

Valve

Valve

Valve

Valve

Valve

Check valve

Check valve

Check valve

Safety valve

Safety valve
Full trycock

Manual vent

Isolation pump inlet

Isolation pump vent

Saturation isolation

Saturation pressure

Manual vent pump sump

Dispensing drain

Vacuum gauge tube

Safety selector

Evacuation

Stack drain

Auxiliary top fill

Transport return

Transport suction

N2 purge

Sample isolation

Sample vent

Sample purge

Top fill isolation

Vehicle fill isolation

PSV-101A test

PSV-101B test

PSV-105B test

PSV-105A test

PSV-104C test

PSV-104B test

Fill

Saturation return

Discharge

Inner vessel

Inner vessel 
Table 2-6. (continued).

\begin{tabular}{|c|c|c|}
\hline Component ID & Component Type & Notes \\
\hline PSV-101C & Safety valve & Saturation pressure \\
\hline PSV-102A & Safety valve & Pump sump \\
\hline PSV-102B & Safety valve & Dispense line \\
\hline PSV-103 & Safety valve & Transport suction line \\
\hline PSV-104A & Safety valve & Top fill line \\
\hline PSV-104B & Safety valve & Top fill line \\
\hline PSV-104C & Safety valve & Saturation return line \\
\hline PSV-104D & Safety valve & Saturation return line \\
\hline PSV-105A & Safety valve & Pump vent line \\
\hline PSV-105B & Safety valve & Pump feed line \\
\hline PSE-101A & Rupture disk & Inner vessel \\
\hline PSE-101B & Rupture disk & Inner vessel \\
\hline PSE-101C & Rupture disk & Outer vessel \\
\hline PSE-102 & Rupture disk & Pump sump \\
\hline E-101 & Saturation coil & - \\
\hline F -1 & Filter & Transfer line \\
\hline TC-1 & Vacuum probe & - \\
\hline PDI-101 & Liquid level indicator & - \\
\hline PDT-101 & Liquid level transmitter & - \\
\hline $\mathbf{M}-1$ & Meter & - \\
\hline$P-101$ & Pump & - \\
\hline PI-101A & Pressure indicator & Inner vessel \\
\hline PI-101B & Pressure indicator & Saturation \\
\hline PI-102A & Pressure indicator & Pump Sump \\
\hline PI-102B & Pressure indicator & Dispenser \\
\hline PT-101A & Pressure transmitter & Inner vessel \\
\hline PT-101B & Pressure transmitter & Saturation \\
\hline TT-102 & Temperature sensor & - \\
\hline TH-1 & Transfer hose & - \\
\hline FC-1 & Connection & Top fill \\
\hline FC-2 & Connection & Vehicle fill \\
\hline FC-3 & Connection & Transport return \\
\hline
\end{tabular}


Table 2-6. (continued).

\begin{tabular}{lll}
\hline Component ID & \multicolumn{1}{c}{ Component Type } & \multicolumn{1}{c}{ Notes } \\
\hline FC-4 & Connection & Transport suction \\
C-1 & Connection & Sample cylinder \\
C-2 & Connection & Sample vent \\
C-3 & Connection & Sample purge \\
C-4 & Connection & Vehicle vent \\
C-5 & Comnection & N2 purge \\
-0 & Connection to vent stack & - \\
\hline & Vent to atmosphere & - \\
\hline
\end{tabular}




\section{QUALITATIVE RISK ASSESSMENT}

\subsection{Introduction}

This section documents the results of a qualitative risk assessment performed for a generic LNG refueling station and summarizes the approach used to obtain these results. The objectives of this assessment are to:

- Identify accident scenarios relevant to a broad spectrum of stations

- Determine which of these scenarios may be significant risk contributors.

Potential risk significance is determined through qualitative assessments of scenario relative likelihood and consequences. The scenario consequences are expressed in terms of the following potential outcomes: a large LNG release, onsite ignition of a large LNG release, and a large LNG offsite release. The analysis does not directly address public and worker health consequence measures (e.g., severe injuries and fatalities). However, these can be directly related to the three outcomes identified, especially when a quantitative analysis is performed. The analysis also does not address offsite ignition, as this would require treatment of offsite features (e.g., traffic, industry, population) judged to be beyond the scope of this study.

It must be emphasized that the results of this qualitative risk assessment are relative. The potentially dominant scenarios identified are believed to be more risk significant than other scenarios studied. Thus, the study results should be helpful to station designers and operators. However, a quantitative analysis is needed to determine if the scenarios identified are risk significant in an absolute sense. Such an analysis is needed when supporting policy decisions.

\subsection{Approach}

Serious accidents can often be viewed as the culmination of a sequence of failures involving humans, hardware, or both. Such a sequence consists of an initial fault, an "initiating event, followed by failures of safety barriers (either engineered or natural) that would otherwise limit the severity of the accident. For example, in the 1944 Cleveland tank accident, the initial storage tank failure was followed by the failure of the bund wall to perform its intended function. The subsequent ignition of the gas and the failure of the second storage tank can also be viewed as failures of safety barriers, even though an engineered mitigating system was not involved.

Given this view of accidents, it can be seen that event trees, which graphically depict the different possible sequences of safety barrier successes and failures following an initiating event, provide a natural means to model accident scenarios. Event trees were introduced to risk assessment in the landmark Reactor Safety Study (also known as WASH-1400) performed by the U.S. Nuclear Regulatory Commission (USNRC 1975). Since that study, event trees have been used in many risk assessment applications. A number of transportation risk assessment studies use event trees (Rhoads 1978), as does a recent investigation of oil spill accidents (Siu et al. 1995). 
An example event tree for scenarios initiated by an operator tank filling error is shown in Figure 3-1. The safety barriers challenged following the initiating event are listed at the top of the tree; these are called "top events." Each node in the tree represents a safety barrier challenge; the path leading to the right of the node represents success of the safety barrier, while the path leading down from the node represents failure.

Figure 3-1 shows that the event tree is an inductive diagram; it shows what happens after a given initiating event. Clearly, therefore, the qualitative risk assessment must include multiple event trees, each one corresponding to a different initiating event. Furthermore, efforts must be spent to ensure that the list of initiating events considered is reasonably complete. If an initiating event is not addressed, the analysis will not treat the risk contributions from scenarios associated with that initiating event. On the other hand, analysis resources can be exhausted if too many initiating events are treated. Practical risk assessment requires a balance between the desire for completeness and available resources.

With these issues in mind, the steps employed in this study to perform the qualitative risk assessment are as follows:

1. Develop list of initiating events
a. Identify candidate initiating events
b. Group initiating events

2. Develop event trees
a. Identify event tree "top events"
b. Identify dependencies between top events and initiating events
c. Develop accident scenarios

3. Analyze accident scenarios

a. Identify scenarios leading to severe consequences

b. Identify potentially dominant scenarios

c. Determine refueling station characteristics affecting likelihood of dominant scenarios.

\subsection{Initiating Event Identification}

\subsubsection{Candidate Initiating Events}

As in many studies and recommended in the Probabilistic Risk Assessment (PRA) Procedures Guide (ANS 1980), this study employs a variety of methods to identify candidate initiating events, i.e., initiating events that might be treated in the analysis. The principal method used is the Master Logic Diagram 
(MLD). Other methods used include Failure Modes and Effects Analysis (FMEA), event sequence and task analyses, operating experience review, and review of other relevant studies.

A MLD is a logic diagram which is used to deduce how a single top event can be caused by underlying events (ANS 1980). MLDs are similar to fault trees in that they are deductive in nature. They are different in that they do not generally show all of the conditions that must arise for the top event to occur. (In other words, they do not generally include "AND" gates.)

Figures 3-2 through 3-4 show the MLDs developed for this study. The top events, shown in Figures 3-2 and 3-3 respectively, are "Serious Onsite Injury and/or Fatality" and "Serious Offsite Injury and/or Fatality." All of the branches in the diagrams represent "OR" gates. For example, Figure 3-2 shows that a serious onsite injury and/or fatality can involve an acute injury or fatality or a chronic injury. An acute injury or fatality, in turn, can involve asphyxiation, trauma, thermal burns, or cryogenic burns. The triangles in the diagram represent transfers to another tree (Figure 3-4); the diamonds represent events that can be (but are not) further defined.

Both Figures 3-2 and 3-3 show that LNG releases are a major (if not sole) contributor to the top event. They both transfer to Figure 3-4, which identifies several potential failures (hardware, human, and external) that may lead to a release. It should be emphasized that while these failures may lead to an LNG release, they do not necessarily guarantee the occurrence of the release. The additional failures that must occur before a release can happen are identified in the event tree analysis, discussed in Section 3.4 below. Note also that the failure events are defined generically. This allows the broad application of this study's results to different refueling stations.

To supplement the MLD analysis, an FMEA' was performed on the system shown in Figure 2-1 (Facility Number 1). This FMEA is provided in Appendix A. It shows that there are a number of single point failures (primarily involving relief valves) which can lead to releases of LNG to the enviromment. Event sequence and task analyses (defining the sequence of actions taken during station and end user vehicle refueling), reviews of past events, and reviews of other studies were also performed to supplement the MID.

Regarding other studies, Williamson and Edeskuty (1983) defined several hazards which involve or influence the occurrence of initiating events:

- Storage tank failures

- Unloading and transfer leaks

- Corrosion of dissimilar metals in systems and foreign material induced corrosion

- Collisions of transport vehicles

- Vaporization system failure

- Fires and explosions

c. A Failure Modes and Effects Analysis (FMEA) is an inductive exercise which postulates the failure of every system component and determines the consequences of these failures. 
- Gas-air vapor cloud dispersion

- Temperature extremes

- Personnel exposure (cryogenic temperatures and flames)

- Human factors

- Reactivity of cryogens.

Melchers and Feutrill (1995), in their report on an ongoing risk assessment on LPG-fueled vehicles, identify the following initiating event classes:

- Cold catastrophic failure of a tank (due to metal fatigue, corrosion, or overfilling)

- Flame impingement on a tank

- Impact by vehicles

- Negligent action by operators or drivers (driveaways, uncoupling hoses with valves open, etc.)

- Poor maintenance (unrepaired hose wear and tear, or valve spring corrosion, etc.)

- Vandalism and attempts at fuel theft.

Selected results of these other studies have been integrated into the LNG release MLD shown in Figure $3-4$ as appropriate. 


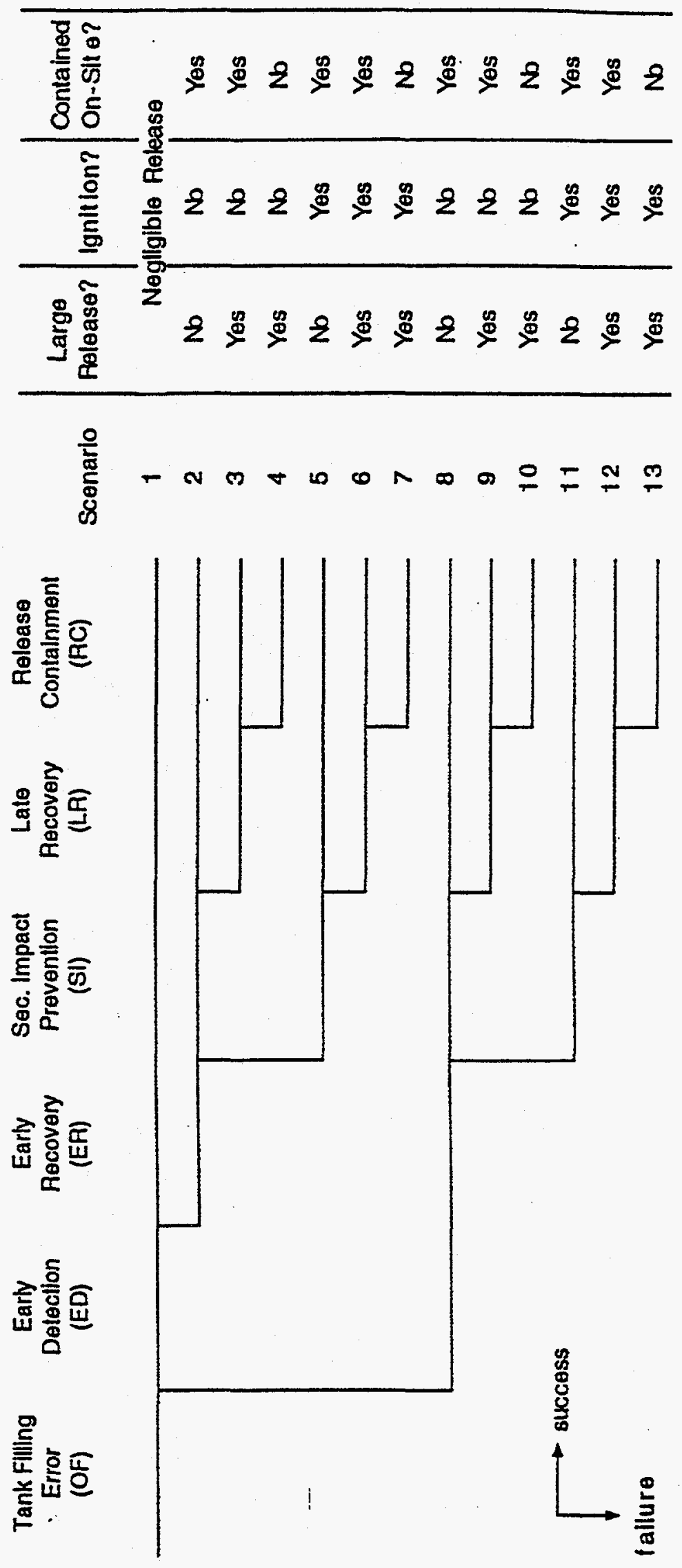

홀 


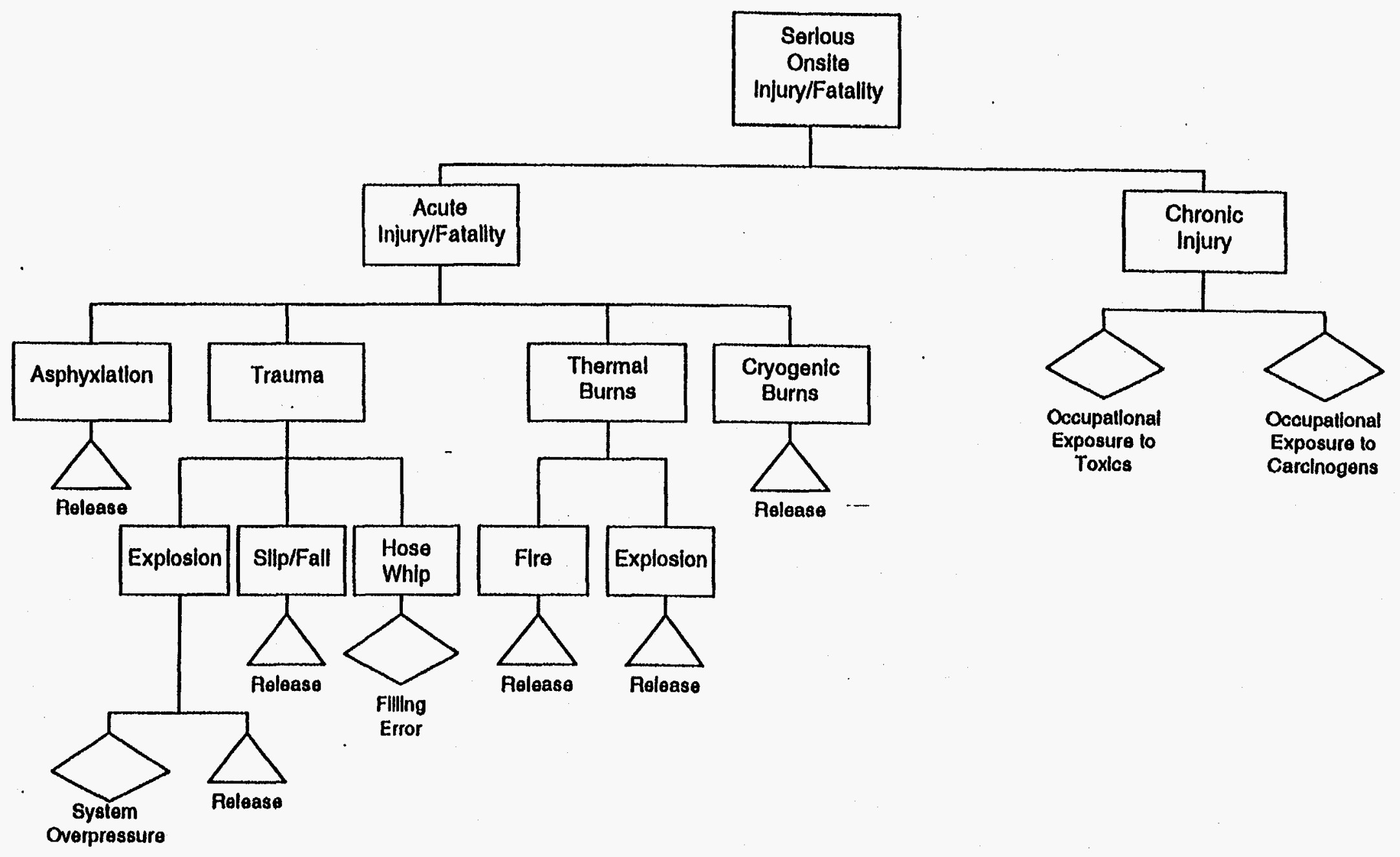

-Addresses only lasues that might distinguish LNG from dlesel luel.

Figure 3-2. Master Logic Diagram: Onsite Serious Injury or Fatality 


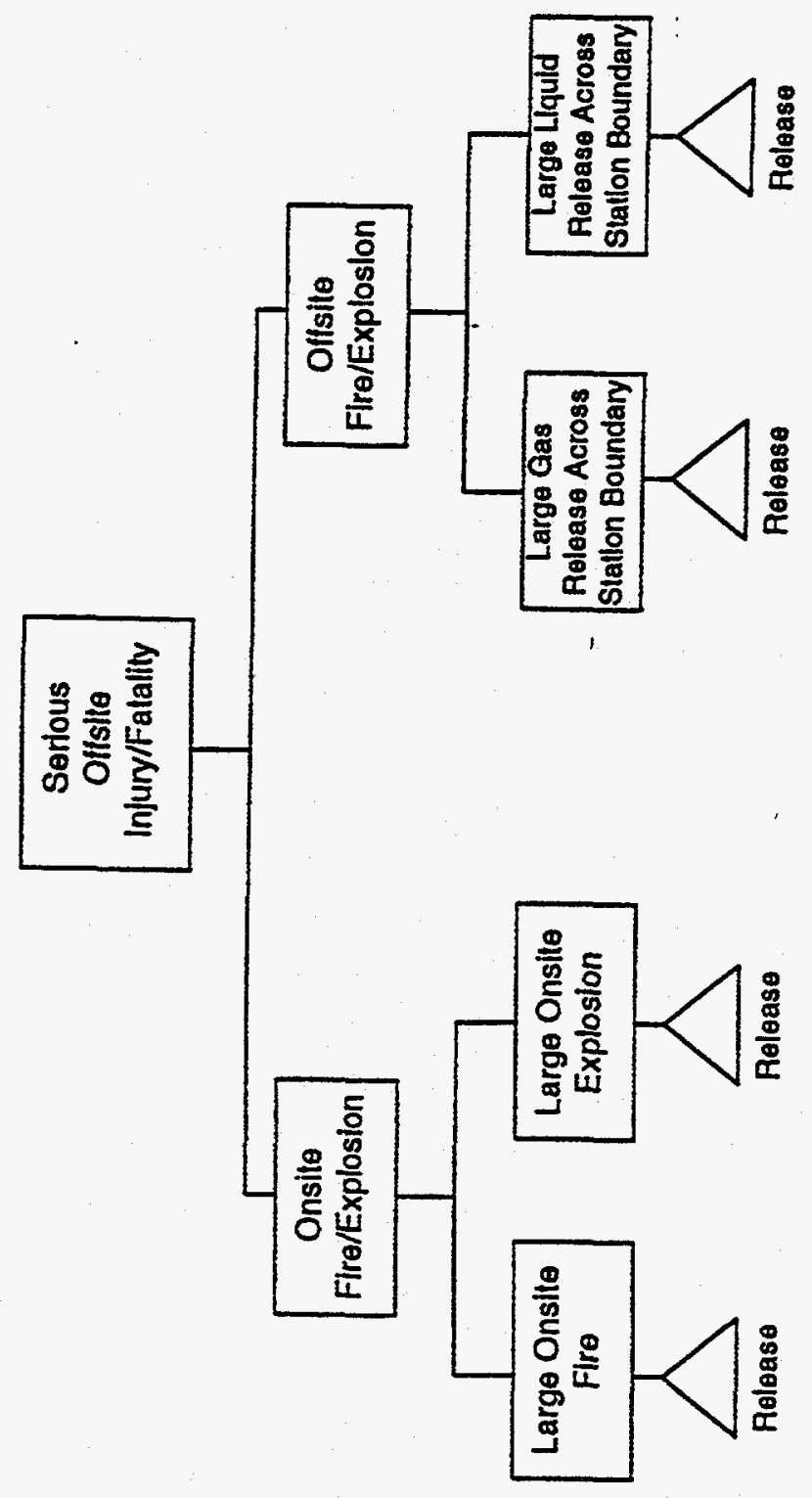

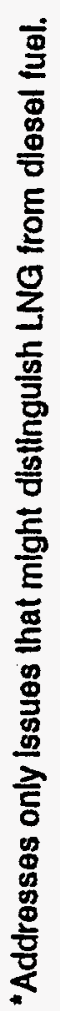

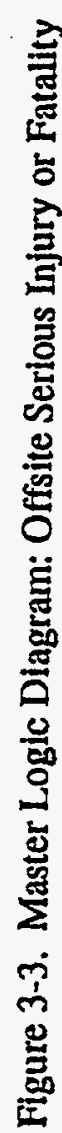




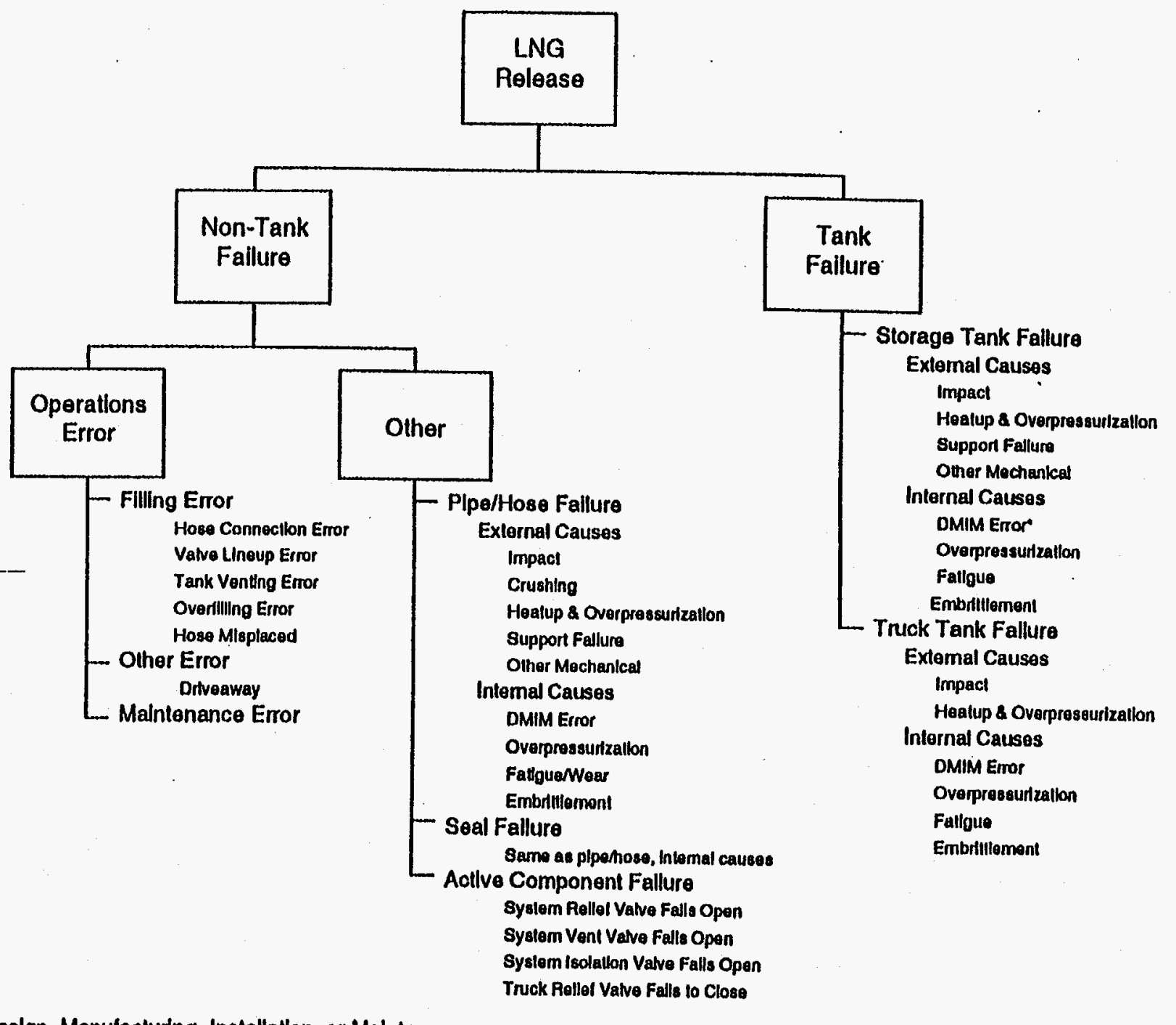

-DMIM = Deslgn, Manufacturing, Installatlon, or Malntenance

Figure 3-4. Master Logic Diagram Continuation: LNG Release 
This page intentionally left blank. 


\subsubsection{Initiating Event Grouping}

In order to keep the analysis tractable, the candidate initiating events shown in Figure 3-4 were grouped. [While two of the candidate events shown in Figure 3-2 (i.e., chronic injuries due to occupational exposures to toxins and carcinogens) are not included in Figure 3-4, these events are believed to be of lesser significance and are not further addressed in this study.] The groups were distinguished based on:

- Potential impact on the safety functions modeled in the event trees (see Figure 3-1 and Section 3.4)

- Potential impact on the likelihood of recovery efforts

- Potential magnitude of releases.

For example, all internal failure causes for the storage tank (i.e., design, manufacturing, installation, and maintenance errors; overpressurization; fatigue; embrittlement) are grouped together because the particular failure cause is not expected to affect the likelihood of recovery, ignition, containment, and so forth. Operator errors leading to release are grouped together because they imply the immediate presence of an operator during the event; this should increase the chances for recovery. Events potentially involving multiple tanks (e.g., driveaway accidents which could involve both the storage and vehicle tanks) are distinguished from other events because they can lead to larger releases of LNG.

Table 3-1 lists the initiating events resulting from this grouping process and provides a map relating these initiating events to the candidate initiating events (MLD failure causes) shown in Figure 3-4. Note that some of the candidate initiating events appear under more than one initiating event. This is because some of the failure causes (e.g., impact) can arise from different sources (e.g., tornadoes, vehicle crashes).

Table 3-1. Initiating events and mapping to MLD failure causes. Initiating Event

\begin{tabular}{|c|c|c|}
\hline Identifier & Description & MLD Failure Causes Included \\
\hline \multirow{4}{*}{ CAI } & \multirow{4}{*}{$\begin{array}{l}\text { Construction } \\
\text { Accident, } \\
\text { Isolable }\end{array}$} & Storage tank failure, external causes: impact, other mechanical \\
\hline & & Pipe/hose failure, external causes: impact, crushing, other mechanical \\
\hline & & Seal failure \\
\hline & & NOTE: "Other mechanical" includes digging and drilling \\
\hline \multirow[t]{4}{*}{ CAU } & \multirow{4}{*}{$\begin{array}{l}\text { Construction } \\
\text { Accident, } \\
\text { Unisolable }\end{array}$} & $\begin{array}{l}\text { Storage tank failure, external causes: impact, other mechanical external causes } \\
\text { (e.g., digging, drilling) }\end{array}$ \\
\hline & & $\begin{array}{l}\text { Pipe/hose failure, external causes: impact, other mechanical external causes } \\
\text { (e.g., digging, drilling) }\end{array}$ \\
\hline & & Seal failure \\
\hline & & NOTE: "Other mechanical" includes digging and drilling \\
\hline \multirow[t]{4}{*}{$\mathrm{EE}$} & \multirow[t]{4}{*}{ External Event } & $\begin{array}{l}\text { Storage tank failure, external causes: impact, heatup and overpressurization, } \\
\text { support failure }\end{array}$ \\
\hline & & Truck fuel tank failure, external causes: heatup and overpressurization \\
\hline & & $\begin{array}{l}\text { Pipe/hose failure, external causes: impact, crushing, heatup and } \\
\text { overpressurization, support failure }\end{array}$ \\
\hline & & Seal failure \\
\hline
\end{tabular}


Table 3-1. (continued).

\begin{tabular}{|c|c|c|}
\hline \multicolumn{2}{|c|}{ Initiating Event } & \multirow[b]{2}{*}{ MLD Failure Causes Included } \\
\hline Identifier & Description & \\
\hline \multirow{3}{*}{ HF } & \multirow{3}{*}{ Hose Failure } & $\begin{array}{l}\text { NOTE: Includes effects of earthquakes, floods, storms, non-LNG fires, aircraft } \\
\text { impact, lightning strike, non-LNG explosions, etc. }\end{array}$ \\
\hline & & $\begin{array}{l}\text { Pipe/hose failure, internal causes: DMMM error, overpressurization, } \\
\text { fatigue/wear, embrittlement }\end{array}$ \\
\hline & & Operations error, filling error: hose misplaced \\
\hline OD & Driveaway & Operations error, other error: driveaway \\
\hline \multirow[t]{3}{*}{ OF } & \multirow[t]{3}{*}{ Filling Error } & Pipe/hose failure, external causes: crushing \\
\hline & & $\begin{array}{l}\text { Operations error, filling error: hose connection error, valve lineup error, tank } \\
\text { venting error, overfilling error }\end{array}$ \\
\hline & & NOTE: Hose crushing due to vehicle driveover \\
\hline \multirow{2}{*}{$\mathrm{OM}$} & \multirow{2}{*}{$\begin{array}{l}\text { Maintenance } \\
\text { Error }\end{array}$} & Operations error, maintenance error \\
\hline & & NOTE: Addresses maintenance-induced leaks \\
\hline PFI & $\begin{array}{l}\text { Pipe Failure, } \\
\text { Isolable }\end{array}$ & $\begin{array}{l}\text { Pipe/hose failure, internal causes: DMMM error, overpressurization, } \\
\text { fatigue/wear, embrittlement }\end{array}$ \\
\hline PFU & $\begin{array}{l}\text { Pipe Failure, } \\
\text { Unisolable }\end{array}$ & $\begin{array}{l}\text { Pipe/hose failure, internal causes: DMMM error, overpressurization, } \\
\text { fatigue/wear, embrittlement }\end{array}$ \\
\hline SFI & $\begin{array}{l}\text { Seal Failure, } \\
\text { Isolable }\end{array}$ & Seal failure: DMIM error, overpressurization, fatigue/wear, embrittlement \\
\hline SFU & $\begin{array}{l}\text { Seal Failure, } \\
\text { Unisolable }\end{array}$ & Seal failure: DMM error, overpressurization, fatigue/wear, embrittlement \\
\hline \multirow[t]{2}{*}{ STF } & \multirow{2}{*}{$\begin{array}{l}\text { Storage Tank } \\
\text { Failure }\end{array}$} & Storage tank failure, external causes: support failure \\
\hline & & $\begin{array}{l}\text { Storage tank failure, internal causes: DMM error, overpressurization, fatigue, } \\
\text { embrittlement }\end{array}$ \\
\hline \multirow[t]{2}{*}{ TTF } & \multirow[t]{2}{*}{$\begin{array}{l}\text { Truck Fuel } \\
\text { Tank Failure }\end{array}$} & $\begin{array}{l}\text { Truck tank failure, internal causes: DMM error, overpressurization, fatigue, } \\
\text { embrittlement }\end{array}$ \\
\hline & & Active component failure: truck relief valve fails to close \\
\hline \multirow[t]{2}{*}{ TTT } & \multirow[t]{2}{*}{$\begin{array}{l}\text { Tanker Truck } \\
\text { Tank Failure }\end{array}$} & $\begin{array}{l}\text { Truck tank failure, internal causes: DMMM error, overpressurization, fatigue, } \\
\text { embrittlement }\end{array}$ \\
\hline & & Active component failure: truck relief valve fails to close \\
\hline \multirow[t]{3}{*}{ VA } & \multirow{3}{*}{$\begin{array}{l}\text { Vehicular } \\
\text { Accident }\end{array}$} & Storage tank failure, external causes: impact \\
\hline & & Truck tank failure, external causes: impact \\
\hline & & Pipe/hose failure, external causes: impact \\
\hline VFI & $\begin{array}{l}\text { Valve Failure, } \\
\text { Isolable }\end{array}$ & $\begin{array}{l}\text { Active component failure: relief valve fails open, vent valve fails open, } \\
\text { isolation valve fails to close }\end{array}$ \\
\hline VFU & $\begin{array}{l}\text { Valve Failure, } \\
\text { Unisolable }\end{array}$ & $\begin{array}{l}\text { Active component failure: relief valve fails open, vent valve fails open, } \\
\text { isolation valve fails to close }\end{array}$ \\
\hline
\end{tabular}

Appendix B presents fault trees for each of the initiating events as applied to a generic refueling station. Unlike an MID, the fault trees identify all necessary and sufficient conditions for the occurrence of the top event. 


\subsection{Event Trees}

\subsubsection{Safety Barrier Definitions}

An event tree, as discussed earlier, is a graphical representation of the possible scenarios that may follow an initiating event. The different scenarios are defined by successes and failures of safety barriers (called "top events" because of their placement in the event tree), both natural and engineered, that can prevent the initiating event from progressing to a major accident.

The top events considered in this study are adapted from those identified in a study on oil spill events (Siu et al. 1995). They are defined in terms of functions rather than engineered systems, in order to allow their application to a wide variety of facilities. They are also defined qualitatively, in keeping with the qualitative nature of this study. The top events are:

- Early Detection (ED): Detection of the release within a few minutes of its occurrence

- Early Recovery (ER): Early (within a few minutes) termination of the release before most of the source inventory is lost

- Secondary Impact Prevention (S1): Prevention of ignition or other additional effects (e.g., large releases from additional sources)

- Late Recovery (LR): Late (several minutes or more) termination of the release before most of the source inventory is lost

- Release Containment (RC): Containment of the release in the vicinity of the release.

\subsubsection{Dependencies}

In order to develop the possible sequences following an initiating event, dependencies between the initiating event and the top events, as well as those between the different top events, must be identified.

Consider the event tree shown in Figure 3-5, which models the possible sequences following a release caused by a severe external event (EE). ${ }^{d}$ It can be seen that the EE event tree has a number of branches labeled "GF," this denotes a "guaranteed failure." This reflects the modeling assumption that an external event severe enough to directly cause a large LNG release is also severe enough to greatly inhibit recovery efforts. Other assumed effects of the different initiating events on the top events are documented in the initiating event-to-safety barrier dependency matrix shown in Table 3-2.

d. The "external events" (i.e., events involving faults external to the system) treated by this tree include natural phenomena (e.g., earthquakes, floods, windstorms, lightning) and non-LNG fires. A number of other external events (e.g., construction accidents) are treated using different event trees. 
Figure 3-5 also shows that given failure of early detection (ED), early recovery (ER) is guaranteed to fail so the success branch is dashed to denote that it is not considered further. This is an example of a top event-to-top event dependency. The full dependency matrix for top event interactions is shown in Table 33.

Both Tables 3-2 and 3-3 represent generic dependency relationships. It is possible that additional dependency relationships exist for particular facilities. For example, in situations where subsequent failures can lead to releases from additional tanks (top event SI), the combined inventories may be large enough to overwhelm existing berms, depending on the sizing of the berms. The characteristics of the three facilities visited with respect to the event tree top events are discussed in Section 3.5.

\subsubsection{Scenario Identification}

Using the relationships shown in Tables 3-2 and 3-3, event trees have been developed for each of the initiating events identified in Table 3-1. The full set of event trees is shown in Appendix C. Figures 3-1 and 3-5 show representative event trees for tank filling errors (OF) and external events (EE), respectively. 


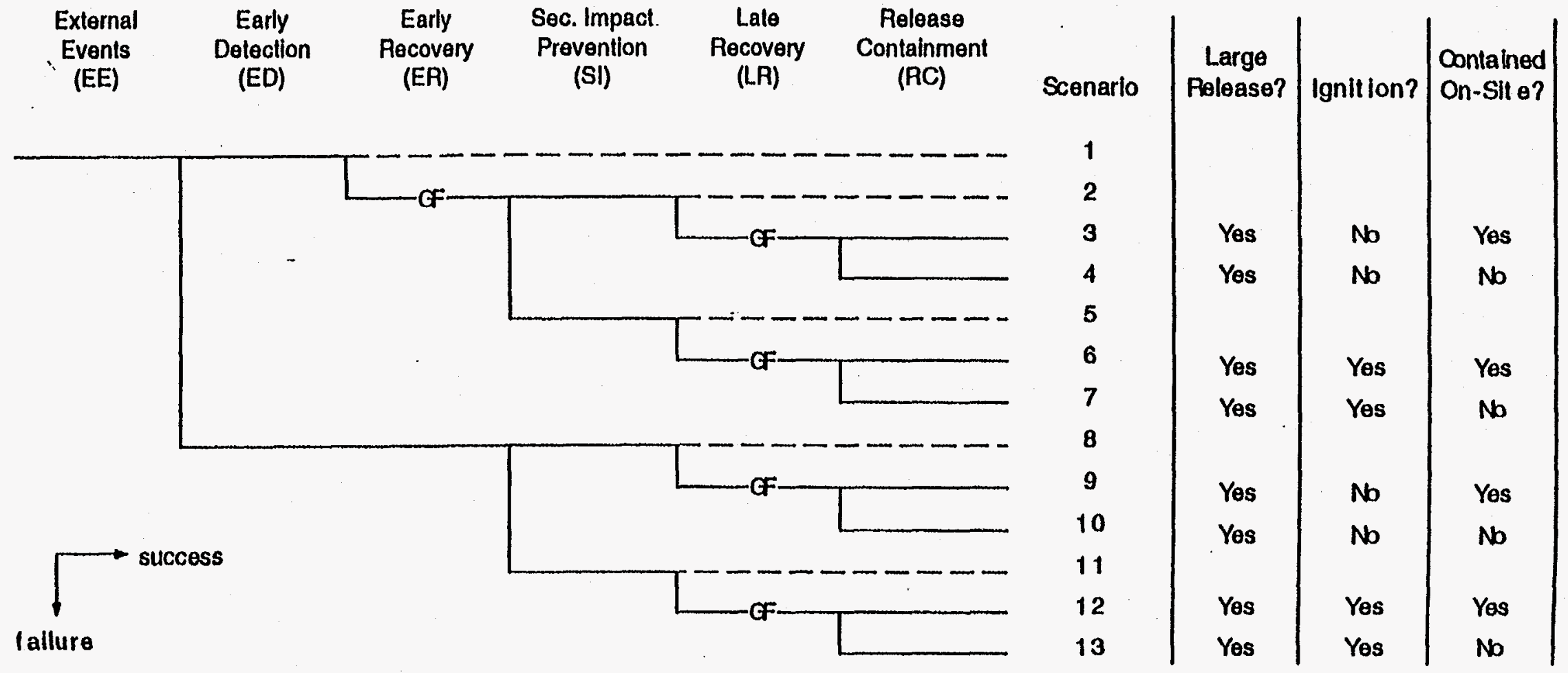

Figure 3-5. External Events Event Tree 
Table 3-2. Initiating event-to-top event dependency matrix.

Top Events

\begin{tabular}{|c|c|c|c|c|c|}
\hline $\mathrm{IE}^{\mathrm{a}}$ & ED & ER & SI & LR & $\mathrm{RC}$ \\
\hline CAI & GS & GF & (1) & - & - \\
\hline CAU & GS & GF & (1) & GF & - \\
\hline $\mathrm{EE}$ & (2) & GF & (3) & GF & (4) \\
\hline HF & (5) & (6) & - & - & - \\
\hline$\overline{O D}$ & GS & - & - & - & (7) \\
\hline OF & (5) & (6) & - & - & - \\
\hline $\mathrm{OM}$ & (8) & - & (9) & - & - \\
\hline PFI & - & - & - & - & - \\
\hline PFU & - & GF & - & GF & - \\
\hline SFI & - & - & - & - & - \\
\hline SFU & - & GF & - & GF & - \\
\hline STF & - & GF & - & GF & - \\
\hline TTF & - & GF & - & GF & (10) \\
\hline TTT & - & GF & - & GF & - \\
\hline VA & GS & GF & (11) & GF & - \\
\hline VFI & - & - & - & - & - \\
\hline VFU & - & GF & - & GF & - \\
\hline
\end{tabular}

a. Descriptions of the Initiating Events are in Table 3-1.

ED Early Detection: Detection of the release within a few minutes of its occurrence

ER Early Recovery: Early (within a few minutes) termination of the release before most of the source inventory is lost

SI Secondary Impact Prevention: Prevention of ignition or other additional effects (e.g., large releases from additional sources)

LR Late Recovery. Late (several minutes or more) termination of the release before most of the source inventory is lost

RC Release Containment: Containment of the release in the vicinity of the release

$\mathrm{GS}=\mathrm{Guaranteed} \mathrm{Success}$

$\mathrm{GF}=$ Guaranteed Failure

Other Notes:

1. Presence of construction activities increases likelihood of ignition sources.

2. Many external events can reduce the likelihood of early detection (e.g., due to loss of power, distraction).

3. Ignition sources are more likely for some external events (e.g., thunderstorms).

4. External events can decrease or increase likelihood of containment success. Examples: earthquake fails dike; storn disperses ING vapor.

5. Presence of personnel increases likelihood of early detection.

6. Presence of personnel increases likelihood of early recovery.

7. Truck release may be close to site boundary.

8. Time to detection depends on size and location (e.g., in yard or in confined space) of leak.

9. Presence of maintenance activities increases likelihood of ignition sources.

10. Containment success likely, given size of fuel tank. (Only containment problem arises if the release occurs near/at site boundary.)

11. Accident environment increases likelihood of ignition sources. 
Table 3-3. Top event-to-top event dependency matrix.

Top Events

\begin{tabular}{|c|c|c|c|c|c|}
\hline$\underline{I E}^{a}$ & ED & ER & SI & LR & $\mathbf{R C}$ \\
\hline ED & - & (1) & - & - & - \\
\hline ER & - & - & (2) & (2) & (2) \\
\hline SI & - & - & - & - & - \\
\hline LR & - & - & - & - & (3) \\
\hline $\mathbf{R C}$ & - & - & - & - & - \\
\hline
\end{tabular}

a. Descriptions of the Initiating Events are in Table 3-1.

ED Early Detection: Detection of the release within a few minutes of its occurrence

ER Early Recovery: Early (within a few minutes) termination of the release before most of the source inventory is lost

SI Secondary Impact Prevention: Prevention of ignition or other additional effects (e.g., large releases from additional sources)

LR Late Recovery: Late (several minutes or more) termination of the release before most of the source inventory is lost

RC Release Containment: Containment of the release in the vicinity of the release

GS $=$ Guaranteed Success

$\mathrm{GF}=$ Guaranted Failure

Other Notes:

1. Failure of ED guarantees failure of ER.

2. Success of ER makes top event irrelevant

3. Success of $L R$ makes top event irrelevant.

4. Top events appear in rough chronological order, only dependencies of later events on earlier events are modeled.

The accident scenarios for each initiating event follow directly from the event trees. For example, Scenario 3 of the EE event tree (Figure 3-5) involves the occurrence of the external event (EE), successful early detection (/ED), guaranteed failure of early recovery (ER'), successful prevention of secondary impacts (/SI), guaranteed failure of late recovery (LR'), and successful containment of the release (/RC). The Boolean representation of this sequence of events is:

Scenario $3=\mathrm{EE}^{*} / \mathrm{ED}^{*} \mathrm{ER}^{\prime *} / \mathrm{SI}^{*} \mathrm{LR}^{\prime *} / \mathrm{RC}$

where the asterisk $\left({ }^{*}\right)$ denotes the logical AND operator, the slash $(\zeta)$ denotes success, no slash denotes failure, and the prime (') denotes a guaranteed event. 


\subsection{Scenario Analysis}

\subsubsection{Scenarios with Severe Consequences}

The event trees in Figures 3-1 and 3-5 show the assumed consequences of each accident scenario. A "large release" is one that poses a significant hazard to onsite and offsite personnel. Depending on the site characteristics, this is generally on the order of several hundreds of gallons." The other consequences are self-explanatory.

Appendix D provides lists of all of the scenarios leading to large releases, large releases ignited onsite, and large releases which go offsite. These lists have been constructed simply by collecting all of the relevant sequences from each event tree.

\subsubsection{Potentially Dominant Scenarios}

The numerous scenarios listed in Appendix $\mathbf{D}$ are not all equal contributors to risk. Two scenarios leading to the same undesired consequences (e.g., onsite ignition of a large release) will have different contributions if their likelihood's differ.

Tables 3-4 and 3-5 show the lists of high consequence scenarios believed to be the most risk significant in terms of onsite ignition (of a large release) and large offsite release, respectively. This list has been developed by employing pairwise qualitative comparisons of scenarios within each event tree. The comparisons generally take advantage of the observation that, generally speaking, failures (human or hardware) are far less likely than successes. ${ }^{f}$ Thus, the risk contribution from one scenario is usually assumed to dominate that from another if: a) both scenarios lead to the same consequences, and b) the first scenario involves fewer failure events than the second. For example, in comparing the first construction accident scenario (CAI) with the second (CAU), both lead to onsite ignition of a large release of LNG. However, the latter scenario (CAU) involves the failure of spill containment. From the standpoint of large release occurrences, therefore, the first scenario should dominate the latter.

Exceptions to this dominance assumption are as follows:

- For the external events (EE) scenarios, it is assumed that failure of early detection (ED) is more likely than success, due to the impact of the external event on facility hardware and operators.

For the maintenance (OM) and isolable pipe (PFI), seal (SFI), and valve (VFI) failure scenarios, it cannot be determined if scenarios involving the success of early detection (/ED) and the failure of early recovery given an initiator (ER/IE) are significantly more likely than scenarios involving the failure of early detection (ED) and the consequent guaranteed failure of early recovery given an initiator (ER'|IE). In other words, it is not clear if

e. Truck fuel tank releases, while generally involving smaller quantities, are modeled as being capable of leading to "large releases" because they can occur close to the site boundary.

f. This rule does not cover situations where failure is guaranteed because of previous occurrences during the scenario. 
Table 3-4. Potentially dominant scenarios: large LNG release and onsite ignition.

IE

\begin{tabular}{|c|c|c|c|c|}
\hline CAI & /ED' & ER' & SI & LR \\
\hline $\mathrm{CAU}$ & /ED' & ER' & SI & $\mathbf{L R}^{\prime}$ \\
\hline EE & ED & ER' $^{\prime}$ & SI & $\mathbf{L R}^{\prime}$ \\
\hline HF & /ED & ER & SI & LR \\
\hline OD & $/ E^{\prime}$ & ER & SI & LR \\
\hline OF & /ED & ER & SI & LR \\
\hline OM & /ED & ER & SI & LR \\
\hline OM & ED & ER' & SI & LR \\
\hline PFI & /ED & ER & SI & LR \\
\hline PFI & ED & ER' $^{\prime}$ & SI & LR \\
\hline PFU & /ED & ER' & SI & $\mathbf{L R}^{\prime}$ \\
\hline SFI & /ED & ER & SI & LR \\
\hline SFI & ED & ER' & SI & LR \\
\hline SFU & /ED & $\mathbf{E R}^{\prime}$ & SI & $\mathbf{L R}^{\prime}$ \\
\hline STF & /ED & ER' & SI & $\mathbf{L R}^{\prime}$ \\
\hline TTF & /ED & ER' & SI & $\mathbf{L R}^{\prime}$ \\
\hline TTT & /ED & $\mathbf{E R}^{\prime}$ & SI & $\mathbf{L R}^{\prime}$ \\
\hline VA & /ED' & ER' $^{\prime}$ & SI & $\mathbf{L R}^{\prime}$ \\
\hline VFI & /ED & ER & SI & LR \\
\hline VFI & ED & ER' & SI & LR \\
\hline VFU & /ED & ER' $^{\prime}$ & SI & LR' $^{\prime}$ \\
\hline
\end{tabular}

Notes

For instance, collisions between construction equipment and refueling station components.

For instance, collisions between construction equipment and refueling station components.

Gasoline pipeline failures and ignition due to large flood in Houston; tank floating has been observed

Failure must occur during refueling to be significant

Driveaways are relatively common; most (if not all) have only involved small spills

Tank venting practices, shipboard overfilling events, and single point failures indicate scenario credibility

Localized explosion has been observed for LNG bus; no procedures; industry is learning

Few or no procedures, no standardized approaches; industry is learning

Passive pipeline failures are relatively unlikely; no known major events

Passive pipeline failures are relatively unlikely; no known major events

Passive pipeline failures are relatively unlikely; no known major events

Given early detection, recovery is likely

Cove Point event involved seal failure, no early detection, migration of vapor, explosion

Possibility depends on system design (isolability of seal leaks)

Cleveland tank employed 3.5\% nickel steel (not used anymore); expect dominance by DMI error

Expect dominance by relief valve failure

Expect dominance by relief valve failure

Must be severe enough to fail pressure boundary; no LNG truck events reviewed have involved LNG fire

Designs allow single-point failures by relief and vent valves

Designs allow single-point failures by relief and vent valves

Possibility depends on system design (isolability of valve)

a. descriptions of the Initiating Events are in Table 3-1.

ED Early Detection: Detection of the release within a few minutes of its occurrence

ER Early Recovery: Early (within a few minutes) termination of the release before most of the source inventory is lost

SI Secondary Impact Prevention: Prevention of ignition or other additional effects (e.g., large releases from additional sources)

LR Late Recovery: Late (several minutes or more) termination of the release before most of the source inventory is lost

RC Release Containment: Containment of the release in the vicinity of the release

Notes:

(1) Slash ( () indicates success; no slash indicates failure. Prime (') indicates success/failure guaranteed.

(2) Shaded scenarios appear to be of lesser concern on a generic basis.. 
Table 3-5. Potentially dominant scenarios: large LNG release offsite.

\begin{tabular}{|c|c|c|c|c|c|c|}
\hline \multirow{3}{*}{$\begin{array}{l}\text { IE } \\
\text { CAI } \\
\text { CAU }\end{array}$} & \multicolumn{5}{|c|}{ Top Events } & \multirow[b]{2}{*}{ Very large and rapid release required } \\
\hline & /ED' & ER' $^{\prime}$ & /SI & LR & $\mathbf{R C}$ & \\
\hline & /ED' & $\mathrm{ER}^{\prime}$ & /SI & LR' & $\mathbf{R C}$ & Very large and rapid release required \\
\hline $\mathrm{EE}$ & ED & ER' & /SI & LR' & $\mathbf{R C}$ & Includes damage to component due to flood, tornado, hurricane, lightning, etc. \\
\hline HF & /ED & ER & /SI & LR & $\mathbf{R C}$ & Very large release required; failure must occur during refueling to be significant \\
\hline OD & /ED' & ER & /SI & LR & $\mathbf{R C}$ & Driveaways are relatively common; most (if not all) have only involved small spills \\
\hline OF & /ED & ER & /SI & LR & $\mathbf{R C}$ & Tank venting practices, shipboard overfilling events, and single point failures indicate scenario credibility \\
\hline OM & /ED & ER & /SI & LR & RC & Event appears possible \\
\hline OM & ED & ER' & /SI & LR & $\mathbf{R C}$ & Early detection of major leak likely \\
\hline PFI & /ED & $\mathrm{ER}$ & /SI & LR & $\mathbf{R C}$ & Very large and rapid release required; passive pipeline failures relatively unlikely; no known major events \\
\hline PFI & ED & ER' & /SI & LR & $\mathbf{R C}$ & Very large and rapid release required; passive pipeline failures relatively unlikely; no known major events \\
\hline PFU & /ED & ER' & ISI & LR' & $\mathbf{R C}$ & Very large and rapid release required; passive pipeline failures relatively unlikely; no known major events \\
\hline SFI & /ED & ER & /SI & LR & $\mathbf{R C}$ & Very large and rapid release required; possibility is site-specific \\
\hline SFI & ED & ER' & /SI & LR & $\mathbf{R C}$ & Very large and rapid release required; possibility is site-specific \\
\hline SFU & /ED & ER' $^{\prime}$ & /SI & LR' & $\mathbf{R C}$ & Very large and rapid release required; possibility is site-specific \\
\hline STF & /ED & ER' & /SI & LR' & RC & Cleveland tank employed 3.5\% nickel steel (not used anymore); expect dominance by DMI error \\
\hline TTT & /ED & ER' & /SI & $\mathbf{L R}^{\prime}$ & $\mathbf{R C}$ & Expect dominance by DMI error \\
\hline VA & /ED' & $\mathbf{E R}^{\prime}$ & /SI & LR' & $\mathbf{R C}$ & Must be severe enough to fail pressure boundary; no LNG truck events reviewed have involved LNG fire \\
\hline VFI & /ED & ER & /SI & LR & $\mathbf{R C}$ & Very large and rapid release required \\
\hline VFI & ED & $\mathbf{E R}^{\prime}$ & /SI & LR & $\mathbf{R C}$ & Very large and rapid release required \\
\hline VFU & /ED & ER' & /SI & LR' & $\mathrm{RC}$ & Possibility depends on system design (isolability of valve) \\
\hline \multicolumn{7}{|c|}{ a. Descriptions of the Initiating Events are in Table 3-1. } \\
\hline ED & \multicolumn{6}{|c|}{ Early Detection: Detection of the release within a few minutes of its occurrence } \\
\hline ER & \multicolumn{6}{|c|}{ Early Recovery: Early (within a few minutes) termination of the release before most of the source inventory is lost } \\
\hline SI & \multicolumn{6}{|c|}{ Secondary Impact Prevention: Prevention of ignition or other additional effects (e.g., large releases from additional sources) } \\
\hline LR & \multicolumn{6}{|c|}{ Late Recovery: Late (several minutes or more) termination of the release before most of the source inventory is lost } \\
\hline RC & \multicolumn{6}{|c|}{ Release Containment: Containment of the release in the vicinity of the release } \\
\hline Notes: & \multirow{2}{*}{\multicolumn{6}{|c|}{$\begin{array}{l}\text { Slash (l) indicates success; no slash indicates failure. Prime (') indicates success/failure guaranteed. } \\
\text { Shaded scenarios appear to be of lesser concern on a generic basis. }\end{array}$}} \\
\hline (1) & & & & & & \\
\hline
\end{tabular}


Probability $\{/ E D * E R \mid I E\} \gg$ Probability $\{E D * E R \mid[E\}$

where Probability $\{\mathrm{A} \mid \mathrm{B}\}$ denotes the conditional probability of event A given event B and "IE" refers to the initiating event.

Tables 3-4 and 3-5 also provide a preliminary comparison of scenarios for different initiating events. Shaded scenarios in the table are believed to be generally less likely than unshaded scenarios; the bases for the scenario classifications are provided in the notes column of the table. Note that the storage tank scenarios (which involve internal failure causes-see Table 3-1) are not shaded. Although catastrophic failures are believed to be very unlikely given current design and construction practices, the potential consequences are believed to be large enough to warrant their inclusion in the group of more important scenarios.

\subsubsection{Station Characteristics Affecting Dominant Scenarios}

Table 3-6 identifies a number of site-specific characteristics for each of the facilities visited relevant to the likelihood of the initiating events considered in this study. Table 3-7 lists those characteristics relevant to the success or failure of the event tree top events (i.e., the safety barriers). Comparing these characteristics with the potentially dominant scenarios listed in Tables 3-4 and 3-5, it can be seen that differences in design, operations, and siting might imply significant differences in risk.

For example, regarding station design, Facility Number 3 has an onsite vehicle maintenance shop whereas the vehicle maintenance shops for Facilities 1 and 2 are a few minutes away. When looking specifically at refueling station risk, therefore, Facility Number 3 is likely to have a higher risk contribution from maintenance activities than the other two facilities. This potentially higher contribution could come from a higher frequency of maintenance-induced releases (initiating event $\mathrm{OM}$ ) as well as an increased number of potential ignition sources (which affects the likelihood of top event Sn). As another example, Facility Number 2 does not have a bund fully surrounding the main LNG storage tank (a trailer tank); while the tank is in a slight pit, it is not clear that, in the event of a full spill, the LNG will be fully contained. This reduces the likelihood of success of top event RC.

Differences in operation also are expected to have impacts on the station risk. Some potentially important factors include the frequency of refueling activities (Facilities 3 and 5 are by far the busiest), the degree of public access to the refueling area (Facility Number 2 is open to the public - the site has a gasoline service station and convenience store). The remaining facilities have varying degrees of restricted access, the training of personnel in fueling vehicles (Facilities $3,4,5,6$, and 7 use specially trained refueling technicians; refueling at Facilities 2,8 and 9 is performed by the truck drivers, some of whom excessively vent their fuel tanks to speed up the process), the location of designated emergency response persomel (depending on the time of day, key staff for Facility Number 2 can be 20 to 30 minutes away from the station when an alarm sounds), and the trained response of all personnel to emergencies (Facility Number 2 allows drivers one override of the emergency shutdown system). These factors affect the frequency of operator errors (initiating events OD and OF) and the likelihood of recovery and accident mitigation (top events ER, LR, and SI). 
Table 3-6. Noteworthy site-specific features affecting initiating event occurrence, Facilities 1, 2 and 3."

\begin{tabular}{|c|c|c|c|c|}
\hline \multirow[b]{2}{*}{$\underline{\mathbf{E}}$} & \multirow[b]{2}{*}{ Causes Include } & \multicolumn{3}{|c|}{ Factors Affecting Initiating Event Frequency } \\
\hline & & Facility Number 1 & Facility Number 2 & Facility Number 3 \\
\hline $\begin{array}{l}\text { CAI, } \\
\text { CAU }\end{array}$ & $\begin{array}{l}\text { Digging, drilling, } \\
\text { falling objects, other } \\
\text { impact }\end{array}$ & $\begin{array}{l}\text { System is aboveground. Low activity in } \\
\text { immediate area. }\end{array}$ & $\begin{array}{l}\text { System is aboveground or in concrete- } \\
\text { lined open trenches covered by steel } \\
\text { grates. Low activity in immediate area. }\end{array}$ & $\begin{array}{l}\text { System is aboveground or in open, } \\
\text { concrete-lined pit. }\end{array}$ \\
\hline EE & $\begin{array}{l}\text { Earthquake, flood, } \\
\text { storm, fire (non- } \\
\text { LNG), aircraft }\end{array}$ & $\begin{array}{l}\text { Out of flood zone; desert siting. Low } \\
\text { potential for local fires (low traffic, no } \\
\text { fixed combustibles). Range fires have } \\
\text { occurred in area. Well away from } \\
\text { regular flightpaths. }\end{array}$ & $\begin{array}{l}\text { Out of flood zone. Low traffic area. } \\
\text { Airport is about } 15 \text { miles away. }\end{array}$ & $\begin{array}{l}\text { Elevated about } 20 \text { feet above adjacent river. } \\
\text { Urban location provides potential missiles } \\
\text { during storms. Adjacent railyards a } \\
\text { potential source of fire. Airport is about } \\
5 \text { miles away. }\end{array}$ \\
\hline HF & $\begin{array}{l}\text { Internal causes, } \\
\text { DMIM }^{b} \text { error }\end{array}$ & $\begin{array}{l}\text { Hose is stainless steel bellows with } \\
\text { braided metal outer sheath. Facility has } \\
\text { been operating for about } 1.5 \text { years. }\end{array}$ & $\begin{array}{l}\text { Hose is stainless steel bellows with } \\
\text { coiled plastic outer sheath. Facility has } \\
\text { been operating for about } 1 \text { year. }\end{array}$ & $\begin{array}{l}\text { Hose is stainless steel bellows with braided } \\
\text { metal outer sheath. Facility has been } \\
\text { operating for about } 3 \text { years. }\end{array}$ \\
\hline OD & Driveaway Error & $\begin{array}{l}\text { Low number of refueling events per day. } \\
\text { No driveaways reported. Storage tank } \\
\text { and vehicle tank isolation provided by } \\
\text { nozzle design, check valves. }\end{array}$ & $\begin{array}{l}\text { No driveaways reported. Storage tank } \\
\text { and vehicle tank isolation provided by } \\
\text { nozzle design, check valves. }\end{array}$ & $\begin{array}{l}\text { Driveaways occur about once per month. } \\
\text { Storage tank and vehicle tank isolation } \\
\text { provided by nozzle design, check valves. }\end{array}$ \\
\hline OF & $\begin{array}{l}\text { Hose connection } \\
\text { error, valve lineup } \\
\text { error, tank venting } \\
\text { error, overfilling } \\
\text { error, hose misplaced }\end{array}$ & $\begin{array}{l}\text { Operator does not normally vent vehicle } \\
\text { tank. One interlock: ground must be } \\
\text { attached to actuate pump and allow } \\
\text { LNG flow to vehicle. Hose can be left } \\
\text { on ground. }\end{array}$ & $\begin{array}{l}\text { Valve lineup controlled by computer. } \\
\text { Vehicle and storage tanks often vented. } \\
\text { Interlock to detect correct nozzle } \\
\text { return. Training of driver-fuelers } \\
\text { variable. }\end{array}$ & $\begin{array}{l}\text { Valve lineup controlled by computer. } \\
\text { Venting not often necessary (high vehicle } \\
\text { usage). Can leave hose on ground or over } \\
\text { bund. Designated refueling technician. }\end{array}$ \\
\hline OM & Maintenance error & $\begin{array}{l}\text { Vehicle maintenance area well separated } \\
\text { from fueling area. }\end{array}$ & $\begin{array}{l}\text { Vehicle maintenance shop a few } \\
\text { minutes away from fueling area. }\end{array}$ & $\begin{array}{l}\text { LNG maintenance performed in onsite } \\
\text { diesel bus shop. }\end{array}$ \\
\hline $\begin{array}{l}\text { PFI, } \\
\text { PFU }\end{array}$ & $\begin{array}{l}\text { Overpressure, } \\
\text { internal causes, } \\
\text { DMIM }^{\text {b error }}\end{array}$ & $\begin{array}{l}\text { Low number of refuelings per day. } \\
\text { Facility has been operating for about } \\
1.5 \text { years. }\end{array}$ & $\begin{array}{l}\text { Low number of refuelings per day. } \\
\text { Facility has been operating for about } \\
1 \text { year. }\end{array}$ & $\begin{array}{l}\text { Equipment is in constant use } 16 \text { hours a } \\
\text { day. Facility has been operating for about } \\
3 \text { years. }\end{array}$ \\
\hline $\begin{array}{l}\text { SFI, } \\
\text { SFU }\end{array}$ & $\begin{array}{l}\text { Overpressure, } \\
\text { material failure, } \\
\text { DMIM }^{\text {b error }}\end{array}$ & $\begin{array}{l}\text { Facility has been operating for about } 1.5 \\
\text { years. }\end{array}$ & $\begin{array}{l}\text { Some problems with valve stem seals. } \\
\text { Facility has been operating for about } \\
1 \text { year. }\end{array}$ & $\begin{array}{l}\text { Has experienced a problem with leakage } \\
\text { around the refueling fitting. Facility has } \\
\text { been operating for about } 3 \text { years. }\end{array}$ \\
\hline STF & $\begin{array}{l}\text { Overpressure, } \\
\text { internal causes, } \\
\text { DMIM }^{b} \text { error }\end{array}$ & $\begin{array}{l}\text { Facility has been operating for about } 1.5 \\
\text { years. }\end{array}$ & $\begin{array}{l}\text { Facility has been operating for about } \\
1 \text { year. }\end{array}$ & $\begin{array}{l}\text { Facility has been operating for about } 3 \\
\text { years. }\end{array}$ \\
\hline
\end{tabular}


Table 3-6. (continued).

Factors Affecting Initiating Event.Frequency

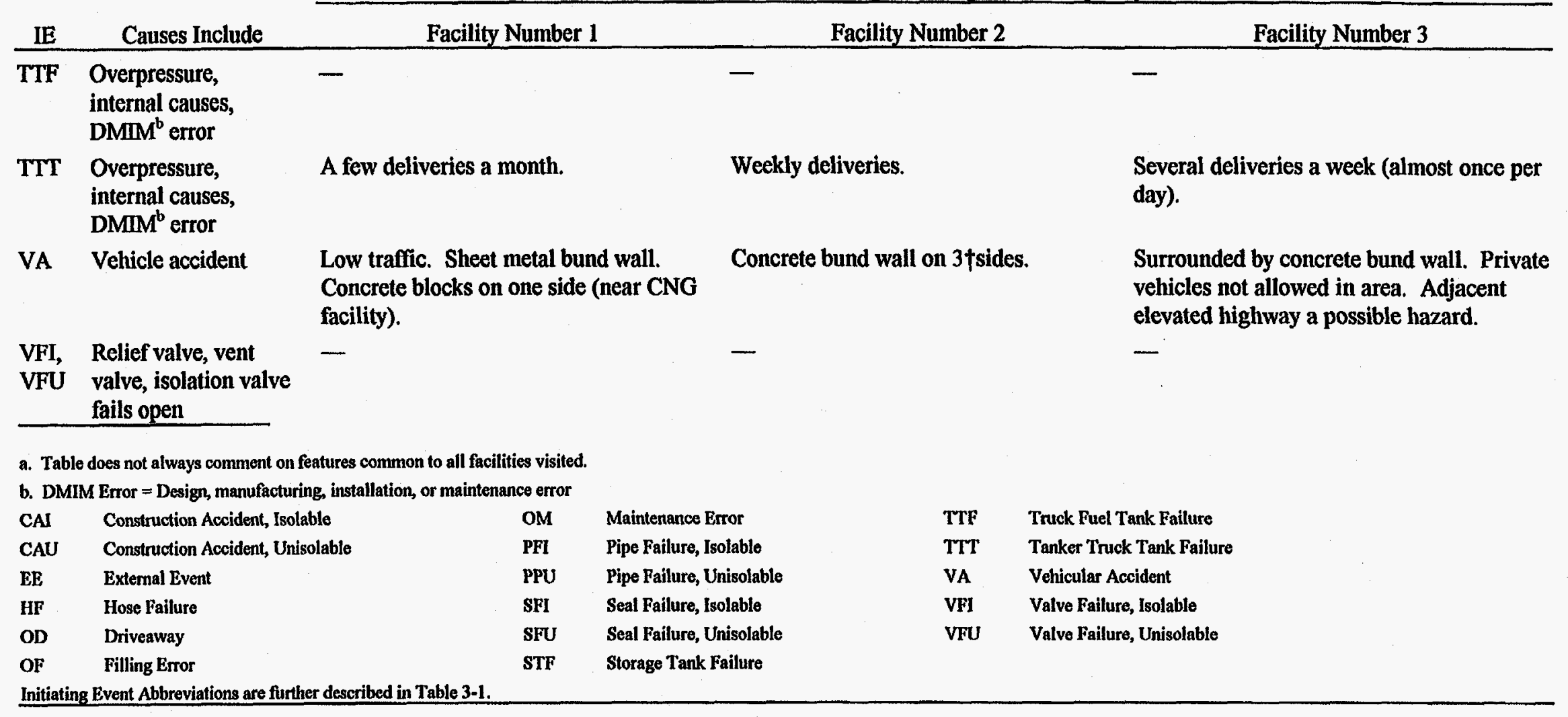


Table 3-7. Noteworthy site-specific features affecting initiating event occurrence, Facilities 4, 5 and $6 .{ }^{\mathrm{a}}$

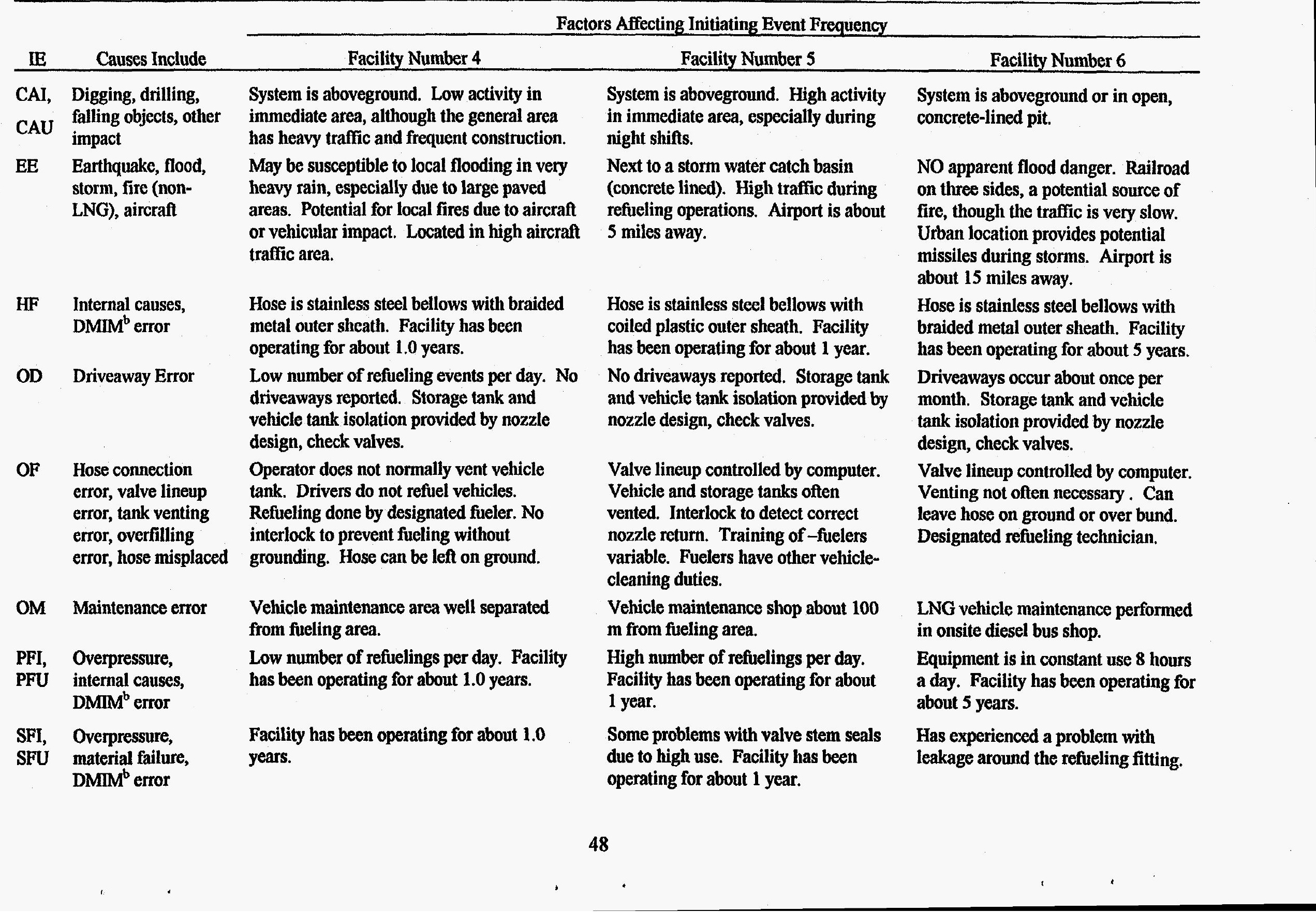


Table 3-7. (continued).

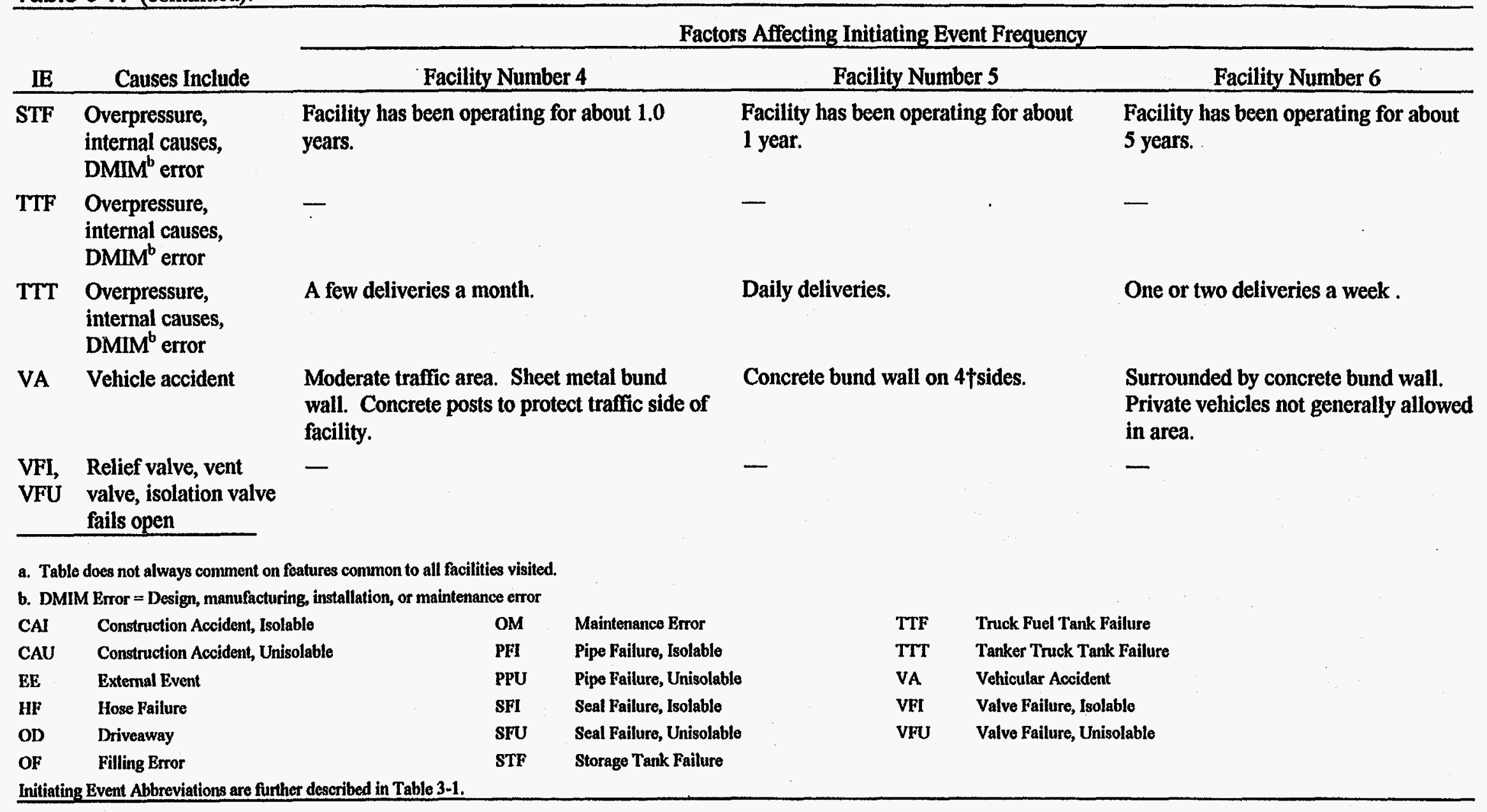


Table 3-8. Noteworthy site-specific features affecting initiating event occurrence, Facilities 7, 8 and 9.2

\begin{tabular}{|c|c|c|c|c|}
\hline \multirow[b]{2}{*}{ IE } & \multirow[b]{2}{*}{ Causes Include } & \multicolumn{3}{|c|}{ Factors Affecting Initiating Event Frequency } \\
\hline & & Facility Number 7 & Facility Number 8 & Facility Number 9 \\
\hline $\begin{array}{l}\text { CAI, } \\
\text { CAU }\end{array}$ & $\begin{array}{l}\text { Digging, drilling, } \\
\text { falling objects, other } \\
\text { impact }\end{array}$ & $\begin{array}{l}\text { System is aboveground. Low activity in } \\
\text { immediate area, though there is high } \\
\text { activity and frequent construction in the } \\
\text { general area. }\end{array}$ & $\begin{array}{l}\text { System is aboveground or in concrete- } \\
\text { lined open trenches covered by steel } \\
\text { grates. High activity in immediate area } \\
\text { (diesel refueling station adjacent). }\end{array}$ & $\begin{array}{l}\text { System is below grade or in a confined } \\
\text { cabinet. }\end{array}$ \\
\hline $\mathrm{EE}$ & $\begin{array}{l}\text { Earthquake, flood, } \\
\text { "storm, fire (non- } \\
\text { LNG), aircraft }\end{array}$ & $\begin{array}{l}\text { Potential for local flooding due to large } \\
\text { paved areas. Potential for local fires due } \\
\text { to vehicle or aircraft impact. Large } \\
\text { propane tank within } 200 \mathrm{~m} \text {. High } \\
\text { aircraft traffic. }\end{array}$ & $\begin{array}{l}\text { Out of flood zone. Several small } \\
\text { airports in vicinity. }\end{array}$ & $\begin{array}{l}\text { No apparent widespread flood danger. } \\
\text { General area is hilly. Runoff may flood } \\
\text { below grade components. Rural } \\
\text { location. Adjacent truck lot and shops } \\
\text { may be a source of fire or vehicular } \\
\text { impact. Airport is about } 5 \text { miles away. }\end{array}$ \\
\hline HF & $\begin{array}{l}\text { Internal causes, } \\
\text { DMIM }^{b} \text { error }\end{array}$ & $\begin{array}{l}\text { Hose is stainless steel bellows with } \\
\text { braided metal outer sheath. Facility has } \\
\text { been operating for about } 2.0 \text { years. }\end{array}$ & $\begin{array}{l}\text { Hose is stainless steel bellows with } \\
\text { coiled plastic outer sheath. Facility has } \\
\text { been operating for about } 1 \text { year. }\end{array}$ & $\begin{array}{l}\text { Hose is stainless steel bellows with } \\
\text { braided metal outer sheath. Facility has } \\
\text { been operating for about } 0.5 \text { years. }\end{array}$ \\
\hline OD & Driveaway Error & $\begin{array}{l}\text { Large number of refueling events during } \\
\text { night shift. No driveaways reported. } \\
\text { Storage tank and vehicle tank isolation } \\
\text { provided by nozzle design, check valves. }\end{array}$ & $\begin{array}{l}\text { No driveaways reported. Storage tank } \\
\text { and vehicle tank isolation provided by } \\
\text { nozzle design, check valves. }\end{array}$ & $\begin{array}{l}\text { No driveaways reported. Storage tank } \\
\text { and vehicle tank isolation provided by } \\
\text { nozzle design, check valves. }\end{array}$ \\
\hline OF & $\begin{array}{l}\text { Hose connection } \\
\text { error, valve lineup } \\
\text { error, tank venting } \\
\text { error, overfilling } \\
\text { error, hose misplaced }\end{array}$ & $\begin{array}{l}\text { Operator does not normally vent vehicle } \\
\text { tank. Hose can be left on ground. }\end{array}$ & $\begin{array}{l}\text { Valve lineup controlled by computer. } \\
\text { Storage tank occasionally vented. } \\
\text { Interlock to detect correct nozzle } \\
\text { return. Training of driver-fuelers } \\
\text { variable. (We observed a driver refuel } \\
\text { for the first time.) }\end{array}$ & $\begin{array}{l}\text { Valve lineup controlled by computer. } \\
\text { Venting may be necessary in summer } \\
\text { due to low vehicle usage, though below } \\
\text { grade location provides some insulation. } \\
\text { Hose attached to movable arm - cannot } \\
\text { be nun over, though a driveaway is } \\
\text { possible. Driver of sole LNG truck also } \\
\text { refuels. Six more trucks on order. }\end{array}$ \\
\hline OM & Maintenance error & $\begin{array}{l}\text { Vehicle maintenance area well separated } \\
\text { from fueling area. }\end{array}$ & $\begin{array}{l}\text { Vehicle maintenance shop } 100 \mathrm{~m} \text { away } \\
\text { from fueling area. }\end{array}$ & $\begin{array}{l}\text { LNG maintenance performed in onsite } \\
\text { diesel bus shop. }\end{array}$ \\
\hline $\begin{array}{l}\text { PFI, } \\
\text { PFU }\end{array}$ & $\begin{array}{l}\text { Overpressure, } \\
\text { internal causes, } \\
\text { DMIM }^{b} \text { error }\end{array}$ & $\begin{array}{l}\text { High number of refuelings during night } \\
\text { shift.. }\end{array}$ & $\begin{array}{l}\text { Low number of refuelings per day. } \\
\text { Facility has been operating for about } \\
2 \text { year. }\end{array}$ & $\begin{array}{l}\text { Equipment is now used once per day. } \\
\text { Facility has been operating for about } 0.5 \\
\text { years. }\end{array}$ \\
\hline
\end{tabular}


Table 3-8. (continued).

Factors Affecting Initiating Event Frequency

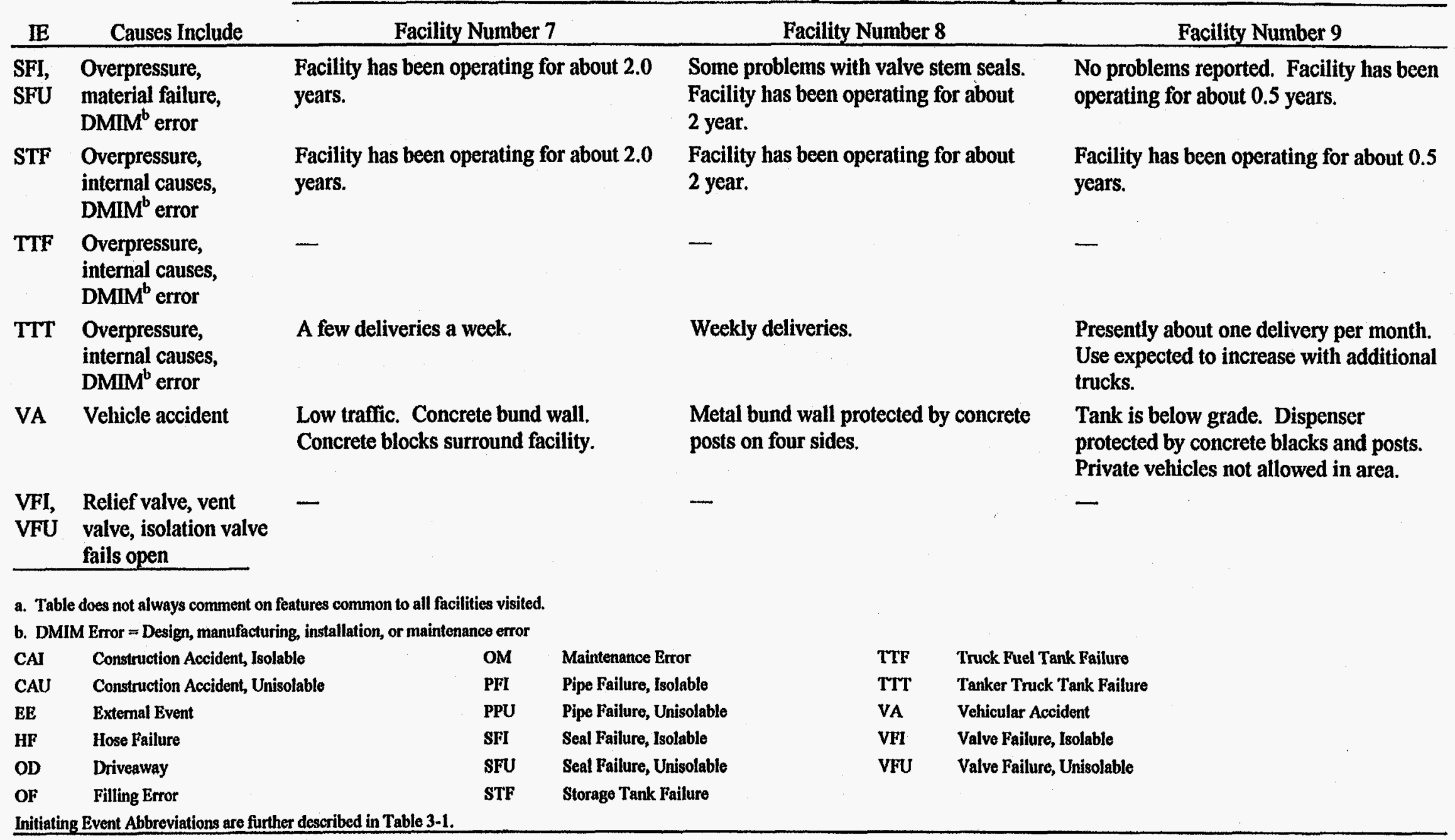


Table 3-9. Noteworthy site-specific features affecting top events, Facilities 1, 2 and 3 .

Factors Affecting Top Event Success Likelihood

\begin{tabular}{|c|c|c|c|c|}
\hline $\begin{array}{l}\text { Top } \\
\text { Event }\end{array}$ & Description & Facility Number 1 & Facility Number 2 & Facility Number 3 \\
\hline ED & Early detection & $\begin{array}{l}\text { Methane detectors located around } \\
\text { storage tank. Two level local } \\
\text { alarm; personnel must call site } \\
\text { Fire Department. }\end{array}$ & $\begin{array}{l}\text { Methane detectors in cabinets, } \\
\text { trenches, within bund. }\end{array}$ & $\begin{array}{l}\text { Methane detectors within bund } \\
\text { (near tank equipment and at } \\
\text { pump), under awning. }\end{array}$ \\
\hline ER & Early recovery & $\begin{array}{l}\text { Other than driver/refueler, few } \\
\text { personnel may be nearby. Manual } \\
\text { emergency shutdown located } \\
\text { nearby. }\end{array}$ & $\begin{array}{l}\text { Drivers and convenience store } \\
\text { personnel nearby. Shutdown } \\
\text { triggered manually or by } \\
\text { detectors. Flashing red light } \\
\text { alarm. Responsible staff may } \\
\text { be onsite or at the shop (a few } \\
\text { minutes away). }\end{array}$ & $\begin{array}{l}\text { Dedicated refueling technicians, } \\
\text { other staff available about } 16 \\
\text { hours/day. }\end{array}$ \\
\hline SI & $\begin{array}{l}\text { Secondary impact } \\
\text { (additional releases } \\
\text { or ignition) } \\
\text { prevention }\end{array}$ & $\begin{array}{l}\text { No additional major storage tanks. } \\
\text { Remote location and low traffic } \\
\text { reduce likelihood of ignition }\end{array}$ & $\begin{array}{l}\text { Site has truck trailer tank as } \\
\text { well as permanent fuel storage } \\
\text { tank. Low traffic and semi- } \\
\text { rural location. }\end{array}$ & $\begin{array}{l}\text { Three storage tanks. Urban } \\
\text { location, heavy traffic increase } \\
\text { number of potential ignition } \\
\text { sources. }\end{array}$ \\
\hline $\mathbf{R C}$ & $\begin{array}{l}\text { Release } \\
\text { containment }\end{array}$ & $\begin{array}{l}\text { Sheet metal bund wall surrounds } \\
\text { storage tank. }\end{array}$ & $\begin{array}{l}\text { Tanks are in shallow pit. } \\
\text { Relatively low concrete bund } \\
\text { wall only on } 3 \text { sides. }\end{array}$ & $\begin{array}{l}\text { Surrounded by } 5 \text {-foot high } \\
\text { concrete bund wall. }\end{array}$ \\
\hline
\end{tabular}


Table 3-10. Noteworthy site-specific features affecting top events, Facilities 4, 5 and 6.

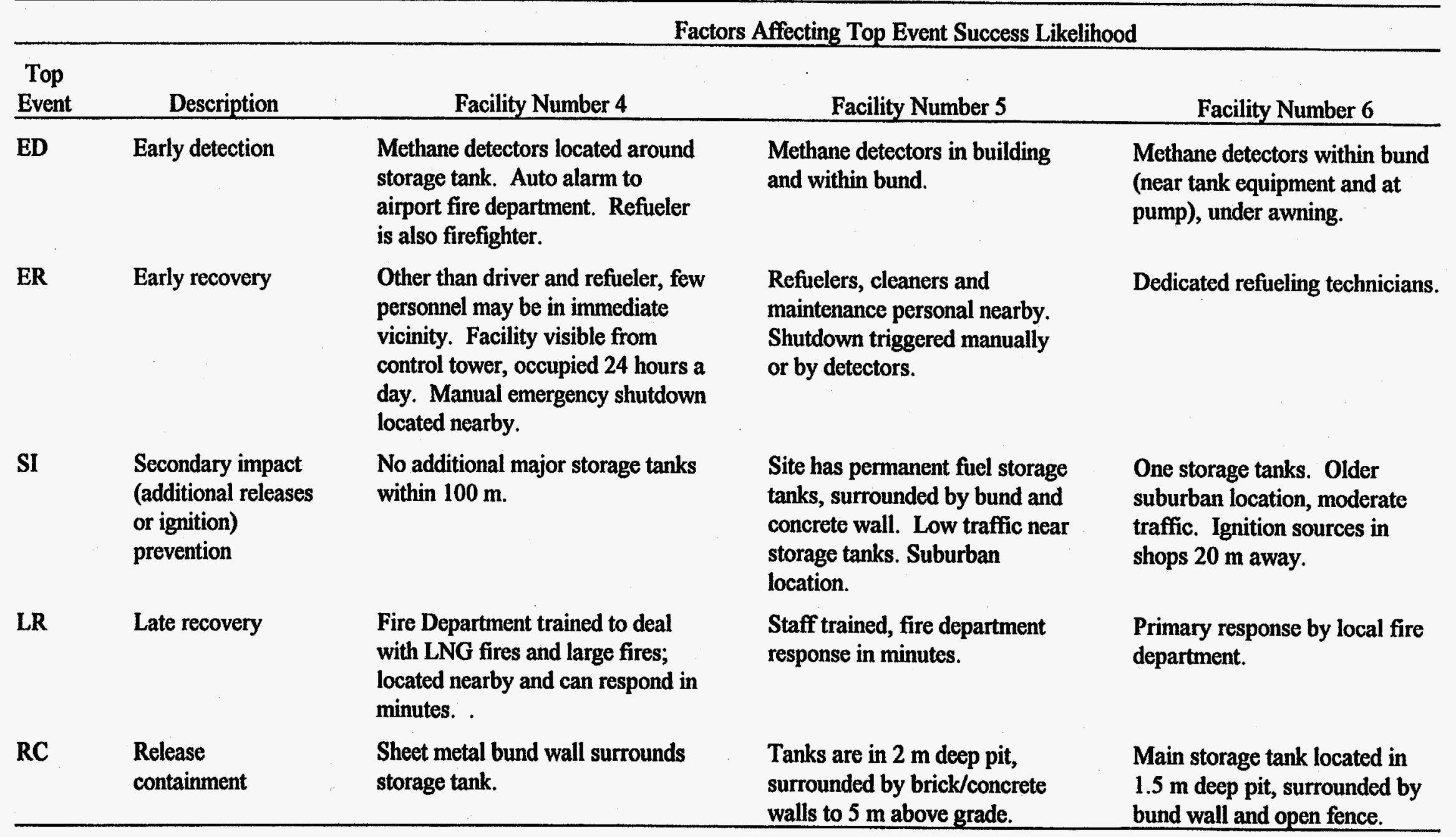


Table 3-11. Noteworthy site-specific features affecting top events, Facilities 7,8 and 9.

\section{Factors Affecting Top Event Success Likelihood}

\begin{tabular}{|c|c|c|c|c|}
\hline $\begin{array}{l}\text { Top } \\
\text { Event }\end{array}$ & Description & Facility Number 7 & Facility Number 8 & Facility Number 9 \\
\hline ED & Early detection & $\begin{array}{l}\text { Methane detectors located around } \\
\text { storage tank. Automatic alarm to } \\
\text { fire department. Visible from } 24 \\
\text { hour a day control tower. }\end{array}$ & $\begin{array}{l}\text { Methane detectors in cabinets } \\
\text { and within bund. }\end{array}$ & $\begin{array}{l}\text { Methane detectors within } \\
\text { cabinet. Tank below grade. } \\
\text { No awning to collect vapors. }\end{array}$ \\
\hline ER & Early recovery & $\begin{array}{l}\text { Other than drivers and refuelers, } \\
\text { few personnel may be in } \\
\text { immediate vicinity. Manual } \\
\text { emergency shutdown located } \\
\text { nearby. }\end{array}$ & $\begin{array}{l}\text { Drivers and maintenance } \\
\text { personnel nearby. Shutdown } \\
\text { triggered manually or by } \\
\text { detectors. }\end{array}$ & $\begin{array}{l}\text { Dedicated refueling technicians } \\
\text { is also the driver of the sole } \\
\text { truck (at present). }\end{array}$ \\
\hline SI & $\begin{array}{l}\text { Secondary impact } \\
\text { (additional releases } \\
\text { or ignition) } \\
\text { prevention }\end{array}$ & $\begin{array}{l}\text { Large propane tank within about } \\
200 \mathrm{~m} \text {. Heavy aircraft traffic } \\
\text { provide additional ignition } \\
\text { sources. }\end{array}$ & $\begin{array}{l}\text { Site is fairly confined in a } \\
\text { suburban location. Yard not } \\
\text { generally accessible to the } \\
\text { public. Diesel refueling station } \\
\text { is adjacent with heavy traffic at } \\
\text { peak periods. }\end{array}$ & $\begin{array}{l}\text { One storage tank, below grade. } \\
\text { Adjacent truck maintenance } \\
\text { shop and parked trucks may } \\
\text { result in additional releases. } \\
\text { Rural location reduces the } \\
\text { chance of other secondary } \\
\text { impacts.. }\end{array}$ \\
\hline LR & Late recovery & $\begin{array}{l}\text { Site fire department trained to deal } \\
\text { with wide variety of large fires and } \\
\text { can respond in minutes. }\end{array}$ & $\begin{array}{l}\text { Uncertain whether local fire } \\
\text { department trained to fight } \\
\text { LNG fires. }\end{array}$ & $\begin{array}{l}\text { Primary response provided by } \\
\text { station staff. Local Fire } \\
\text { Department also available, } \\
\text { though training is unknown. }\end{array}$ \\
\hline $\mathbf{R C}$ & $\begin{array}{l}\text { Release } \\
\text { containment }\end{array}$ & $\begin{array}{l}\text { Concrete bund wall surrounds } \\
\text { storage tank. }\end{array}$ & $\begin{array}{l}\text { Tanks at grade, protected by } \\
\text { the metal bund wall and } \\
\text { concrete posts. }\end{array}$ & $\begin{array}{l}\text { Storage tank is below grade. } \\
\text { Additional equipment in } \\
\text { enclosed cabinet. }\end{array}$ \\
\hline
\end{tabular}


Finally, differences in siting may also have a significant impact on station risk. These differences can affect the likelihood of release due to external events (e.g., earthquakes, fires, explosions, floods, windstorms, lightning strikes, aircraft impacts), the likelihood of ignition given a release, and the public health and safety consequences of an accident. For example, the urban location of Facility Number 3 increases the availability of debris that may be driven by a severe storm. It also increases the availability of potential ignition sources and increases the number of people potentially exposed to the consequences of a major accident.

It should be cautioned that, as noted at the beginning of this section, these insights are relative. Additional, quantitative analysis is needed to determine if the factors identified above have a significant impact on absolute risk. 


\section{PHENOMENOLOGY OF LIQUEFIED NATURAL GAS}

\subsection{Introduction}

This section discusses the properties and behavior of LNG under nominal and accident conditions. (A qualitative comparison of LNG, gasoline, and diesel properties is provided in Table 4-1.) The section also addresses safety issues recently raised by Hunt (1996).

The handling of liquefied natural gas in a refueling station has several aspects common to present day fuels such as gasoline or diesel. With LNG, as well as with gasoline and diesel, all fuel transfers from the storage tank to the vehicle tank are carried out in liquid form. There is some vapor present during the transfer of gasoline and diesel, but the amount is very small and usually ignored. During the transfer of LNG from the storage tank to the vehicle tank, however, there is a need to collapse pressurized vapors in the ullage of the vehicle tank through the addition of colder liquid methane. If the vapors cannot be collapsed, then they must be safely vented. Also, vapors formed during the cooling of the transfer hose and nozzle must be recondensed or safely vented. Thus an LNG station is characterized by closed piping systems and dedicated vent stack to a greater extent than is the case for gasoline and diesel where the underground tanks have elevated vent stacks.

The principal hazard addressed in this report is the accidental combustion of the fuel. All fuels require vaporization as part of the combustion process. All fuels require that the mixtures of air and fuel vapor be within certain flammability limits in order that combustion can be sustained. All liquid fuels will disperse on the ground or water surface if spilled and all liquid fuels require an input of heat for vaporization.

Liquefied natural gas differs in several important ways from the more common liquid fuels, however. Because it is a liquid at $112^{\circ} \mathrm{K}$ at atmospheric pressure, the LNG must be insulated from external sources of heat. If spilled, the liquefied natural gas draws heat from the ground or water, from the air, and from solar insolation. The rate of vaporization is dependent on the heat available from the surroundings and on heat transfer rate from those surroundings.

\subsection{Properties of Liquefied Natural Gas}

\subsubsection{Physical Properties}

The properties of methane are compared to hydrogen and gasoline in Table 4-2. Note that natural gas in the vapor form at nominal temperature and pressure (NTP) is about 6 times lighter than gasoline vapors. Thus the vapors resulting from a spill of LNG will rise after being warmed by the surrounding environment, while gasoline vapors will flow along the ground or water surface until dispersed by diffusion.

An important ramification of the cryogenic nature of LNG is that a trapped volume, e.g. between two valves in a pipe, the pressure increases as the fluid warms by heating from the surroundings. Good insulation can slow the warming process, but eventually, the entire contents of the system will become high pressure vapor if refrigeration is not restored. Thus, it is imperative that all potentially isolated sections of 
piping and tankage be vented through a relief valve. The inclusion of a relief valve for any enclosed volume is a standard practice of cryogenic design.

Table 4-1. Comparison of LNG, diesel, and gasoline.

Fuel

Characteristic LNG Diesel

Gasoline

Storage

$112^{\circ} \mathrm{K}$

temperature

(at $1 \mathrm{~atm}$.)

$-260^{\circ} \mathrm{F}$

$60^{\circ} \mathrm{F}$

$60^{\circ} \mathrm{F}$

Operating

pressure

150 psig

50 psig

50 psig

Storage

pressure

Storage

location

Vapor

pressure at

RT

Vapor

buoyancy

Flammable

limits

Flash point of

liquids

Fluid behavior

Cryogenic-small spills evaporate quickly.

Large spills flow.

Fuel nozzles

Closed connection

Routine

releases from

tanks

Fate of

routine

releases

Chemical

reactivity

Solubility

100 psig

Above ground tanks

1 atmosphere

Rises

$5-15 \%$ at $60^{\circ} \mathrm{F}$

NA

(minimized through design)

Disperses in atmosphere, oxidizes, greenhouse gas

Low reactivity

Grease and oils have low solubility at liquid

$\mathrm{CH}_{4}$ temperatures $100^{\circ} \mathrm{F}$

Like water - familiar

Open to air connection

Very little venting

Hydrostatic pressure only, 0.3 psig per foot

Underground tanks

Small

Settles

Settles

$1.2-8 \%$ at $60^{\circ} \mathrm{F}$

$-50^{\circ} \mathrm{F}$

Like water-familiar

Open to air connection

Little venting

Liquid sinks into ground water, vapors contribute to smog

Solvent

Solvent

Solvent
Liquid sinks into ground water, vapors contribute to smog

Solvent
Hydrostatic pressure only, 0.3 psig per foot

Underground tanks

$0.3 \mathrm{psi}$ 
Table 4-1. (continued).

Fuel

Characteristic LNG Diesel

Gasoline

Autoignition

$1110^{\circ} \mathrm{F}$

$500-700^{\circ} \mathrm{F}$

$440-880^{\circ} \mathrm{F}$

temperature

Spark ignition

$0.3 \mathrm{~mJ}$

$0.3 \mathrm{~mJ}$

$0.3 \mathrm{~mJ}$

energy

Tanks

Double walled, steel,

Single wall, uninsulated

Single wall, uninsulated vacuum insulated

Handling

Not familiar

Familiar

Familiar

Movement

Pressure differentials or pumps

Pumps

Pumps

Odor

Odorless unless odorant chemical is added

Toxicity

No Threshold Limit Value (TLV)

Distinct odor

Distinct odor

Inhalation

hazard

Simple asphyxiant, displaces oxygen ${ }^{2}$

Fuel losses

Storage tanks are well sealed. At some stations a significant fraction (up to $25 \%$ ) can be lost in handling through venting warm tanks ${ }^{b}$

$T L V=400 \mathrm{ppm}$

$\mathrm{TLV}=500 \mathrm{ppm}$

Irritant

Irritant

Small losses from evaporation or spills.

Leaking underground

storage tanks are a

pervasive problem.

Small losses from evaporation or spills. Leaking underground storage tanks are a pervasive problem.

\begin{tabular}{|c|c|c|c|}
\hline $\begin{array}{l}\text { Effects of fuel } \\
\text { losses }\end{array}$ & $\begin{array}{l}\text { Greenhouse gas, } \\
\text { transient fog }\end{array}$ & $\begin{array}{l}\text { Losses limited by EPA } \\
\text { rules on odor and } \\
\text { groundwater pollution }\end{array}$ & $\begin{array}{l}\text { Losses limited by EPA } \\
\text { rules on odor and } \\
\text { groundwater pollution }\end{array}$ \\
\hline Noise & $\begin{array}{l}\text { Unfamiliar noises; gas } \\
\text { venting, compressors } \\
\text { for CNG. }\end{array}$ & Familiar & Familiar \\
\hline Touch & $\begin{array}{l}\text { Cryogenic burns, } \\
\text { hypothermia for long } \\
\text { exposure }\end{array}$ & Skin irritation, rashes & Skin irritation, rashes \\
\hline $\begin{array}{l}\text { Visual } \\
\text { differences }\end{array}$ & $\begin{array}{l}\text { Above ground tanks, } \\
\text { venting gases }\end{array}$ & Underground tanks & Underground tanks \\
\hline $\begin{array}{l}\text { a. Cold methane } \\
\text { spaces. Furtherm }\end{array}$ & $75 \mathrm{~K}$ ) is denser than air a & $\begin{array}{l}\text { fore displaces air and acts a } \\
\text { ane as it boils can displace a }\end{array}$ & $\begin{array}{l}\text { xiant in lower-lying enclosed } \\
\text { sed spaces. }\end{array}$ \\
\hline
\end{tabular}


Table 4-2. Properties of hydrogen, methane and gasoline.

\begin{tabular}{|c|c|c|c|c|}
\hline $\begin{array}{r}\text { Property } \\
\end{array}$ & Hydrogen & Methane & Gasoline & Units \\
\hline Molecular Weight & 2.016 & 16.043 & 107 & amu \\
\hline Triple point pressure & 0.0695 & 0.1159 & - & atm \\
\hline Triple point temperature & 13.803 & 90.68 & 180 to 220 & $\mathbf{K}$ \\
\hline Normal boiling point (NBP) temperature & 20.268 & 11.632 & 310 to 478 & $\mathbf{K}$ \\
\hline Critical pressure & 12.759 & 45.387 & 24.5 to 27 & atm \\
\hline Critical temperature & 32.976 & 190.56 & 540 to 569 & $\mathbf{K}$ \\
\hline Density at critical point & 0.0314 & 0.1604 & 0.23 & $\mathrm{~g} / \mathrm{cm}^{3}$ \\
\hline Density of liquid at triple point & 0.077 & 0.4516 & - & $\mathrm{g} / \mathrm{cm}^{3}$ \\
\hline Density of solid at triple point & 0.0686 & 0.4872 & - & $\mathrm{g} / \mathrm{cm}^{3}$ \\
\hline Density of vapor at triple point & 125.597 & 251.53 & - & $\mathrm{g} / \mathrm{cm}^{3}$ \\
\hline Density of liquid at NBP & 0.0708 & 0.4226 & 0.7 & $\mathrm{~g} / \mathrm{cm}^{3}$ \\
\hline Density of vapor at NBP & 0.0013 & 0.00182 & 0.0045 & $\mathrm{~g} / \mathrm{cm}^{3}$ \\
\hline Density of gas at NTP & 83.764 & 651.19 & 4400 & $\mathrm{~g} / \mathrm{m}^{3}$ \\
\hline Density ratio: NBP liquid to NTP gas & 845 & 649 & 156 & \\
\hline Heat of fusion & 58.23 & 58.47 & 161 & $\mathrm{~J} / \mathrm{g}$ \\
\hline Heat of vaporization & 445.59 & 509.88 & 309 & $\mathrm{~J} / \mathrm{g}$ \\
\hline Heat of sublimation & 507.39 & 602.44 & - & $\mathrm{J} / \mathrm{g}$ \\
\hline Heat of combustion (low) & 119.93 & 50.02 & 44.5 & $\mathrm{~kJ} / \mathrm{g}$ \\
\hline Heat of combustion (high) & 141.86 & 55.53 & 48 & $\mathrm{~kJ} / \mathrm{g}$ \\
\hline Energy density & 8.49 & 21.14 & 31.15 & MJ/litre \\
\hline Specific heat $(\mathrm{Cp})$ of NTP gas & 14.89 & 2.22 & 1.62 & $\mathrm{~J} / \mathrm{g}-\mathrm{K}$ \\
\hline Specific heat (Cp) of NBP liquid & 9.69 & 3.5 & 2.2 & $\mathrm{~J} / \mathrm{g}-\mathrm{K}$ \\
\hline Specific heat ratio $(\mathrm{Cp} / \mathrm{Cv})$ of NTP gas & 1.383 & 1.308 & 1.05 & - \\
\hline Specific heat ratio $(\mathrm{Cp} / \mathrm{Cv})$ of NBP liquid & 1.688 & 1.676 & - & - \\
\hline Viscosity of NTP gas & 0.0000 & 0.00011 & 0.00005 & $\mathrm{~g} / \mathrm{cm}-\mathrm{s}$ \\
\hline Viscosity of NBP liquid & 0.0001 & 0.00113 & 0.002 & $\mathrm{~g} / \mathrm{cm}-\mathrm{s}$ \\
\hline Thermal conductivity of NTP gas & 1.897 & 0.33 & 0.112 & $\mathrm{~mW} / \mathrm{cm}-\mathrm{K}$ \\
\hline Thermal conductivity of NBP liquid & 1 & 1.86 & 1.31 & $\mathrm{~mW} / \mathrm{cm}-\mathrm{K}$ \\
\hline Surface Tension & 0.0019 & 0.01294 & 0.0122 & $\mathbf{N} / \mathbf{m}$ \\
\hline Dielectric constant of NTP gas & 1.0002 & 1.00079 & 1.0035 & 一 \\
\hline Dielectric constant of NBP liquid & 1.233 & 1.6227 & 1.93 & 一 \\
\hline Index of refraction of NTP gas & 1.0001 & 1.0004 & 1.0017 & - \\
\hline Index of refraction of NBP liquid & 1.11 & 1.2739 & 1.39 & 一 \\
\hline Adiabatic sound velocity in NTP gas & 1294 & 448 & 154 & $\mathbf{m} / \mathbf{s}$ \\
\hline Adiabatic sound velocity in NBP liquid & 1093 & 1331 & 1155 & $\mathrm{~m} / \mathrm{s}$ \\
\hline Compressibility factor (Z) of NTP gas & 1.0006 & 1.0243 & 1.0069 & - \\
\hline Compressibility factor $(Z)$ in NBP liquid & 0.0171 & 0.004145 & 0.00643 & - \\
\hline Gas constant $(R)$ & 40.7037 & 5.11477 & 0.77 & $\mathrm{~cm}^{3}-\mathrm{atm} / \mathrm{g}-\mathrm{K}$ \\
\hline Isothermal bulk modulus of NBP liquid & 50.13 & 456.16 & 763 & $\mathrm{MN} / \mathrm{m} 2$ \\
\hline Volume expansivity (b) of NBP liquid & 0.0165 & 0.00346 & 0.0012 & $\mathbb{K}$ \\
\hline \multicolumn{5}{|l|}{ NBP $=$ Normal boiling point } \\
\hline \multicolumn{5}{|l|}{$\mathrm{NTP}=1 \mathrm{~atm}$ and $20 \mathrm{C}\left(293.15^{\circ} \mathrm{K}\right)$} \\
\hline Source: (Hord 1978) & & & & \\
\hline
\end{tabular}


Another important physical property of methane is its lack of odor. Although ethyl mercaptan is added at $25 \mathrm{ppm}$ to give the odor we associate with natural gas, it cannot be used in LNG. At LNG temperatures, the mercaptan compounds freeze and are not carried along with the gas. There bave been attempts to develop cryogenic odorants that will remain in solution in LNG, such as tetrahydrothiophene (THTP) (Mulliner 1974). The lack of odor greatly increases the importance of methane detectors to detect leaks and spills.

\subsubsection{Combustion Properties}

Four conditions are necessary for a self-sustaining combustion reaction. First, the fuel and oxygen must be intimately mixed in vapor form. Second, the proportions of fuel and oxygen must be within the flammability limits. Since we are here concerned with accidental combustion in air, we will discuss flammability limits as volume percent of fuel in air. Third, within the region where the fuel and air are within the flammability limits, there must be an energy source capable of initiating the chain of chemical reactions that constitutes the combustion process. The combustion process will not be self-sustaining if strong heat sinks are present within the reacting mixture of gases. These heat sinks may be in the form of water droplets, solid particles or the metal walls of a tank or pipe. The final condition necessary for a selfsustaining combustion reaction is that the chain reaction be complete and that intermediate products not be removed so as to interrupt the chain.

The combustion properties of hydrogen, methane and gasoline are compared in Table 4-3.

Flammability Limits. Methane and air are combustible when the methane volume fraction is between about 5 and 15 percent. The flammability limits are somewhat dependent on the initial temperature of the mixture, as shown in Table 4-4. When the vapor is very cold, the flammability limits are more narrow than at room temperature. Note also in the table that the density of methane at $175^{\circ} \mathrm{K}$ is about the same as air at $300^{\circ} \mathrm{K}$. Thus methane rises and disperses at temperatures above $175^{\circ} \mathrm{K}$.

Distinction Between Deflagration and Detonation. A deflagration is a subsonic combustion wave sustained by chemical reactions in a reactive mixture of gases. The diffusion of heat and species from the reaction zone into the unburned gases is responsible for the initiation of chemical reactions ahead of a deflagration. Thus the speed of propagation of a deflagration is limited by the molecular diffusivities within the gas to about one meter per second. A deflagration can be ignited by a weak energy source with an energy of only a fraction of a millijoule. Deflagration combustion pressures are generally much less than 1 psi.

The initiation of chemical reactions in a detonation, on the other hand, is due to an adiabatic shock compression wave passing through the unburned gases. The combustion reactions take place in highly compressed and preheated gases and the wave propagates very rapidly. Typical propagation velocities are of the order of kilometers per second and the pressures produced are generally several psi. The instantaneous ignition of a detonation in an unconfined mixture of reactive gases requires several orders of magnitude more energy than that necessary to ignite a deflagration. The energy necessary to initiate a detonation can be reduced if the mixture is confined by hard, reflecting walls, such that the shock can pass through the mixture several times.

Deflagration Conditions. As noted in Table 4-2, the energy necessary to ignite a deflagration is only about $0.3 \mathrm{~mJ}$ for either methane or gasoline. Such energy is easily available from a match, an open flame, or a spark. As noted above, the flammability limits for methane are somewhat higher for methane (5 to 15 volume percent in air) than for gasoline ( 1.2 to 8 volume percent in air.) 
Table 4-3. Combustion properties of hydrogen methane and gasoline.

\begin{tabular}{|c|c|c|c|c|}
\hline $\begin{array}{c}\text { Property } \\
\end{array}$ & Hydrogen & Methane & Gasoline & Units \\
\hline Limits of flammability in air & 4.0 to 75.0 & 5.3 to 15.0 & 1.0 to 7.6 & vol \% \\
\hline Limits of detonability in air & 18.3 to 59 & 6.3 to 13.5 & 1.1 to 3.3 & vol \% \\
\hline $\begin{array}{l}\text { Stoichiometric composition } \\
\text { in air }\end{array}$ & 29.53 & 9.48 & 1.76 & vol \% \\
\hline $\begin{array}{l}\text { Minimum energy for } \\
\text { ignition in air }\end{array}$ & 0.02 & 0.29 & 0.24 & $\mathrm{~mJ}$ \\
\hline Autoignition temperature & 858 & 813 & 501 to 744 & $\mathbf{K}$ \\
\hline $\begin{array}{l}\text { Hot air-jet ignition } \\
\text { temperature }\end{array}$ & 943 & 1493 & 1313 & $\mathbf{K}$ \\
\hline Flame temperature in air & 2318 & 2148 & 2470 & $\mathbf{K}$ \\
\hline $\begin{array}{l}\text { Percentage of thermal } \\
\text { energy radiated from flame } \\
\text { to surroundings }\end{array}$ & 17 to 25 & 23 to 33 & 30 to 42 & $\%$ \\
\hline Burning velocity in NTP air & 265 to 325 & 37 to 45 & 37 to 43 & $\mathrm{~cm} / \mathrm{s}$ \\
\hline $\begin{array}{l}\text { Detonation velocity in NTP } \\
\text { air }\end{array}$ & 1.48 to 2.15 & 1.39 to 1.64 & 1.4 to 1.7 & $\mathrm{~km} / \mathrm{s}$ \\
\hline $\begin{array}{l}\text { Diffusion coefficient in NTP } \\
\text { air }\end{array}$ & 0.61 & 0.16 & 0.05 & $\mathrm{~cm}^{2} / \mathrm{s}$ \\
\hline $\begin{array}{l}\text { Diffusion velocity in NTP } \\
\text { air }\end{array}$ & $<2.00$ & $<0.51$ & $<0.17$ & $\mathrm{~cm} / \mathrm{s}$ \\
\hline Buoyant velocity in NTP air & 1.2 to 9.0 & 0.8 to 6.0 & Nonbuoyant & $\mathbf{m} / \mathbf{s}$ \\
\hline $\begin{array}{l}\text { Maximum experimental safe } \\
\text { gap in NTP air }\end{array}$ & 0.008 & 0.12 & 0.07 & $\mathrm{~cm}$ \\
\hline Quenching gap in NTP air & 0.064 & 0.203 & 0.2 & $\mathrm{~cm}$ \\
\hline $\begin{array}{l}\text { Detonation induction } \\
\text { distance in NTP air }\end{array}$ & $\mathrm{L} / \mathrm{D}=100$ & & & \\
\hline Limiting oxygen index & 5 & 12.1 & 11.6 & vol \% \\
\hline $\begin{array}{l}\text { Vaporization rates (steady } \\
\text { state) of liquid pools without } \\
\text { burning }\end{array}$ & 2.5 to 5.0 & 0.05 to 0.5 & $\begin{array}{l}0.005 \text { to } \\
0.02\end{array}$ & $\mathrm{~cm} / \mathrm{min}$ \\
\hline $\begin{array}{l}\text { Burning rates of spilled } \\
\text { liquid pools }\end{array}$ & 3.0 to 6.6 & 0.3 to 1.2 & 0.2 to 0.9 & $\mathrm{~cm} / \min$ \\
\hline Flash point & Gaseous & Gaseous & 230 & $\mathbf{K}$ \\
\hline Toxicity & $\begin{array}{l}\text { Nontoxic } \\
\text { (asphyxiant) }\end{array}$ & $\begin{array}{l}\text { Nontoxic } \\
\text { (asphyxiant) }\end{array}$ & $\begin{array}{l}\text { Slight } \\
\text { (asphyxiant) }\end{array}$ & Slight (asphyxiant \\
\hline Energy of explosion, & 24 & 11 & 10 & g TNT/g fuel \\
\hline Energy of explosion & 1.71 & 4.56 & 7.04 & $\begin{array}{l}\mathrm{g} T N T / \mathrm{cm}^{3} \mathrm{NBP} \text { liquid } \\
\text { fuel }\end{array}$ \\
\hline Energy of explosion & 2.02 & 7.03 & 44.22 & $\begin{array}{l}\mathrm{kg} \mathrm{TNT} / \mathrm{m}^{3} \mathrm{NTP} \\
\text { gaseous fuel }\end{array}$ \\
\hline \multicolumn{4}{|c|}{$\mathrm{NTP}=1 \mathrm{~atm}$ and $20 \mathrm{C}\left(293.15^{\circ} \mathrm{K}\right)$} & \\
\hline
\end{tabular}


Table 4-4. Temperature dependence of flammability limits for methane-air mixtures.

\begin{tabular}{|c|c|c|c|c|c|c|}
\hline \multicolumn{3}{|c|}{ Temperature } & \multirow{2}{*}{$\begin{array}{c}\text { Lower } \\
\text { Flammability } \\
\text { Limit } \\
(\%) \\
\end{array}$} & \multirow{2}{*}{$\begin{array}{c}\text { Upper } \\
\text { Flammability } \\
\text { Limit } \\
(\%) \\
\end{array}$} & \multirow[b]{2}{*}{$\begin{array}{l}\rho \mathrm{CH}_{4} \\
\mathrm{~kg} / \mathrm{m} 3\end{array}$} & \multirow[b]{2}{*}{$\begin{array}{c}\rho \text { air } \\
\mathrm{kg} / \mathrm{m} 3\end{array}$} \\
\hline$\underline{K}$ & C & $F$ & & & & \\
\hline 111.6 & -161 & -258.5 & 5.7 & 13.0 & 1.8159 & - \\
\hline 150 & -123 & -189.4 & 5.5 & 13.4 & 1.3229 & - \\
\hline 175 & -98 & -144.4 & 5.4 & 13.7 & 1.1279 & - \\
\hline 200 & -73 & -99.4 & 5.4 & 13.9 & 0.9843 & 1.7690 \\
\hline 225 & -48 & -54.4 & 5.3 & 14.2 & 0.8726 & - \\
\hline 250 & -23 & -9.4 & 5.2 & 14.5 & 0.7843 & - \\
\hline 300 & 27 & 80.6 & 5.0 & 15.0 & 0.6527 & 1.1769 \\
\hline 350 & 77 & 170.6 & 4.8 & 15.6 & 0.5593 & - \\
\hline 400 & 127 & 260.6 & 4.6 & 16.1 & 0.4890 & 0.8826 \\
\hline
\end{tabular}

Detonation Conditions. D. C. Bull and coworkers (Bull 1976; Baker 1991) performed a series of experiments to determine the energy needed to initiate a detonation in mixtures of methane and oxygen diluted by nitrogen. In his experiments, the gaseous mixtures were confined by thin plastic membranes, thus simulating an unconfined cloud of methane and air. The mixture consisted of $\mathrm{CH}_{4}+2 \mathrm{O}_{2}+\mathrm{xN}_{2}$.

He found that a detonation could be initiated by $1 \mathrm{gm}$ of the high explosive Tetryl at $\mathrm{x}=2$, but that $1000 \mathrm{gm}$ of Tetryl was required at $\mathrm{x}=6$. Extrapolating to a mixture of methane and air $(x=7.4)$ he found that $22 \mathrm{~kg}$ of Tetryl would be necessary to initiate a detonation. That quantity of Tetryl releases about $300 \mathrm{MJ}$, some twelve orders of magnitude higher than the spark ignition energy. Tests with other gases showed that ethane/air would detonate with about 50 grams of Tetryl, propane/air with 90 grams and butane/air with about 100 grams.

The lower energy requirement for ethane is important when considering the use of 'weathered' LNG, which may contain several percent ethane due to the selective vaporization of methane from the liquid. Weathering is discussed in a later section.

\subsubsection{Chemical Hazards}

In additional to the hazards of accidental combustion of LNG, its ability to displace breathing air and to cause cryogenic burns must be considered.

Toxicity Limits. Natural gas, per se, is non-toxic. However, it can be an asphyxiant if air is displaced and the oxygen content of the breathing atmosphere falls below 15\% (ACGIH 1996). Since methane at temperatures below $165^{\circ} \mathrm{K}$ is denser than air at room temperature, cold methane gas will pool in low sections of a facility, such as the bund enclosure, pumping pits, basements, and pits in vehicle maintenance facilities. Maintenance facilities specifically designed for LNG vehicles do not have pits 
(Thomas 1996). Note that the danger of asphyxiation is increased in LNG facilities due to the absence of an odorant in the gas, as discussed earlier.

Considering LNG leaks and the volume expansion that occurs upon boiling, the issue of displacing air is a toxicity concern. Workers are restricted by law from entering atmospheres with less than $19.5 \%$ volume of oxygen (normally $21 \%$ at sea level) without precautions (OSHA 1996) such as breathing apparatus. This $19.5 \%$ value is for workers of average health; it may be taxing to children and elder people. No guidelines for acceptable levels of oxygen deficiency for the general public were found in the literature. The expectation is that any deficiency should be less than that allowed for healthy workers (i.e., only oxygen concentrations greater than 19.5\%). The Compressed Gas Association (CGA 1992) gives some symptoms of oxygen deficiency. At values of $12-15 \%$, judgment and coordination are impaired, so it is questionable if a person can evade the hazard without assistance. At oxygen concentrations at the 4 to $6 \%$ level, a person can enter a coma in less than a minute, followed by convulsions and death.

Carcinogenicity. Methane, or natural gas, is not a carcinogen; it has no threshold limit value. It is a simple asphyxiant gas as indicated above.

\subsubsection{Cryogenic Hazards}

As a cryogenic liquid, LNG can cause burns to workers if it comes in contact with the skin. The hazard is further complicated since LNG is about $42 \%$ the density of water and handled at pressures of 15 to $250 \mathrm{psi}$. Therefore the possibility of cold liquid spraying into a worker's face or onto a worker's clothing must be guarded against. Personal protective equipment (PPE), such as impervious gloves that extend to the elbow, full face shields with chin protection, and an impervious apron, is necessary.

According to the fueler in one location we visited, if LNG hits an exposed portion of ordinary clothing, the worker should immediately hold that area of clothing away from the skin to prevent cryogenic burns. This action is also given in LNG safety manuals. It is also important that 'cut-offs' and trousers with cuffs not be allowed in the refueling area. Cut-offs expose the legs to immediate cryogenic burns. Trousers with cuffs can hold a pool of cryogenic liquid next to the ankles. Note that at other locations visited, workers refueling with LNG did not wear their protective equipment when refueling. In some instances the protective equipment consisted only of short (wrist-length) work gloves and safety glasses.

A second cryogenic health hazard is associated with LNG vapors; breathing cold vapors from LNG evaporation or boiling can damage the lungs (GRI 1994). While methane does not chemically react with the lungs (i.e., it is a 'simple' asphyxiant that creates a hazard by displacing air), the cold vapor from LNG can cause "frosting the lungs." This effect is also a health concern in extremely cold winter weather. Breathing super cold air or methane vapor can frost or freeze lung tissues. When the tissues freeze, ice forms. Since ice occupies more volume than a similar quantity of water and since ice crystals are also sharp, the cells can be ruptured and will likely die upon thawing. If alveoli cells are destroyed, a person could experience edema, pneumonia-like symptoms, and emphysema-like symptoms. The type of symptoms and their severity are directly related to the severity of exposure.

Regarding potential component damage caused by exposure to $L N G$, all components normally in contact with LNG are metals that do not undergo a ductile to brittle transition (DBT), e.g., austenitic stainless steel, aluminum, brass, copper. However, the ordinary structural steel commonly used for buildings, ships, etc. does undergo a DBT at $200-300^{\circ} \mathrm{K}$. Our research has found reports of cracking of carbon steel deck plates on LNG carrier ships as a result of spills on the deck. The spill did not necessarily pool on the deck, but enough heat was removed from the deck plates to cause cracking. The cracking was due to a combination of contraction and embrittlement (Harris 1993). In these incidents, the damage was 
apparently localized and was generally repaired at the next scheduled maintenance. However, the DBT phenomenon presents an opportunity for a minor spill to become a major spill if a structural steel component, such as a tank support column, fails due to embrittlement.

\subsection{Phenomena in Routine Handling}

Because LNG is a cryogenic fluid, its routine handling is different from the handling of gasoline and diesel fuel. This section discusses how the composition of LNG can change over time due to the selective vaporization of methane ("weathering"), how differences in density between new LNG and that already in the storage tank can cause a sudden pressure rise in the ullage volume ("rollover"), and how vapor can be evolved in a flowing stream ("geysering"). It also discusses the issues of static electricity buildup and vapor accumulation and associated potential hazards.

\subsubsection{Weathering}

LNG as delivered to a storage facility often has a mixture of methane, ethane, propane, and butane, with lesser amounts of other hydrocarbons. Typically, the methane content of LNG is at least $95 \%$, though weathered LNG can have methane contents as low as $85 \%$. While weathering is an issue in peakshaving plants, the LNG used for vehicles is generally of high purity (e.g. 99.5\% methane, Pentz 1995) and is used at a high rate. Both factors greatly decrease the importance of weathering in the use of $L N G$ as a vehicle fuel.

Although weathering is generally not important in vehicular use, operators should be familiar with the phenomena when handling impure fuel or storing it for extended periods. A comparison of the vapor pressures and heats of combustion for four energy gases is shown in Table 4-5. Note that, at $150^{\circ} \mathrm{K}$, the vapor pressure of methane is two orders of magnitude higher than that of ethane and probably three and four orders of magnitude higher than that of propane and butane, respectively. Thus the ullage volume at the top of a storage tank of LNG will contain vapor that is at least $99 \%$ methane. As that vapor volume is vented or consumed, methane will be selectively extracted from the liquid and the methane content of the liquid will decrease. Since the volumetric energy content of ethane is nearly twice that of methane, the energy density of the remaining fuel increases.

Weathering in vehicle tanks is not a problem when the vehicles are frequently refueled. Operational issues include engine knock (and possible damage) caused by the use of lower octane fuel (the octane rating of pure methane is about 140 , while that of a $90 \%$ methane/10\% ethane mixture is about 134). Weathering is a safety issue in that the energy required to initiate a detonation in ethane is about two orders of magnitude lower than that for methane.

The rate of weathering is dependent on the rate of heat leakage through the insulation into the storage tank, since the boil-off of the methane is the primary heat absorption process. Shah and Aarts (Shah 1974) have developed correlations for predicting the rate of weathering in storage tanks. Typically, weathering times are around 150 days for a $48,000-\mathrm{m}^{3}$ storage tank with a boil-off rate of $0.05 \%$ per day. Weathering times for a $125,000-\mathrm{m}^{3}$ LNG carrier ship having a boil-off rate of $0.25 \%$ per day are around 10 days. 
Table 4-5. Vapor pressures and heats of combustion for four energy gases.

Vapor Pressures

$(\mathrm{MPa})$

\begin{tabular}{|c|c|c|c|c|c|c|}
\hline & $\begin{array}{c}100^{\circ} \mathrm{K} \\
\left(-279.4^{\circ} \mathrm{F}\right) \\
\end{array}$ & $\begin{array}{c}125^{\circ} \mathrm{K} \\
\left(-234.4^{\circ} \mathrm{F}\right)\end{array}$ & $\begin{array}{c}150^{\circ} \mathrm{K} \\
\left(-189.4^{\circ} \mathrm{F}\right) \\
\end{array}$ & $\begin{array}{c}175^{\circ} \mathrm{K} \\
\left(-144.4^{\circ} \mathrm{F}\right) \\
\end{array}$ & $\begin{array}{r}200^{\circ} \mathrm{K} \\
\left(-99.4^{\circ} \mathrm{F}\right) \\
\end{array}$ & $\begin{array}{c}\begin{array}{c}\text { Heat of } \\
\text { Combustion }\end{array} \\
(\mathrm{MJ} / \mathrm{m} 3)\end{array}$ \\
\hline Methane & 0.0345 & 0.2694 & 1.041 & 2.78 & - & 39.77 \\
\hline Ethane & - & - & 0.0096 & 0.2563 & 0.2200 & 69.67 \\
\hline Propane & - & - & - & - & 0.0200 & 99.16 \\
\hline Butane & - & - & - & - & 0.0019 & 128.57 \\
\hline
\end{tabular}

Weathering can be reduced by several techniques. High methane contents (e.g. $99 \%$ ) can be specified in the fuel purchase contract. Fuel to be consumed in a vehicle should be taken from the liquid contents of the vehicle tank to prevent a long term buildup of ethane. Both storage and vehicle tanks should be well insulated to reduce vaporization in the tanks as much as possible. The effects of weathering in large storage tanks can also be reduced through mechanical refrigeration and reliquefaction of the ullage vapor. Vehicle tanks are designed to use only $90 \%$ of the gross tank volume to reduce the rate of pressure rise in the ullage $e^{8}$ and the subsequent venting of methane-rich vapors. In order to prevent venting of the vehicle tanks in potentially hazardous locations, such as within an enclosure, fueling schedules should be arranged to assure rapid turnover of the fuel in both the storage and vehicle tanks.

\subsubsection{Rollover}

Rollover is a phenomenon seen in large (>30,000-gallon) storage tanks when new LNG is added to LNG of a different composition already in the tank. The mixing of the two compositions can cause large, unexpected and sudden releases of vapor, commonly referred to as 'rollover.' This rollover causes a pressure rise in the tank and may challenge the pressure or venting capacity of the tank. No damage has been reported in any incidents of rollover, but the magnitude and rate of vapor release must be accounted for in storage tank design (Drake 1973).

New LNG being added to a storage tank is usually higher in methane content than the LNG already present, due to weathering. The colder, lighter ${ }^{\mathrm{h}} \mathrm{LNG}$ added to the top of the tank forms one convective cell, driven by heat inleakage through the walls of the tank and boiloff at the surface. The older, heavier, warmer LNG already in the tank forms a cell at the bottom of the tank, also driven by heat inleakage, but without boiloff. These cells remain separate until heat and mass transfer processes bring the upper and lower layer densities close enough to allow rapid mixing. When that mixing takes place, the warmer lower layer in the tank heats the methane-rich upper layer, causing the rapid evolution of methane gas into the ullage volume.

g. Note that pressure in the ullage volume increases faster when the vehicle is not in use than while fuel is being consumed.

h. The new LNG has higher methane content and is therefore lighter than the older, weathered methane. 
Large bulk tanks are equipped with top-fill vapor collapse headers which can reduce any possible effects of associated with non-methane content of the vapor space. Operational procedures should assure the use of the top-fill headers when warranted.

The dangers of rollover can be reduced or eliminated by three actions in the loading of an LNG storage tank. First, the formation of separate convective cells can be avoided if there is adequate mixing of the incoming LNG with all the LNG previously in the tank. This mixing can be done with recirculation pumps, which, however, increase the heating of the LNG. Another approach uses the momentum of the feed stream to mix the incoming with the stored LNG. Buoyant forces can aid in mixing if lighter LNG is always bottom-loaded and heavier LNG is always top loaded.

Overpressurization of the storage tank during a rollover can be avoided if venting or pressure capacity is adequate to handle the maximum amount of vapor that can be generated during a rollover. Finally, concerns for rollover (and weathering) can be reduced if the range of LNG compositions to be added to the tank is limited. In recent years, the methane content of LNG has increased and become more consistent because of more thorough removal of ethane, propane and butane at the liquefaction plant.

\subsubsection{Geysering}

Geysering is caused by heat inleakage to a feed or vent pipe connected to both the bottom and upper portions of a deep storage tank (Morioka 1986). Because the area to volume ratio is higher for the pipe than for the overall tank, the fluid in the pipe becomes heated above saturation, forming bubbles and decreasing in density. The bubbles cause upward flow through the pipe and possible rapid methane vapor evolution in the ullage volume. Because the heat transfer rates are low and the mass of LNG is large, geysering sometimes develops into a transient phenomenon called bumping. Burmping is more frequent in vertical pipes. Transient boiling and condensation within piping to an LNG storage tank can also cause 'water hammer' and possible damage to the piping system.

\subsubsection{Static Electricity and Grounding}

Static electricity is the separation of positive and negative charges and the continued separation of the charges because no conducting path is available for the charges to reunite. Static electricity can be generated by friction in flowing low conductivity fluids, such as gasoline or LNG. Static electricity can also be generated by friction between solid surfaces or by connection to atmospheric static discharges. Five conditions must be present to produce a static spark capable of igniting a flammable mixture:

1. A mechanism for generating the static charge separation

2. A means of accumulating the charge, i.e. a capacitance

3. A suitable gap across which the previously separated charges can flow

4. A voltage difference across the gap sufficient to cause electrical breakdown

5. Sufficient energy released in the spark to meet the minimum ignition energy requirements of the flammable mixture (Mancini 1988).

As discussed earlier, the ignition energy for both methane and gasoline is about $0.3 \mathrm{~mJ}$. Gasoline is usually carried in metal tanks and the flexible hose and spout are electrically bonded. Furthermore, the 
area surrounding gasoline pumps is usually concrete, to resist chemical attack from spilled gasoline. The electrical conductivity of concrete is about two orders of magnitude higher than that of asphalt. Thus charges separated by friction in the flow of gasoline are reunited along paths in the hose, concrete, and tires.

Because of its cryogenic properties, LNG is transferred in metal rather than rubber or plastic hoses and tanks. Seals are also generally metallic. Thus separated charges flow through the metal bellows hoses and nozzle connections without sparking. For added safety, a separate grounding wire has been provided at each of the refueling stations we visited. It is not clear that such a separate wire is needed. (As it turns out, because the wire can become entangled with the LNG fill hose, particularly in one facility, the grounding wire was not always used. If the function of the grounding wire is needed, the design of future stations should rely on intrinsic grounding and bonding mechanisms and not rely on the operator's attaching a separate grounding wire.)

\subsubsection{Vapor Accumulation}

The accident at Cove Point, Maryland on October 6, 1979, in which one person was killed, was the result of vapor accumulation in a motor controller building. The vapor flowed into the building through an improperly sealed conduit from a submerged pump to the building. Since the LNG was not odorized, and since there were no methane sensors in the building, the supervisor did not recognize that natural gas had accumulated in the building and a spark from the control circuitry in a cabinet ignited an explosion (see Section 2.3.3).

While accumulation of a flammable mixture and ignition of an explosion of methane in the open air is difficult, vapor accumulation within a building can easily result in large volumes of an explosive mixture. Furthermore, the reflection of shock waves off the interior walls, floor and ceiling intensify the shock heating process and therefore reduce the energy required to initiate a detonation. Thus a prime concern in the handling of LNG is the accumulation of vapors within enclosures.

After the Cove Point accident a number of changes were mandated in the design and construction of LNG facilities. Among those changes was the requirement for vents and a section of solid conductor in any conduit run between any source of natural gas and an ignition source. The vents are located outside of any enclosure and release any vapors flowing within the conduit. The solid conductor interrupts the vapor path in the interstitial passages between stranded conductor. Tests done after the Cove Point accident indicated that vapors could flow along the interstices in stranded wire if the driving pressure is sufficient (NTSB 1980, Van Meerbeke 1982, IFC 1980).

\subsection{Phenomena Under Accident Conditions}

Under accident conditions, a quantity of LNG may be spilled on the ground or on a water surface. The flow, dispersion, and possible ignition of the LNG vapors following such a spill in large part determine the severity of the accident. As a low density cryogenic liquid, LNG has several characteristics different from those of more common liquid fuels. 


\subsubsection{Spills}

LNG is stored and transferred at pressures of 45 to $200 \mathrm{psi}(0.3$ to $1.4 \mathrm{MPa})$. As noted in Table $4-2$, the viscosity of liquid methane at $112^{\circ} \mathrm{K}$, its boiling point at atmospheric pressure, is $0.00113 \mathrm{~g} / \mathrm{cm}-\mathrm{s}$. By comparison, the viscosity of gasoline is $0.002 \mathrm{~g} / \mathrm{cm}-\mathrm{s}$ and that of water is roughly the same in the range $300^{\circ} \mathrm{K}$ to $400^{\circ} \mathrm{K}$. Thus, LNG can be expected to spill and flow somewhat more easily than water.

\subsubsection{Dispersion}

The dispersion of methane after a spill of $L N G$ has been the subject of several series of experiments over the last thirty years. Several phenomena govern the behavior of methane after the open pool of liquid has been established. The LNG is vaporized by heat input from the underlying water or soil, from the air above the pool and from insolation. Spills on water can continue to draw heat from the water because of its high thermal capacity and convective currents. However, spills on soils cause freezing of the soil and a marked decrease in thermal conductivity. In a deep pool of LNG, convective currents will be formed in the pool itself.

The critical parameter in the investigation of vapor dispersion is the extent of the region wherein the methane concentration is between the upper and lower flammability limits, i.e. between 5 and 15 volume percent. Unlike gasoline and propane, methane is lighter than air when in thermal equilibrium and thus the vapor will rise when warmed sufficiently by the surroundings. As stated earlier in this section, methane at $165^{\circ} \mathrm{K}$ has the same density as air at $300^{\circ} \mathrm{K}$. Thus, the methane vapor will begin to rise as soon as it is warmed (by the water, soil, and air) from its release temperature of $115-120^{\circ} \mathrm{K}$ to $165^{\circ} \mathrm{K}$.

Finite element models have been developed to simulate the dispersion of $L N G$ and its vapor after a spill. These models and the experiments that validated the models are discussed later in this section and in Chan (1992).

\subsubsection{Boiling Liquid Expanding Vapor Explosions}

A Boiling Liquid Expanding Vapor Explosion (BLEVE) occurs as a result of a fire surrounding a pressure or other storage vessel containing flammable liquid. Typically, the fire is fed by a leak in the storage vessel. The liquid within the vessel heats up and the pressure rises. Relief valves are challenged to open at their set point pressures, but if the valves are not large enough, or do not function on demand, then the flow through the valve is insufficient to reduce the pressure and in any case, flammable liquid or vapor issuing from the relief valve further intensifies the fire beneath the storage vessel. The walls of the vessel begin to creep as their temperature rises and finally the wall fails, often in a lower portion of the tank exposed to the most intense external fire. At this point the remaining contents of the tanks are discharged to the atmosphere in a preheated condition and are immediately ignited by the initial fire, exploding in a classic mushroom fireball. The blast effects of such explosions are not usually too severe, but debris may be scattered over a wide area (Thomson 1987). Often there is a domino effect, where the first BLEVE scatters debris which lights further fires and causes additional vessel failures. In the U.S., there were twelve BLEVEs between 1970 and 1975 (GAO 1978). Several of these were in strings of railroad tank cars carrying propane. A derailment would cause the failure of one or a few cars and the ensuing fire would cause a BLEVE in those cars with a domino effect to the other cars.

Several distinctions between propane and LNG tank cars are worthy of note. First, since LNG must be shipped at $112-130^{\circ} \mathrm{K}$, the storage and transport tanks are well insulated from the external atmosphere. The external shell must be strong enough to maintain the annular vacuum insulation, but the pressure 
boundary is the internal shell. On the other hand, tanks for the shipment and storage of propane are singlewalled and often uninsulated, since propane is a liquid at $300^{\circ} \mathrm{K}$ and $1.0 \mathrm{MPa}$ (145 psi). Thus heating of the walls and heat transport to the stored liquid are much more rapid with propane than with LNG. Our research has found no reports of BLEVEs involving LNG, though we have obtained reports of propane BLEVEs from several sources.

The incidence of propane BLEVEs has decreased markedly since the 1970s due to federally mandated improvements to railcars, such as end shields for the tanks, couplers which would not slip apart during a derailment and protection of valving. The improved couplers were necessary because the initial tank failures were often caused by the coupler of an adjacent car.

\subsubsection{Unconfined Vapor Cloud Explosions}

Unconfined vapor cloud explosions (UVCEs) occur when a cloud of flammable vapor is released and becomes mixed with the air over a period of time before ignition occurs. If the mixture then detonates, it produces a shock wave traveling at a few kilometers per second and overpressures of a few atmospheres.

As discussed elsewhere in this section, Bull and coworkers (Bull 1976) ignited UVCEs in mixtures of methane, oxygen, and nitrogen. He found, by extrapolation, that $22 \mathrm{~kg}$ of high explosive would be necessary to detonate a methane air mixture, but that propane and ethane could be ignited by a few tens of grams. Furthermore, at the same temperature and pressure, methane is about 0.55 the density of air, while ethane and propane are 1.03 and 1.52 times the density of air, respectively. Thus, methane disperses into the atmosphere as it heats while ethane, propane, and heavier hydrocarbons vapors can flow into low spots at ground level. The likelihood of a methane cloud detonation therefore appears to be low.

A methane cloud deflagration, on the other hand, is possible. Gugan (1979) reports an unconfined vapor cloud explosion involving a perhaps $500 \mathrm{~kg}$ cloud of methane at a chemical process plant on a cold $\left(-12^{\circ} \mathrm{F}\right)$ day. The cloud edge was some 50 meters away from its source when ignition occurred. The explosion broke several windows (the flying glass caused numerous injuries, some of them serious) but otherwise caused little damage. The damage observed (which implies a relatively slow speed of pressure rise) indicates that the explosion did not involve a detonation.

\subsection{Experiments}

The U.S. Department of Energy (DOE) has constructed the Liquefied Gaseous Fuels Spill Test Facility (LGFSTF) on and adjacent to the dry bed of Frenchman Lake at the Nevada Test Site, 75 miles northwest of Las Vegas (Leone 1990). One feature of the LGFSTF is the Large Scale Test Area, where the storage tanks can supply spill rates of 5 to $100 \mathrm{~m}^{3} / \mathrm{min}$ (1000 to 26,000 gpm) onto ground or water surfaces. The cryogenic system can supply total spill volumes of 5 to $200 \mathrm{~m}^{3}$ (1000 to 53,000 gallons). The LGFSTF has the capability to test phenomena such as source definition, dispersion, rapid phase transition, pool fire and vapor burn.

i. It is not known if this possibility should be discounted entirely, as deflagration-to-detonation transitions are possible in UVCEs, depending on the size of the cloud and various environmental conditions. 
In 1987 the Gas Research Institute and the U.S. DOT performed a series of five releases of LNG ranging from 6500 gallons to 26,000 gallons. The program tested the effectiveness of vapor fences in mitigating LNG releases at peakshaving plants.

The parameters for four of the five 1987 experiments are shown in Table 4-6 (Chan 1992). The last column contains the results of a numerical simulation of the Falcon-4 experiment in which the vapor-dispersing fence was removed from the model. Note that the spill volumes range from 5,400 to 17,500 gallons, easily encompassing the largest size tanker truck expected at an LNG refueling station. The first three tests had spill durations of less than three minutes, while the fourth test had a spill duration of slightly over five minutes. Winds were light and the weather conditions were moderately stable. The spills were made on the surface of a $60 \mathrm{~m} \times 40 \mathrm{~m}$ pond, about $0.76 \mathrm{~m}$ deep. The fiberglass vapor fence surrounding the pond was $44 \mathrm{~m}$ wide and $88 \mathrm{~m}$ long and $8.7 \mathrm{~m}$ high. The test area also included a billboard-line barrier $17.1 \mathrm{~m}$ long and $13.3 \mathrm{~m}$ high. The purpose of the tests was to validate the codes and

Table 4-6. Parameters for Falcon experiments.

\begin{tabular}{|c|c|c|c|c|c|}
\hline & Falcon-1 & Falcon-2 & Falcon-3 & Falcon-4 & $\begin{array}{c}\text { Falcon }-4 \\
\text { (simulation, no fence) }\end{array}$ \\
\hline Spill volume $\left(\mathrm{m}^{3}\right)$ & 66.4 & 20.6 & 50.7 & 44.9 & 44.9 \\
\hline Spill volume (gallons) & 17540 & 5440 & 13400 & 11860 & 11860 \\
\hline Spill rate $\left(\mathrm{m}^{3} / \mathrm{min}\right)$ & 28.7 & 15.9 & 18.9 & 8.7 & 8.7 \\
\hline Spill rate (gpm) & 7580 & 4200 & 4990 & 2300 & 2300 \\
\hline $\begin{array}{l}\text { Average windspeed at } \\
2 \mathrm{~m}(\mathrm{~m} / \mathrm{s})\end{array}$ & 1.7 & 4.7 & 4.1 & 5.2 & 5.2 \\
\hline $\begin{array}{l}\text { Average windspeed at } \\
2 \mathrm{~m} \text { (mph) }\end{array}$ & 3.8 & 10.5 & 9.2 & 11.6 & 11.6 \\
\hline Pasquill stability class & $\mathbf{G}$ & D & $\mathbf{D}$ & $\mathbf{D} / \mathbf{E}$ & $D / E$ \\
\hline $\begin{array}{l}\text { Downwind distance to } \\
2.5 \text { volume \% } \\
\text { concentration (m) }\end{array}$ & 440 & {$[200]$} & 353 & 203 & [365] \\
\hline $\begin{array}{l}\text { Downwind distance to } \\
2.5 \text { volume } \% \\
\text { concentration (ft) }\end{array}$ & 1444 & {$[656]$} & 1158 & 666 & [1198] \\
\hline $\begin{array}{l}\text { Downwind distance to } \\
5 \text { volume \% } \\
\text { concentration (m) }\end{array}$ & 330 & {$[70]$} & 230 & 28 & [230] \\
\hline $\begin{array}{l}\text { Downwind distance to } \\
5 \text { volume \% } \\
\text { concentration (ft) }\end{array}$ & 1083 & {$[230]$} & 755 & 92 & [755] \\
\hline \multicolumn{6}{|c|}{ Distances in brackets are results from FEM3A runs; other distances are experimental data } \\
\hline
\end{tabular}


wind tunnel model used in simulating vapor dispersion and to assess the effectiveness of vapor fences for mitigating $L N G$ vapor dispersion hazards in the event of a large accidental spill. The code FEM3A generally predicted the results of the experiments within $25 \%$, though the experimental downwind $5 \%$ concentration distance was less than $45 \%$ of the distance predicted by the model.

Experimental results and the simulation of Falcon-4 without a vapor fence indicated that a vapor fence has the following advantages: significantly reduced methane concentrations in the near field, delayed cloud arrival times at downwind locations, and a much shorter downwind distance where the methane concentration is in the flammable range. However, a vapor fence retains the vapor cloud longer near the source, thus increasing the potential for ignition. Methane concentrations within the vapor fence were above the upper flammable limit ( $15 \mathrm{vol}$. \%) for the first four minutes of the Falcon- 1 and Falcon-4 tests. (Interior concentrations were not reported for the other tests.)

Earlier, some 130 experimental spills of LNG on water were carried out between 1970 and 1981 (Puttock 1982). Liquid volumes spilled ranged from $0.04 \mathrm{~m}^{3}$ to $198 \mathrm{~m}^{3}$. Sixteen of the tests were intentionally ignited. Spills onto ground were conducted by Gaz de France at Nantes in 1972 and by Battelle/AGA near San Clemente in 1974. In the ground spills, evaporation from a soil surface rapidly decreased as the soil cooled and the maximum hazard occurred soon after the LNG was spilled. Because of water in the soil and humidity in the air, a visible cloud was observed to separate from the plume remaining after the initial burst of vapor. It was found from concentration measurements that the flammable region was always contained within the visible cloud.

Shell conducted about ten experimental spills of LNG, eight continuous and two instantaneous in late summer 1980 at Maplin Sands along the Thames: Spill volumes were between $4 \mathrm{~m}^{3}$ and $20 \mathrm{~m}^{3}$. Instrumentation surrounded the spill site on a tidal flat in a semi-circular pattern, $400 \mathrm{~m}$ in radius. In one of the tests, LNG was injected as a jet $0.25 \mathrm{~m}$ below the water surface at the rate of $3.9 \mathrm{~m}^{3} / \mathrm{min}$ for 5.0 minutes. The LNG formed a highly buoyant cloud which passed above even the closest methane sensors located $2.4 \mathrm{~m}$ above the sea surface and $40 \mathrm{~m}$ from the release point. This test is good indication that the rapid phase transitions caused by mixing of $L N G$ and water are not violent.

\subsection{Current Outstanding Issues in LNG Safety}

In an October 15, 1996 memo to Thomas Grumbly (Hunt 1996) Peter Hunt raised a number of important safety issues in the use of LNG as a transportation fuel. The issues involve:

- The hazard of a fire or explosion in the methane vapor cloud released in an LNG spill

- The danger of lung damage or asphyxiation due to the low temperature of the vapor cloud

- Material failures due to contraction and embrittlement if structural steel is exposed to LNG

- The rapid phase transition that will occur if LNG is injected into water or another warm liquid.

Our review of the literature and field observations lead to the following conclusions about the status of each of these issues. 
Regarding the first issue, DOE and the LNG industry have conducted both experiments and numerical simulations of the release and dispersions of large quantities of LNG, as noted in the preceding section. These tests have resulted in the development of guidelines for the size of LNG facilities to assure no offsite transport of flammable mixtures (Ong 1985). However, it is not clear if these guidelines are being met; based on the results of the Falcon tests and associated simulations, it appears that under some weather conditions, credible (though quite unlikely) spills at two of the facilities visited can lead to flammable concentrations offsite.

The DOE and industry tests and simulations have also led to the development of vapor fences surrounding LNG storage tanks that greatly reduce the region of flammability (Chan 1992). Again, it is not clear that these fences are widely deployed; none of the facilities visited had fences especially designed to enhance LNG vapor dispersion. (Note that the effectiveness of conventional, e.g., chain link, fences in dispersing $L N G$ is also unclear.)

If a large release occurs and is not quickly dispersed, unconfined methane vapor cloud explosions are possible (see Section 4.4.4). Although such explosions are unlikely to involve detonations, deflagrations are capable of causing extensive injuries and property damage.

Regarding the second issue, there clearly is a danger of asphyxiation and lung damage if one enters a low temperature LNG cloud. Such accidents are not expected to be common events, since the cloud is usually quite visible in the daytime due to condensation of humidity from the air. Furthermore, areas where such cold clouds can accumulate are normally contained within a bund wall or pit surrounding an LNG storage tank, where workers are not routinely present and where the public should not be allowed. However, the possibility of these accidents cannot be discounted; analogous occurrences have been observed in non-LNG facilities. (For example, Medard (1970) describes a 1968 event in France in which a semi-trailer truck filled with ammonia ruptured. The release formed a white, mushroom shaped cloud. Six nearby workers went to investigate the noise and were enveloped by the cloud; three collapsed and died.)

Regarding the third issue, material failures have occurred on LNG carrier ships when LNG has spilled on steel deck plates, causing contraction and brittle failure. However, these incidents apparently have not involved widespread damage and have not led to severe consequences (Harris 1993 and Frondeville 1977). It should be noted that the 1944 Cleveland accident was caused by a material failure of the tank wall itself. That grade of steel, containing 3.5\% nickel, is no longer used for LNG tanks; $9 \%$ nickel steel is used instead. This change precludes tank membrane failure by brittle fracture (assuming there are no significant design or manufacturing errors in tank construction).

Regarding the fourth issue, a rapid phase transition is possible if LNG is finely dispersed in a much warmer liquid, such as water at $300^{\circ} \mathrm{K}$. However, the water would have to fall into the LNG or the LNG would have to be injected below the water surface. Numerous experiments where LNG has been spilled on the water surface have not resulted in any violent phase transitions. 


\section{CASE HISTORIES OF LNG INCIDENTS}

This chapter describes accident events that have occurred with facilities that handle liquefied natural gas. Gaseous natural gas events, such as pipeline breaks, explosions in homes, etc., are not included here. Information about such events can be found in the literature, such as [Jones et al., 1986], National Transportation Safety Board pipeline accident reports, and other documents. Every effort to be thorough in the collection of LNG events has been taken, including manual, computerized, and internet literature searches. It is possible that some events, especially events outside the U.S., may not have been captured by these searches, but it is believed that any event which might have been overlooked is not as consequential as those events that have been captured. These events are discussed in chronological order.

\subsection{East Ohio Gas Co. Explosion [BOM, 1946]}

The cold wave of the winter of 1940 taxed the gas supply to Cleveland, Ohio. To augment the gas supply, the gas company could have either built a 12-inch diameter high pressure pipeline from the Hope Natural Gas Company to Cleveland ( 150 miles distant) at a cost of $\$ 2.5 \mathrm{M}$, or they could store gas from existing pipelines by using a liquefaction and storage plant in Cleveland at an estimated cost of $\$ 0.75 \mathrm{M}$. Erection of the liquefaction plant began in September 1940 and was completed in Jamuary 1941. The plant, the largest of its kind in the world, proved to be successful. In 1943, a cylindrical storage tank was added to increase LNG storage to meet Cleveland's peak gas demands while still supplying the increased base load demand for war industries. At 2:40 pm on October 20, 1944, the cylindrical LNG storage tank of the East Ohio Gas Company failed, spilling 1.1 million gallons of liquefied natural gas.

The results of this release were disastrous. The cylindrical tank apparently cracked and then collapsed. The release began as cold vapor and then liquid flowed out. The liquid rushed over the short dam around the tank. The surging liquid was energetic enough to move parked automobiles. While much of the LNG vaporized, some ran into the storm sewer at 66 th Street. The LNG vapor was burning atop the flow of LNG, but investigators did not try to locate the ignition source since many were available in nearby machine shops, electrical instruments, compressor house, etc. Flames were estimated to reach about 0.5 mile above the tank. Dwellings near the plant site were ignited by radiant heating from the burning gas, or gas up from the sewer was ignited inside the buildings. A north-northeast wind drifted the burning gas over buildings on 61st Street, and the buildings caught fire. The investigation report also states that gas leaked into some basements of buildings on 61 st and 62 nd Streets, formed an explosive mixture and ignited, razing the buildings.

The heat from the fire caused heatup and failure of one of the nearby spherical (57 foot inner diameter) storage tanks. About 20 minutes into the event, it spilled its entire contents, about half the amount that was stored in the cylindrical tank. 
The LNG that reached the storm sewer system at 62 nd Street vaporized and was ignited. The overpressure from the deflagration caused streets to crack or collapse, and weakened building foundations. Buildings caught fire from the radiant heat from the burning tank and from the deflagration. The fire damage was seen to extend about 0.25 mile in a radius around the cylindrical tank.

The cylindrical tank was made from $3.5 \%$ nickel steel, which was judged by metallurgists of the time to be an acceptable material for cryogenic applications. The nickel steel was also less expensive than other materials known to be acceptable for cryogenic uses (copper, bronze, Monel, red brass, and stainless steel). Since this event, it is known that $9 \%$ nickel steel will not embrittle like $3.5 \%$ nickel steel. The $3.5 \%$ nickel steel is no longer used for cryogenic applications.

Other investigator recommendations were to build dams around the tanks that would confine large spills, not just small leaks. Ignition sources were to be excluded from the vicinity of tanks. Remote siting of at least a half-mile distance was strongly recommended.

In this event, 128 people died and hundreds more were injured. The property damage cost of the event was estimated to be $\$ 6.8 \mathrm{M}$ in 1944 ( $\$ 65 \mathrm{M}$ in 1997 dollars). This event has been credited with delaying the liquefaction and storage of LNG in the U.S. for over 20 years [Zabetakis, 1967].

An events and causal factors table is given in Table 5-1. In this case, the initiating event is rather straightforward, a materials failure. Aggravating conditions were the site's proximity to a city, the small bund wall around each of the tanks, the spherical tank supports that allowed tank collapse, and site elevations that allowed LNG to drain to storm sewers.

\subsection{Raunheim, Germany explosion [CCPS, 1994]}

On January 16,1966 , a plant was unintentionally venting methane to the atmosphere. The LNG was passed through a vaporizer. The vaporizer used a liquid level controller to operate the vaporizer below its maximum capacity of $4000 \mathrm{~kg}$. The exact cause of the release is not known; apparently, the liquid level controller failed and allowed a slug of liquid methane to be ejected from the vaporizer's gas vent (probably less than $500 \mathrm{~kg}$ of LNG was released). This release occurred at the top of the vaporizer vent ( $25 \mathrm{~m}$ high). Control room operators saw a white cloud slowly expanding and drifting toward the control room, which was $50 \mathrm{~m}$ from the vaporizer. The outside temperature was $10^{\circ} \mathrm{F}$, with low wind. The cloud ignited, probably from ground level furnaces that were $50 \mathrm{~m}$ from the cloud in the opposite direction as the control room. One person was killed and seventy-five were injured, primarily from flying glass.

This event description was not detailed enough to construct an events and causal factors table. 


\subsection{Portland, Oregon LNG tank explosion [ENR, 1968]}

The details of this event are few. In March 1968, workmen were completing construction of a 118 foot diameter, 95 feet tall LNG storage tank in Portland, Oregon. The tank was believed to be the largest of its kind in the U.S. at the time. The inner tank was made of aluminum, with a perlite insulation annulus and a steel outer shell. Natural gas from inlet lines had apparently leaked into the inner tank. A slip blind (i.e., a blank flange, or cutoff) had been removed from a pipe six days before the accident to allow insulation operations on the valve and a valve had been partially opened (24 threads on the valve stem), apparently to test the 6-inch diameter line. Natural gas, routinely used to perform leak tests at the facility, had backed through the no-longer-isolated line and the partially opened valve to accumulate inside the aluminum tank. The gas was ignited by an unspecified source and four workmen in the tank were killed in the explosion.

This event description was not detailed enough to construct an events and causal factors table.

\subsection{Quebec, Canada control room explosion [LNG, 1972]}

On January 27, 1972, a natural gas explosion severely damaged the control room of the LNG liquefaction and peakshaving plant in Montreal East, Quebec. This plant was operated by Gaz Metropolitain. At the time of the explosion, the plant was operating in peak mode, that is, it was vaporizing stored LNG, reodorizing the gas, and sending it to the gas distribution piping. The plant used a 75-psi nitrogen gas system for manually controlled purging of equipment for startup, shutdown, and maintenance, pressurization of gas storage tanks, backup of the instrument air system, and as a seal gas on the compressors when they are derimed (i.e., defrosted). Shortly before the explosion, the recycle compressor had been derimed. Typically, at the end of the deriming cycle, the compressor is filled with 250 to $350 \mathrm{psi}$ warm natural gas from the pipeline. During this derime, the instrument air compressor was shut down for maintenance and the pneumatically controlled instruments were being operated using the 75 psi nitrogen backup. Three manual shutoff valves between the nitrogen system and the recycle compressor were inadvertently left open, allowing natural gas at a minimum of 250 psi to back up into the 75 psi nitrogen system. As a result, the instrumentation was running on unodorized natural gas instead of air or nitrogen. Some unodorized natural gas vented from the instruments into the control room. The gas rose to the ceiling and began banking down toward the floor. The control room was considered a non-hazardous area because normally there are no flammable gases or vapors present. Two of the five operators were smoking at their control panels, which was permitted under company rules for non hazardous locations. The two smokers saw flames flash toward the instrument control panels and the explosion occurred. Being somewhat protected by the instrument control panels, the five operators sustained only minor injuries. The blast vented to the rear and sides of the room, and through the roof. The fires that followed were confined to paint on the panels and plastic instrument faces.

This event shows the importance of monitoring where the natural gas is being used in the plant. An event and causal factor table was not constructed since insufficient information was provided about the factors in this event. 


\subsection{Staten Island LNG tank explosion [GPO, 1973]}

The Texas Eastern Transmission Company (TETCo) and its satellite company Texas Eastern Cryogenics Company owned an LNG storage tank on Staten Island. This tank was built of concrete and used an inner layer of thermal insulation and a tank liner held in place by aluminum struts. The insulation was polyurethane with a protective liner of mylar and aluminum, then another 1 inch thick polyurethane coat on the mylar. Other storage tanks of this era used perlite as thermal insulation, but the size of this tank (168 feet in diameter, 61-foot cylinder with a domed roof, and 24 inch thick concrete walls) meant that it required better insulation. The tank became operational in April 1970. The tank was determined to be leaking LNG through the liner in 1971. The tank was emptied of LNG in February 1972 and was entered while under one atmosphere of nitrogen gas in March 1972 to identify the leak location. The location could not be found under those inspection conditions, so the tank was brought to air at ambient conditions. With this easier inspectability, a ten foot long rip in the liner bottom was discovered. A decision was made to repair the rip and to augment the tank for holding heavier LNG (colder LNG required additional ballast blocks, downcomers and nozzles, and a splash plate). This repair and augmentation work commenced on the tank. On February 10, 1973, at about 1 p.m., a fire swept through the tank. The overpressure (over 1 psig) caused by hot combustion products in the tank caused the tank roof to raise. The roof fractured and fell in pieces back into the tank. 40 workmen were trapped in the tank when the roof collapsed.

The fire is believed to have been an insulation fire - burning polyurethane insulation, believed to be accelerated by trapped pockets of methane gas that lingered from when LNG had leaked into the insulation while the liner had been breached. Some speculation exists that the falling barometric pressure allowed the polyurethane to give off some of the trapped methane gas, making it easy to ignite a fire while workmen were repairing the liner. Since the tank had been warm for about 11 months prior to the event, this was not an LNG event; it was a gaseous methane and combustible insulation event. Nonetheless, it is included here since many safety researchers include the LNG tank as LNG equipment.

The fire may have been ignited by any of several tools in use in the tank. Electric fans were in use to move air for ventilation where epoxy glue was in use to secure ballast blocks to the floor and where the fire watch noted a methane buildup (the fans dispersed it throughout the tank). Electric irons were in use to seal strips of mylar liner to each other. Vacuum cleaners were used to clean the tank of any debris prior to gluing or sealing operations. Two-way radios and floodlights were in use in the tank. However, personnel were required to wear only cotton clothing and cotton slippers (to protect the liner and reduce static electricity), and leave all smoking materials outside to eliminate an ignition source and maintain cleanliness in the tank. Unfortunately, smoking materials were found on three of the deceased workmen, so this ignition source cannot be ruled out. A very old .22 caliber handgun was found on the remains of one worker, but the spent cartridges showed no firing pin marks (investigators believed that the fire heat caused the bullets to fire; this fact and the location where the firearm was found indicate that it was not the ignition source). Most of the repair equipment was not explosion proof. One of the small hand irons used for mylar repair was tested and found to not ignite a methane-air flammable atmosphere in a test chamber until it was unplugged (i.e., the sparks created by pulling the plug from the electrical socket). There was new polyurethane and polyethylene sheeting in the tank as well as mylar to serve as fuel during a fire. Bureau of Mines testing showed that adding methane hydrocarbon gas to polyurethane would easily allow faster burning and give the pressure rise needed to lift the tank roof. While the polyurethane would easily ignite and burn without 
any other hydrocarbons present, the Bureau of Mines believed that pressure rise would not be enough to lift the tank roof; therefore, the trapped methane increased the severity of the event. The workmen died of asphyxiation, as reported by the Medical Examiner. Apparently, the rapid burning fire had simultaneously taken oxygen from the air and filled the tank with combustion products. The workers' positions did not indicate any bunching up at the scaffold stairway to exit, nor were there any clusters of workers at the safety shack in the center of the tank. Although the tank roof collapsed rather quickly in this tragic event, the postmortem indicated asphyxiation as the cause of death for the 40 men.

An events and causal factors table for this event is given in Table 5-2.

\subsection{Cove Point, Maryland explosion at a peakshaving plant [NTSB, 1980; GPO, 1980]}

The LNG peakshaving facility located at Cove Point, Maryland, began operation on March 13, 1978. Cove Point is located in a sparsely populated area about 60 miles south of Baltimore, Maryland, 50 miles southeast of Washington DC, and about 80 miles northeast of Richmond, Virginia. No part of the facility was closer than 0.33 mile from the company's property line. The facility received deliveries from tanker ships that brought LNG from Algeria, Africa. The LNG was off-loaded into two 32-inch pipes at low pressure into four large (about 16 million gallons each) storage tanks. The tank pressure is under 2 psig. When needed, the LNG is pumped at 60 psig in one pumping stage, then booster pumped up to 1300 psig. The high pressure LNG is vaporized to $55 \mathrm{~F}$ and injected into a 36 inch diameter transmission pipeline.

The ten booster pumps that raise LNG from 60 to 1300 psig are pump-motor units totally submerged in LNG within pressure vessels. The benefits of submerged pumps are that there is no pump shaft seal, the LNG provides cooling to the motor, and the only penetrations are for fluid flow and 4160 Volt three-phase power to the 1250 horsepower electric motor. Rotating shaft seals are reputed to leak more frequently than fixed seals, and they require more maintenance. The three electrical cables that sent power to the motor passed through penetrations that prevent LNG vapors from leaking out of the pressure vessel. The penetration serves as an electrical insulator and high pressure seal material. G-10, a synthetic insulator (an

epoxy impregnated glass fiber; this material hardens into a strong solid material), and asbestos were used to seal the electrical junction box from the pump's pressure vessel.

In normal conditions, small amounts of heating from the electrical cables would vaporize some LNG and thus form a small, warm gas zone or barrier at the seal location so that no LNG touched the penetration seal during pump operation. The electrical conduits from the junction box were constructed of polyvinyl chloride piping encased in concrete. The conduit also had a seal where wires passed through sealing compound. That type of seal was rated for only $0.25 \mathrm{psig}$ pressure difference, according to an Underwriters Laboratories standard. Reference [GPO, 1980] discusses how the intent of the National Electric Code was not met by this design, since the second seal was not LNG-proof. Reference [GPO, 1980] contends that the Department of Transportation's Materials Transportation Board acted in haste when adopting the National Electrical Code for cryogenic facilities.

One of the ten booster pumps, pump 105JK, developed a seal leak at the electrical cable penetration, probably the gas leaked first, then LNG contacted the electrical penetration and that increased the leak rate 
until LNG was leaking into the junction box. LNG flowed from the junction box to the conduit. The natural gas in the conduit warmed and the pressure of expansion was much greater than what the $0.25 \mathrm{psig}$ conduit seal could withstand.

On October 6, 1979, the Cove Point plant was in storage mode. The booster pumps were not operating, but they were being held at 60 psig and at LNG temperature (this is typical for a cryogenic plant to maintain equipment at cryogenic temperatures to avoid time-consuming, wearing, and costly warm-up and cool-down cycles). The 1:30 a.m. operator walkthrough did not detect any unusual events. At about 3:10 a.m., another operator left monitor house No. 1 to take equipment readings. At about 3:20 a.m., he radioed the operator/controller at monitor house No. 1 that he had found LNG leakage into the second stage pumphouse. There was radio interference, but his report was understood well enough in the monitor house. The roving shift supervisor was in monitor house No. 1 and heard the report. He left to assist the operator. The operator radioed again to say that the leak was from pump 105JK, with LNG leaking from that pump's electrical junction box in the pump house. Note that in reference [GPO, 1980], the leak is described as liquid 'pouring out of the junction box in a ten foot radius.' The supervisor and operator determined that the best course of action would be to isolate the pump so that it would not accidentally be started, since remote starting was possible. At about 3:30 a.m., the supervisor telephoned the monitor house No. 1 to inform the operator there that he would disengage the circuit breaker for the $105 \mathrm{JK}$ pump in the Substation No 2 building. At 3:34 a.m., the operator depressed the circuit breaker interlock release, and an explosion followed which destroyed Substation No. 2, several electrical transformers, and heavily damaged adjacent structures. Transformer oil spread over the area and ignited.

LNG does not have any odorant included with it, since most odorants will freeze out or not mix at LNG temperatures. When the LNG vaporized, it became odorless natural gas. The LNG flooded the electrical junction box in the pump house and then flowed into the PVC conduit for the electrical cables. There the gas vaporized and flowed down about 210 feet of conduit into the Substation No. 2. While the Columbia facility had 109 combustible gas indicating meters (CGIs) onsite, none were in the electrical substation No. 2 building since this building was considered to be a non-hazardous area (where gas would not be found). The CGIs in the 105J pumphouse were operating, but did not send in an alarm although large quantities of LNG were leaking into the pump house. Calibration dates on the CGIs showed that at least 17 months had elapsed since the last calibration (industry consultants advised that 1 to 3 months is an adequate recalibration period for CGIs).

Investigators believed that the leak probably started in small amounts a few days, or even weeks, before the accident. The LNG penetration seal bolts were not torqued tight enough to prevent leakage. After the pump was shut down, 19.5 hours prior to the accident, the gas covering the penetration seal began leaking out and then LNG touched the seal. The LNG leaked under pressure into the junction box and down the conduit. The operator noted LNG leaking from the junction box in the pump house, but did not consider that LNG or gas might be routed down the conduit to the electrical substation. Since the natural gas was odorless and probably quite warm by that time, there was no indication for the operator. When the operator opened the circuit breaker for the pump in the substation, an electric arc occurred, igniting the natural gas that had accumulated in the building. The operator was badly burned but was rescued by other personnel responding to the explosion. The shift supervisor was killed by a falling roof truss; the explosion blew out the walls so that the roof collapsed [GPO, 1980].

Table 5-3 shows the events and causal factors table for this event. 


\subsection{Liquefied Gaseous Fuels Spill Test Facility flash fire [NVO, 1987]}

Due to large scale explosion events such as the propylene explosion in East St. Louis in 1972, the Mexico City propane explosion in 1984, and other events, The U.S. government allocated funds to construct a spill test facility in 1982. Construction began in 1984, and the facility at the Nevada Test Site began operation in 1986. The spill test facility performs release tests to better understand the characteristics of spill dispersion, and to test potential barriers to mitigate effects of such spills. Objects like fences will alter the flow of cold gas and can cause the gas to loft into the air so that dispersion is achieved in a faster time frame [Leone, 1990].

The Falcon test series of 5 to 7 planned tests was intended to determine the usefulness of vapor barriers. These tests were carried out in 1987. During the fifth test in the series, 13,000 gallons $\left(50 \mathrm{~m}^{3}\right)$ of LNG were released to observe the gas dispersion characteristics downwind of the spill location when a vapor barrier fence impeded the gas flow. The LNG release resulted in several rapid phase transition (RPT) pressure explosions as the LNG quickly flashed to vapor and expanded greatly with the phase transition. These RPTs were expected and had been witnessed in prior tests in the Falcon series.

From the video and movie camera records being taken of the test, investigators were able to determine that a so-called 'doublet', or two simultaneous RPTs occurred in the fifth test. After this, the information is less definitive, only most probable causes are discussed. Apparently, one of the guy wires that was used to support the vapor barrier parted under the load from the doublet RPT and began to whip. The gas flowed over the vapor barrier, and the guy wire scraped against the fiberglass and aluminum barrier. The frayed end of the guy wire cable is probably responsible for generating a static electricity spark and igniting the methane vapors outside the vapor barrier. The "cold flame" then raced out through the vapor to the edges of the flammable limits and also back toward the source of the methane. The fire was of short duration, about 30 seconds, until the fuel within the flammable range was exhausted. There were no personnel injuries, since persomnel are not allowed near the test site while tests are in progress. The estimated damage was between $\$ 70 \mathrm{k}$ and $\$ 95 \mathrm{k}$. Other damage to the test apparatus was incurred, but since this fifth test was declared the final test in the series, the equipment had only salvage value and was not added into the damage estimate.

\subsection{Summary}

Generally, accidents have been found to be the result of a confluence of several factors or conditions; accidents are rarely the result of just one cause. For this reason, accident investigators use the events and causal factors method, as shown in Tables 5-1 through 5-3. The events and causal factors table supports identification of accident causes, and the tables have been used in this summary. The multiple cause result is seen even in the Cleveland, Ohio accident. While the main cause was material embrittlement failure, other factors exacerbated the event. For example, siting within a city was more a decision based on operational convenience and business costs than on safety, the low dam around the tanks meant that neither 
the company nor the regulators had considered a large failure of a tank (only small leaks were considered), the open storm sewers only a few blocks away meant no one considered a large liquid release or else a higher tank bund or diversion dams would have precluded the LNG from pouring into the sewers, and ignition sources would have been precluded from the area if large releases were considered possible.

The Raunheim event did not have as much obtainable published detail as other events, but the consequences of releasing LNG liquid when warm natural gas is expected are illustrated. A faulty process controller allowed liquid rather than gas to be stacked. The still-cold liquid then vaporized and sank toward the ground instead of the stack function of warm gas dispersing into the air. The white cloud seen by personnel denoted freezing humidity from the air (note: firemen generally believe that the white cloud is a rough demarcation of the edges of the flammable zone for LNG releases). Before the cloud could warm and disperse, the vapor found an ignition source, probably the process furnaces onsite.

The Portland event with the storage tank involved several factors. While it was recognized that allowing the process liquid to leak into an empty tank that is occupied by workers is very dangerous (e.g., hazardous material exposure, fire, etc.) that was still allowed to occur due to several factors - concurrent operations allowed a valve to be opened and the blank flange removed, and the testing gas used onsite was methane (sometimes test gases are nitrogen or other inert gases, but these can grow to be expensive so LNG storage sites often use vaporized product instead). This event is another case of natural gas vapors being trapped within a volume and exploding/catching fire. A lock out/tag out program might have prevented the concurrent operations from continuing to the point of releasing natural gas vapors into the tank, at least until workers were finished inside the tank.

The Quebec event also had several factors that contributed to the accident. First, the instrument air compressor went down for maintenance during a plant recycle compressor deriming cycle. Next, three valves were inadvertently left open between the plant compressor and the nitrogen backup to the instrument air lines. The report does not give enough detail to know why the three valves were open (possible reasons could be that operators closed the wrong valves, neglected to verify that the valves are still closed, they might have forgotten to perform a procedure step, etc.). These two conditions allowed the warm, high pressure, unodorized natural gas flush from the plant compressor to flow to the instrument air system. Unodorized gas was probably used to keep high purity in the compressor, so no odorant would freeze inside the unit. This unodorized natural gas leaked into the control room from the instrument air lines. Since the control room was rated as an environment that would not have any hazardous or explosive gases, operators were allowed to smoke at their controls. The cigarette smoldering ignited the natural gas and the flame raced into the control panels, deflagrating the gas behind the panels.

Staten Island was an unusual type of construction accident. The safety personnel recognized the hazard of allowing natural gas to be piped into the tank while workmen were inside, so all lines were positively valved shut and the tank was warm and empty for several months prior to starting the task. Therefore, an event like the Portland storage tank fire could not occur with the Staten Island tank. There had been controversy over the tank thermal insulation (polyurethane) flammability and a regulatory decision to proceed with the tank construction was based on the idea that the risk of insulation fire was highest during construction and the insulation was already installed before objections were raised by the Fire Department. The idea of possible tank repair activities was not fully taken into account. Apparently, LNG leaked into the thermal insulation under the mylar liner and then vaporized when the tank was warmed. The vapor remained trapped in the cells of the polyurethane (the tiny cavities in the material). Investigators believed that when the barometric pressure would drop, some methane would emanate from the polyurethane. With the mylar liner rolled up from the base of the tank to 8 feet high to perform repairs and augmentation of the tank, methane could escape into the tank. Apparently the methane was ignited by the work being 
performed in the tank (exact ignitor is unknown) and the burning methane ignited the polyurethane, which burned faster than normal due to the trapped methane within it and the vertical configuration of polyurethane that allowed the fire to pre-heat the material. The hot combustion products and heated air due to the fire caused a slight pressurization of the tank (about 1 psig); however, this pressure was enough to lift the tank roof and cause the roof to collapse into the tank. Since the victims were not found near work locations and not clustered at the scaffold stairway or at the emergency shelter (a shack in the center of the floor of the tank), the fire was fast burning. The company had received test results showing there was no appreciable accumulation of methane in the polyurethane blocks on the LNG side of the mylar, but they did not test the polyurethane on the other side of the mylar (which was exposed when the mylar was rolled up). This event was another case of trapping methane gas, in this instance it was trapped in an umusual way.

The event at Cove Point was a case of not understanding the possible pathways that LNG could take. It is similar to the Quebec event, where gas was routed down an unlikely path. At Cove Point, a seal was not properly tightened after a maintenance session, so LNG leaked past the electrical seal into an electrical junction box. The pressure allowed the LNG to leak down the electrical conduit, where it warmed and vaporized. The pressure created by the volume expansion was much more than what was needed to force the gas past the second conduit seal. The gas exited into an electrical substation building, which was not rated for hazardous atmospheres (this non-hazard area is similar to the Quebec control room). When the operator tried to de-energize the pump that was leaking, the circuit breaker produced an electrical arc that ignited the natural gas.

The rapid phase transition event and subsequent fire ignition at the Nevada Test Site was unlike other events in this section. This was a test, an intentional release for examining gas dispersion. The gas was inadvertently ignited by an unanticipated ignition source, most probably involving static electricity and a broken guy wire. The probable ignitor was very unusual. Gas explosion ignitors are more often pilot light flames, electric lights, internal combustion engines, hot work or sparks produced by industrial operations, etc., rather than static discharges.

\subsection{Conclusions}

LNG facility designers should try to improve designs based on operating experience in other facilities that handle natural gas. While the LNG vehicle fuel industry lays claim about varying widely from LNG peakshaving plants (refueling stations are much smaller, have more constant throughput, do not use heated vaporizers), there are some issues to address from these events.

First, materials must be compatible with LNG. This lesson has been learned at a terrible price from the Cleveland event. Proper materials would include the supports for the tanks, so that tanks do not fail when a significant spill cools down the supports.

Next, the possible routes of natural gas flow must be analyzed for the entire station, including reverse flow events. Liquid and gas must both be considered. There have been events where the LNG traveled down a conduit (Cove Point), LNG traveled down a line thought to only contain gaseous natural gas (Raunheim), events where gas traveled down a line thought to be closed (Portland), and a line thought to use only air or nitrogen (Quebec). Leaks from instrumentation, and into instrumentation cabinets, must be analyzed. 
Facilities should be analyzed for gas entrapment. The Staten Island event was a disaster because the trapped methane increased the burning rate of the polyurethane, so the forty workmen did not have the time to evacuate once the insulation caught fire. Trapping a combustible gas increases the likelihood of a powerful deflagration, or even a detonation event. In either event, the barriers that trap the gas will see overpressures. Trapped gas at a refueling station might be in the annulus of double walled piping, in control panels, inside pump compartments, under awnings or other roof assemblies that protect personnel and equipment from weather, in vehicle maintenance buildings, or other places. Gas vaporizing from a liquid pool is a safety concern, since the liquid pool could flow toward low areas (maintenance pit, depression in the surrounding ground, a sewer opening, etc.).

Use of more, rather than fewer, combustible gas indicators is a good safety practice around non-odorized natural gas. It is expensive to buy and maintain these gas sensors, but investigators believed that if a working unit had been in the substation building at Cove Point, a life would have been saved, and sensors in the control room at the Quebec plant would have saved the company much money, by avoiding personnel injury and plant repairs.

Ignition sources must be analyzed for their possible contribution to accident events. The Nevada event provided an opportunity to analyze tapes from video cameras and movie cameras, and the energy of an RPT to determine if these energy sources could ignite a natural gas fire or explosion. The analysis showed that the voltages of cameras were insufficient to cause a spark energetic enough to ignite natural gas vapor, and the RPT pressure wave was also thought to not produce enough energy for ignition. Still, as unlikely as an ignition source might be, if it is identified then it can be protected or possibly precluded. Power poles with transformers for service drops, street lights, electrostatic discharge, and other potential sources of ignition energy must be investigated to determine if they possess enough energy to ignite natural gas vapor. The issue of bonding and grounding must be reviewed. 
Table 5-1 Events and Causal Factors Table for the Cleveland Ohio Event

Time and Date

1890-1940

1940

pre-1940

1937

January 1940

January-

February 1940

February 1940

February 1940
Event

East Ohio Gas Co. supplies Cleveland with natural gas for residential and industrial uses

East Ohio Gas Co. is using four 20-inch diameter and 18-inch diameter lines to pipe natural gas from the Hope Natural Gas Company, 150 miles away.

The Bureau of Mines demonstrated that liquefying natural gas was practical by their use of helium liquefying equipment.

The Hope Natural Gas Co. investigated building a natural gas liquefaction pilot plant.

The Hope pilot plant in Cornwell, WV is completed.

The pilot plant delivers liquefied natural gas (LNG), demonstrating how natural gas can be stored in a compact liquid form in amounts that are relevant to gas company operations.

East Ohio Gas Co. decides to build a liquefaction, storage, and regasification plant (LSR) to handle peak demands of gas in the wintertime. pipelines are the most efficient means for gas transport

science of cryogenics

a possible business venture success gives credibility to the concept

winter had been harsh and gas demand was high

An extra high pressure pipeline to the Hope Co. would cost $\$ 2.5 \mathrm{M}$, an LSR plant cost an estimated $\$ 0.75 \mathrm{M}$.

East Ohio Co. selects site at its No. 2 works in Cleveland.

Site was chosen for its improved gas distribution to Cleveland

The liquefaction, storage, and regasification (LSR) plant uses three spherical tanks, each stores $50 \mathrm{M}$ cubic feet of gas equivalent.

Tank sizing was not discussed, presumably this size meets peak demands 
Table 5-1 Events and Causal Factors Table for the Cleveland Ohio Event - cont.

Time and Date

Event

Causal factors

September 1940 Construction began on LSR plant

January 1941 LSR plant completed, largest in the world

February 7, $1941 \quad$ First LNG produced at LSR plant

December 8, U.S. enters World War II

1941

$1942-1943 \quad$ LSR plant proves to be successful

Storage of LNG is shown to be a good means for peakshaving

Spring 1943

East Ohio Gas Co. decides to add another large storage tank to meet the city's peak demands while meeting baseload war industry demands

Spring 1943 East Ohio Gas Co. chose a cylindrical, toro-segmental tank of $90 \mathrm{M}$ cubic feet of gas equiv. It was labeled as tank No. 4.

War industry is a large scale user of natural gas

Very large spherical tanks, due to their supports, can experience excessive bending stresses at the girdle and also have fatigue with fill and drain cycles

Spring 1943 The tank designer chose to use steel (carbon $<0.09 \%$ and nickel of $3.5 \%$ ) since this metal had adequate low temp. properties, adequate strength, and lowest cost

Technology at the time recognized these metals for cryogenic service:

pure copper

bronze

Monel metal

red brass

stainless steel steel $(<0.09 \%$ carbon and $>3.5 \%$ nickel)

Summer 1943 Tank No. 4 has difficulties with rock wool insulation settling, another 2 to 2.5 rail cars of rock wool are needed to complete the insulation. Over $1 \mathrm{M}$ pounds of rock wool are used for the $42 \mathrm{ft}$ high and $70 \mathrm{ft}$ diameter tank

October 1943

Tank No. 4 is placed in service

October 19, 1943

Tanks 2, 3, and 4 have been "topped off." These tanks are isolated from the LSR plant.

preparation for winter 
Table 5-1 Events and Causal Factors Table for the Cleveland Ohio Event - cont.

Time and Date

Event

Causal factors

8 a.m. October

Tank pressures are: $2.5,2.5,2.6$, and 2.4

20,1943

psig, respectively

October 20, 1943 Tank No. 1 is being "topped off."

preparation for winter

1: 50 p.m.

Mr. Freightner, assistant plant engineer,

Tank No. 4 has had cold spot

October 20, 1943 makes a casual inspection of the Tank No. 4 footings, nothing unusual observed.

formations due to insulation gaps

2 p.m. October

LSR plant is being taken off line.

Service is completed

20,1943

2:25 p.m.

LSR compressors taken off line.

part of the shut down evolution

October 20, 1943

2:25 p.m.

October 20, 1943

Liquid level in Tank No. 4 drops suddenly.

Investigators believe that the time was slow or the chart was not aligned, all witnesses verify that it was 2:40 p.m., and the outer wall of the tank would not hold the LNG for 15 minutes.

2:40 p.m.

October 20, 1943

Tank No. 4 failed, releasing about $1.1 \mathrm{M}$ gallons of LNG at $-250 \mathrm{~F}$.

Investigators believed the cause was failure by embrittlement.

Four employees witnessed vapor or liquid mist cloud issuing from the tank prior to its complete collapse.

Witnesses saw clouds of vapor first and fire subsequently. Witnesses also saw a burning cloud and burning vapor above flowing liquid. The fires ignited buildings and equipment.

LNG surged over the short dam around the tank, then sought low levels. LNG poured into storm sewers, vaporized, and later ignited.

Note: final damage was 128 fatalities, 200 to 400 injured, and property damage of about $\$ 6.8 \mathrm{M}$. The fire damage was confined to about 0.25 mile around tank No. 4. 
Table 5-1 Events and Causal Factors Table for the Cleveland Ohio Event - cont.

Time and Date

about 3 p.m.,

October 20, 1943

October 21, 1943

October 22, 1943

October 22, 1943 1943

Mid-November
Event

Causal factors

Tank No. 3 supports failed, causing the tank to fail and discharge its contents, about $600 \mathrm{k}$ gallons of LNG

The main body of the fire was brought under control. Gas vents from tanks No. 1 and No. 2 were still burning, and the coal pile south of tank No. 2 continued to burn

Smoke from No. 2 tank was determined to be burning cork insulation. Dry ice was added to the tank annulus to extinguish the cork combustion.

Rehabilitation was initiated. Steam from locomotives on the tracks to the north was used to vaporize the $L N G$ in tanks 1 and 2.

The empty tanks were purged with inert gas.
Cork dust layer will burn on the order of $200 \mathrm{C}$; radiant heating easily started this fire. heat of fire and possible impacts of objects swept along by the surge from tank No. 4 
Table 5-2 Events and Causal Factors Table for the Staten Island Event.

Time and Date

August 1960

October 1961

Summer 1962

August 1962

August 1962 to

November 1963

Early 1963

May 1964

1964

1964

1965

1966

October 18, 1966

October 19, 1966
Event

Causal factors

The Texas Eastern Transmission

Company (TETCo) hires the Battelle

Memorial Institute (BMI) to conduct a

technical and economic feasibility study

for large volume LNG storage.

BMI reports that such storage is feasible.

BMI constructs a 53,780 gallon model tank for proof of principle.

The model tank is completed.

Model tank is successfully tested using liquid nitrogen.

BMI began to design a large commercial LNG storage tank.

BMI publishes a detailed design.

TETCo secures Brown and Root

Engineers to develop the engineering and construction details for this tank.

TETCo retains Bilbyrne Corp., professional engineers, to apply for $N Y$ approval and construction permit.

Bilbyme delivers request to the Federal Power Commission (FPC). FPC invites Bureau of Mines to comment on request.

Bilbyrne files request to construct with the NY City Dept. of Marine and Aviation.

NY City Dept. of Marine and Aviation (DMA) denies application to construct tank.

Bilbyme appeals denial to the NY City Board of Standards and Appeals (BSA). 
Table 5-2 Events and Causal Factors Table for the Staten Island Event. - cont.

Time and Date

December 14, 1966

December 1966

1966

January 18, 1967

Early 1967

Early 1967

March 10, 1967

April 15, 1967

July 1,1968

Early 1969

June 1969
Event The NY City BSA forwarded information to the NY Fire Department (FD), requesting comment

The NY FD requests help from the NY Board of Fire Prevention Regulations (BFPR).

FPC approves plans and specifications.

NY FD notifies the BSA that it opposes tank construction.

BSA holds hearings, FD opposes tank construction

TETCo makes safety additions for FD: two roads, fire extinguishment systems, fire alarm company, other additions

BSA approves tank installation, leaves construction responsibility to DMA and fire protection to the FD

DMA approves construction plans.

DMA approves construction start

FPC announces U.S. shortfall in natural gas supplies, condones importation as a means to meet demand

During tank construction, a NY FD inspection reveals that the tank insulation will burn. The FD objects that construction specifications are not being met. Tank is $80 \%$ complete, insulation is already installed.
Objections:

tank large size and its unfamiliar construction materials, initial hydrostatic pressure and 5 year tests could not be done, lack of NY FD experience with such large LNG storage tanks, siting in congested area, and inability of the NY FD to extinguish a major tank fire

see above causes

ASTM D-1692-69T standard is not met 
Time and Date

June 1969

June 1969

Summer 1969

Fall 1969

March 31, 1970

April 1, 1970

April, 1970

April, 1970

October 20, 1970

February 17 , 1971

March 1, 1971
Event

Causal factors

TETCo responds that the insulation was a fire retardant grade furnished by the supplier while attempting to meet the necessary density and thermal conductivity requirements.

The BFPR decides to accept installation as it is.

Schedule pressure to finish tank, combustible insulation is most hazardous in construction (insulation was already in place), BFPR ruled that it was more hazardous to replace the polyurethane insulation than to complete the tank.

unspecified delays

Construction delays with liquefaction plant prevented filling the tank by pipeline gas liquefaction

TETCo requests LNG importation permission from the FPC

liquefaction plant cannot fill the tank for the winter.

FPC approves TETCo plan to import LNG.

Algerian LNG arrived on the ship "Esso Brega", loaded into tank

More LNG arrives on the ship "Methane Princess," loaded into tank

TETCo's liquefaction plant comes on line, starts filling tank with LNG

TETCo notes that instrumentation shows that there is a leak in the tank liner at the $52^{\prime} 4.25^{\prime \prime}$ level.

The NY BFPR rules that the tank should be emptied for repair by April 1, 1971, stipulates that an extension could be obtained if proof is offered that there is no hazard.

TETCo requests an extension to the date for emptying tank.
Reports from BMI and TETCo engineer show there is no hazard. 
Time and Date

March 29, 1971

April 27, 1971

mber 1 , 1971

September 1, 1971

November 10, 1971

January 5,1972

January 1972

January 1972

February 13, 1972

March 14, 1972

March 15, 1972

March 1972

April 5, 1972

April 11, 1972

April 1972
Event

BMI submits report that there is a liner leak, not a tank leak.

BFPR grants extension to April 1, 1972, require that TETCo look at issue again in September.

Bilbyrne and BMI submit reports to BFPR, reports state there is no cause for concern.

TETCo requests permission for a temporary pipeline for loading the tank with Libyan LNG.

BFPR gives tentative approval to the pipeline request.

BFPR gives full approval to the pipeline request.

Libyan tanker does not arrive

Unknown reasons, speculation was lack of LNG tankers or a purchasing problem

TETCo decides to repair the storage tank leaking liner

Good timing to prepare for upcoming winter.

Make the tank habitable

TETCo removes tank from service, warms tank with hot natural gas.

NY FD reviews safety plan from TETCo

The tank is purged with nitrogen

Remove combustible gas

An inert-gas entry is made into the tank to identify the leak location. Leaks could not be located in those conditions.

TETCo decides to bring the tank to air to help locate the leak

NY FD reviewed safety procedures for TETCo work

TETCo asks BMI to perform an analysis of insulation
Speedy problem definition, to aid TETC $O$ in decision making.

Safety/operability concern over insulation 
Table 5-2 Events and Causal Factors Table for the Staten Island Event. - cont.

Time and Date

April 1972

April 1972

May 1972 and

on

May 15, 1972

Summer-fall

1972

Jamuary 16 , 1973

January 25 , 1973

February 10, 1973
Event

TETCo found a $10^{\prime} 3^{\prime \prime}$ rip of the liner at the tank bottom, and several small punctures.

TETCo decides to repair the tank's liner, water-stop, and pumps, and modify the tank to allow it to receive heavier LNG [more ballast blocks, new unloading downcomers and nozzles, a splash plate]

To make repairs, portions of the $1 "$ protective polyurethane were removed, then the mylar liner was rolled up from the tank bottom to about 8 ' height to expose more polyurethane insulation

BMI concludes that polyurethane insulation contained $3.5 \%$ methane in the cells. Insulation was NOT saturated with methane.

Apparently repairs are behind schedule, tank is not ready to store LNG for the winter season

A NY FD inspection shows that all safety precautions within FD jurisdiction appeared to be observed. FD ascertained that the tank would be ready for service by the end of March 1973.

Two laborers punched small holes into the tank liner

Early morning hours, the Wells Fargo fire alarm company is notified to ignore any fire alarms from the plant until further notice.
Causal factors

Speculated cause was insufficient slack in the liner.

Desire to return tank to optimum condition, prepare tank for colder LNG

Access required for repair operations, this act exposes insulation that is now believed to be saturated with vapor

The insulation samples were from the $I^{\prime \prime}$ cover on the LNG side of the mylar liner, not the tank

Reasons unknown, not addressed in investigation

They confessed that they did this act because they wanted to prolong the well-paying job

Welding tasks were scheduled onsite and these often tripped the UV fire detectors. 
Table 5-2 Events and Causal Factors Table for the Staten Island Event. - cont.

Time and Date

February 10, 1973

February 10, 1973

February 10, 1973

February 10, 1973

February 10, 1973

February 10, 1973
Event

About 1300 hours, a fire starts inside the tank

At about 1310 hours, two workers on the tank's interior scaffolding stairway used for tank floor access notice flame/disturbance on tank's south wall. They evacuate.

The tank internal pressure increases over 1 psig, lifts the tank roof. Evidence suggests that this happened very fast (about a minute) after the fire flared up.

Tank roof cracks, collapses into the tank

An operator notices smoke issuing from the top of the tank, he pulls the Wells Fargo fire alarm and goes to get the plant fire truck.

He realizes the plant fire truck will be ineffectual against such a large fire, he heads to the tank to assist injured personnel.

He radios the control room to phone the Wells Fargo alarm company so that they will turn in an alarm.

A crane operator returning from lunch notices smoke and goes to a pull box to send in a fire alarm.

1313 hours, NY FD receives an alarm for an explosion and fire at the TETCo LNG facility
Causal factors

Rapid burning fire: investigators believe that methane trapped in the polyurethane cells under mylar liner allowed easy ignition and fast burn, also the vertical orientation allows fire to pre-heat fuel and spread rapidly; Low barometric pressure may have allowed methane to evolve from the bared insulation

Fast burning fire in wall insulation

Roof was not being supported as designed 
Table 5-2 Events and Causal Factors Table for the Staten Island Event. - cont.

Time and Date Event

Causal factors

February 10, 1973

February 10, 1973

February 10, 1973

February 10, 1973

February 10, 1973

February 10, 1973

February 10, 1973

February 10, 1973

February 11, 1973

February 21, 1973

February 23, 1973

April 11, 1973
1321 hours, NY FD is on the scene.

Second alarm is ordered. Hose lines are put in operation toward the smoke.

1346 hours, FD orders third alarm

1430 hours, hose lines were shut down. Smoke still obscures any view into the tank.

After 1430 hours, the crane for this tank lowers FD Rescue Officer into the tank. The rescue officer wore breathing apparatus.

The officer saw no signs of life.

1700 hours, smoke dissipated enough to view the bottom of the tank.

1725 hours, sunset.

After sunset, Rescue Company personnel were lowered into the tank for a search.

0100 hours, searchers found 4 bodies. Searchers realized no survivors would be found. They discontinued operations until daylight.

The last of the 40 victims was located at 0645 hours.

1643 hours, the search was ended.

1645 hours, TETCo completed cleanup operations on the tank.
Reduce water accumulation in the tank

Survey the tank interior for survivors

Medical Examiner report states the 40 men died from asphyxiation.
Searchers realized that conditions of smoke and roof collapse would not allow survival of workers in the tank.

Efforts were hampered by cold temperatures and extreme difficulty of moving roof sections

The search continued after the 40th victim to verify that no unreported persomnel were in the tank when the fire occurred. 
Table 5-3 Events and Causal Factors Table for the Cove Point, Maryland Event.

Time and Date

November 1977

March 31, 1978

July 11,1978

Fall 1978

October 5, 1979

October 6, 1979
Event

Causal factors
Calvert County electrical inspector approves the pump electrical junction boxes and their seals at the Cove Point LNG facility.

The Cove Point LNG storage facility of the Columbia LNG Corporation began operation.

The booster pump 105JK was removed for repairs.

The pump was reinstalled, the electrical penetration seals were rebolted, but not to any particular standard.

6 a.m., The booster pump $105 \mathrm{JK}$ is shut down.

1:30 a.m., the facility operator taking equipment readings did not notice anything unusual.

3:10 a.m., another facility operator starts making rounds for taking equipment readings.

3:20 a.m., the operator radios the monitor house to tell the operator/controller there that LNG is leaking into the second stage pump house.
Apparently these were built to electrical code requirements.

The code had little provision for cryogenic applications.

business venture

Type of repair was not specified.

There were no standards or guides for tightening seal bolts.

normal operational evolution

normal operator duty

normal operator duty

Incorrectly tightened seal allowed LNG to leak into the electrical cable junction box.

Junction box flange was not rated to hold the $60 \mathrm{psig}$ pressure.
3:25 a.m., the shift supervisor, who was in the monitor house to hear the radio call, radioed the operator to find out if pump $105 \mathrm{JK}$ was leaking. He told the operator that he would contact the monitoring house by telephone from the electrical substation.

3:30 a.m., the supervisor and the operator arrived at the Substation No. 2 building. 
Table 5-3 Events and Causal Factors Table for the Cove Point, Maryland Event - cont.

Time and Date

October 6, 1979
Event

About 3:30 a.m., the supervisor phoned the controller/operator in the monitoring house to advise him that they were going to open the circuit breaker for the 105JK pump.

3:34 a.m., the operator depressed the circuit breaker interlock release.

3:34 a.m., an explosion occurred.

3:34 a.m., building walls blew out, building roof collapsed. The shift supervisor was struck by a falling roof truss. The operator was burned.

3:34 a.m., the explosion damages facility transformers adjacent to the Substation No. 2 building, oil from the transformers is dispersed and begins to burn.

3:34 a.m., the explosion damaged a water main to the deluge system, and the transformer loss depowered the electric firewater pump, leaving only the diesel firewater pump. The fire system is rendered totally ineffective by this damage.

3:35 a.m., monitoring house 1 and 2 operators ascertained that the explosion was their facility and initiated emergency shut down.
Causal factors

Supervisor wanted to prevent possible pump startup

Spark from breaker ignited natural gas vapors in the room.

Natural gas was in the Substation building because the electrical cable conduit routed it there.

Second seal in the conduit was not a cryogenic seal and was not rated for over 0.25 psig.

explosion overpressure

explosion overpressure and heat

explosion overpressure 
Table 5-3 Events and Causal Factors Table for the Cove Point, Maryland Event -cont.

Time and Date

October 6, 1979 About 3:40 a.m., the safety and fire technician with the plant fire truck meets the controller/operator from monitoring house No. 2 at the Substation No. 2 building. They assisted the operator from the fire.

The safety and fire technician tried to reach the supervisor but the intense heat prevented this. He then discharged one ton of dry chemical fire extinguishing agent onto the fire in an attempt to extinguish the fire (with no effect) and then he waited for the Solomons Volunteer Rescue Squad and Fire Department (SVRSFD) to arrive.

3:45 a.m., Columbia company officials in Wilmington, Delaware were informed of the event

October 6, 1979

October 6, 1979
3:56 a.m., the Solomons Volunteer Rescue Squad and Fire Department (SVRSFD) arrived and the Captain assumed on scene command.

3:56 a.m., the Columbia fire and safety supervisor arrived on scene. He spotted the supervisor's body under one of the building roof support beams. He judged that the supervisor was beyond help.

About 3:56 a.m., the plant manager arrived. He checked facility status and went to the accident scene. Then he went to monitoring house No 1 and saw the burned operator.

After 4 a.m., the plant manager ordered all offduty personnel to report to the facility and that the facility be secured.

4:30 a.m., the fire was extinguished by the SVRSFD.
Plant personnel were confused. The supervisor had been killed and there was no plan for anyone else to assume command. 
Table 5-3 Events and Causal Factors Table for the Cove Point, Maryland Event -cont.

Time and Date

October 6, 1979
Event

About 4:30 a.m., the operations superintendent informed the plant manager of the LNG leak in the pump house.

These two men walked to the pump house and saw the junction box and conduit covered with frost, the concrete surrounding the conduit was frozen, and LNG spraying about 12 feet out from the junction box flanges.

The 105JK pump inlet valve was closed and the LNG flow stopped shortly afterward.

About 6:45 a.m., Columbia officials from Delaware arrived and surveyed the scene.

About 7:40 a.m., these officials realized that no one had called the DOT Materials Transportation Board as required by federal regulations.

About 7:50 a.m., Columbia officials called the DOT Materials Transportation Board (MTB) to notify them of the explosion.

7:55 a.m., the DOT MTB phoned the National Transportation Safety Board (NTSB) to inform them of the event.

8:15 a.m., an NTSB investigator was dispatched to the scene.

11:45 a.m., SVRSFD departed from the Columbia LNG facility. insufficient emergency response plan 


\section{THE IMPACT OF USING LIQUEFIED NATURAL GAS IN THE CONTEXT OF GLOBAL CLIMATE CHANGE}

\subsection{Introduction}

While natural gas (methane) emits less carbon dioxide per unit of energy released than other transportation fuels, methane itself is a powerful greenhouse gas, capturing infrared radiation in the atmosphere and re-radiating that infrared back toward the surface of the earth. Thus the benefits of lower carbon dioxide emissions from the use of natural gas can be lost if a significant fraction (greater than 5 percent) of the methane leaks or is vented in the course of production, refining, storage, and use. This brief section will describe the effects of fugitive methane as a greenhouse gas, summarize the sources of fugitive methane at LNG refueling stations, and suggest some basic means of controlling these fugitive emissions. A full discussion of all these subjects was beyond the funding allowed to complete this report and they are mentioned for completeness and as a potential sign of future environmental issues in the use of LNG.

\subsection{Carbon Emissions per unit Energy}

Methane is richer in hydrogen than gasoline, diesel or other conventional fuels. Thus, during combustion the fuel forms more water vapor and less carbon dioxide per unit energy delivered than any other conventional transportation fuel. Only pure hydrogen would release smaller amounts of greenhouse gases per unit energy delivered. Table 6-1 lists the carbon released to the environment as carbon dioxide per unit energy.

Table 6-1 Carbon Emissions per unit Energy Output

\begin{tabular}{|l|cccc|}
\hline \multicolumn{5}{|c|}{ Carbon Emissions per unit Energy Output } \\
\hline Hydrocarbon & $\begin{array}{c}\text { Higher heating } \\
\text { value } \\
\text { (MJ/kg) }\end{array}$ & $\begin{array}{c}\text { Molecular } \\
\text { Weight }\end{array}$ & Carbon & Carbon Emissions \\
\hline methane & 55.5 & 16 & 12 & (g C/MJ) \\
ethane & 51.9 & 30 & 24 & 13.5 \\
propane & 50.4 & 44 & 36 & 15.4 \\
methanol & 22.7 & 32 & 12 & 16.2 \\
ethylene & 50.3 & 28 & 24 & 16.5 \\
ethanol & 29.7 & 46 & 24 & 17.0 \\
gasoline & 47.5 & 114 & 96 & 17.6 \\
acetylene & 50.0 & 26 & 24 & 17.7 \\
toulene & 43.0 & 93 & 84 & 18.5 \\
benzene & 42.3 & 78 & 72 & 21.0 \\
coal & 24.4 & - & $80 \%$ & 21.8 \\
\hline
\end{tabular}




\subsection{Methane as a Greenhouse Gas}

Carbon dioxide, methane, and most other gasses absorb light at certain frequencies of the infrared region and re-radiate that energy isotropically. Because each of the gases has certain 'windows' of wavelength at which the light is passed and other bands in which the light is strongly absorbed, the various gasses have widely differing characteristics as greenhouse gasses. In addition, the chemical activity of the gasses and the rate at which they are oxidized or are washed out of the atmosphere determine an average lifetime of each gas. Without further releases the concentration of a gas will decrease exponentially. A comparison of the direct effect of eight gasses is shown in Table 6-2. The gasses of interest in this study are carbon dioxide, methane, and nitrous oxide.

Table 6-2 Global Warming Potentials

\begin{tabular}{|l|cccc|}
\hline \multicolumn{4}{|c|}{ Numerical Estimates of Global Warning Potentials Relative to Carbon Dioxide } \\
\hline Gas & Lifetime & \multicolumn{2}{c|}{ Direct Effect for Time Horizons of } \\
& (years) & 20 years & 100 years & 500 years \\
\hline Carbon Dioxide & 120 & 1 & 1 & 1 \\
Methane & 14.5 & 62 & 24.5 & 7.5 \\
Nitrous Oxide & 120 & 290 & 320 & 180 \\
Carbon Tetrachloride & 42 & 2000 & 1400 & 500 \\
Methyl Chloroform & 5.4 & 360 & 110 & 35 \\
Methylene Chloride & 0.41 & 28 & 9 & 3 \\
Chloroform & 0.55 & 15 & 5 & 1 \\
Sulfur Hexafluoride & 3200 & 16500 & 24900 & 36500 \\
\hline \multicolumn{4}{|c|}{ Source: D. L. Albritton, et al. "Trace Gas Radiative Forcing Indices," in J. T. Houghton, et al., Climate } \\
\multicolumn{4}{r}{ Change 1994 (Cambridge, UK, Cambridge University Press, 1995) p. 222. } \\
\hline
\end{tabular}

\subsection{Means of Reducing the Amount of Methane Released}

The amount of carbon dioxide released is largely governed by the fuel chosen and the nitrous oxide releases are governed by the temperature of combustion, the stoichiometry, and the type of engine. All these parameters are outside the control of the refueling stations designer and operator. The releases of methane, on the other hand, can be controlled by the procedures chosen for venting, the LNG transfer techniques, the venting of vehicle tanks, the conversion of vented LNG into CNG, the catalytic combustion of vented methane, and the design of transport, storage, and vehicle LNG tanks. We observed a wide variation in techniques for controlling pressure and venting methane vapors in our nine station visits. In some stations the methane vapors were compressed and used in the CNG station in the same facility. In others, the rate of vehicle use was high enough that both the storage and the vehicle tanks remained cold and very little venting (or compression) was necessary. In one of the stations, the vehicle tanks were routinely vented in order to lower vehicle tank pressure and speed refueling.

Finally, Table 6-2 demonstrates that carbon dioxide is a relatively weak greenhouse gas, compared with the others listed. A comprehensive approach to reducing the effects of fossil fuel combustion must consider all greenhouse gases and not just $\mathrm{CO}_{2}$. 


\section{CONCLUSIONS AND RECOMMENDATIONS}

\subsection{Study Results}

A number of potentially risk significant refueling station accident scenarios have been identified in this study. These scenarios, listed in Tables 3-4 and 3-5 and summarized in Tables 1-2 and 1-3, are not believed to be likely, due to the relatively low likelihood of some of the initiating events (e.g., relief valves failing open, tank/piping failure due to a severe external event) or to the requirement for multiple failures in the scenario (e.g., an initial error during refueling followed by failure of early recovery efforts). However, based on reports and past events involving LNG or other gaseous vehicle fuels, it appears that these scenarios are not so unlikely as to be incredible. ${ }^{j}$ Designers of new facilities and operators of existing ones need to ensure that their facilities are adequately protected with respect to both scenario initiation and progression.

This study also shows how observed differences in station design, operational practices, and siting can affect the likelihood of different initiating events and safety barrier (top event) failures, thereby affecting station risk. Example differences in design involve the extent and size of bunds for spill containment and the location of maintenance facilities. Some potentially important differences in operations and operational practices involve the frequency of refueling activities, the accessibility of the station to the public, and the emergency response training of vehicle refuelers (drivers or designated staff) and other station personnel. Differences in station siting can affect the likelihood of external hazards to the station as well as the exposure of the public to station accidents.

Finally, this study has reviewed a wide range of documents relevant to LNG safety issues recently raised by Hunt (see Section 4.6). Focusing just on LNG safety, it appears that at least two of these issues (vapor cloud ignition and injuries/fatalities due to exposure to an LNG vapor cloud) are reasonable concerns and need to be addressed in station design, operations, and siting. However, it should be cautioned that this study, being qualitative in nature and focused on LNG, has not addressed the issues of absolute risk (e.g., what is the probability of the events in question) or relative risk (e.g., how does the LNG risk compare with risks from conventional fuels). A quantitative analysis is needed before the true safety significance of these issues can be determined.

\subsection{Recommendations}

The following recommendations are based on the results of this study. They involve: a) potential design and operational improvements at LNG refueling stations; and b) additional studies that need to be performed to clarify key issues. Regarding the design and operational improvements, it is recommended that:

j. It should be noted that lessons learned from major past incidents involving LNG have been used to improve designs and equipment. The investigation following the 1944 Cleveland release and explosions led to the use of steels that would not become brittle at $112^{\circ} \mathrm{K}$ (BOM, 1946). The accident at Cove Point in 1978 led to the rewriting standards for the sealing conduits and for the calibration of methane detectors (Van Meerbeke, 1982). 
Improvements should be made in procedures and training. Variances in operational practices that may have an impact on safety (e.g., tank venting, use of grounding wires, use of PPE), improper responses to alarms, and the lack of procedures during maintenance (which leads to learning by trial and error) are potentially important safety issues that need to be addressed. It is useful to observe that improvements in training and procedures are relatively inexpensive means to reduce risk.

In particular, we observed a rather casual attitude toward working in confined spaces at some stations. With the potential for displacement of air by cold methane, confined spaces should be approached with more respect. We also saw some instances of common industrial hazards, such as unrestrained compressed gas cylinders and inappropriate fittings for high pressure use. While the physical characteristics of LNG should make it safer than gasoline, LNG is new and unfamiliar to the general public. Thus any accident at an LNG station could set the vehicular LNG industry back a decade.

The observations from visits to nine refueling stations having various configurations have been compiled. All the stations served a well-defined fleet of vehicles and did not cater to the general public, although the degree of public accessibility varied from station to station. In six of the stations the refueling was done by a designated, specially trained fueler. It is our considered observation that refueling should be done by a specific, trained person. The handling of $L N G$ is sufficiently different from the handling of gasoline to require specific training. After the LNG industry has grown for a few years in the relatively protected niche of fleet operations, it will be ready of public, self-serve retail operations. At the present time, however, a single, well-publicized incident at an LNG station in which a member of the public is injured or killed would set the LNG industry back decades.

Station designs should account for: a) the possibility of LNG leakage along unexpected pathways (e.g., past seals) to enclosed spaces, and b) the possibility of complete LNG inventory losses. Although neither event is likely, they have been historically observed (albeit in different facilities) and prudence dictates that they be addressed. This recommendation implies, for example, the use of methane detectors in all enclosed spaces, designing/backfitting to prevent the buildup of methane in all enclosed spaces (assuming a leak), and the provision of appropriately sized bund walls completely surrounding the main LNG storage tank(s).

The dissemination of best practices among stations should be strongly supported. This recommendation supports the preceding ones, and is driven by the same issues.

The above recommendations are based on field observations at nine different LNG refueling stations and on information gathered from a number of papers and reports. The stations visited represent a fairly wide sample in terms of design, operational, and siting characteristics, although only one of the stations was openly accessible to the public. A number of follow-on safety studies are therefore recommended. These studies will validate and modify, as appropriate, the conclusions of this study, and will provide a stronger basis for suggested changes in current practices.

In addition to these safety studies, additional studies regarding key phenomenology during LNG accidents are recommended. These latter studies are needed to more completely address the issues raised in the Hunt memo (Hunt 1996). Moreover, they will provide invaluable support to qualitative and quantitative risk assessment efforts which need better answers to such questions as how large must a spill be to pose a significant hazard offsite.

The particular studies recommended for the near term are as follows. 
- An in-depth review of LNG accident/event reports (case studies) was performed in section 5. More work should be done with this review to support assessment of accident scenario likelihood.

- A detailed review on post-1978 experimental data relevant to predicting LNG hazards. This review, which will identify sources, models, and codes, will provide a more definitive picture of what is known concerning LNG dispersion and ignition behavior under realistic accident conditions. This is needed to determine the risk significance of the two Hunt memo issues of potential concern (i.e., unconfined vapor cloud fires or explosions and direct exposure to LNG vapor).

Finally, it is recommended that the following two studies be performed as time and resources permit. While they are of lesser urgency than the preceding studies, their results should be very useful to the industry.

- A study should be performed to determine which current safety practices (e.g., use of grounding strap) are truly necessary. For those which are needed, steps should be taken to ensure compliance. This study addresses the possibility that overly conservative requirements may lead to an indiscriminate attitude towards all safety requirements on the part of some drivers and station personnel.

- The qualitative scenarios identified in this report should be quantified for LNG and conventional (gasoline and diesel) refueling stations. Such a risk assessment will allow an improved prioritization of accident scenarios, and will support detailed design and operational trade-offs. It will also provide an improved basis for evaluating the overall safety of LNG fueling stations. 


\section{BASIC DEFINITIONS}

Deflagration Combustion of a gaseous mixture of fuel and oxygen, where the combustion wave front is subsonic.

Detonation Rapid combustion of a fuel-oxygen mixture where the combustion wave front travels at the sonic velocity. Detonations are regarded as much more severe than deflagrations because of the overpressure and rapid liberation of thermal energy.

Geysering Flow surges of a vapor-liquid mixture in vertical tubes caused by heat inleakage and the formation of bubbles within the liquid.

Inerting Filling an enclosed space, such as a tank or room, with a gas that will not support combustion. Nitrogen and argon are examples.

Rollover Delayed, but vigorous mixing of new and old LNG caused by differences in composition and temperature.

Simmer A condition where a relief valve is opening slightly and reclosing due to system pressure hovering near the valve setpoint.

Sparger A piping arrangement that introduces a fluid into a tank at many positions simultaneously. LNG tanks use spargers either in the top of the gas ullage or at the bottom of the tank in the liquid.

Trycock valve A small valve used to draw samples.

Ullage Vapor space at the top of the tank.

Weathering Change in the composition of stored LNG due to the more rapid vaporization of methane compared with ethane, propane or the higher hydrocarbons. 


\section{REFERENCES}

ACGIH, 1996

ANS, 1983

ASME, 1995.

ATA, 1995.

Baker, 1991

BOM, 1946.

Bull, 1976

CCPS, 1994

CGA, 1992

Chan, 1992
American Conference of Governmental Industrial Hygienists, 1996 TLVs and BEIs, Threshold Limit Values for Chemical Substances and Physical Agents, and Biological Exposure Indices, ISBN 1882417-13-5, ACGIH, Cincinnati, Ohio, 1996.

American Nuclear Society and the Institute of Electrical and Electronics Engineers, PRA Procedures Guide, a Guide to the Performance of Probabilistic Risk Assessments for Nuclear Power Plants, NUREG/CR-2300, prepared for the U.S. Nuclear Regulatory Commission, January 1983.

Risk-Based Inspection - Development of Guidelines, Volume 1: General Document, American Society of Mechanical Engineers, 1991.

Recommended Practices for LNG Powered Heavy Duty Trucks, ATA Foundation Alternative Fuels Task Force, The American Trucking Associations Foundation, Inc., 1995.

Baker; Wilfred E., and Tang; Ming Jun, Gas, Dust and Hybrid Explosions, Elsevier, Amsterdam, 1991.

M. A. Elliot et al., Report on the Investigation of the Fire at the Liquefaction, Storage, and Regasification Plant of the East Ohio Gas Company Cleveland Ohio, October 20, 1944, Report of Investigation 3867, Bureau of Mines, Pittsburgh, PA, 1946.

Bull, D.C., Elsworth, J. E., Hooper, G., and Quinn, C. P., "A study of spherical detonation in mixtures of methane and oxygen diluted by nitrogen," J. Phys. D. Vol. 9, pp. 1991-2000, 1976.

Center for Chemical Process Safety, Guidelines for Evaluating the Characteristics of Vapor Cloud Explosions, Flash Fires, and BLEVEs, American Institute of Chemical Engineers, 1994, section 2.

Compressed Gas Association, Accident Prevention in Oxygen-Rich and Oxygen-Deficient Atmospheres, CGA P-14-1992, CGA, Inc., Arkington, VA, 1992.

Chan, S.T., "Numerical Simulations of LNG Vapor Dispersion from a Fenced Storage Area," Journal of Hazardous Materials, 30, (1992), 195-224. 
Drake, 1973

ENR, 1968.

Frondeville, 1977.

GAO, 1978.

Geffen, 1980.

GPO, 1973.

GPO, 1980.

GRI, 1994.

GRI, 1996

Gugan, 1979.

Harris, 1993.

Hord 1978
Drake, Elizabeth M, Geist, J. M., and Smith, K. A., "Prevent LNG 'rollover'," Hydrocarbon Processing, Vol 52, March 1973, pp 87-90.

"Explosion Rips Largest Gas Tank, Killing Four," Engineering News Record, April 4, 1968, page 31, and "Explosion Inquiry Blames Open Valve, Missing Cutoff," Engineering News Record, May 16, 1968, page 29.

B. de Frondeville, "Reliability and Safety of LNG Shipping: Lessons from Experience," SNAME Transactions, 85, 1977, pp. 459-480.

Liquefied Energy Gases Safety, GAO-EMD-78-28, General Accounting Office, Washington DC, July 31, 1978.

C. A. Geffen, An Assessment of the Risk of Transporting Propane by Truck and Train, PNL-3308, Battelle Pacific Northwest Laboratory, March 1980.

Staten Island Explosion: Safety Issues Concerning LNG Storage Facilities, Hearings before the Special Subcommittee on Investigations of the Committee on Interstate and Foreign Commerce, House of Representatives, 93rd Congress, first session on Legislative Issues Relating to the Safety of Storing Liquefied Natural Gas, July 1-013, 1973, Serial No. 93-42, U.S. GPO, Washington, DC, 1973.

Report prepared for the use of the Committee on Interstate and Foreign Commerce, United States House of Representatives and its Subcommittee on Energy and Power, LNG Facility Accident at Cove Point, Maryland 96th Congress, 2nd session, Committee Print 96IFC 46, U.S. Govermment Printing Office, May 1980.

Gas Research Institute, An Introduction to LNG Vehicle Safety, GRI92/0465, accession number PB94-176112, March 1994.

Midgett, Dan E. II, Best Available Practices for LNG Fueling of Fleet Vehicles, GRI-96/0180, Gas Research Institute (prepared by the M. W. Kellogg Company, Houston, Texas), February 1996.

K. Gugan, Unconfined Vapor Cloud Explosions, The Institution of Chemical Engineers, 1979.

F. S. Harris, "Safety features on LNG ships," Crvogenics, $\underline{33}$, pp.772-777, 1993.

Hord, J., "Is Hydrogen Safe?" International Joumal of Hydrogen Energy, Vol. 3, pp. 157-176, 1978. 
Hunt, 1996.

IFC, 1980

Jones et al., 1986.

Kaplan and Garrick, 1981.

Kazarians, 1997.

Leone, 1990

LNG, 1972.

Mancini, 1988

Medard, 1970.

Melchers and Feutrill, 1995.

Morioka, 1986

Mulliner, 1974

NGV, 1996.
P. Hunt, Peter Hunt Associates, 7501 Elba Road, Alexandria, VA 22305, letter to Thomas Grumbly, Assistant Secretary of Energy, October 15, 1996.

LNG Facility Accident at Cove Point, Maryland Committee Print 96IFC 46, Committee on Interstate and Foreign Commerce, U.S. House of Rep., U. S. Govt. Printing Office, Washington, 1980.

D. J. Jones et al., An Analysis of Reportable Incidents for Natural Gas Transmission and Gathering Lines, 1970 Through June 1984, NG-18 Report No. 158, performed by Battelle Columbus for the American Gas Association, March 3, 1986.

S. Kaplan and B.J. Garrick, "On the Quantitative Definition of Risk," Risk Analysis, 1, pp. 11-37, 1981.

M. Kazarians, Personal communication with N. Siu, January 1997.

F.A. Leone, "Hazard Materials Testing at the U.S. Department of Energy's Liquefied Gaseous Fuels Spill Test Facility," Plant/Operations Progress, Vol. 9, No. 4, October 1990, pp. 226-230.

"LNG Plant Explosion," Fire Journal, 66, July 1972, pages 38-39.

R.A. Mancini, "The Use (and Misuse) of Bonding for Control of Static Ignition Hazards," Plant/Operations Progress, 7, No. 1, January 1988, pp. 23-31.

L. Medard, "Rupture of an Ammonia Road Tanker," Ammonia Plant Safety and Related Facilities, 12, American Institute of Chemical Engineers, 1970, pp. 17-18.

R. E. Melchers and W. R. Feutrill, "Risk Assessment for Automotive LPG Facilities," in Risk and Safety Assessments: Where Is the Balance?, PVP-Vol. 296, SERA-Vol. 3, American Society of Mechanical Engineers, 1995, pp. 457-462.

Morioka, Mikio; Obama, Toshio; Kouda, Yasuo; Mori, Mikio; Tomura, S. and Shintaro, E., "Simulation of the Geysering Phenomenon in LNG Pipes," in Advances in Cryogenic Engineering Vol 31, R. W. Fast, ed., Plenum Press, New York, 1986, pp. 11111119.

Mulliner, David K., "Now - A Practical Method For Odorizing LNG," Pipeline and Gas Journal, Vol. 201, June 1974, pp. 78-84.

"LNG Safety Performance about Same as Diesel' Say Experienced Fleet Managers," LNG Express, August 1996, pp. 6-8. 
NTSB, 1980

NVO, 1987.

Ong, 1985

OSHA, 1996

Pentz 1995

Puttock, 1982

Rhoads, 1978.

SAIC, 1990.

Siu et al., 1995.

Shah, 1974

Thomas, 1996

Thomson, 1987
"Columbia Liquified Natural Gas Corporation Explosion and Fire, Cove Point, Maryland, October 6, 1979," Pipeline Accident Report, NTSB-PAR-80-2, National Transportation Safety Board, Washington, DC, 20594, adopted April 16, 1980.

U.S. Department of Energy, Nevada Operations Office, Report of the Investigation Board for the Unplanned Fire at the Liquefied Gaseous Fuels Spill Test Facility on August 29, 1987, NVO-319, October 23, 1987.

Ong, Han, I., "Development of LNG Facilities Safety Standards," Bulletin of the Association of Engineering Geologists, Vol. XXII, No. 1, Feb. 1985, pp. 25-38.

U.S. Code of Federal Regulations, Title 29, Labor, Part 29CFR1917.23, Hazardous Atmospheres and Substances, July 1996, and 30CFR57.5015, July 1996.

Pentz, Russell, "Liquified Natural Gas Experience of a Large Transit Fleet," American Energy Week '95 Conference and Exhibition, Jan 31-Feb. 2, 1995, Houston, TX, Book 3, Atternative Fuel Vehicles '95.

Puttock, J. S., Blackmore, D. R, and Colenbrander, G. W., "Field Experiments on Dense Gas Dispersion," Journal of Hazardous Materials, 6 (1982) 13-41.

R. E. Rhoads, An Assessment of the Risk of Transporting Gasoline by Truck, PNL-2133, Battelle Pacific Northwest Laboratory, November 1978.

D. M. Friedman et al., Risk Assessment of Indoor Refueling and Servicing of CNG-fueled Mass Transit Buses, GRI-90/0191, Gas Research Institute and Science Applications International Corporation, accession number PB91-161364, August 1990.

N. O. Siu et al., Evaluating Risk Assessment Approaches in Oil Spill Prevention Applications, INEL-95/0401, Idaho National Engineering Laboratory, August 1995.

Shah, J. M., and Aarts, J. J., "Effect of Weathering of LNG in Storage Tanks, " in Advances in Cryogenic Engineering. Vol 19, $\mathrm{K}$. D. Timmerhaus, ed., Plenum Press, New York, 1974, pp. 253-260.

Thomas, Theodore A., INEL, private communication concerning design of INEL bus maintenance facility, October 17, 1996.

Thomson, J. R., Engineering Safety Assessment. An Introduction. Chapter 5, Major Industrial Hazards, Longman Scientific and Technical, London, 1987. 
USNRC, 1975.

Van Horn and Wilson, 1977.

Van Meerbeke, 1982

Welker and Schorr, 1979.

Williamson and Edeskuty, 1983.

Zabetakis, 1967.
U.S. Nuclear Regulatory Commission, Reactor Safety Study, An Assessment of Accident Risks in Commercial Nuclear Power Plants, NUREG-75/014, WASH-1400, October 1975.

A. J. Van Horn and R. Wilson, "The Potential Risks of Liquefied Natural Gas," Energy, 2, 1977, pp. 375-389.

Van Meerbeke, R. C., "Accident At the Cove Point LNG Facility," Chemical Engineering Progress, January 1982, pp. 39-45.

J. R. Welker and H. P. Schorr, "LNG Plant Experience Data Base," paper 79-T-21, American Gas Association Transmission Conference, May 21-23, 1979, New Orleans, LA, pp. T-263 to T-266.

K. D. Williamson, Jr., and F. J. Edeskuty, Liquid Cryogens, CRC Press, Boca Raton, FL, 1983.

M. G. Zabetakis, Safety with Cryogenic Fluids, Plenum Press, New York, 1967. 
APPENDIX A - Failure Modes and Effects Analysis for Facility Number 1 


\section{APPENDIX A - Failure Modes and Effects Analysis for Facility Number 1}

This appendix contains a Failure Modes and Effects Analysis (FMEA) performed for the Facility 1 fuel dispensing system. Details of that system are contained in Figure 2-1 and Table 2-6. The analysis considers each component and postulates the system effects or responses to the various ways in which the component could fail. The FMEA provides some insights into the failure modes and behavior of the components in the system.

There are many valves in the system, including over 30 manual valves, 12 relief valves, 3 check valves, and 5 flow control valves. The FMEA shows that these valves, which constitute about two-thirds of the system components are only a safety concern if the failure mode is external leakage or relief valve venting. LNG valve data must be reviewed to determine if external leakage (i.e., stem leakage or valve body cracking) are frequent events that warrant attention.

The other components include rupture disks, instruments, fill connections, the pump and meter, and the tanks. Instruments could be a source of concern if they leak at penetrations, leak from instrument taps, or give false indications. The connection lines appear to be benign, used infrequently, and provided with isolation valves. Any pump and meter failures require the opening of the pressure tank for repair or replacement, but do not appear to pose safety concerns.

In general, most of the failures hypothesized in the FMEA result in the inability of the system to deliver fuel to end use vehicles (EUVs) or to receive incoming fuel shipments. While this downtime is an operational inconvenience, it is not a safety concern. Catastrophic events, such as pump impeller catastrophic failure followed by impeller debris piercing the pressure tank (PT) wall, were not considered because this is not a typical failure mode for a centrifugal pump. The system analyzed is not very complex and has little automated control.

One insight from the FMEA is that there are a number of single point failures that can lead to a release of LNG. In particular, the pressure relief valves for the storage tank (ST) and PT are single barriers between the LNG and the atmosphere. These relief valves are vented up the facility stack (which helps to loft the gas for dispersion); any failure of these valves is a single failure leading to a release. For example, a valve might successfully open to relieve a mild system overpressure, but then fail in the open position (e.g., due to buildup of ice from atmospheric humidity). As a second problem, if the valves are not well insulated, ice could build up on them when they are closed; causing them to remain closed when they are demanded to open. This could also be true for the rupture disks. Relief valve failure rates tend to be low (on the order of $10^{-4}$ to $10^{-3}$ per demand) but there are several of these valves in the fuel dispensing system.

A second insight concerns the degree of redundancy provided by the standard double-walled storage tank construction. If air or LNG leaks into the vacuum space between the two walls, a heat transfer path will be provided to the inner tank. Without mitigative action, eventually the LNG in the tank will boil and vent. (This problem is well recognized; tanks must typically be refurbished in 5 to 7 years.) Furthermore, the outer vessel walls are generally constructed of carbon steel to reduce the cost of the tank, and so are susceptible to brittle fracture if cooled to LNG temperatures. Thus, a failure of the inner vessel will lead to a release of $L N G$ into the vacuum space which, in turn, can lead to failure of the outer vessel. The double wall does not mean double containment in the case of cryogens. 
Table A-1 Failure Modes and Effects Analysis

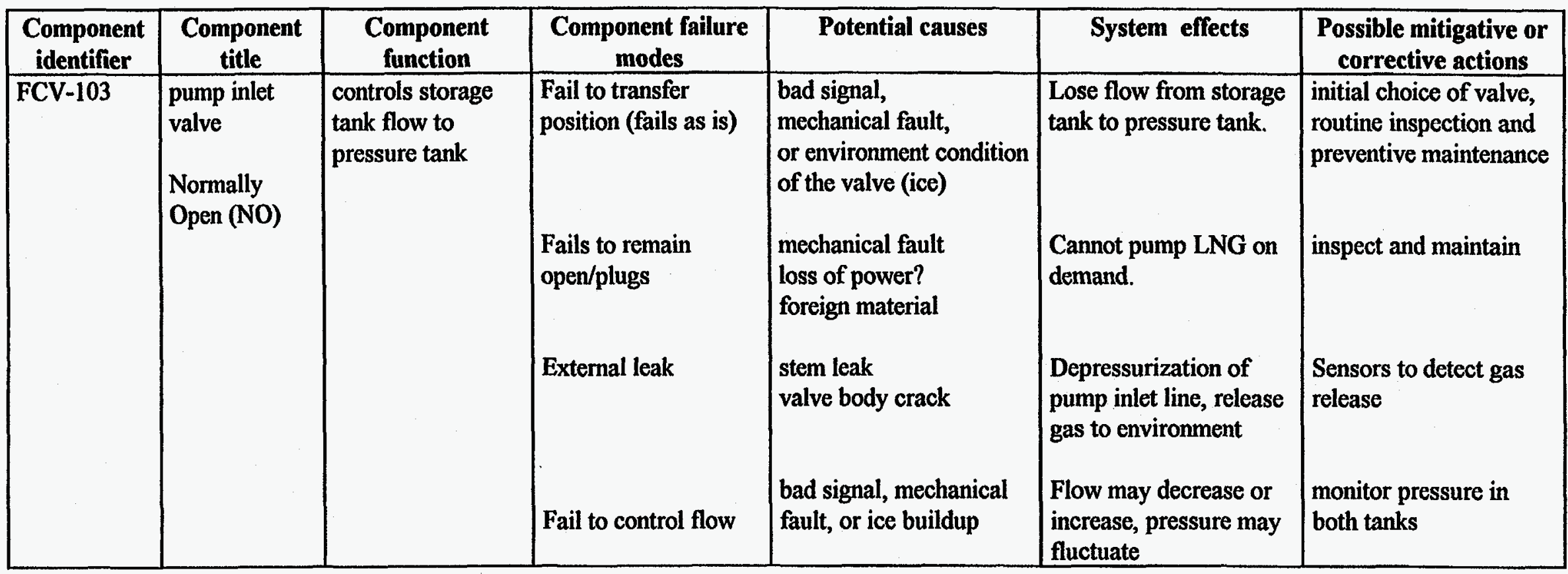




\begin{tabular}{|c|c|c|c|c|c|c|}
\hline $\begin{array}{l}\text { Component } \\
\text { identifier }\end{array}$ & $\begin{array}{l}\text { Component } \\
\text { title }\end{array}$ & $\begin{array}{c}\text { Component } \\
\text { function }\end{array}$ & $\begin{array}{c}\text { Component failure } \\
\text { modes } \\
\end{array}$ & Potential causes & System effects & $\begin{array}{c}\text { Possible mitigative or } \\
\text { corrective actions }\end{array}$ \\
\hline FCV-104 & $\begin{array}{l}\text { pump vent } \\
\text { valve } \\
\text { NO }\end{array}$ & $\begin{array}{l}\text { controls gas vent } \\
\text { flow from } \\
\text { pressure tank } \\
\text { ullage to storage } \\
\text { tank ullage }\end{array}$ & 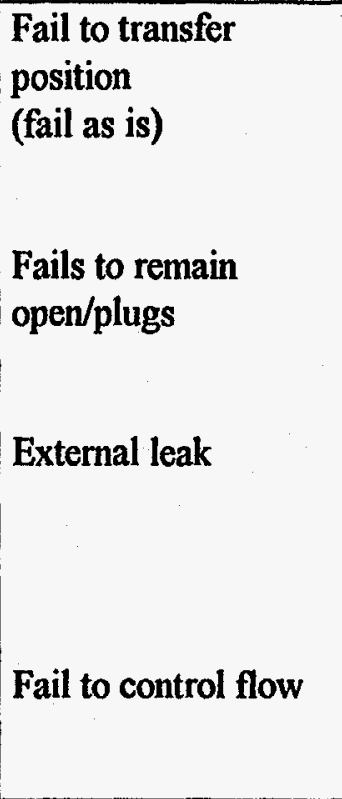 & $\begin{array}{l}\text { bad signal, } \\
\text { mechanical fault, } \\
\text { or environment condition } \\
\text { of the valve (ice) } \\
\text { mechanical fault } \\
\text { loss of power? } \\
\text { foreign material } \\
\text { stem leak } \\
\text { valve body crack } \\
\\
\text { bad signal, mechanical } \\
\text { fault, or ice buildup }\end{array}$ & $\begin{array}{l}\text { Lose flow from } \\
\text { pressure tank ullage to } \\
\text { storage tank ullage. } \\
\text { Cannot flow gaseous } \\
\text { NG back to storage } \\
\text { tank, P increase in PT. } \\
\text { Depressurization } \\
\text { of PT ullage line, } \\
\text { release gas to } \\
\text { environment } \\
\text { Flow may decrease or } \\
\text { increase, pressure may } \\
\text { fluctuate }\end{array}$ & $\begin{array}{l}\text { initial choice of valve, } \\
\text { routine inspection and } \\
\text { preventive maintenance } \\
\text { inspect and maintain } \\
\text { Sensors to detect gas } \\
\text { release } \\
\text { monitor pressure in } \\
\text { both tanks }\end{array}$ \\
\hline FCV-105 & $\begin{array}{l}\text { recirculation } \\
\text { valve } \\
\text { NO }\end{array}$ & $\begin{array}{l}\text { controls } \\
\text { recirculation flow } \\
\text { to the storage tank }\end{array}$ & $\begin{array}{l}\text { Fail to transfer } \\
\text { position } \\
\text { (fail as is) } \\
\text { Fails to remain } \\
\text { open/plugs } \\
\text { External leak } \\
\text { Fail to control flow }\end{array}$ & $\begin{array}{l}\text { bad signal, mechanical } \\
\text { fault, or environment } \\
\text { condition of the valve } \\
\text { (ice) } \\
\text { mechanical fault } \\
\text { loss of power? } \\
\text { foreign material } \\
\text { stem leak } \\
\text { valve body crack } \\
\text { bad signal, mechanical } \\
\text { fault, or ice buildup }\end{array}$ & $\begin{array}{l}\text { Lose saturation flow } \\
\text { from pressure tank to } \\
\text { storage tank. } \\
\text { Cannot flow saturated } \\
\text { LNG back to storage } \\
\text { tank, P increase in PT. } \\
\text { Depressurization of PT, } \\
\text { release LNG and gas to } \\
\text { environment } \\
\text { Flow may decrease or } \\
\text { increase, pressure may } \\
\text { fluctuate }\end{array}$ & $\begin{array}{l}\text { initial choice of valve, } \\
\text { routine inspection and } \\
\text { preventive maintenance } \\
\text { inspect and maintain } \\
\text { Sensors to detect gas } \\
\text { release } \\
\text { monitor pressure in } \\
\text { both tanks }\end{array}$ \\
\hline
\end{tabular}




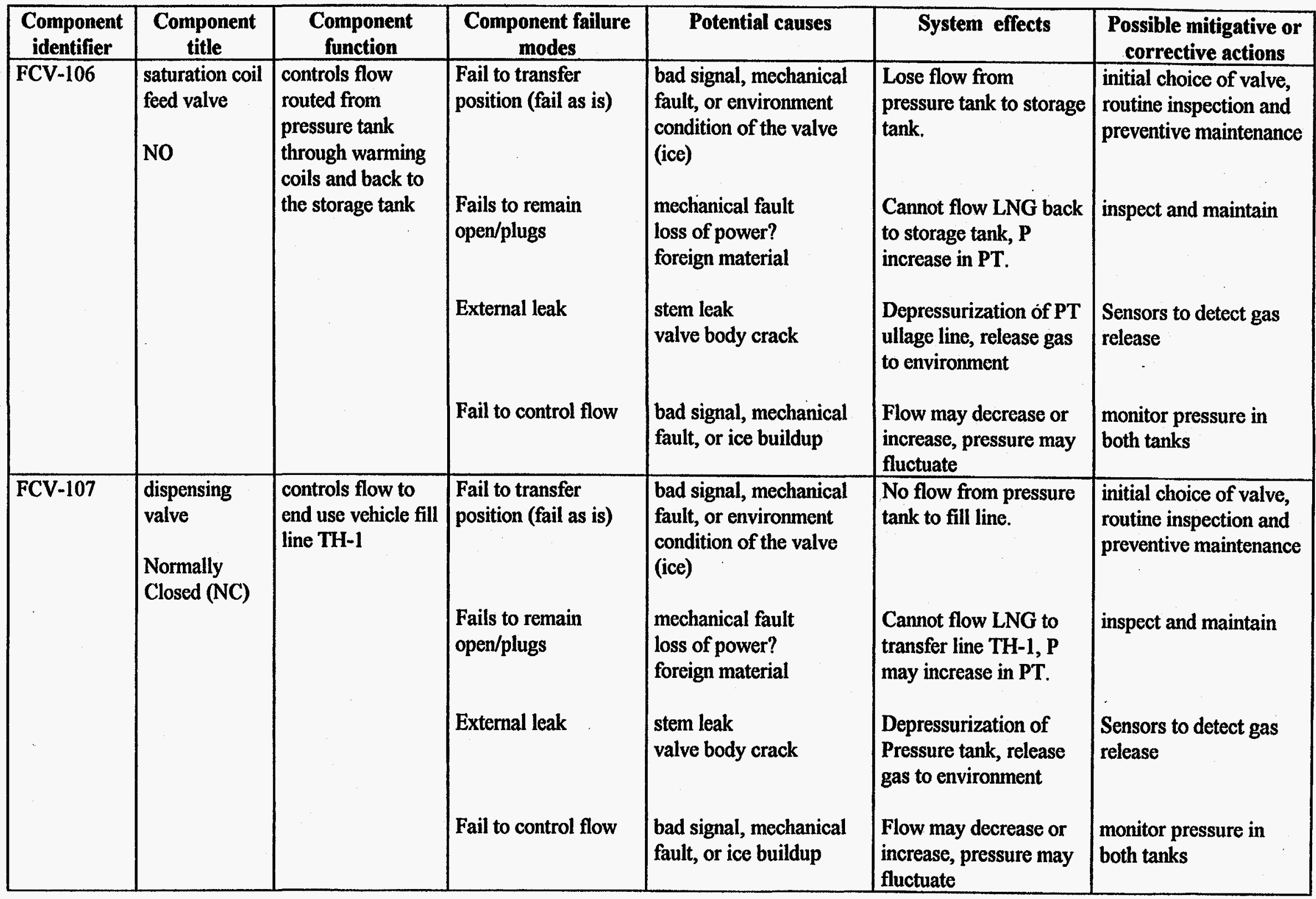




\begin{tabular}{|c|c|c|c|c|c|c|}
\hline $\begin{array}{c}\text { Component } \\
\text { identifier }\end{array}$ & $\begin{array}{c}\text { Component } \\
\text { title } \\
\end{array}$ & $\begin{array}{c}\begin{array}{c}\text { Component } \\
\text { function }\end{array} \\
\end{array}$ & $\begin{array}{c}\text { Component failure } \\
\text { modes } \\
\end{array}$ & Potential causes & System effects & $\begin{array}{l}\text { Possible mitigative or } \\
\text { corrective actions }\end{array}$ \\
\hline V-1 & $\begin{array}{l}\text { top fill valve } \\
\mathrm{NC}\end{array}$ & $\begin{array}{l}\text { shut off valve for } \\
\text { storage tank top } \\
\text { fill from tanker, } \\
\text { part of double } \\
\text { block valving with } \\
\text { V-30 }\end{array}$ & $\begin{array}{l}\text { External leak } \\
\text { Internal leak }\end{array}$ & $\begin{array}{l}\text { mechanical fault } \\
\text { (jammed) } \\
\text { ice buildup } \\
\text { stem leak } \\
\text { valve body crack } \\
\text { seat scored } \\
\text { ice buildup } \\
\end{array}$ & $\begin{array}{l}\text { cannot top fill the } \\
\text { storage tank } \\
\text { release gas to } \\
\text { environment } \\
\text { allow foreign material } \\
\text { intrusion into fill line }\end{array}$ & $\begin{array}{l}\text { repair is required } \\
\text { sensors to detect gas } \\
\text { release } \\
\text { inspect and maintain }\end{array}$ \\
\hline $\mathrm{V}-2$ & $\begin{array}{l}\text { hose drain } \\
\text { valve } \\
\mathrm{NC}\end{array}$ & $\begin{array}{l}\text { shut off valve to } \\
\text { stack for tanker } \\
\text { hose venting }\end{array}$ & $\begin{array}{l}\text { External leak } \\
\text { Internal leak }\end{array}$ & $\begin{array}{l}\text { mechanical fault } \\
\text { (jammed) } \\
\text { ice buildup } \\
\text { stem leak } \\
\text { valve body crack } \\
\\
\text { seat scored } \\
\text { ice buildup }\end{array}$ & $\begin{array}{l}\text { cannot vent hose line, } \\
\text { must rely on PSV- } \\
104 \mathrm{~A} \\
\text { release gas to } \\
\text { environment at ground } \\
\text { level, not up stack } \\
\text { losing LNG up the } \\
\text { stack instead of going } \\
\text { to storage tank }\end{array}$ & $\begin{array}{l}\text { inspect and maintain } \\
\text { sensors detect gas } \\
\text { release } \\
\text { metering on tank truck } \\
\text { should provide warning } \\
\text { that there is leakage, } \\
\text { vent noise also is a } \\
\text { warning of leakage }\end{array}$ \\
\hline V-8 & $\begin{array}{l}\text { liquid phase } \\
\text { valve } \\
\text { NO }\end{array}$ & $\begin{array}{l}\text { shut off valve for } \\
\text { instruments } \\
\text { monitoring storage } \\
\text { LNG }\end{array}$ & External leak & $\begin{array}{l}\text { mechanical fault } \\
\text { ice buildup } \\
\text { steam leak } \\
\text { valve body crack }\end{array}$ & $\begin{array}{l}\text { Lose LNG flow to } \\
\text { pressure and } \\
\text { differential pressure } \\
\text { instruments } \\
\text { release LNG to } \\
\text { environment at ground } \\
\text { level, not up stack }\end{array}$ & $\begin{array}{l}\text { Alarms on pressure } \\
\text { indicators will alert } \\
\text { operators to loss of } \\
\text { flow } \\
\text { sensors detect LNG/gas } \\
\text { release }\end{array}$ \\
\hline
\end{tabular}




\begin{tabular}{|c|c|c|c|c|c|c|}
\hline $\begin{array}{c}\text { Component } \\
\text { identifier }\end{array}$ & $\begin{array}{c}\text { Component } \\
\text { title }\end{array}$ & $\begin{array}{c}\begin{array}{c}\text { Component } \\
\text { function }\end{array} \\
\end{array}$ & \begin{tabular}{|c|}
$\begin{array}{c}\text { Component failure } \\
\text { modes }\end{array}$ \\
\end{tabular} & Potential causes & System effects & $\begin{array}{l}\text { Possible mitigative or } \\
\text { corrective actions }\end{array}$ \\
\hline V-10 & $\begin{array}{l}\text { LI-1 } \\
\text { equalization } \\
\text { valve } \\
\text { NO }\end{array}$ & $\begin{array}{l}\text { valve that } \\
\text { balances inputs to } \\
\text { pressure and } \\
\text { differential } \\
\text { pressure indicators } \\
\text { so they will } \\
\text { indicate storage } \\
\text { tank level } \\
\end{array}$ & $\begin{array}{l}\text { Fail to remain } \\
\text { open/plugs }\end{array}$ & $\begin{array}{l}\text { mechanical fault } \\
\text { ice buildup }\end{array}$ & $\begin{array}{l}\text { Creates erroneous } \\
\text { readings in } P \text { and DP } \\
\text { instruments } \\
\text { release gas to } \\
\text { environment at ground } \\
\text { level, not up stack }\end{array}$ & $\begin{array}{l}\text { Alarms on pressure } \\
\text { indicators may alert } \\
\text { operators to loss of } \\
\text { flow } \\
\text { sensors detect gas } \\
\text { release }\end{array}$ \\
\hline
\end{tabular}




\begin{tabular}{|c|c|c|c|c|c|c|}
\hline $\begin{array}{c}\text { Component } \\
\text { identifier }\end{array}$ & $\begin{array}{c}\text { Component } \\
\text { title }\end{array}$ & $\begin{array}{c}\text { Component } \\
\text { function } \\
\end{array}$ & $\begin{array}{c}\text { Component failure } \\
\text { modes }\end{array}$ & Potential causes & System effects & $\begin{array}{c}\text { Possible mitigative or } \\
\text { corrective actions }\end{array}$ \\
\hline $\mathrm{V}-12$ & $\begin{array}{l}\text { manual vent } \\
\text { valve } \\
\mathrm{NC}\end{array}$ & $\begin{array}{l}\text { valve to vent } \\
\text { gaseous NG from } \\
\text { storage tank to the } \\
\text { stack }\end{array}$ & $\begin{array}{l}\text { External leak } \\
\text { Internal leak }\end{array}$ & $\begin{array}{l}\text { stem leak } \\
\text { valve body crack } \\
\text { scored valve seat }\end{array}$ & $\begin{array}{l}\text { Vents gas from the } \\
\text { storage tank to the } \\
\text { stack } \\
\text { vents gas from storage } \\
\text { tank to environment as } \\
\text { ground level release } \\
\text { Vents small gas } \\
\text { quantities from the } \\
\text { storage tank to the } \\
\text { stack }\end{array}$ & $\begin{array}{l}\text { Tank instruments will } \\
\text { note loss of inventory } \\
\text { and alarm } \\
\text { sensors detect gas } \\
\text { release } \\
\text { may only be noticed by } \\
\text { viewing stack } \\
\text { emissions, inventory } \\
\text { loss may be thought to } \\
\text { be part of normal } \\
\text { effluent }\end{array}$ \\
\hline V-13 & $\begin{array}{l}\text { pump inlet } \\
\text { isolation valve } \\
\text { NO }\end{array}$ & $\begin{array}{l}\text { isolation of } \\
\text { storage tank flow } \\
\text { to pump in } \\
\text { pressure tank }\end{array}$ & $\begin{array}{l}\text { Fails to remain } \\
\text { open/plugs } \\
\text { External leak }\end{array}$ & 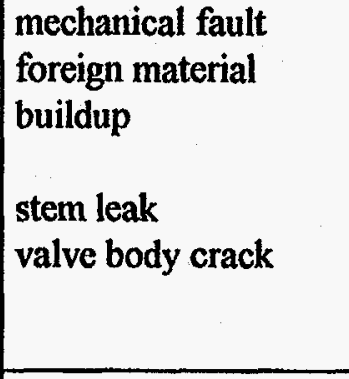 & $\begin{array}{l}\text { Cannot pump LNG on } \\
\text { demand. } \\
\text { Depressurization } \\
\text { of pump inlet line, } \\
\text { release gas to } \\
\text { environment }\end{array}$ & $\begin{array}{l}\text { inspect and maintain } \\
\text { Sensors to detect gas } \\
\text { release }\end{array}$ \\
\hline V-14 & $\begin{array}{l}\text { pump vent } \\
\text { isolation valve } \\
\text { NO }\end{array}$ & $\begin{array}{l}\text { isolation of } \\
\text { pressure tank } \\
\text { gaseous NG vent } \\
\text { to storage tank } \\
\text { ullage }\end{array}$ & $\begin{array}{l}\text { Fails to remain } \\
\text { open/plugs }\end{array}$ & $\begin{array}{l}\text { mechanical fault } \\
\text { foreign material } \\
\text { buildup } \\
\text { stem leak } \\
\text { valve body crack }\end{array}$ & $\begin{array}{l}\text { Cannot pump LNG on } \\
\text { demand, pressure in } \\
\text { system cannot equalize. } \\
\text { Depressurization } \\
\text { of pump outlet line, } \\
\text { release gas to } \\
\text { environment }\end{array}$ & $\begin{array}{l}\text { inspect and maintain } \\
\text { Sensors to detect gas } \\
\text { release }\end{array}$ \\
\hline
\end{tabular}




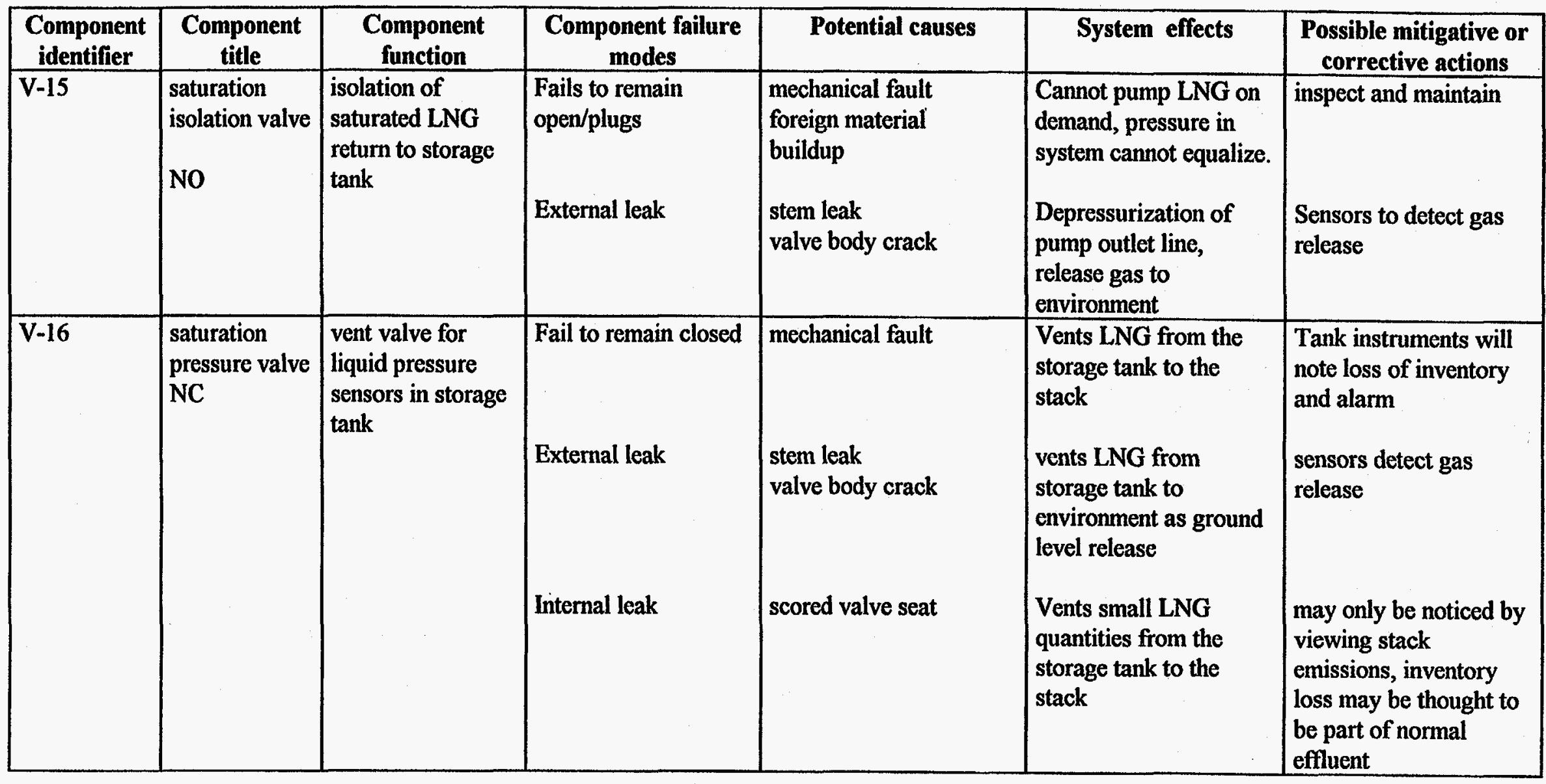




\begin{tabular}{|c|c|c|c|c|c|c|}
\hline $\begin{array}{l}\text { Component } \\
\text { identifier }\end{array}$ & $\begin{array}{c}\text { Component } \\
\text { title }\end{array}$ & $\begin{array}{c}\text { Component } \\
\text { function }\end{array}$ & $\begin{array}{c}\text { Component failure } \\
\text { modes }\end{array}$ & Potential causes & System effects & $\begin{array}{l}\text { Possible mitigative or } \\
\text { corrective actions }\end{array}$ \\
\hline$V-17$ & $\begin{array}{l}\text { pump sump } \\
\text { manual vent } \\
\text { valve } \\
\mathrm{NC}\end{array}$ & $\begin{array}{l}\text { valve to vent } \\
\text { gaseous NG to } \\
\text { stack from ullage } \\
\text { of pressure tank }\end{array}$ & $\begin{array}{l}\text { External leak } \\
\text { Internal leak }\end{array}$ & $\begin{array}{l}\text { stem leak } \\
\text { valve body crack } \\
\text { scored valve seat }\end{array}$ & $\begin{array}{l}\text { Vents gas from the } \\
\text { pressure tank to the } \\
\text { stack } \\
\text { vents gas from pressure } \\
\text { tank to environment as } \\
\text { ground level release } \\
\text { Vents small gas } \\
\text { quantities from the } \\
\text { pressure tank to the } \\
\text { stack }\end{array}$ & $\begin{array}{l}\text { Tank instruments will } \\
\text { note loss of inventory } \\
\text { and alarm } \\
\text { sensors detect gas } \\
\text { release } \\
\text { may only be noticed by } \\
\text { viewing stack } \\
\text { emissions, inventory } \\
\text { loss may be thought to } \\
\text { be part of normal } \\
\text { effluent }\end{array}$ \\
\hline V-18 & $\begin{array}{l}\text { dispensing } \\
\text { drain valve } \\
\mathrm{NC}\end{array}$ & $\begin{array}{l}\text { valve to vent } \\
\text { gaseous NG to } \\
\text { stack from fill line } \\
\text { TH-1 }\end{array}$ & $\begin{array}{l}\text { Fail to remain closed } \\
\text { External leak } \\
\text { Internal leak }\end{array}$ & $\begin{array}{l}\text { mechanical fault } \\
\text { stem leak } \\
\text { valve body crack } \\
\text { scored valve seat }\end{array}$ & $\begin{array}{l}\text { Vents gas from the } \\
\text { transfer hose volume to } \\
\text { the stack } \\
\text { vents gas from the } \\
\text { transfer hose volume to } \\
\text { the environment as a } \\
\text { ground level release } \\
\text { Vents small gas } \\
\text { quantities from the TH- } \\
1 \text { to the stack }\end{array}$ & $\begin{array}{l}\text { Tank instruments will } \\
\text { note loss of inventory } \\
\text { and alarm } \\
\text { sensors detect gas } \\
\text { release } \\
\text { may only be noticed by } \\
\text { viewing stack } \\
\text { emissions, inventory } \\
\text { loss may be thought to } \\
\text { be part of normal } \\
\text { effluent }\end{array}$ \\
\hline
\end{tabular}




\begin{tabular}{|c|c|c|c|c|c|c|}
\hline $\begin{array}{c}\text { Component } \\
\text { identifier }\end{array}$ & $\begin{array}{c}\begin{array}{c}\text { Component } \\
\text { title }\end{array} \\
\end{array}$ & \begin{tabular}{|c|}
$\begin{array}{c}\text { Component } \\
\text { function }\end{array}$ \\
\end{tabular} & \begin{tabular}{|c|}
$\begin{array}{c}\text { Component failure } \\
\text { modes }\end{array}$ \\
\end{tabular} & Potential causes & System effects & $\begin{array}{c}\text { Possible mitigative or } \\
\text { corrective actions }\end{array}$ \\
\hline V-19 & $\begin{array}{l}\text { vacuum gauge } \\
\text { tube valve } \\
\text { NO }\end{array}$ & $\begin{array}{l}\text { shut off valve to } \\
\text { storage tank } \\
\text { annulus vacuum } \\
\text { gauge }\end{array}$ & $\begin{array}{l}\text { Fail to remain } \\
\text { open/plugs } \\
\text { External leak }\end{array}$ & $\begin{array}{l}\text { mechanical fault } \\
\text { ice buildup } \\
\text { stem leak } \\
\text { valve body crack }\end{array}$ & $\begin{array}{l}\text { Lose vacuum reading } \\
\text { on storage tank } \\
\text { releases LNG from } \\
\text { storage tank to } \\
\text { environment as ground } \\
\text { level release }\end{array}$ & $\begin{array}{l}\text { Alarm on vacuum } \\
\text { value? } \\
\text { sensors detect } \mathrm{LNG} / \mathrm{gas} \\
\text { release }\end{array}$ \\
\hline V-20 & $\begin{array}{l}\text { safety selector } \\
\text { valve } \\
\text { NO, aligned to } \\
\text { PSV-101A } \\
\text { and PSE- } \\
\text { 101A } \\
\end{array}$ & $\begin{array}{l}\text { Valve to route } \\
\text { storage tank } \\
\text { effluent to sets of } \\
\text { relief valves and } \\
\text { rupture disks }\end{array}$ & $\begin{array}{l}\text { Fails to open } \\
\text { secondary line }\end{array}$ & $\begin{array}{l}\text { mechanical fault } \\
\text { ice buildup } \\
\text { mechanical fault } \\
\text { ice buildup } \\
\end{array}$ & $\begin{array}{l}\text { Safety equipment, may } \\
\text { not know of fault until } \\
\text { an accident event } \\
\text { occurs }\end{array}$ & $\begin{array}{l}\text { regular testing and } \\
\text { inspections }\end{array}$ \\
\hline V-21 & $\begin{array}{l}\text { evacuation } \\
\text { valve } \\
\mathrm{NC}\end{array}$ & $\begin{array}{l}\text { Shut off valve to } \\
\text { storage tank } \\
\text { annulus, used to } \\
\text { draw fresh } \\
\text { vacuum on } \\
\text { annulus. } \\
\text { Infrequently used } \\
\text { (1/yr?) }\end{array}$ & 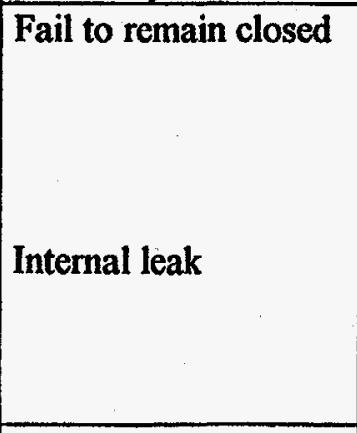 & 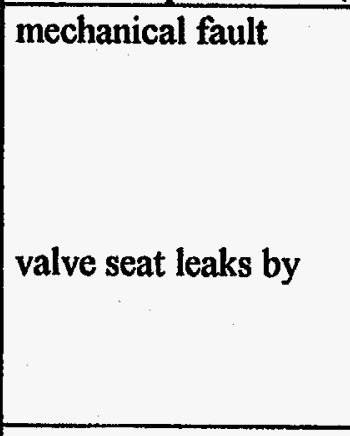 & $\begin{array}{l}\text { Large air ingress to } \\
\text { storage tank annulus, } \\
\text { will boil LNG as heat } \\
\text { transfers } \\
\text { Cannot maintain proper } \\
\text { vacuum, boil off rate } \\
\text { slowly rises for storage } \\
\text { tank }\end{array}$ & $\begin{array}{l}\text { regular testing and } \\
\text { inspection } \\
\text { Monitoring vacuum } \\
\text { with TC-1 }\end{array}$ \\
\hline $\mathrm{V}-22$ & $\begin{array}{l}\text { stack drain } \\
\text { valve } \\
\text { NC }\end{array}$ & $\begin{array}{l}\text { valve to drain any } \\
\text { liquid that } \\
\text { accumulates in the } \\
\text { vent stack }\end{array}$ & $\begin{array}{l}\text { Fails to remain closed } \\
\text { Internal leak } \\
\text { External leak }\end{array}$ & $\begin{array}{l}\text { mechanical fault } \\
\text { valve seat scored } \\
\text { valve stem leak } \\
\text { valve body crack }\end{array}$ & $\begin{array}{l}\text { could vent to ground } \\
\text { instead of up stack } \\
\text { during accident } \\
\text { small leak at ground } \\
\text { level during accident } \\
\text { small leak at ground } \\
\text { level during accident }\end{array}$ & $\begin{array}{l}\text { inspect and maintain } \\
\text { inspect and maintain }\end{array}$ \\
\hline
\end{tabular}




\begin{tabular}{|c|c|c|c|c|c|c|}
\hline $\begin{array}{c}\text { Component } \\
\text { identifier }\end{array}$ & $\begin{array}{c}\begin{array}{c}\text { Component } \\
\text { title }\end{array} \\
\end{array}$ & $\begin{array}{c}\begin{array}{c}\text { Component } \\
\text { function }\end{array} \\
\end{array}$ & $\begin{array}{c}\text { Component failure } \\
\text { modes }\end{array}$ & Potential causes & System effects & $\begin{array}{c}\text { Possible mitigative or } \\
\text { corrective actions }\end{array}$ \\
\hline V-24 & $\begin{array}{l}\text { transport } \\
\text { return valve } \\
\text { NC }\end{array}$ & $\begin{array}{l}\text { gaseous NG return } \\
\text { to tanker ullage } \\
\text { from pressure tank } \\
\text { ullage }\end{array}$ & $\begin{array}{l}\text { Fail to remain closed } \\
\text { Internal leak } \\
\text { External leak }\end{array}$ & $\begin{array}{l}\text { valve seat scored } \\
\text { valve stem leak } \\
\text { valve body crack }\end{array}$ & $\begin{array}{l}\text { Large gas release at } \\
\text { ground level } \\
\text { small gas release at } \\
\text { ground level } \\
\text { small gas release at } \\
\text { ground level }\end{array}$ & $\begin{array}{l}\text { Alarm on tank level } \\
\text { sensors detect gas } \\
\text { release } \\
\text { sensors detect gas } \\
\text { release }\end{array}$ \\
\hline V-26 & $\begin{array}{l}\text { N2 purge } \\
\text { valve } \\
\text { NC }\end{array}$ & $\begin{array}{l}\text { valve between N2 } \\
\text { gas bottles and } \\
\text { ullage of pressure } \\
\text { tank to purge the } \\
\text { tank of } \\
\text { condensables and } \\
\text { other impurity } \\
\text { gases }\end{array}$ & $\begin{array}{l}\text { Fails to remain closed } \\
\text { Internal leak }\end{array}$ & $\begin{array}{l}\text { mechanical fault } \\
\text { valve seat scored } \\
\text { valve stem leak } \\
\text { valve body crack }\end{array}$ & $\begin{array}{l}\text { Large gas release at } \\
\text { ground level } \\
\text { small gas release at } \\
\text { ground level } \\
\text { small gas release at } \\
\text { ground level }\end{array}$ & $\begin{array}{l}\text { Alarm on tank level } \\
\text { sensors detect gas } \\
\text { release } \\
\text { sensors detect gas } \\
\text { release }\end{array}$ \\
\hline
\end{tabular}




\begin{tabular}{|c|c|c|c|c|c|c|}
\hline $\begin{array}{c}\text { Component } \\
\text { identifier }\end{array}$ & $\begin{array}{c}\text { Component } \\
\text { title }\end{array}$ & \begin{tabular}{|c|}
$\begin{array}{c}\text { Component } \\
\text { function }\end{array}$ \\
\end{tabular} & $\begin{array}{c}\begin{array}{c}\text { Component failure } \\
\text { modes }\end{array} \\
\end{array}$ & Potential causes & System effects & $\begin{array}{c}\text { Possible mitigative or } \\
\text { corrective actions }\end{array}$ \\
\hline V-27 & $\begin{array}{l}\text { sample } \\
\text { isolation valve } \\
\mathrm{NC}\end{array}$ & $\begin{array}{l}\text { shut off valve for } \\
\text { sample cylinder } \\
\text { connection C-1 }\end{array}$ & $\begin{array}{l}\text { Internal leak } \\
\text { External leak }\end{array}$ & $\begin{array}{l}\text { valve seat scored } \\
\text { valve stem leak } \\
\text { valve body crack }\end{array}$ & $\begin{array}{l}\text { Large LNG release at } \\
\text { ground level } \\
\text { small LNG release at } \\
\text { ground level } \\
\text { small LNG release at } \\
\text { ground level } \\
\end{array}$ & $\begin{array}{l}\text { Alarm on tank level } \\
\text { sensors detect gas } \\
\text { release } \\
\text { sensors detect gas } \\
\text { release } \\
\end{array}$ \\
\hline$V-28$ & $\begin{array}{l}\text { sample vent } \\
\text { valve } \\
\mathrm{NC}\end{array}$ & $\begin{array}{l}\text { shut off valve for } \\
\text { sample cylinder } \\
\text { vent through } \\
\text { connection } \mathrm{C}-2\end{array}$ & $\begin{array}{l}\text { Fails to remain closed } \\
\text { Internal leak } \\
\text { External leak }\end{array}$ & $\begin{array}{l}\text { mechanical fault } \\
\text { valve seat scored } \\
\text { valve stem leak } \\
\text { valve body crack }\end{array}$ & $\begin{array}{l}\text { no effect until taking a } \\
\text { sample } \\
\text { no effect until taking a } \\
\text { sample } \\
\text { no effect until taking a } \\
\text { sample } \\
\end{array}$ & \\
\hline V-29 & $\begin{array}{l}\text { sample purge } \\
\text { valve } \\
\\
\mathrm{NC}\end{array}$ & $\begin{array}{l}\text { shut off valve for } \\
\text { purging the } \\
\text { sample line, } \\
\text { connects to C-3 }\end{array}$ & $\begin{array}{l}\text { Fails to remain closed } \\
\text { Internal leak } \\
\text { External leak }\end{array}$ & $\begin{array}{l}\text { mechanical fault } \\
\text { valve seat scored } \\
\text { valve stem leak } \\
\text { valve body crack } \\
\end{array}$ & $\begin{array}{l}\text { no effect until taking a } \\
\text { sample } \\
\text { no effect until taking a } \\
\text { sample } \\
\text { no effect until taking a } \\
\text { sample }\end{array}$ & \\
\hline $\mathrm{V}-30$ & \begin{tabular}{|l} 
top fill \\
isolation valve \\
$\mathrm{NC}$
\end{tabular} & $\begin{array}{l}\text { second shut off } \\
\text { valve with V-1 } \\
\text { double block for } \\
\text { storage tank top } \\
\text { fill from tanker }\end{array}$ & $\begin{array}{l}\text { Fails to remain closed } \\
\text { Internal leak } \\
\text { External leak }\end{array}$ & $\begin{array}{l}\text { valve seat scored } \\
\text { valve stem leak } \\
\text { valve body crack }\end{array}$ & $\begin{array}{l}\text { Large gas release at } \\
\text { ground level } \\
\text { small gas release at } \\
\text { ground level } \\
\text { small gas release at } \\
\text { ground level }\end{array}$ & $\begin{array}{l}\text { Alarm on tank level } \\
\text { sensors detect gas } \\
\text { release } \\
\text { sensors detect gas } \\
\text { release }\end{array}$ \\
\hline
\end{tabular}




\begin{tabular}{|c|c|c|c|c|c|c|}
\hline $\begin{array}{l}\text { Component } \\
\text { identifier }\end{array}$ & $\begin{array}{c}\text { Component } \\
\text { title }\end{array}$ & $\begin{array}{c}\text { Component } \\
\text { function }\end{array}$ & $\begin{array}{c}\text { Component failure } \\
\text { modes } \\
\end{array}$ & Potential causes & System effects & $\begin{array}{c}\text { Possible mitigative or } \\
\text { corrective actions }\end{array}$ \\
\hline V-31 & $\begin{array}{l}\text { F-1 isolation } \\
\text { valve } \\
\mathrm{NC}\end{array}$ & $\begin{array}{l}\text { isolates the fill line } \\
\text { to end use vehicles }\end{array}$ & $\begin{array}{l}\text { Internal leak } \\
\text { External leak }\end{array}$ & $\begin{array}{l}\text { valve seat scored } \\
\text { valve stem leak } \\
\text { valve body crack }\end{array}$ & $\begin{array}{l}\text { Large LNG release } \\
\text { through transfer hose } \\
\text { small gas release } \\
\text { through transfer hose } \\
\text { small gas release } \\
\text { through transfer hose }\end{array}$ & $\begin{array}{l}\text { Alarm on tank level } \\
\text { sensors detect gas } \\
\text { release } \\
\text { sensors detect gas } \\
\text { release } \\
\end{array}$ \\
\hline $\mathrm{V}-32$ & $\begin{array}{l}\text { PSV } 101 \mathrm{~A} \\
\text { test valve } \\
\mathrm{NC}\end{array}$ & $\begin{array}{l}\text { bypass valve to } \\
\text { stack for pressure } \\
\text { relief valve } 101 \mathrm{~A}\end{array}$ & $\begin{array}{l}\text { Fails to remain closed } \\
\text { Internal leak } \\
\text { External leak }\end{array}$ & $\begin{array}{l}\text { mechanical fault } \\
\text { valve seat scored } \\
\text { valve stem leak } \\
\text { valve body crack }\end{array}$ & $\begin{array}{l}\text { Large gas release to the } \\
\text { stack } \\
\text { small gas release to } \\
\text { stack } \\
\text { small gas release to } \\
\text { ground level }\end{array}$ & $\begin{array}{l}\text { Alarm on storage tank } \\
\text { liquid level } \\
\text { tank pressure decrease } \\
\text { sensors detect gas } \\
\text { release }\end{array}$ \\
\hline V-33 & $\begin{array}{l}\text { PSV-101B } \\
\text { test valve } \\
\mathrm{NC}\end{array}$ & $\begin{array}{l}\text { bypass valve to } \\
\text { stack for pressure } \\
\text { relief valve } 101 \mathrm{~B}\end{array}$ & $\begin{array}{l}\text { Fails to remain closed } \\
\text { Internal leak } \\
\text { External leak }\end{array}$ & $\begin{array}{l}\text { mechanical fault } \\
\text { valve seat scored } \\
\text { valve stem leak } \\
\text { valve body crack }\end{array}$ & $\begin{array}{l}\text { Large gas release to the } \\
\text { stack } \\
\text { small gas release to } \\
\text { stack } \\
\text { small gas release to } \\
\text { ground level }\end{array}$ & $\begin{array}{l}\text { Alarm on storage tank } \\
\text { liquid level } \\
\text { tank pressure decrease } \\
\text { sensors detect gas } \\
\text { release } \\
\end{array}$ \\
\hline V-34 & $\begin{array}{l}\text { PSV-105B } \\
\text { test valve } \\
\text { NC }\end{array}$ & $\begin{array}{l}\text { bypass valve to } \\
\text { stack for pressure } \\
\text { relief valve } 105 \mathrm{~B}\end{array}$ & $\begin{array}{l}\text { Fails to remain closed } \\
\text { Internal leak } \\
\text { External leak }\end{array}$ & $\begin{array}{l}\text { valve seat scored } \\
\text { valve stem leak } \\
\text { valve body crack }\end{array}$ & $\begin{array}{l}\text { Large LNG release to } \\
\text { the stack } \\
\text { small LNG release to } \\
\text { stack } \\
\text { small LNG release to } \\
\text { ground level }\end{array}$ & $\begin{array}{l}\text { Alarm on storage tank } \\
\text { liquid level } \\
\text { tank pressure decrease } \\
\text { sensors detect gas } \\
\text { release }\end{array}$ \\
\hline
\end{tabular}




\begin{tabular}{|c|c|c|c|c|c|c|}
\hline $\begin{array}{c}\text { Component } \\
\text { identifier }\end{array}$ & $\begin{array}{c}\text { Component } \\
\text { title } \\
\end{array}$ & $\begin{array}{c}\text { Component } \\
\text { function } \\
\end{array}$ & $\begin{array}{c}\begin{array}{c}\text { Component failure } \\
\text { modes }\end{array} \\
\end{array}$ & Potential causes & System effects & $\begin{array}{l}\text { Possible mitigative or } \\
\text { corrective actions }\end{array}$ \\
\hline V-35 & $\begin{array}{l}\text { PSV-105A } \\
\text { test valve } \\
\mathrm{NC}\end{array}$ & $\begin{array}{l}\text { bypass valve to } \\
\text { stack for pressure } \\
\text { relief valve } 105 A\end{array}$ & $\begin{array}{l}\text { Internal leak } \\
\text { External leak }\end{array}$ & $\begin{array}{l}\text { valve stem leak } \\
\text { valve body crack }\end{array}$ & $\begin{array}{l}\text { Large gas release to the } \\
\text { stack } \\
\text { small gas release to } \\
\text { stack } \\
\text { small gas release to } \\
\text { ground level }\end{array}$ & $\begin{array}{l}\text { Alarm on storage tank } \\
\text { liquid level } \\
\text { tank pressure decrease }\end{array}$ \\
\hline V-36 & $\begin{array}{l}\text { PSV-104C } \\
\text { test valve } \\
\mathrm{NC}\end{array}$ & $\begin{array}{l}\text { bypass valve to } \\
\text { stack for pressure } \\
\text { relief valve } 104 \mathrm{C}\end{array}$ & $\begin{array}{l}\text { Fails to remain closed } \\
\text { Internal leak } \\
\text { External leak }\end{array}$ & $\begin{array}{l}\text { mechanical fault } \\
\text { valve seat scored } \\
\text { valve stem leak } \\
\text { valve body crack }\end{array}$ & $\begin{array}{l}\text { Large gas release to the } \\
\text { stack } \\
\text { small gas release to } \\
\text { stack } \\
\text { small gas release to } \\
\text { ground level }\end{array}$ & $\begin{array}{l}\text { Alarm on storage tank } \\
\text { liquid level } \\
\text { tank pressure decrease } \\
\text { sensors detect gas } \\
\text { release }\end{array}$ \\
\hline $\mathrm{CV}-1$ & $\begin{array}{l}\text { fill check } \\
\text { valve } \\
\text { NC }\end{array}$ & $\begin{array}{l}\text { prevent reverse } \\
\text { flow into tanker } \\
\text { when top filling } \\
\text { storage tank }\end{array}$ & $\begin{array}{l}\text { Fails to remain closed } \\
\text { External leak }\end{array}$ & mechanical fault & $\begin{array}{l}\text { small gas release to the } \\
\text { stack } \\
\text { small gas release to } \\
\text { ground level }\end{array}$ & fill line not alarmed \\
\hline
\end{tabular}




\begin{tabular}{|c|c|c|c|c|c|c|}
\hline $\begin{array}{c}\text { Component } \\
\text { identifier }\end{array}$ & $\begin{array}{c}\begin{array}{c}\text { Component } \\
\text { title }\end{array} \\
\end{array}$ & \begin{tabular}{|c|}
$\begin{array}{c}\text { Component } \\
\text { function }\end{array}$ \\
\end{tabular} & \begin{tabular}{|c|}
$\begin{array}{c}\text { Component failure } \\
\text { modes }\end{array}$ \\
\end{tabular} & Potential causes & System effects & $\begin{array}{l}\text { Possible mitigative or } \\
\text { corrective actions }\end{array}$ \\
\hline PSV-101B & $\begin{array}{l}\text { inner vessel } \\
\text { safety valve } \\
\mathrm{NC}\end{array}$ & $\begin{array}{l}\text { second in line } \\
\text { overpressure relief } \\
\text { for storage tank } \\
\text { ullage, vents to } \\
\text { stack }\end{array}$ & $\begin{array}{l}\text { Fails to remain closed } \\
\text { Fail to open on } \\
\text { demand }\end{array}$ & $\begin{array}{l}\text { spring failure } \\
\text { freeze up, } \\
\text { mechanical fault }\end{array}$ & $\begin{array}{l}\text { no release unless V-20 } \\
\text { also leaks } \\
\text { rupture disks still } \\
\text { available }\end{array}$ & $\begin{array}{l}\text { no release } \\
\text { level sensors will detect } \\
\text { tank level decrease }\end{array}$ \\
\hline
\end{tabular}




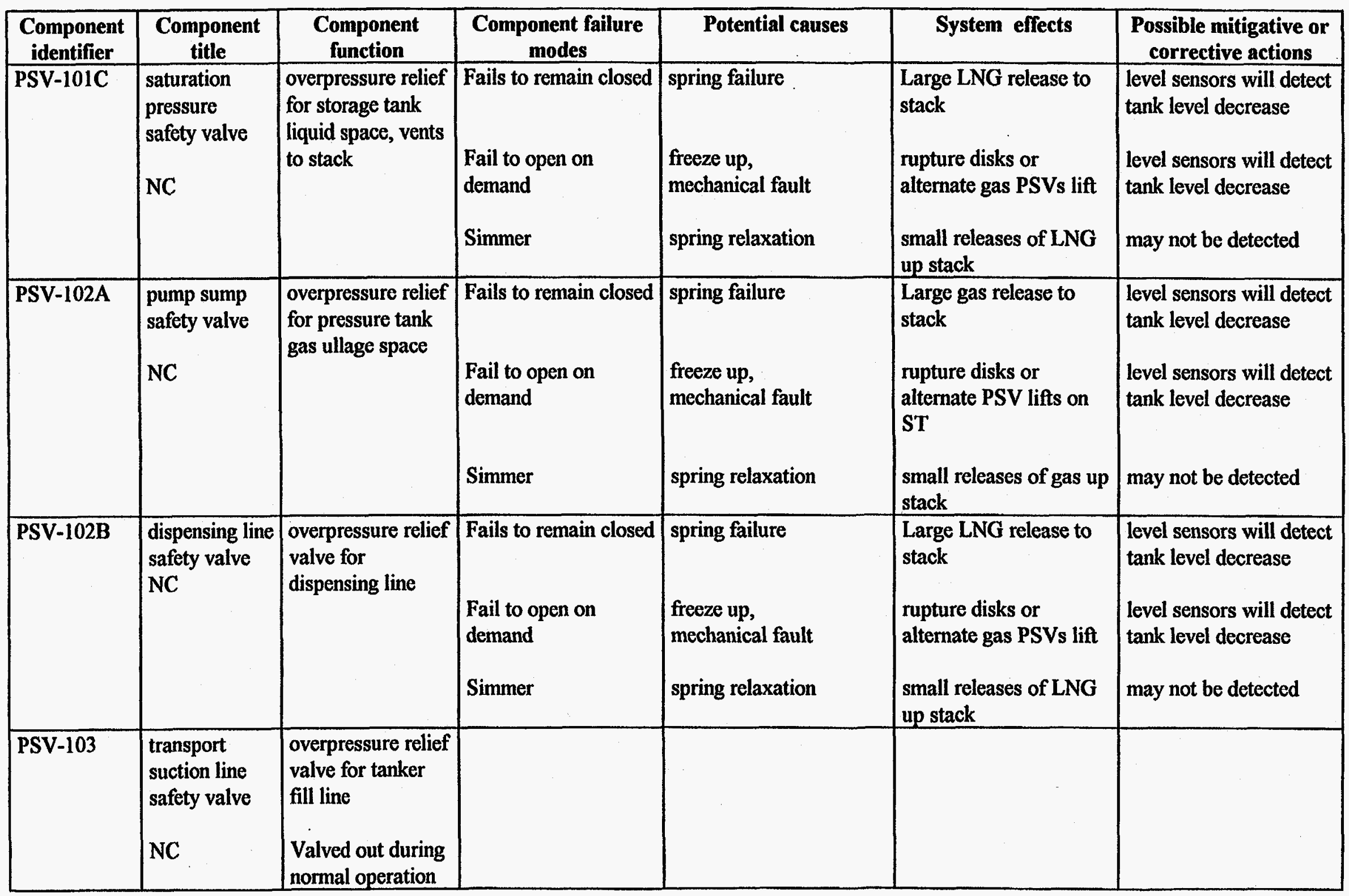




\begin{tabular}{|c|c|c|c|c|c|c|}
\hline $\begin{array}{l}\text { Component } \\
\text { identifier }\end{array}$ & $\begin{array}{c}\text { Component } \\
\text { title }\end{array}$ & \begin{tabular}{|c|}
$\begin{array}{c}\text { Component } \\
\text { function }\end{array}$ \\
\end{tabular} & $\begin{array}{c}\text { Component failure } \\
\text { modes }\end{array}$ & Potential causes & System effects & $\begin{array}{c}\text { Possible mitigative or } \\
\text { corrective actions }\end{array}$ \\
\hline PSV-104A & $\begin{array}{l}\text { top fill line } \\
\text { safety valve } \\
\text { NC }\end{array}$ & $\begin{array}{l}\text { overpressure relief } \\
\text { valve for top fill } \\
\text { line } \\
\text { Valved out during } \\
\text { normal operation }\end{array}$ & & & & \\
\hline PSV-104B & $\begin{array}{l}\text { top fill line } \\
\text { safety valve } \\
\text { NC }\end{array}$ & $\begin{array}{l}\text { overpressure relief } \\
\text { valve for V-1, V- } \\
30 \text { double block } \\
\text { on top fill line } \\
\text { Valved out during } \\
\text { normal operation } \\
\end{array}$ & & & & \\
\hline PSV-104C & $\begin{array}{l}\text { saturation } \\
\text { return line } \\
\text { safety valve } \\
\mathrm{NC}\end{array}$ & $\begin{array}{l}\text { overpressure relief } \\
\text { valve for } \\
\text { saturation gas line } \\
\text { to storage tank } \\
\text { between V-15 and } \\
\text { V-23 }\end{array}$ & $\begin{array}{l}\text { Fails to remain closed } \\
\text { Fail to open on } \\
\text { demand } \\
\text { Simmer }\end{array}$ & $\begin{array}{l}\text { spring failure } \\
\text { freeze up, } \\
\text { mechanical fault } \\
\text { spring relaxation }\end{array}$ & $\begin{array}{l}\text { Large gas release to } \\
\text { stack } \\
\text { alternate gas PSV lifts } \\
\text { small releases of gas up } \\
\text { stack }\end{array}$ & $\begin{array}{l}\text { level sensors will detect } \\
\text { tank level decrease } \\
\text { level sensors will detect } \\
\text { tank level decrease } \\
\text { may not be detected }\end{array}$ \\
\hline PSV-104D & $\begin{array}{l}\text { saturation } \\
\text { return line } \\
\text { safety valve } \\
\text { NC }\end{array}$ & $\begin{array}{l}\text { overpressure relief } \\
\text { valve for } \\
\text { saturation gas } \\
\text { return line } \\
\text { between V-15 and } \\
\text { V-23 }\end{array}$ & $\begin{array}{l}\text { Fails to remain closed } \\
\text { Fail to open on } \\
\text { demand } \\
\text { Simmer }\end{array}$ & $\begin{array}{l}\text { spring failure } \\
\text { freeze up, } \\
\text { mechanical fault } \\
\text { spring relaxation }\end{array}$ & $\begin{array}{l}\text { Large gas release to } \\
\text { stack } \\
\text { alternate gas PSV lifts } \\
\text { small releases of gas up } \\
\text { stack }\end{array}$ & $\begin{array}{l}\text { level sensors will detect } \\
\text { tank level decrease } \\
\text { level sensors will detect } \\
\text { tank level decrease } \\
\text { may not be detected }\end{array}$ \\
\hline
\end{tabular}




\begin{tabular}{|c|c|c|c|c|c|c|}
\hline $\begin{array}{l}\text { Component } \\
\text { identifier }\end{array}$ & $\begin{array}{c}\text { Component } \\
\text { title }\end{array}$ & $\begin{array}{c}\text { Component } \\
\text { function }\end{array}$ & $\begin{array}{c}\begin{array}{c}\text { Component failure } \\
\text { modes }\end{array} \\
\end{array}$ & Potential causes & System effects & $\begin{array}{c}\text { Possible mitigative or } \\
\text { corrective actions }\end{array}$ \\
\hline PSV-105B & $\begin{array}{l}\text { pump feed line } \\
\text { safety valve } \\
\text { NC }\end{array}$ & $\begin{array}{l}\text { overpressure relief } \\
\text { valve for pump } \\
\text { feed line }\end{array}$ & $\begin{array}{l}\text { Fails to remain closed } \\
\text { Fail to open on } \\
\text { demand } \\
\text { Simmer }\end{array}$ & $\begin{array}{l}\text { spring failure } \\
\text { freeze up, } \\
\text { mechanical fault } \\
\text { spring relaxation }\end{array}$ & $\begin{array}{l}\text { Large LNG release to } \\
\text { stack } \\
\text { rupture disks or } \\
\text { alternate gas PSVs lift } \\
\text { small releases of LNG } \\
\text { up stack }\end{array}$ & $\begin{array}{l}\text { level sensors will detect } \\
\text { tank level decrease } \\
\text { level sensors will detect } \\
\text { tank level decrease } \\
\text { may not be detected }\end{array}$ \\
\hline PSE-101B & $\begin{array}{l}\text { rupture disk, } \\
\text { inner vessel } \\
\mathrm{NC}\end{array}$ & $\begin{array}{l}\text { secondary path of } \\
\text { overpressure gas } \\
\text { from V-20, opens } \\
\text { to stack }\end{array}$ & $\begin{array}{l}\text { Fail to open on } \\
\text { demand }\end{array}$ & ice buildup or blockage & $\begin{array}{l}\text { alternative pressure } \\
\text { relief devices are } \\
\text { challenged }\end{array}$ & $\begin{array}{l}\text { level sensors will detect } \\
\text { tank level decrease }\end{array}$ \\
\hline
\end{tabular}




\begin{tabular}{|c|c|c|c|c|c|c|}
\hline $\begin{array}{c}\text { Component } \\
\text { identifier }\end{array}$ & $\begin{array}{c}\text { Component } \\
\text { title }\end{array}$ & $\begin{array}{c}\text { Component } \\
\text { function } \\
\end{array}$ & $\begin{array}{c}\text { Component failure } \\
\text { modes } \\
\end{array}$ & Potential causes & System effects & $\begin{array}{c}\text { Possible mitigative or } \\
\text { corrective actions }\end{array}$ \\
\hline PSE-102 & $\begin{array}{l}\text { rupture disk, } \\
\text { pump sump } \\
\text { NC }\end{array}$ & $\begin{array}{l}\text { pressure relief for } \\
\text { pressure tank }\end{array}$ & $\begin{array}{l}\text { Internal leak } \\
\text { Spuriously open } \\
\text { Fail to open on } \\
\text { demand }\end{array}$ & $\begin{array}{l}\text { flaws in metal } \\
\text { metal fatigue } \\
\text { ice buildup or } \\
\text { blockage }\end{array}$ & $\begin{array}{l}\text { small release of gas up } \\
\text { the stack } \\
\text { large release of gas up } \\
\text { the stack. } \\
\text { alternative pressure } \\
\text { relief devices are } \\
\text { challenged }\end{array}$ & $\begin{array}{l}\text { may not be detected } \\
\text { level sensors will detect } \\
\text { tank level decrease } \\
\text { level sensors will detect } \\
\text { tank level decrease }\end{array}$ \\
\hline E-101 & saturation coil & $\begin{array}{l}\text { finned heat } \\
\text { exchanger to } \\
\text { warm LNG to } \\
\text { saturated vapor to } \\
\text { replenish storage } \\
\text { tank ullage }\end{array}$ & Thermal failure & $\begin{array}{l}\text { humidity ice buildup on } \\
\text { fins retards heat transfer } \\
\text { from air }\end{array}$ & $\begin{array}{l}\text { pressurized liquid goes } \\
\text { into storage tank, not } \\
\text { enough volume makeup } \\
\text { for tank, ST pressure } \\
\text { drops boiling could } \\
\text { occur } \\
\text { leak gas/LNG to } \\
\text { environment at ground } \\
\text { level } \\
\end{array}$ & $\begin{array}{l}\text { sensors detect gas/LNG } \\
\text { release }\end{array}$ \\
\hline
\end{tabular}




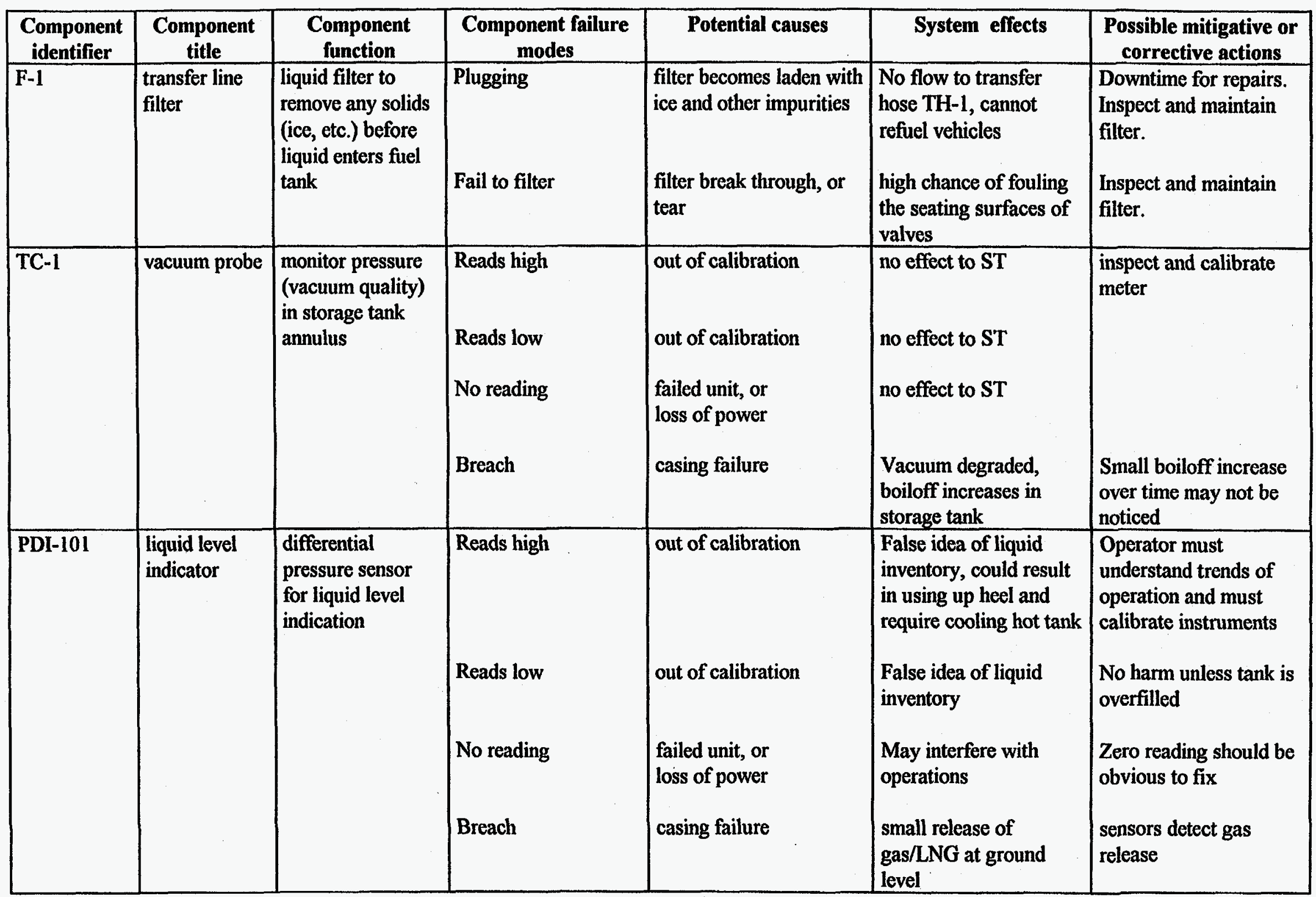




\begin{tabular}{|c|c|c|c|c|c|c|}
\hline $\begin{array}{c}\text { Component } \\
\text { identifier }\end{array}$ & $\begin{array}{c}\text { Component } \\
\text { title }\end{array}$ & $\begin{array}{c}\text { Component } \\
\text { function } \\
\end{array}$ & \begin{tabular}{|c|c|}
$\begin{array}{c}\text { Component failure } \\
\text { modes }\end{array}$ \\
\end{tabular} & Potential causes & System effects & \begin{tabular}{|c|}
$\begin{array}{c}\text { Possible mitigative or } \\
\text { corrective actions }\end{array}$ \\
\end{tabular} \\
\hline PDT-101 & $\begin{array}{l}\text { liquid level } \\
\text { transmitter }\end{array}$ & \begin{tabular}{|l} 
differential \\
pressure \\
transmitter for \\
local indication
\end{tabular} & $\begin{array}{l}\text { Low signal } \\
\text { No signal }\end{array}$ & $\begin{array}{l}\text { out of calibration } \\
\text { failed unit, or loss of } \\
\text { power }\end{array}$ & $\begin{array}{l}\text { False idea of liquid } \\
\text { inventory, could result } \\
\text { in using up heel and } \\
\text { require cooling hot tank } \\
\text { False idea of liquid } \\
\text { inventory } \\
\text { May interfere with } \\
\text { operations }\end{array}$ & $\begin{array}{l}\text { Operator must } \\
\text { understand trends of } \\
\text { operation and must } \\
\text { calibrate instruments } \\
\text { No harm unless tank is } \\
\text { overfilled } \\
\text { Zero reading should be } \\
\text { obvious to fix }\end{array}$ \\
\hline M-1 & meter & $\begin{array}{l}\text { instrument to } \\
\text { measure the } \\
\text { quantity of fluid } \\
\text { dispensed }\end{array}$ & $\begin{array}{l}\text { Plugging } \\
\text { External leak } \\
\text { Incorrect } \\
\text { measurement }\end{array}$ & $\begin{array}{l}\text { ice buildup } \\
\text { casing failure }\end{array}$ & $\begin{array}{l}\text { No flow to end use } \\
\text { vehicle tank } \\
\text { Reduced flow to end } \\
\text { use vehicle tank, recirc } \\
\text { in PT } \\
\text { False idea of liquid } \\
\text { inventory dispensed. } \\
\text { Will not agree with } \\
\text { level indication. }\end{array}$ & $\begin{array}{l}\text { Routine inspection and } \\
\text { maintenance } \\
\text { choice of meter } \\
\text { influences failure } \\
\text { frequency } \\
\text { Operators must watch } \\
\text { for these deviations }\end{array}$ \\
\hline
\end{tabular}




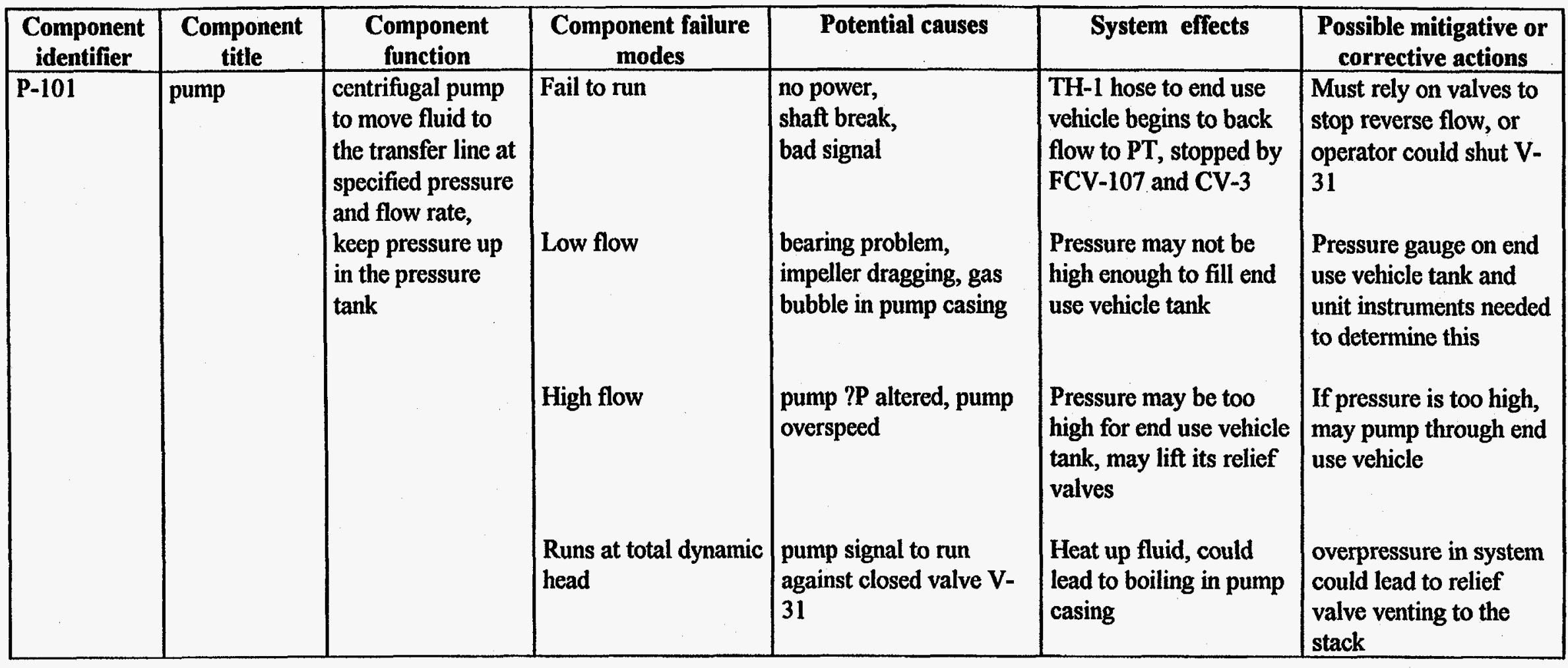




\begin{tabular}{|c|c|c|c|c|c|c|}
\hline $\begin{array}{c}\text { Component } \\
\text { identifier }\end{array}$ & $\begin{array}{c}\text { Component } \\
\text { title }\end{array}$ & $\begin{array}{c}\text { Component } \\
\text { function } \\
\end{array}$ & $\begin{array}{c}\text { Component failure } \\
\text { modes } \\
\end{array}$ & Potential causes & System effects & $\begin{array}{c}\text { Possible mitigative or } \\
\text { corrective actions }\end{array}$ \\
\hline PI-101A & $\begin{array}{l}\text { inner vessel } \\
\text { pressure } \\
\text { indicator }\end{array}$ & $\begin{array}{l}\text { instrument to } \\
\text { measure gas } \\
\text { pressure in storage } \\
\text { tank }\end{array}$ & $\begin{array}{l}\text { Reads low } \\
\text { No reading } \\
\text { Breach }\end{array}$ & $\begin{array}{l}\text { out of calibration } \\
\text { failed unit, or } \\
\text { loss of power } \\
\text { casing failure }\end{array}$ & $\begin{array}{l}\text { False idea of gas } \\
\text { pressure - hence liquid } \\
\text { inventory, could result } \\
\text { in using up heel and } \\
\text { require cooling hot tank } \\
\text { False idea of gas/liquid } \\
\text { inventory } \\
\text { May interfere with } \\
\text { operations } \\
\text { small release of } \\
\text { gas/LNG at ground } \\
\text { level }\end{array}$ & $\begin{array}{l}\text { Operator must } \\
\text { understand trends of } \\
\text { operation and must } \\
\text { calibrate instruments } \\
\text { No harm unless tank is } \\
\text { overfilled } \\
\text { Zero reading should be } \\
\text { obvious to fix } \\
\text { sensors detect gas } \\
\text { release }\end{array}$ \\
\hline PI-101B & $\begin{array}{l}\text { inner vessel } \\
\text { pressure } \\
\text { indicator }\end{array}$ & $\begin{array}{l}\text { instrument to } \\
\text { measure liquid } \\
\text { pressure in storage } \\
\text { tank }\end{array}$ & $\begin{array}{l}\text { Reads high } \\
\text { Reads low } \\
\text { No reading } \\
\text { Breach }\end{array}$ & $\begin{array}{l}\text { out of calibration } \\
\text { out of calibration } \\
\text { failed unit, or } \\
\text { loss of power } \\
\text { casing failure }\end{array}$ & $\begin{array}{l}\text { False idea of liquid } \\
\text { inventory, could result } \\
\text { in using up heel and } \\
\text { require cooling hot tank } \\
\text { False idea of liquid } \\
\text { inventory } \\
\text { May interfere with } \\
\text { operations } \\
\text { small release of LNG at } \\
\text { ground level }\end{array}$ & $\begin{array}{l}\text { Operator must } \\
\text { understand trends of } \\
\text { operation and must } \\
\text { calibrate instruments } \\
\text { No harm unless tank is } \\
\text { overfilled } \\
\text { Zero reading should be } \\
\text { obvious to fix } \\
\text { sensors detect gas } \\
\text { release }\end{array}$ \\
\hline
\end{tabular}




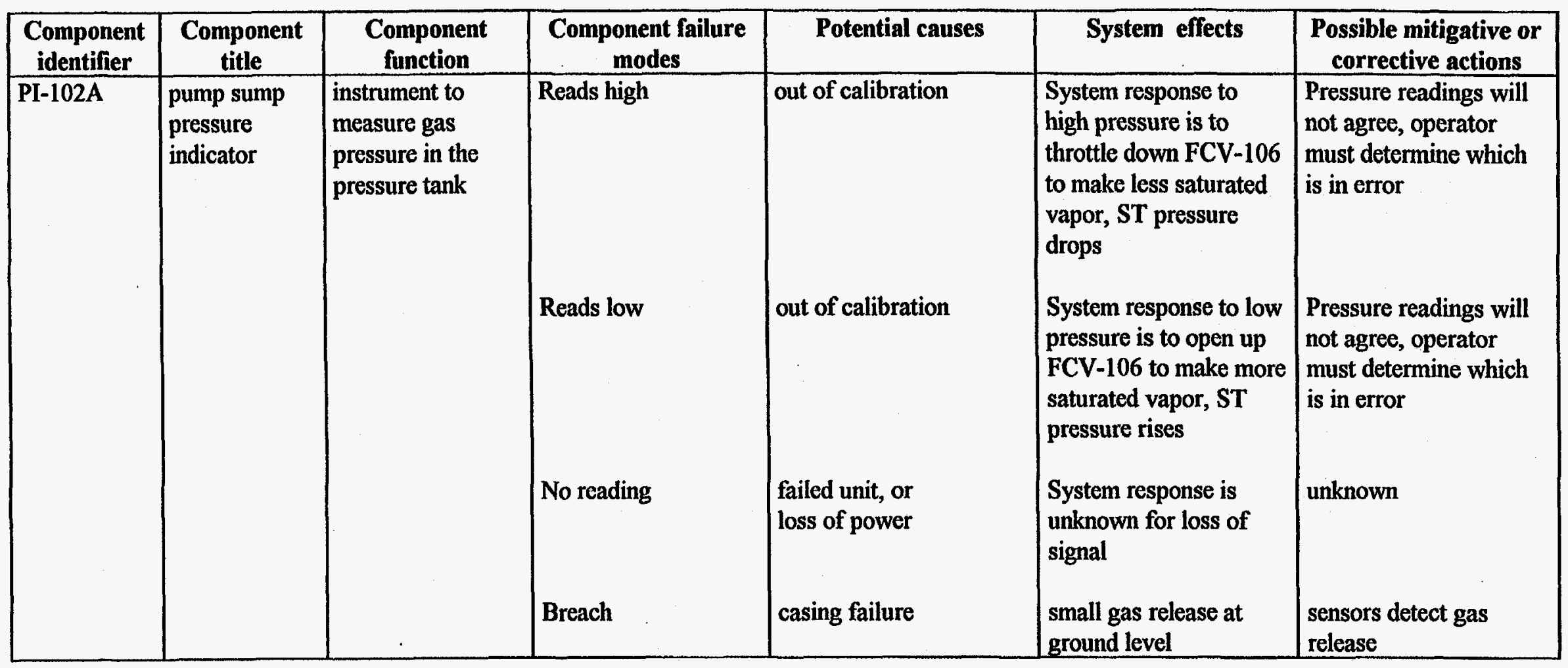




\begin{tabular}{|c|c|c|c|c|c|c|}
\hline $\begin{array}{c}\text { Component } \\
\text { identifier }\end{array}$ & $\begin{array}{c}\text { Component } \\
\text { title }\end{array}$ & $\begin{array}{c}\text { Component } \\
\text { function } \\
\end{array}$ & $\begin{array}{c}\begin{array}{c}\text { Component failure } \\
\text { modes }\end{array} \\
\end{array}$ & Potential causes & System effects & $\begin{array}{c}\text { Possible mitigative or } \\
\text { corrective actions }\end{array}$ \\
\hline PI-102B & $\begin{array}{l}\text { dispensing line } \\
\text { pressure } \\
\text { indicator }\end{array}$ & $\begin{array}{l}\text { instrument to } \\
\text { measure liquid } \\
\text { pressure in } \\
\text { transfer line }\end{array}$ & $\begin{array}{l}\text { Reads low } \\
\text { No reading } \\
\text { Breach }\end{array}$ & $\begin{array}{l}\text { out of calibration } \\
\text { failed unit, or } \\
\text { loss of power } \\
\text { casing failure }\end{array}$ & $\begin{array}{l}\text { May lead FCV-107 to } \\
\text { open while still below } \\
\text { end use vehicle tank } \\
\text { pressure. Back flow } \\
\text { into pressure tank } \\
\text { May lead FCV-107 to } \\
\text { open when greatly } \\
\text { above end use vehicle } \\
\text { tank pressure. Could } \\
\text { cause overfill of end } \\
\text { use vehicle tank. } \\
\text { FCV-107 will not open, } \\
\text { no flow to EUV } \\
\text { small release of LNG at } \\
\text { ground level }\end{array}$ & $\begin{array}{l}\text { No harm unless end use } \\
\text { vehicle tank is } \\
\text { overfilled } \\
\text { Zero reading should be } \\
\text { obvious to fix } \\
\text { sensors detect gas } \\
\text { release }\end{array}$ \\
\hline PT-101A & $\begin{array}{l}\text { inner vessel } \\
\text { pressure } \\
\text { transmitter }\end{array}$ & $\begin{array}{l}\text { pressure } \\
\text { transmitter for gas } \\
\text { pressure from } \\
\text { storage tank }\end{array}$ & $\begin{array}{l}\text { Low signal } \\
\text { No signal }\end{array}$ & $\begin{array}{l}\text { out of calibration } \\
\text { failed unit, or loss of } \\
\text { power }\end{array}$ & $\begin{array}{l}\text { False idea of liquid } \\
\text { inventory, could result } \\
\text { in using up heel and } \\
\text { require cooling hot tank } \\
\text { False idea of liquid } \\
\text { inventory } \\
\text { May interfere with } \\
\text { operations }\end{array}$ & $\begin{array}{l}\text { Operator must } \\
\text { understand trends of } \\
\text { operation and must } \\
\text { calibrate instruments } \\
\text { No harm unless tank is } \\
\text { overfilled } \\
\text { Zero reading should be } \\
\text { obvious to fix }\end{array}$ \\
\hline
\end{tabular}




\begin{tabular}{|c|c|c|c|c|c|c|}
\hline $\begin{array}{c}\text { Component } \\
\text { identifier }\end{array}$ & $\begin{array}{c}\text { Component } \\
\text { title }\end{array}$ & $\begin{array}{c}\text { Component } \\
\text { function }\end{array}$ & $\begin{array}{c}\text { Component failure } \\
\text { modes } \\
\end{array}$ & Potential causes & System effects & $\begin{array}{c}\text { Possible mitigative or } \\
\text { corrective actions }\end{array}$ \\
\hline TT-102 & $\begin{array}{l}\text { temperature } \\
\text { sensor }\end{array}$ & $\begin{array}{l}\text { temperature } \\
\text { sensor for gas } \\
\text { ullage in the } \\
\text { pressure tank, } \\
\text { with T and P } \\
\text { known, operators } \\
\text { can define the } \\
\text { thermodynamic } \\
\text { state of LNG } \\
\end{array}$ & $\begin{array}{l}\text { High signal } \\
\text { Low signal } \\
\text { No signal }\end{array}$ & $\begin{array}{l}\text { out of calibration } \\
\text { failed unit, or loss of } \\
\text { power }\end{array}$ & $\begin{array}{l}\text { False idea of state of } \\
\text { LNG } \\
\text { False idea of state of } \\
\text { LNG } \\
\text { May interfere with } \\
\text { operations }\end{array}$ & $\begin{array}{l}\text { LNG could be okay or } \\
\text { subcooling } \\
\text { LNG could be okay or } \\
\text { warming } \\
\text { Zero reading should be } \\
\text { obvious to fix }\end{array}$ \\
\hline TH-1 & $\begin{array}{l}\text { metal braided } \\
\text { transfer hose }\end{array}$ & $\begin{array}{l}\text { flexible hose to } \\
\text { connect to end use } \\
\text { vehicle for } \\
\text { refueling }\end{array}$ & $\begin{array}{l}\text { Plugging } \\
\text { External leak } \\
\text { Incomplete seal }\end{array}$ & $\begin{array}{l}\text { ice or hydrates built up } \\
\text { wear, abrasion } \\
\text { foreign material } \\
\text { intrusion, operator error }\end{array}$ & $\begin{array}{l}\text { No flow to end use } \\
\text { vehicle } \\
\text { small LNG release at } \\
\text { ground level } \\
\text { small or large LNG } \\
\text { release at ground level }\end{array}$ & $\begin{array}{l}\text { Operator should notice } \\
\text { degraded flow } \\
\text { Inspect and maintain } \\
\text { equipment } \\
\text { Inspect and maintain } \\
\text { equipment }\end{array}$ \\
\hline FC-1 & $\begin{array}{l}\text { top fill } \\
\text { connection } \\
\mathrm{NC}\end{array}$ & $\begin{array}{l}\text { connector for tank } \\
\text { truck to fill } \\
\text { storage tank } \\
\text { Not used in this } \\
\text { mode of operation }\end{array}$ & & & & \\
\hline
\end{tabular}




\begin{tabular}{|c|c|c|c|c|c|c|}
\hline $\begin{array}{l}\text { Component } \\
\text { identifier }\end{array}$ & $\begin{array}{c}\text { Component } \\
\text { title } \\
\end{array}$ & $\begin{array}{c}\begin{array}{c}\text { Component } \\
\text { function }\end{array} \\
\end{array}$ & $\begin{array}{c}\text { Component failure } \\
\text { modes }\end{array}$ & Potential causes & System effects & $\begin{array}{l}\text { Possible mitigative or } \\
\text { corrective actions }\end{array}$ \\
\hline$\overline{F C-2}$ & $\begin{array}{l}\text { vehicle fill } \\
\text { connection } \\
\text { NC }\end{array}$ & $\begin{array}{l}\text { connector at end } \\
\text { of TH-1 to } \\
\text { connect to end use } \\
\text { vehicle }\end{array}$ & $\begin{array}{l}\text { Incomplete seal } \\
\text { Fail to seal } \\
\text { Fail to detach }\end{array}$ & $\begin{array}{l}\text { ice or hydrates built up, } \\
\text { foreign material } \\
\text { intrusion, operator error } \\
\text { mechanical failure } \\
\text { mechanical failure, } \\
\text { jammed }\end{array}$ & $\begin{array}{l}\text { small or large LNG } \\
\text { release at ground level } \\
\text { Cannot fill end use } \\
\text { vehicle tank } \\
\text { Stops operation, cannot } \\
\text { fuel other vehicles }\end{array}$ & $\begin{array}{l}\text { Inspect and maintain } \\
\text { equipment } \\
\text { Inspect and maintain } \\
\text { equipment } \\
\text { Inspect and maintain } \\
\text { equipment }\end{array}$ \\
\hline FC-3 & $\begin{array}{l}\text { transport } \\
\text { return } \\
\text { connection } \\
\mathrm{NC}\end{array}$ & $\begin{array}{l}\text { gas return to the } \\
\text { ullage of the tank } \\
\text { truck when } \\
\text { refueling the } \\
\text { storage tank } \\
\text { Not used in this } \\
\text { mode of operation }\end{array}$ & & & & \\
\hline FC-4 & $\begin{array}{l}\text { transport } \\
\text { suction } \\
\text { connection } \\
\text { NC }\end{array}$ & $\begin{array}{l}\text { liquid input for } \\
\text { bottom filling the } \\
\text { storage tank from } \\
\text { tank truck } \\
\text { Not used in this } \\
\text { mode of operation }\end{array}$ & & & & \\
\hline $\mathrm{C}-1$ & $\begin{array}{l}\text { sample } \\
\text { cylinder } \\
\text { connection } \\
\mathrm{NC}\end{array}$ & $\begin{array}{l}\text { connection to take } \\
\text { fuel samples to } \\
\text { test for impurities }\end{array}$ & $\begin{array}{l}\text { Incomplete seal } \\
\text { Fail to seal } \\
\text { Fail to detach }\end{array}$ & $\begin{array}{l}\text { foreign material } \\
\text { intrusion (dirt), operator } \\
\text { error } \\
\text { mechanical failure } \\
\text { mechanical failure, } \\
\text { jammed }\end{array}$ & $\begin{array}{l}\text { small LNG release at } \\
\text { ground level } \\
\text { Cannot take LNG } \\
\text { sample } \\
\text { Cannot remove sample }\end{array}$ & $\begin{array}{l}\text { Inspect and maintain } \\
\text { equipment } \\
\text { Inspect and maintain } \\
\text { equipment } \\
\text { Inspect and maintain } \\
\text { equipment }\end{array}$ \\
\hline
\end{tabular}




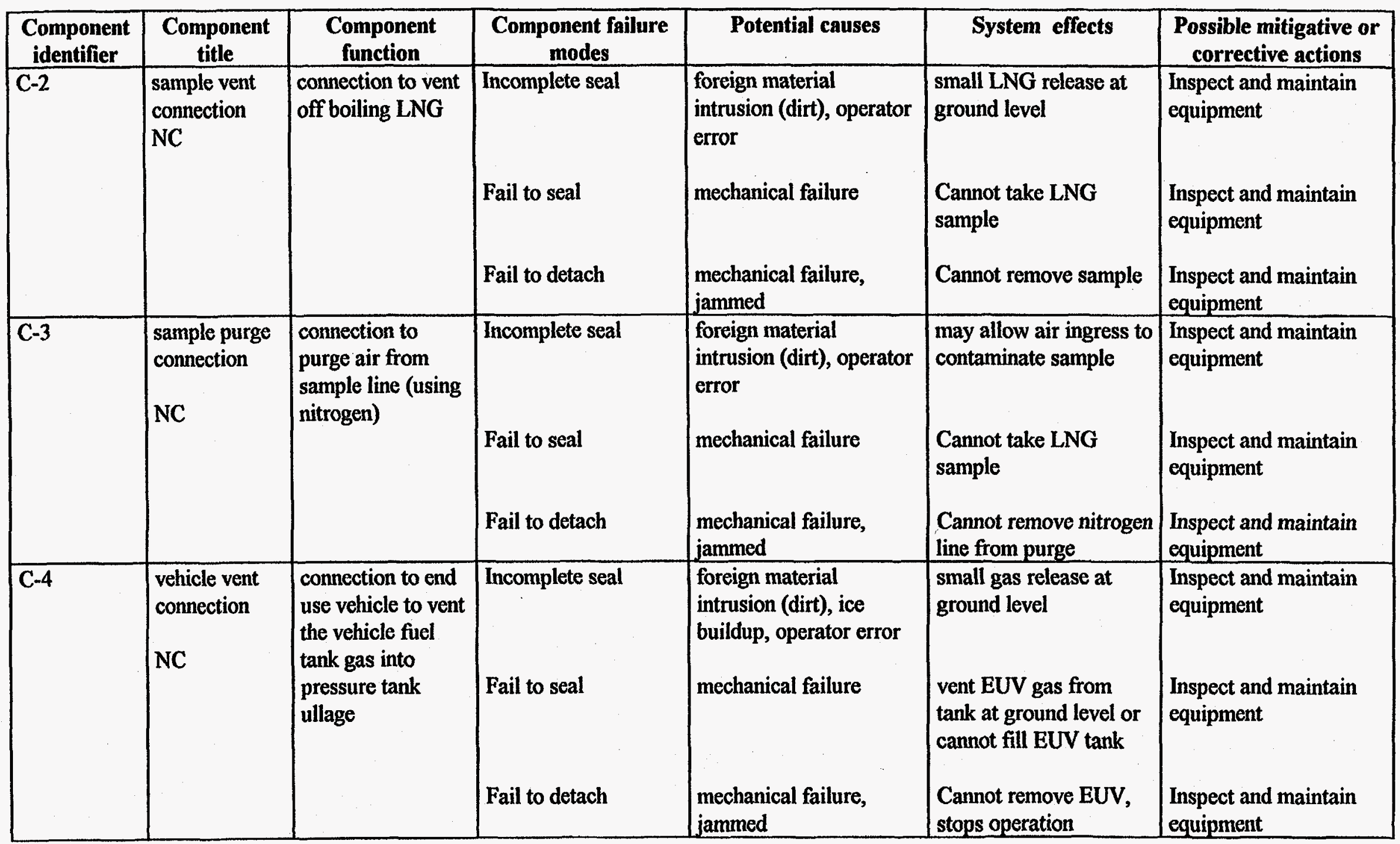




\begin{tabular}{|c|c|c|c|c|c|c|}
\hline $\begin{array}{l}\text { Component } \\
\text { identifier }\end{array}$ & $\begin{array}{c}\text { Component } \\
\text { title }\end{array}$ & $\begin{array}{c}\text { Component } \\
\text { function } \\
\end{array}$ & $\begin{array}{c}\text { Component failure } \\
\text { modes } \\
\end{array}$ & Potential causes & System effects & $\begin{array}{c}\text { Possible mitigative or } \\
\text { corrective actions }\end{array}$ \\
\hline C-5 & $\begin{array}{l}\text { N2 purge } \\
\text { connection } \\
\mathrm{NC}\end{array}$ & $\begin{array}{l}\text { connection to } \\
\text { sweep nitrogen } \\
\text { gas when purging } \\
\text { tank of } \\
\text { condensables }\end{array}$ & $\begin{array}{l}\text { Fail to seal } \\
\text { Fail to detach }\end{array}$ & $\begin{array}{l}\text { foreign material } \\
\text { intrusion (dirt), operator } \\
\text { error } \\
\text { mechanical failure } \\
\text { mechanical failure, } \\
\text { jammed }\end{array}$ & $\begin{array}{l}\text { small LNG release at } \\
\text { ground level } \\
\text { Cannot take LNG } \\
\text { sample } \\
\text { Cannot remove sample }\end{array}$ & $\begin{array}{l}\text { Inspect and maintain } \\
\text { equipment } \\
\text { Inspect and maintain } \\
\text { equipment }\end{array}$ \\
\hline $\begin{array}{l}\text { PT } \\
\text { (assumed) }\end{array}$ & pressure tank & $\begin{array}{l}\text { vacuum insulated } \\
\text { tank, houses } \\
\text { transfer pump for } \\
\text { LNG transfer }\end{array}$ & $\begin{array}{l}\text { Outer wall leak } \\
\text { Outer wall failure } \\
\text { Inner wall leak } \\
\text { Inner wall failure }\end{array}$ & $\begin{array}{l}\text { fatigue crack, } \\
\text { weld flaw } \\
\text { large crack or weld } \\
\text { failure } \\
\text { fatigue crack, } \\
\text { weld flaw } \\
\text { large crack or weld } \\
\text { failure } \\
\end{array}$ & $\begin{array}{l}\text { air admission, LNG } \\
\text { boiloff rate is high } \\
\text { air admission, LNG } \\
\text { boils } \\
\text { gas admission to } \\
\text { annulus, LNG boiloff } \\
\text { rate increases } \\
\text { gas admission to } \\
\text { annulus, LNG boils }\end{array}$ & $\begin{array}{l}\text { venting to storage tank } \\
\text { is high } \\
\text { overpressure relief } \\
\text { valves } \\
\text { venting to storage tank } \\
\text { is high } \\
\text { overpressure relief } \\
\text { valves }\end{array}$ \\
\hline $\begin{array}{l}\text { ST } \\
\text { (assumed) }\end{array}$ & storage tank & $\begin{array}{l}\text { vacuum insulated } \\
\text { tank, contains } \\
\text { LNG for storage } \\
\text { until dispensed to } \\
\text { end use vehicles }\end{array}$ & $\begin{array}{l}\text { Outer wall failure } \\
\text { Inner wall leak } \\
\text { Inner wall failure }\end{array}$ & $\begin{array}{l}\text { fatigue crack, } \\
\text { weld flaw } \\
\text { large crack or weld } \\
\text { failure } \\
\text { fatigue crack, } \\
\text { weld flaw } \\
\text { large crack or weld } \\
\text { failure }\end{array}$ & $\begin{array}{l}\text { air admission, LNG } \\
\text { boiloff rate is high } \\
\text { air admission, LNG } \\
\text { boils } \\
\text { gas admission to } \\
\text { annulus, LNG boiloff } \\
\text { rate increases } \\
\text { gas admission to } \\
\text { annulus, LNG boils }\end{array}$ & $\begin{array}{l}\text { venting to storage tank } \\
\text { is high } \\
\text { overpressure relief } \\
\text { valves } \\
\text { venting to storage tank } \\
\text { is high }\end{array}$ \\
\hline
\end{tabular}




\begin{tabular}{|c|c|c|c|c|c|c|}
\hline $\begin{array}{c}\text { Component } \\
\text { identifier }\end{array}$ & $\begin{array}{c}\text { Component } \\
\text { title } \\
\end{array}$ & $\begin{array}{c}\text { Component } \\
\text { function } \\
\end{array}$ & $\begin{array}{c}\begin{array}{c}\text { Component failure } \\
\text { modes }\end{array} \\
\end{array}$ & Potential causes & System effects & $\begin{array}{c}\text { Possible mitigative or } \\
\text { corrective actions }\end{array}$ \\
\hline
\end{tabular}




\begin{tabular}{|c|c|c|c|c|c|c|}
\hline $\begin{array}{c}\text { Component } \\
\text { identifier }\end{array}$ & $\begin{array}{c}\text { Component } \\
\text { title }\end{array}$ & $\begin{array}{c}\text { Component } \\
\text { function } \\
\end{array}$ & $\begin{array}{c}\text { Component failure } \\
\text { modes } \\
\end{array}$ & Potential causes & System effects & $\begin{array}{c}\text { Possible mitigative or } \\
\text { corrective actions }\end{array}$ \\
\hline other piping & $\begin{array}{l}\text { assumed } \\
\text { designator }\end{array}$ & $\begin{array}{l}\text { piping for } \\
\text { instruments, relief } \\
\text { valves, and for gas } \\
\text { flow }\end{array}$ & $\begin{array}{l}\text { Rupture } \\
\text { Plugging }\end{array}$ & $\begin{array}{l}\text { fatigue crack, } \\
\text { weld flaw } \\
\text { large crack or weld } \\
\text { failure } \\
\text { foreign material, } \\
\text { hydrates, ice, etc. }\end{array}$ & $\begin{array}{l}\text { gas release at ground } \\
\text { level } \\
\text { large gas release at } \\
\text { ground level } \\
\text { no flow, valves or } \\
\text { instruments may be } \\
\text { isolated }\end{array}$ & $\begin{array}{l}\text { sensors detect gas } \\
\text { release } \\
\text { sensors detect gas } \\
\text { release } \\
\text { Disrupts operation, } \\
\text { must repair. Inspect } \\
\text { and maintain system. }\end{array}$ \\
\hline
\end{tabular}




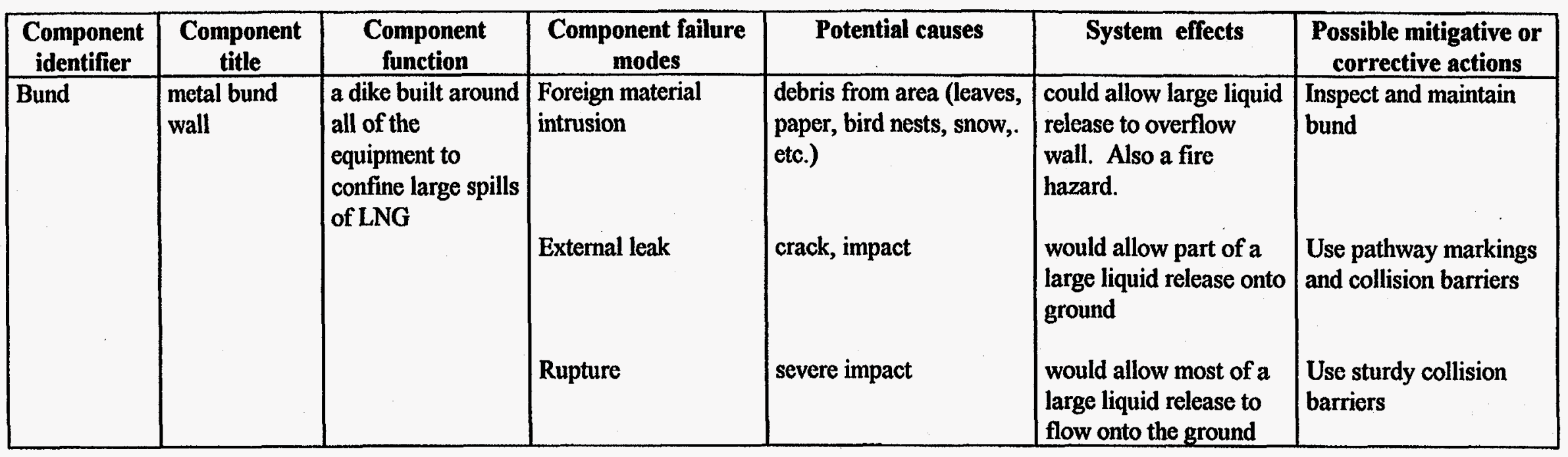

Note: EUV is end use vehicle

ST is storage tank

PT is pressure tank that houses the pump and meter 
Appendix B - Fault Trees for Initiating Events

B-1 

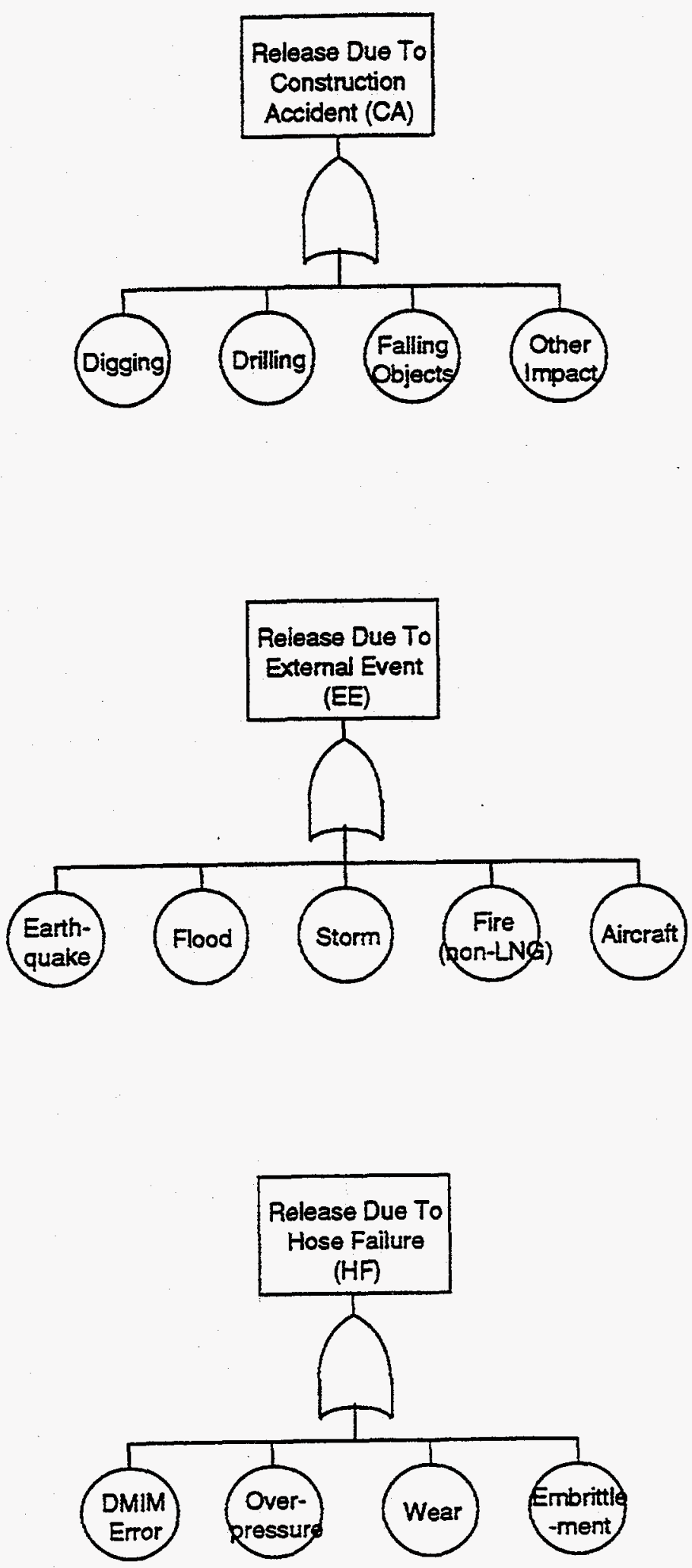


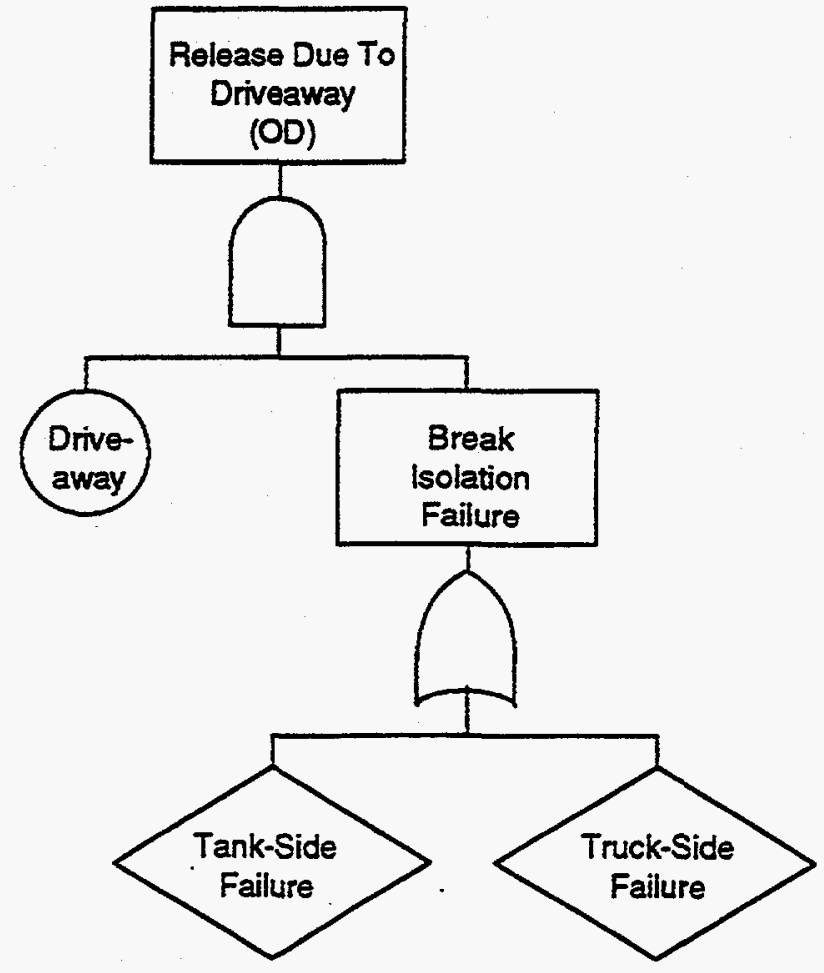



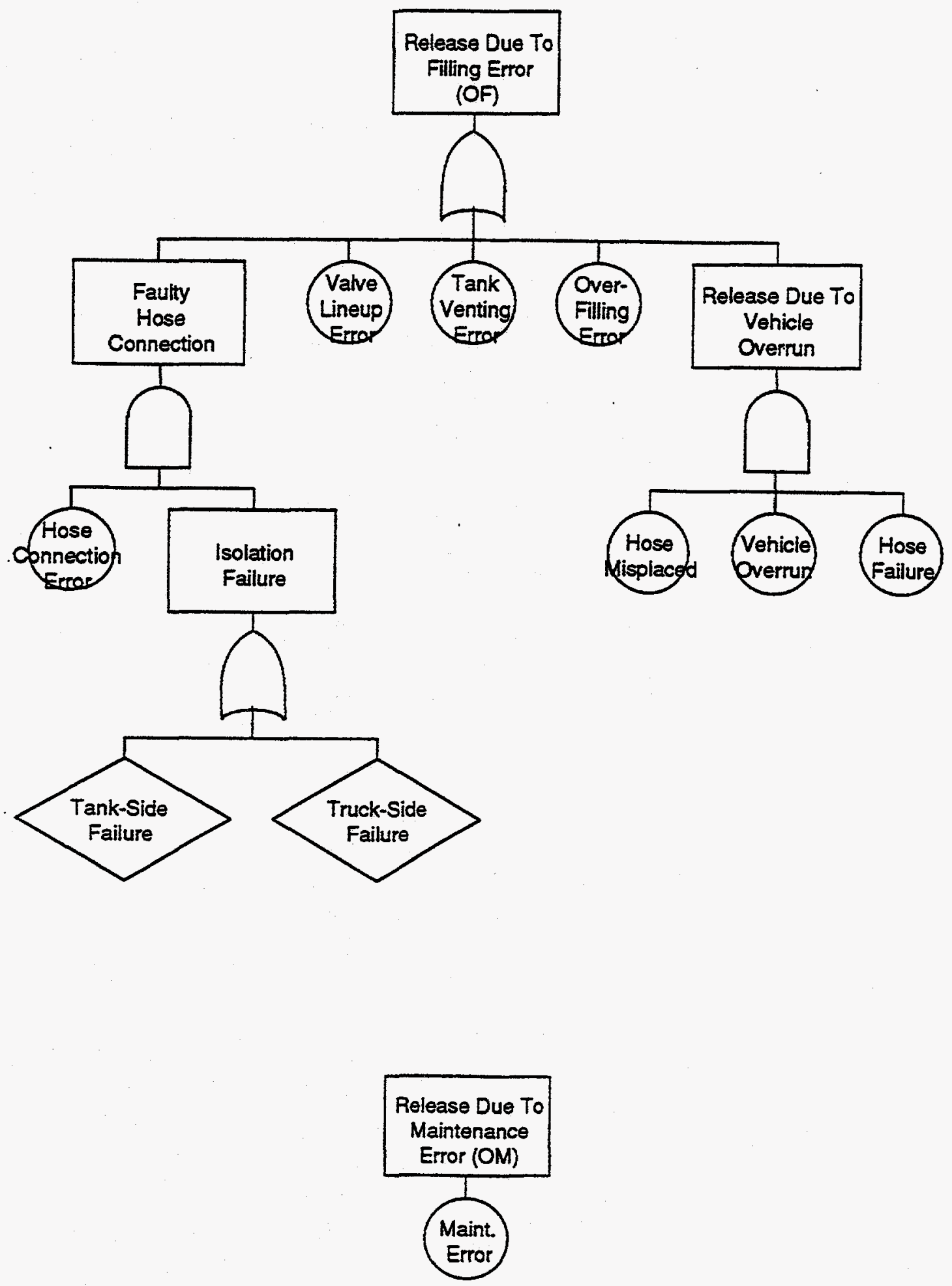

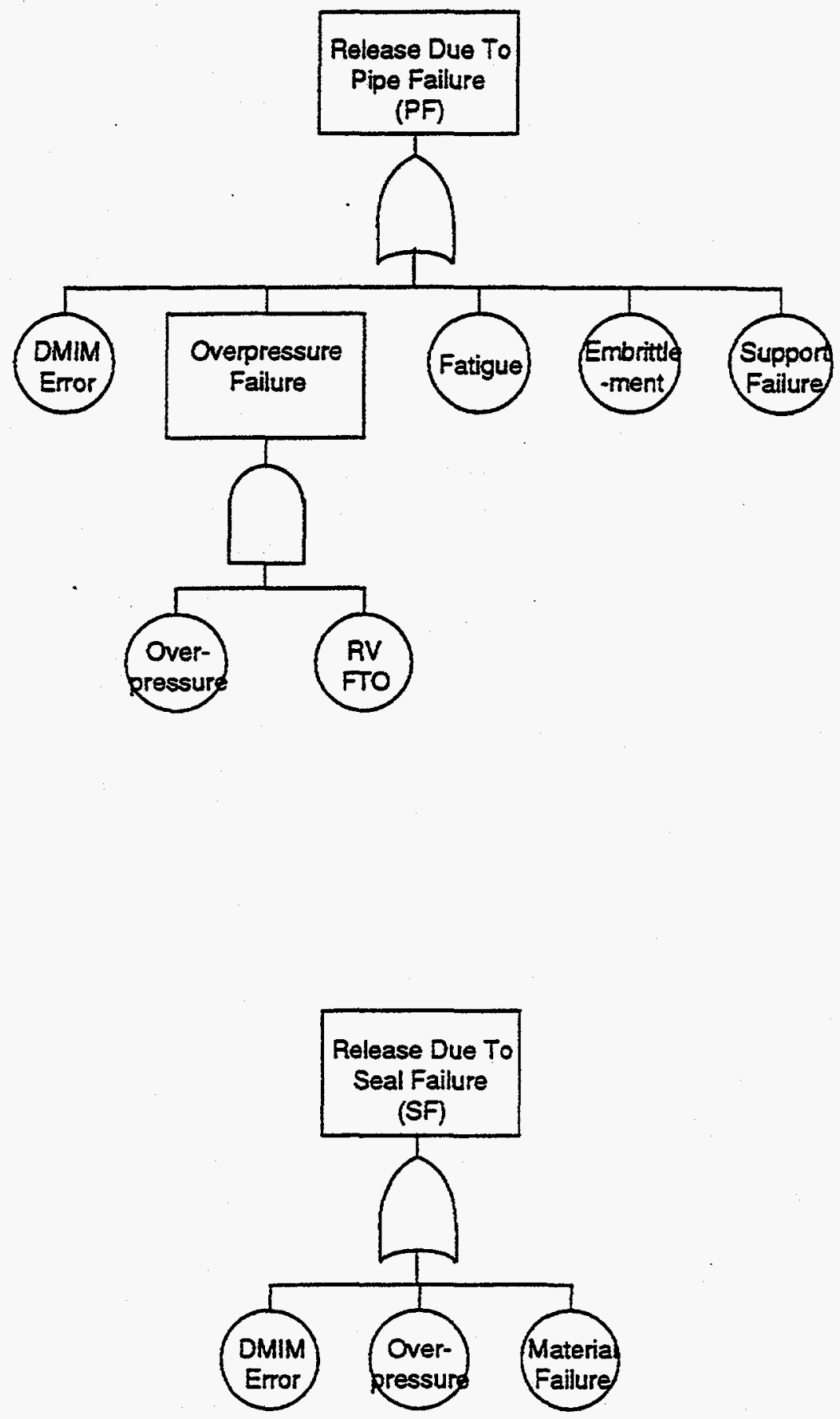

B-5 

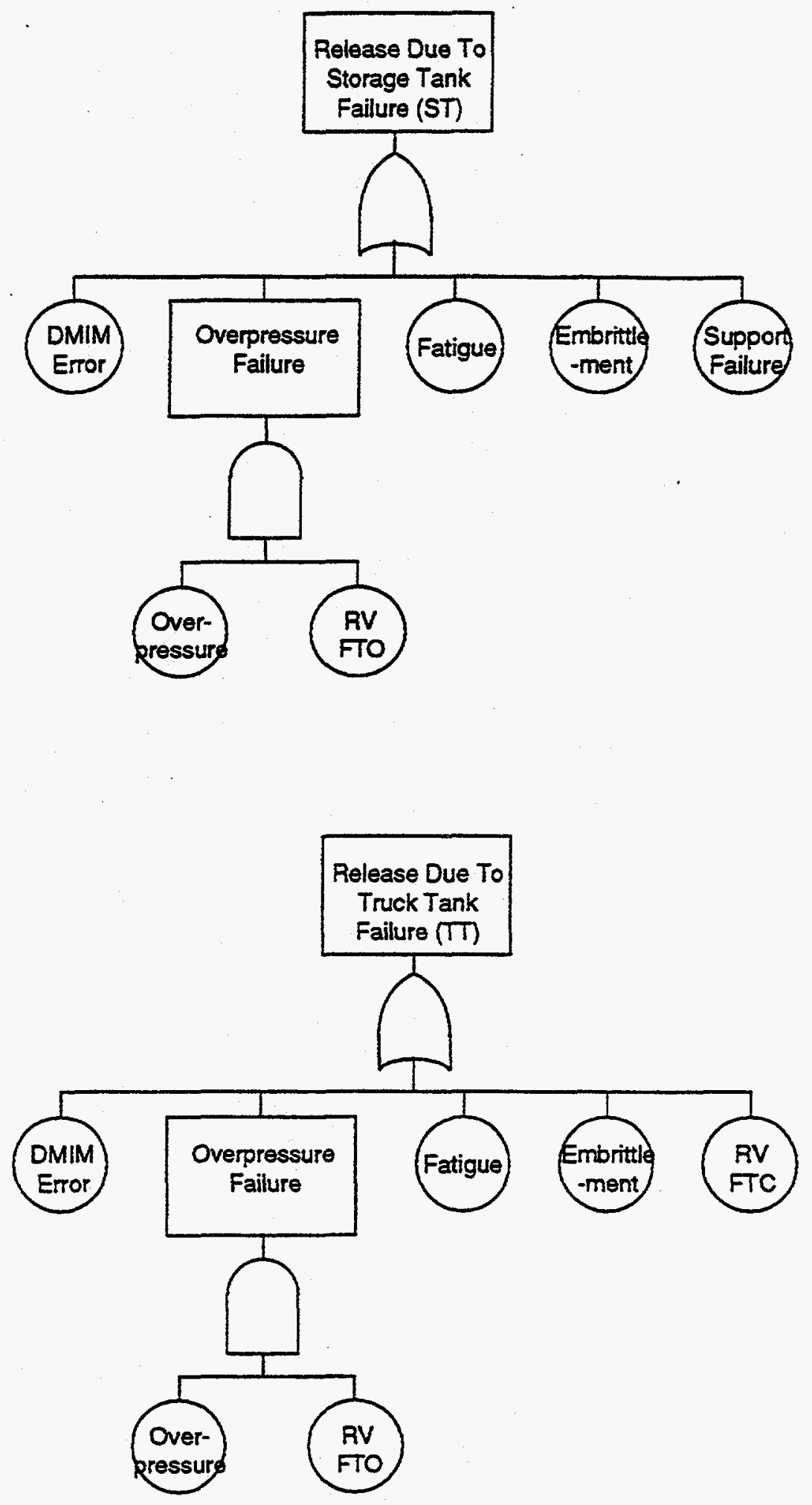

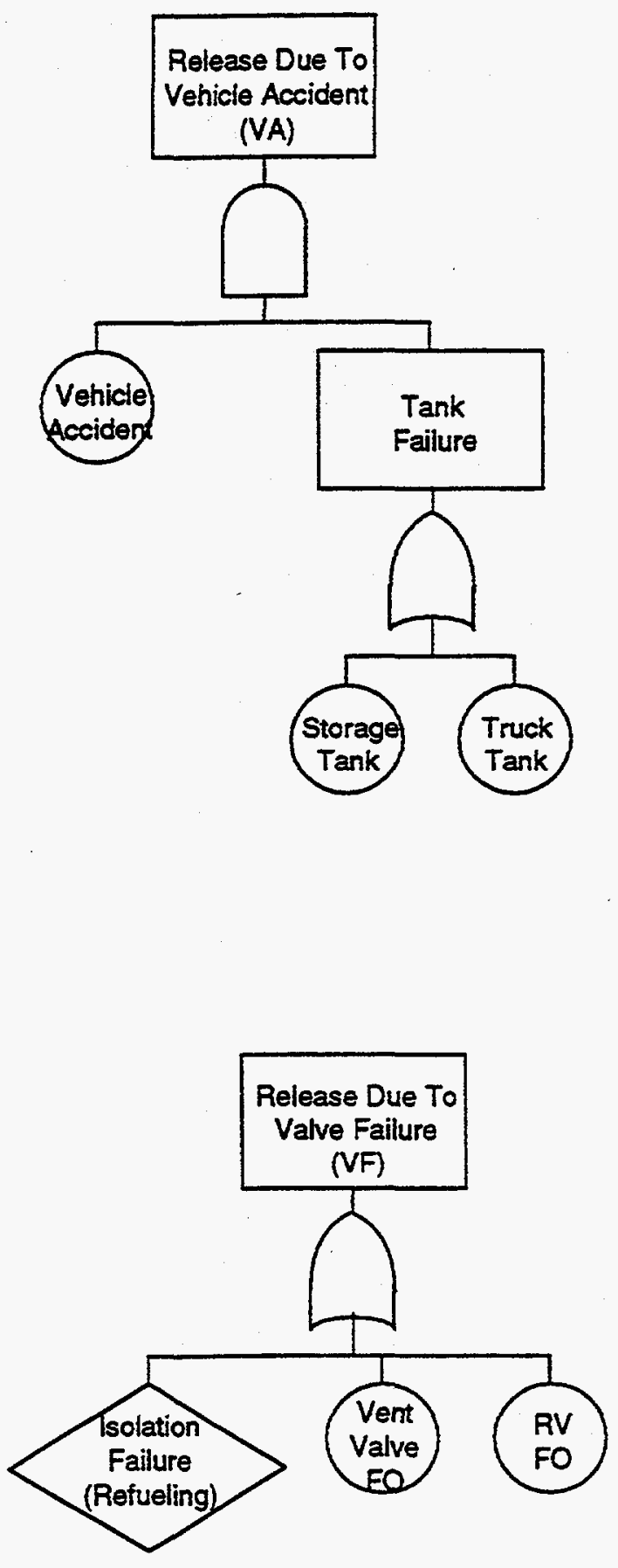
Appendix C - Event Trees for Refueling Station Qualitative Risk Assessment 


\section{Event Tree \\ Construction Accident - Isolable Release}

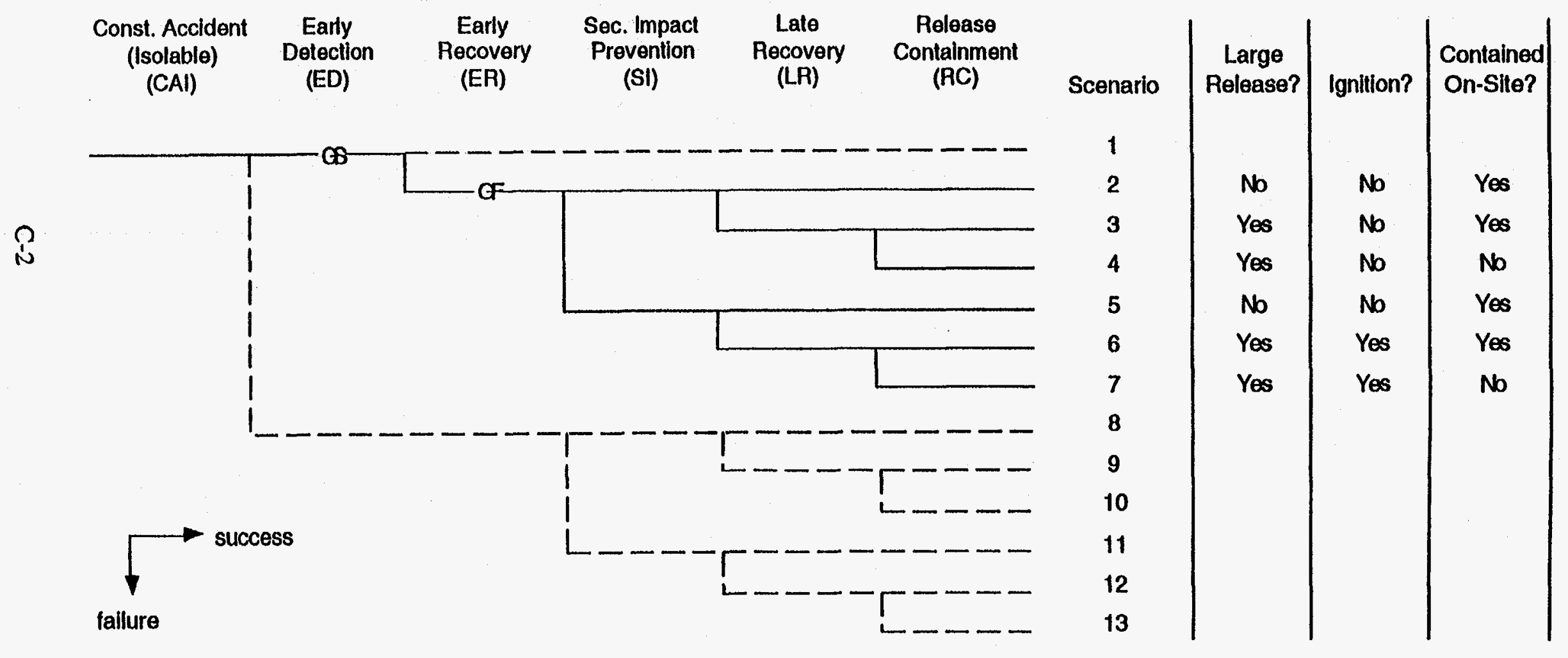




\section{Event Tree \\ Construction Accident - Unisolable Release}

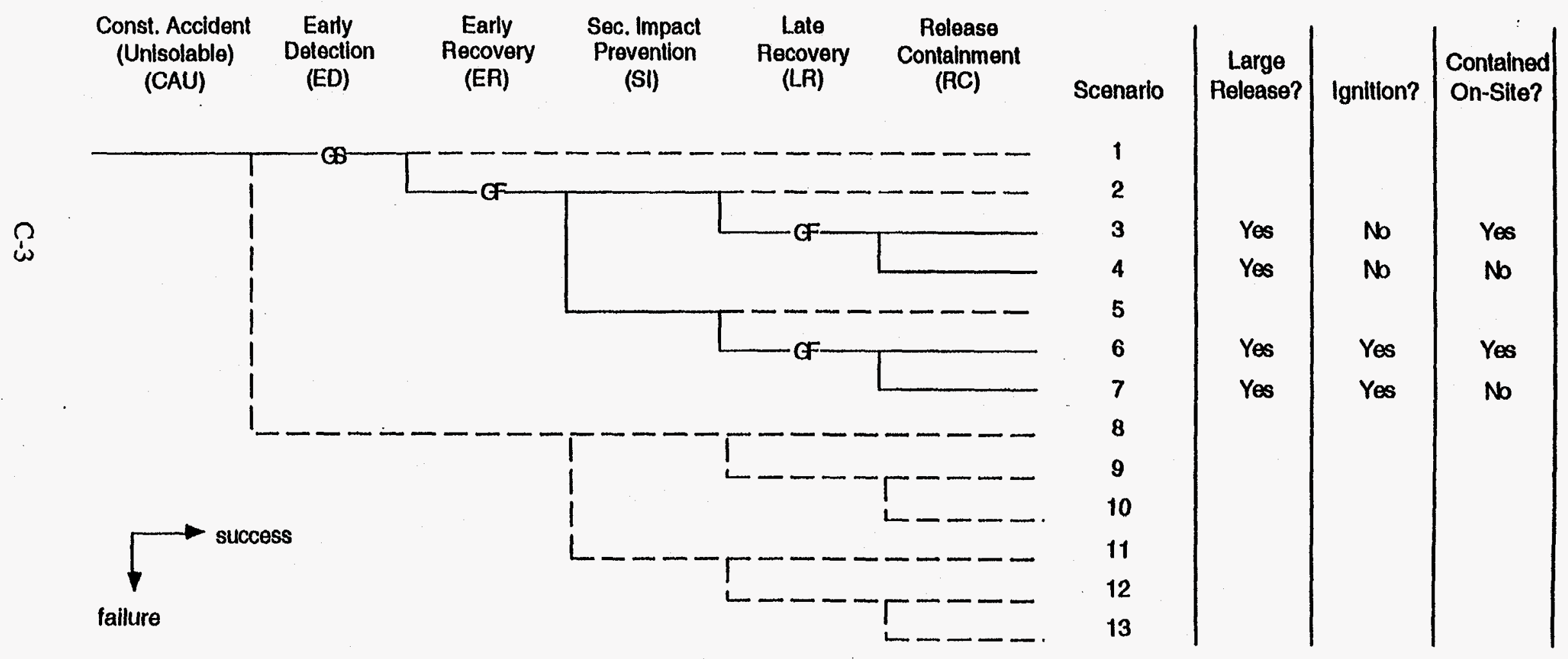




\section{Event Tree \\ External Events}

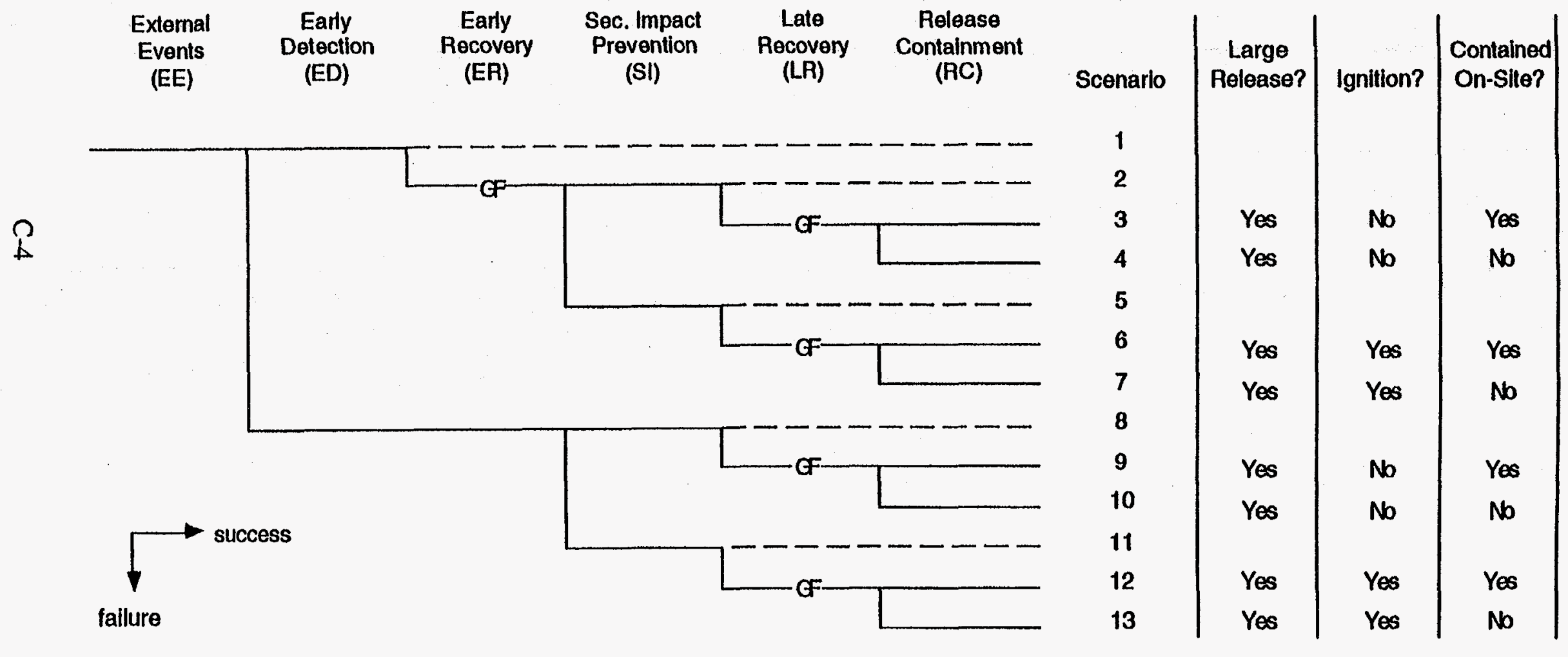




\section{Event Tree \\ Hose Failure}

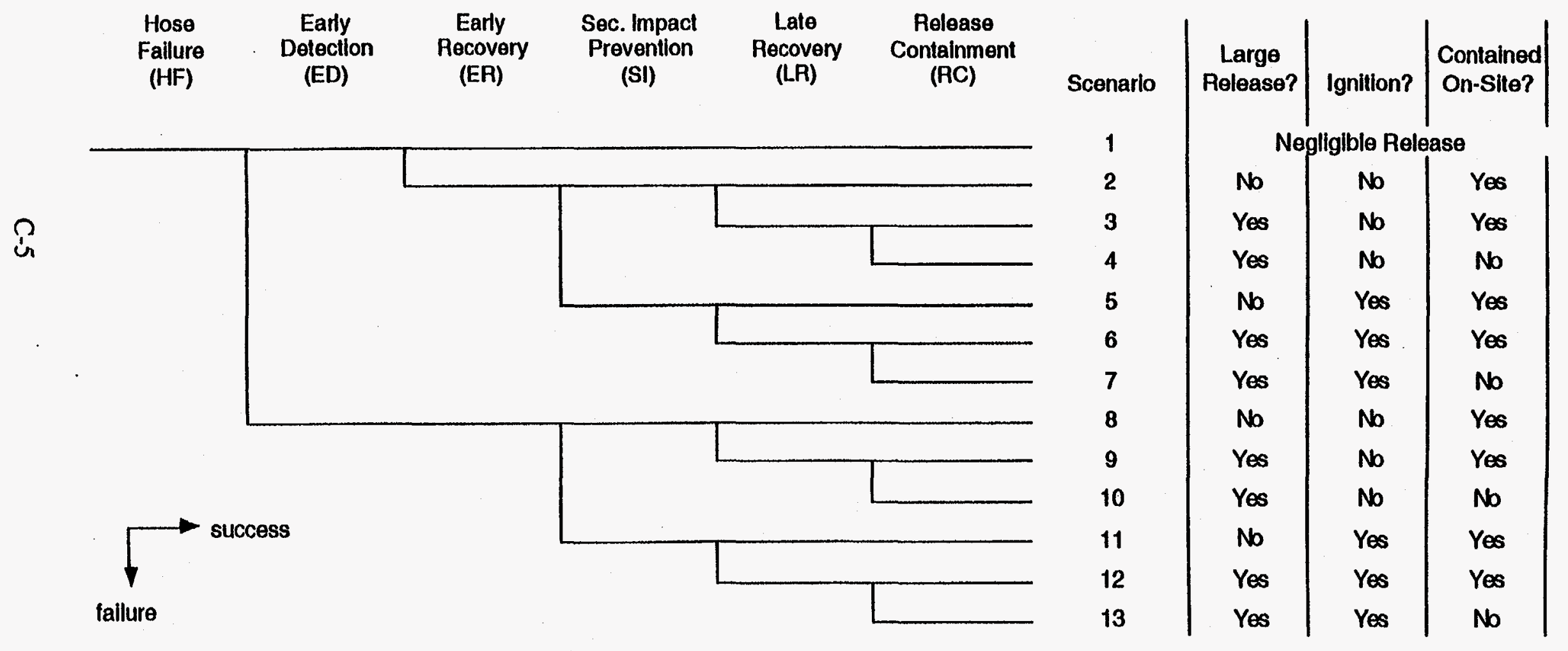




\section{Event Tree Driveaway}

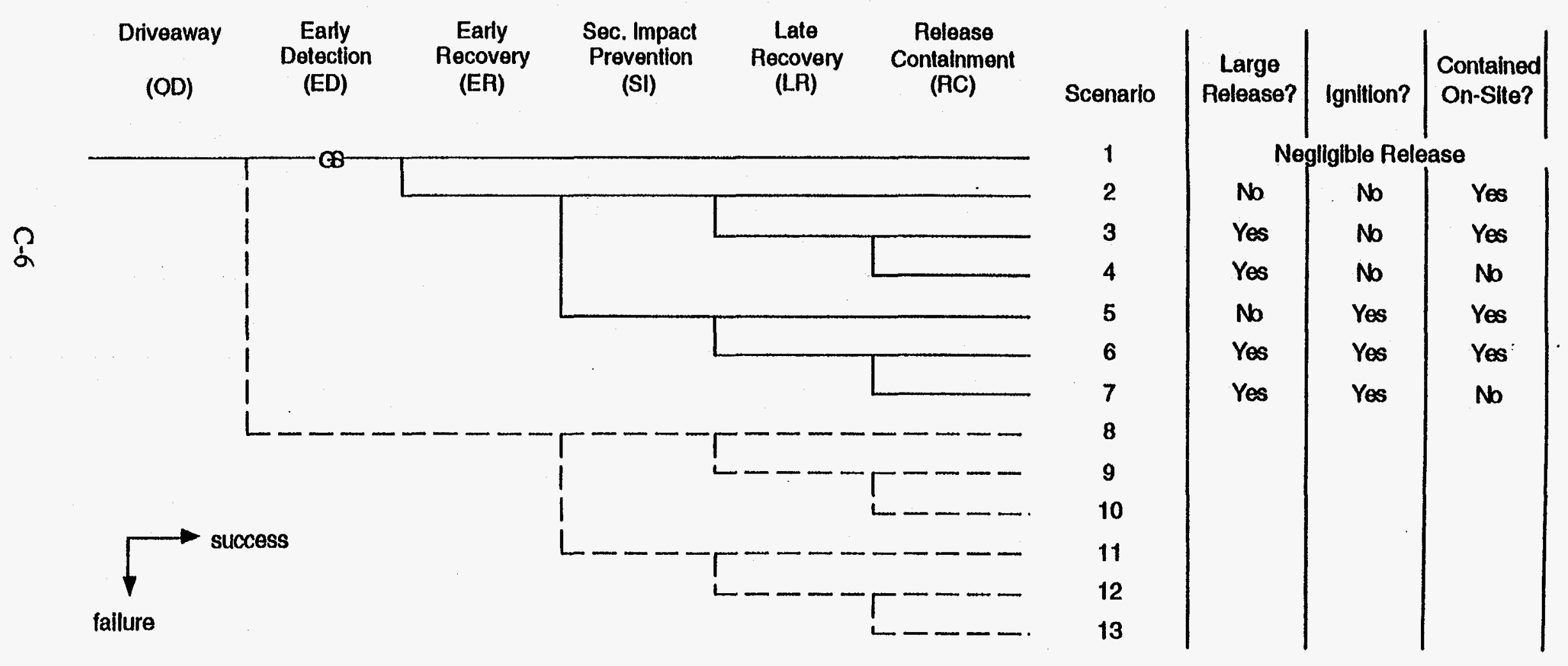




\section{Event Tree \\ Tank Filling Error}

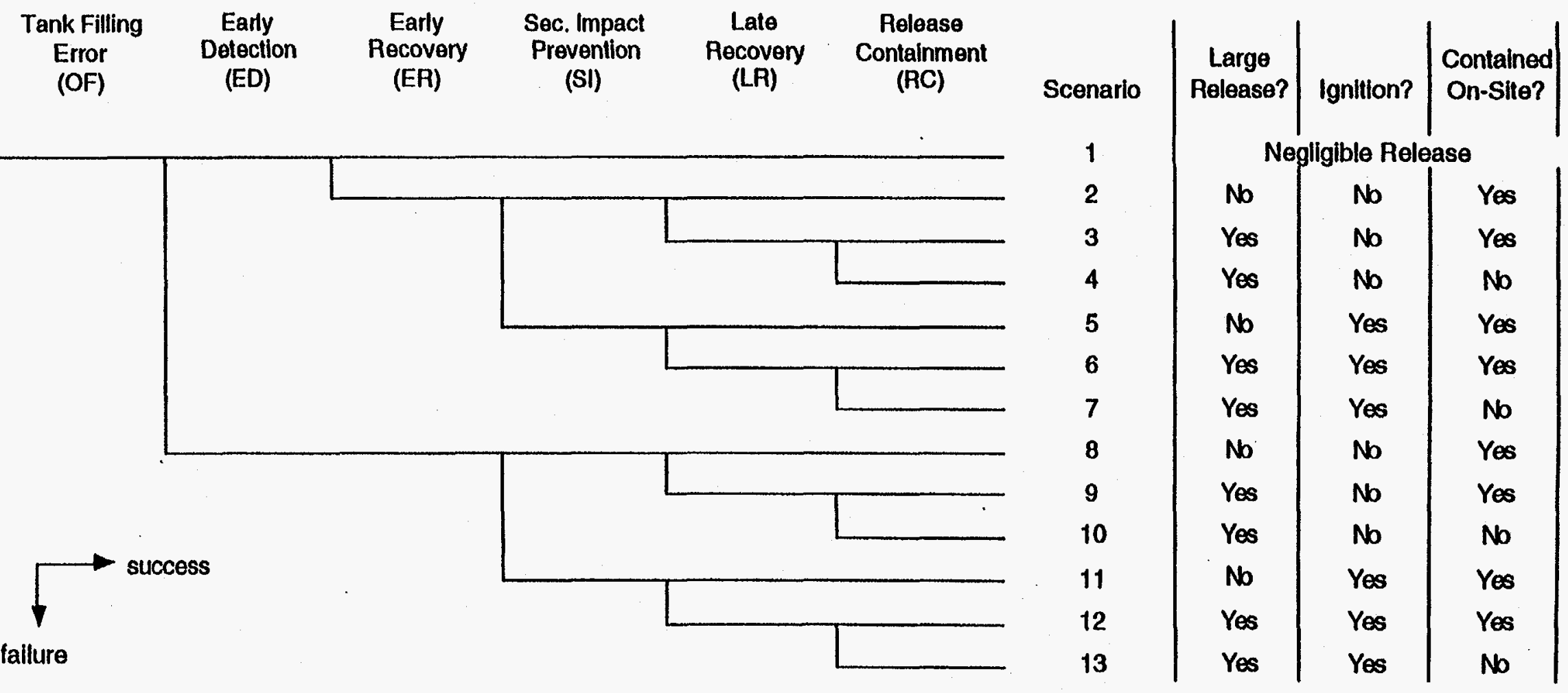




\section{Event Tree \\ Maintenance Error}

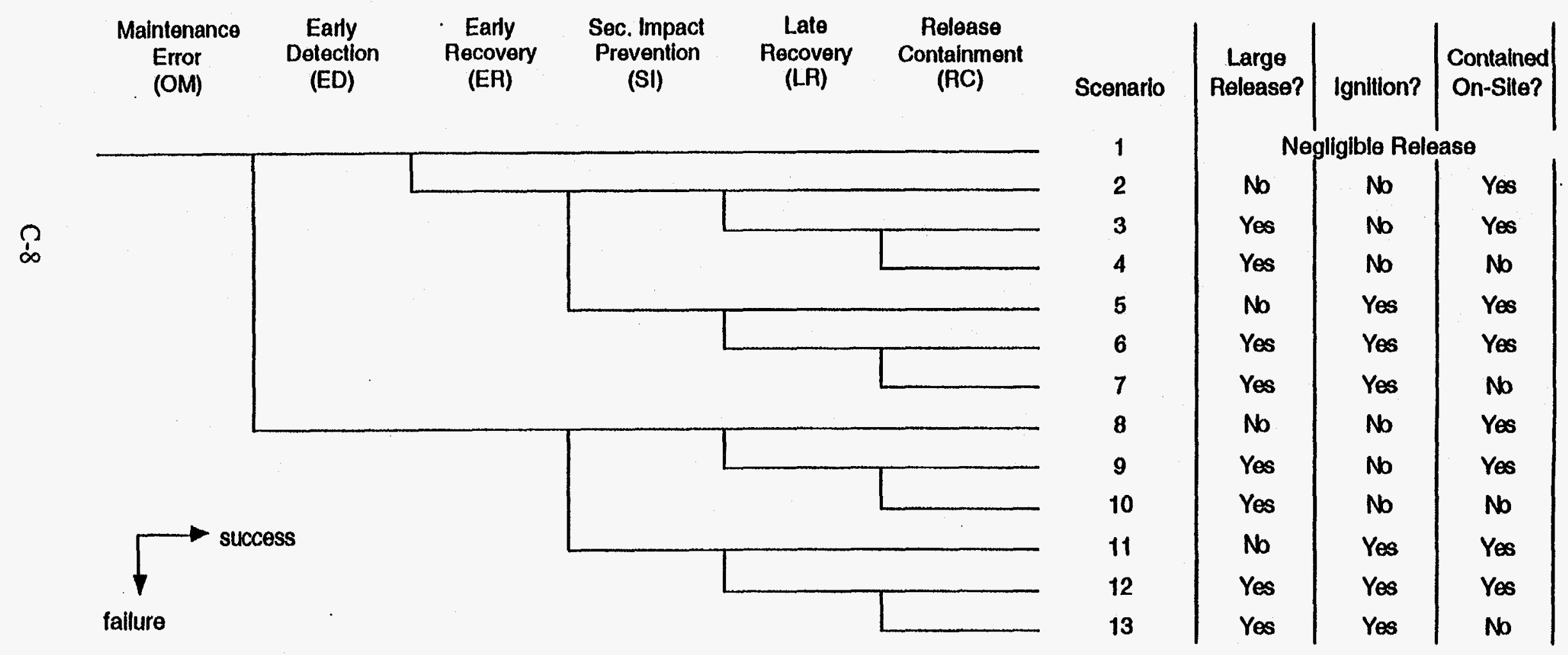




\section{Event Tree \\ Pipe Failure - Isolable}

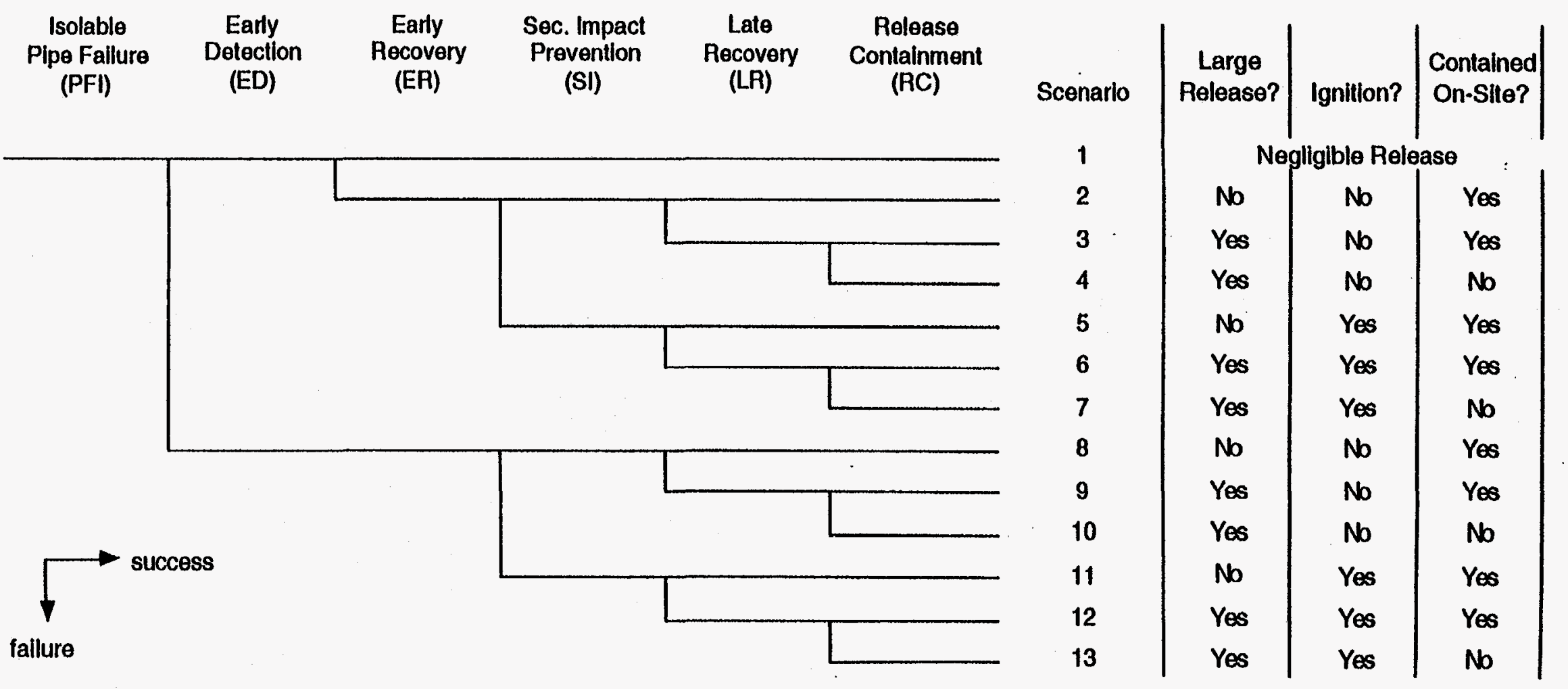




\section{Event Tree \\ Pipe Failure - Unisolable}

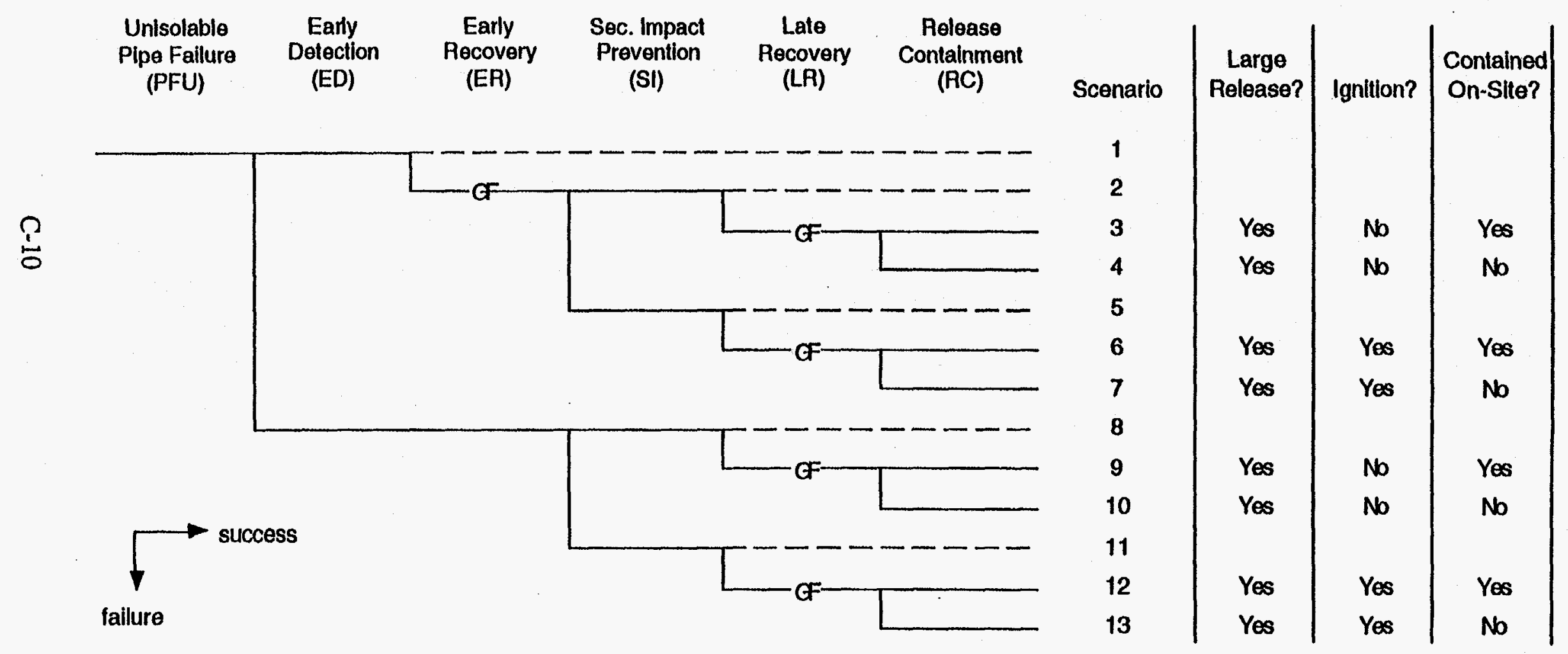




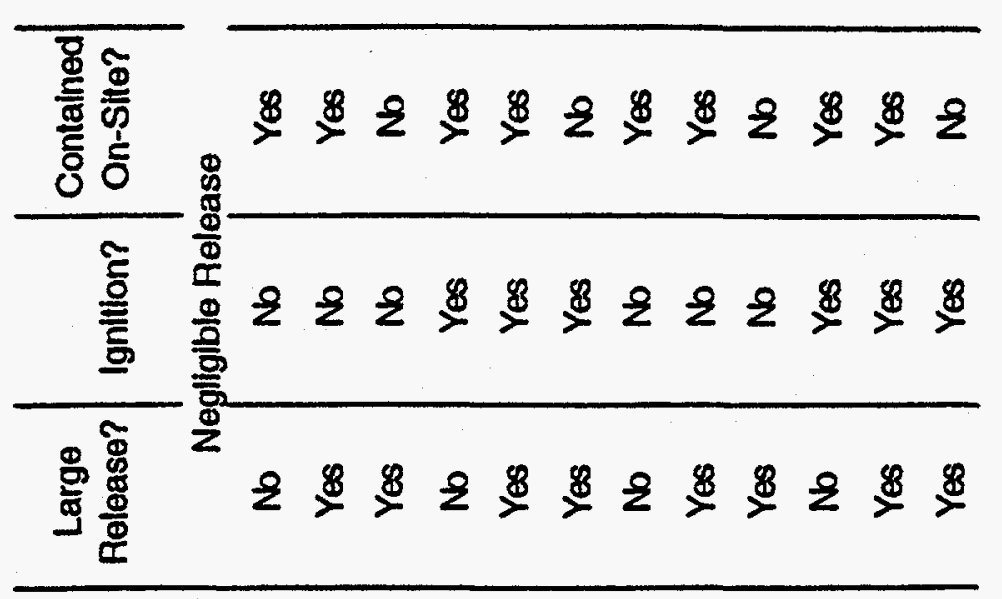

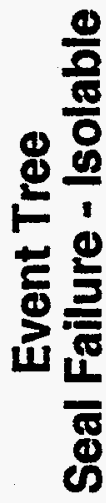

$$
\text { 을 }
$$
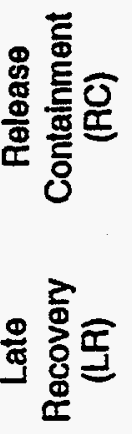

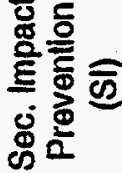

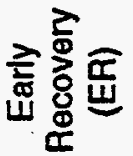

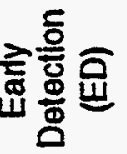

定总

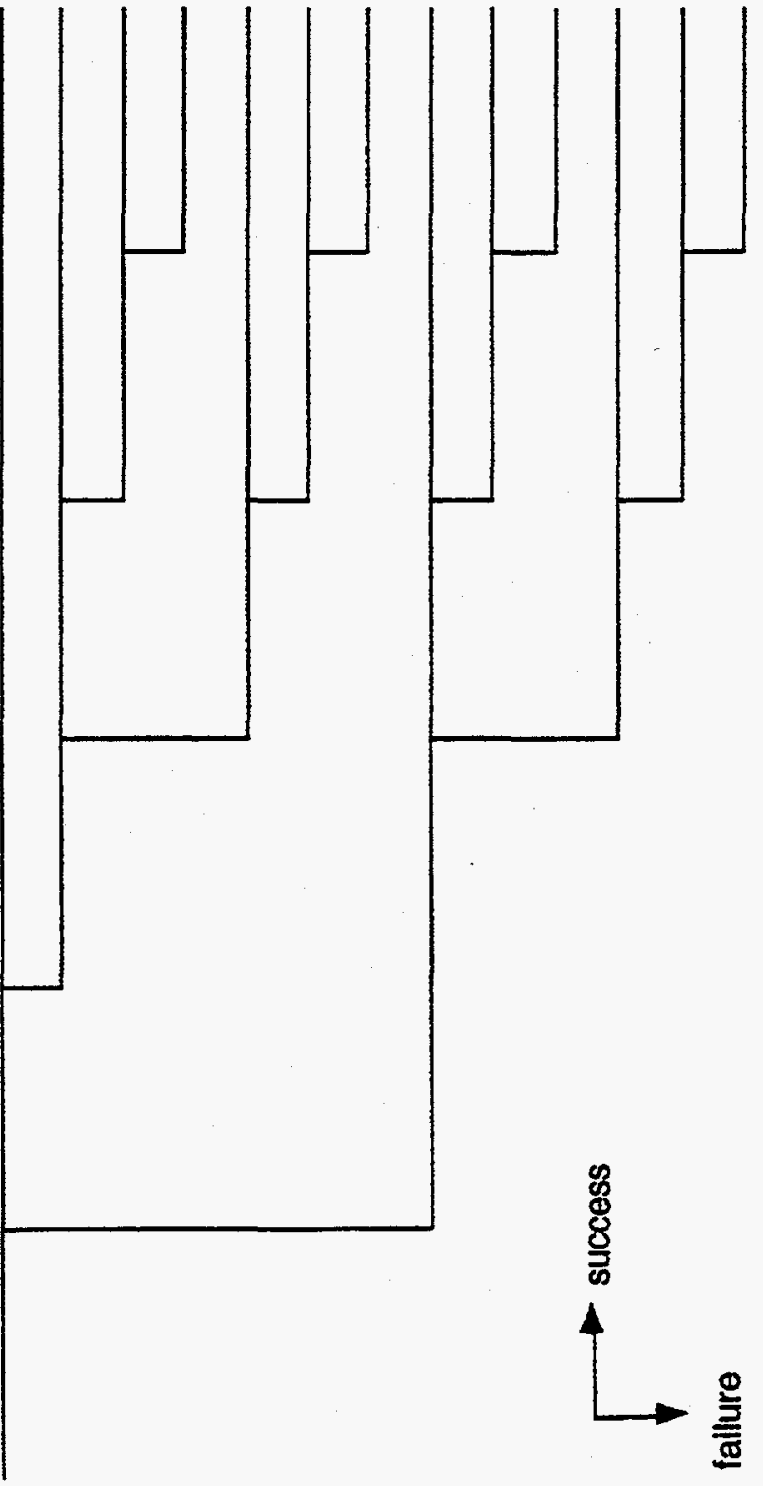

C-11 


\section{Event Tree \\ Seal Failure - Unisolable}

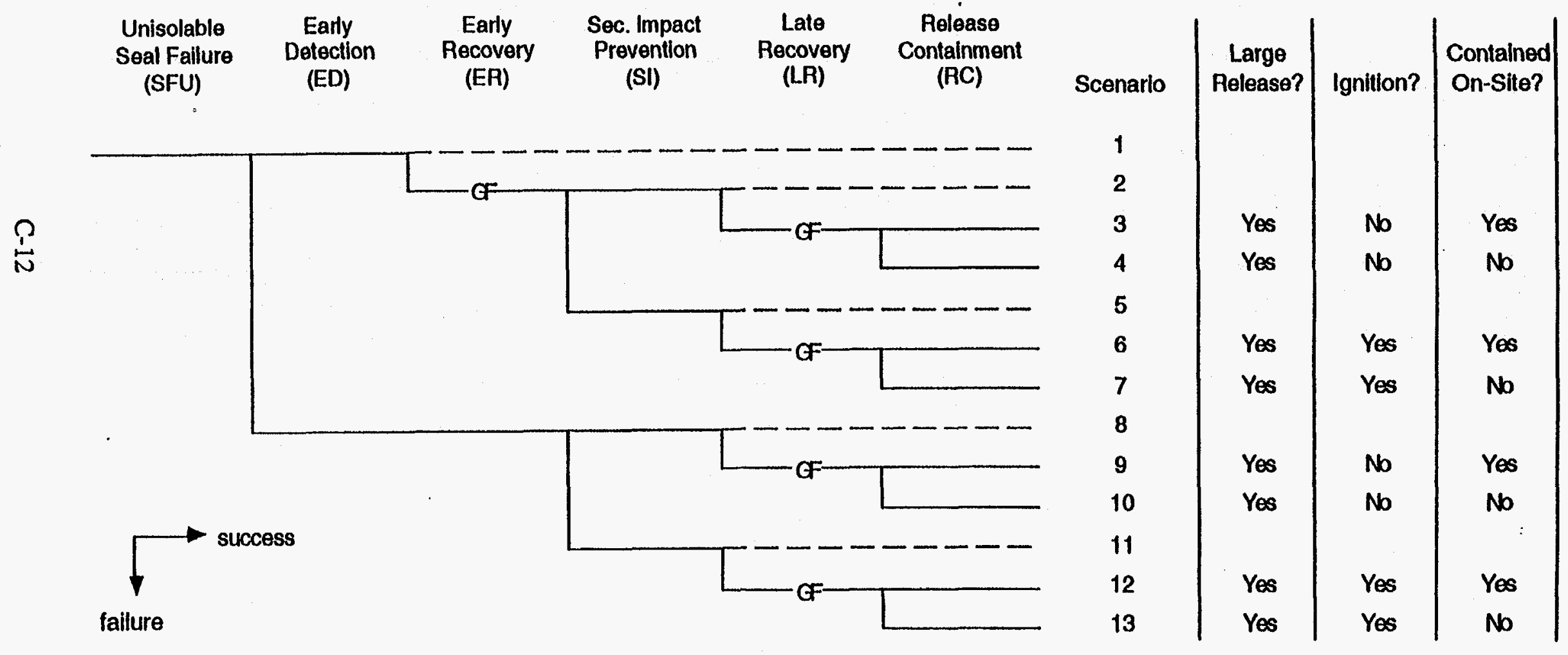




\section{Event Tree \\ Storage Tank Failure}

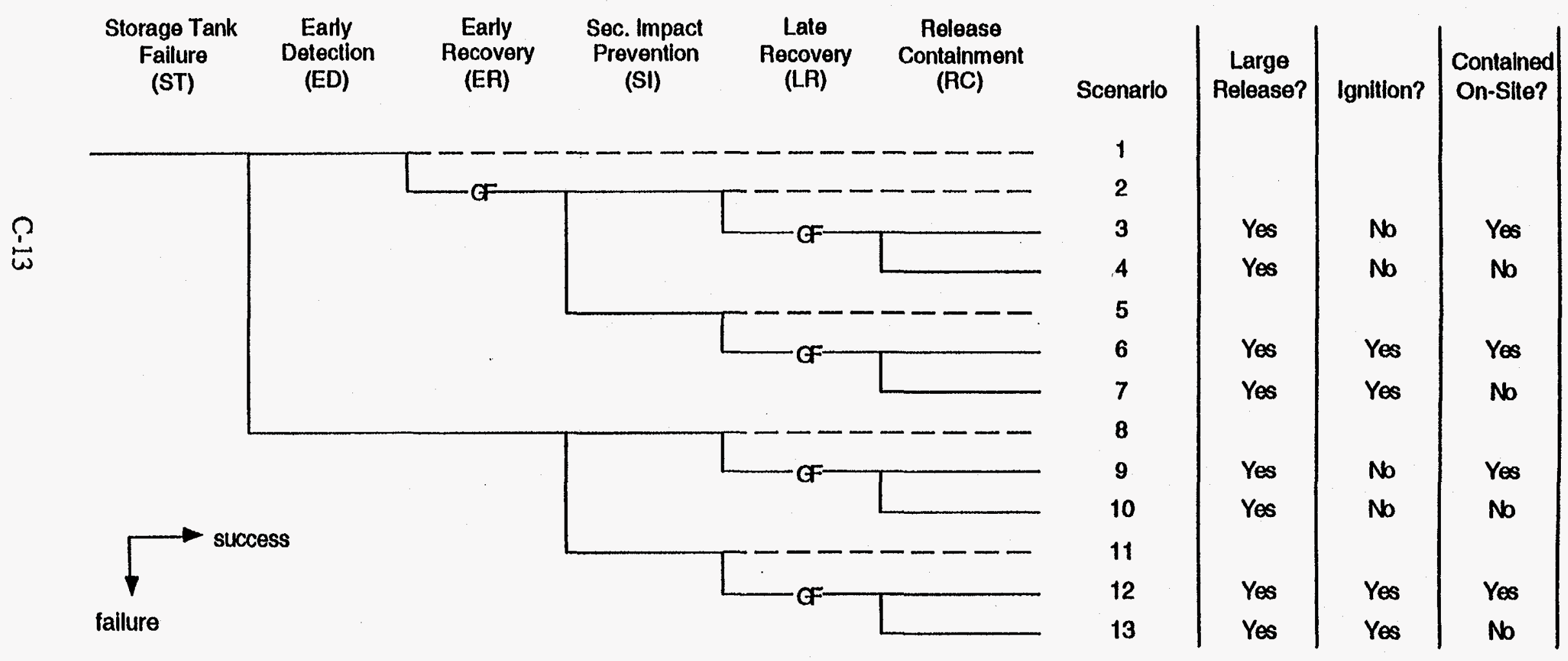




\section{Truck Fuel Tank Failure}

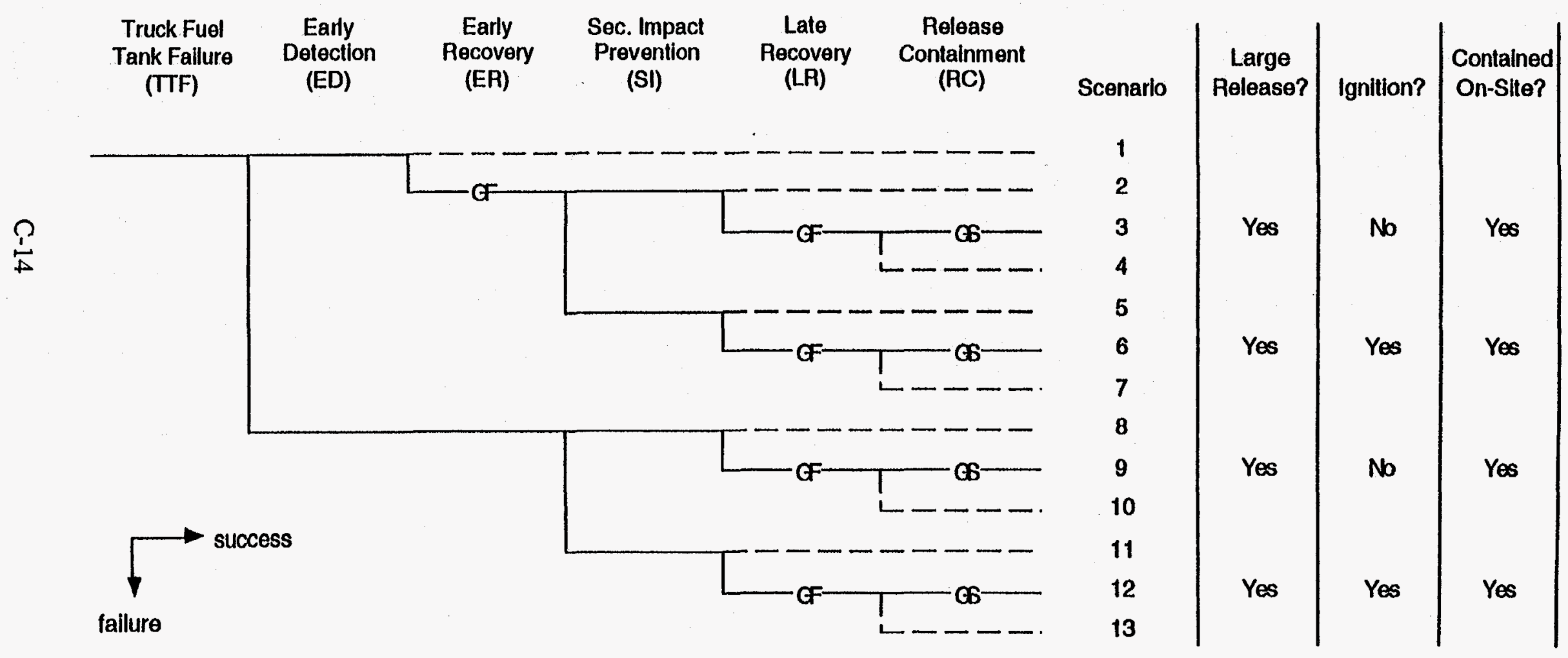




\section{Event Tree \\ Tanker Truck Failure}

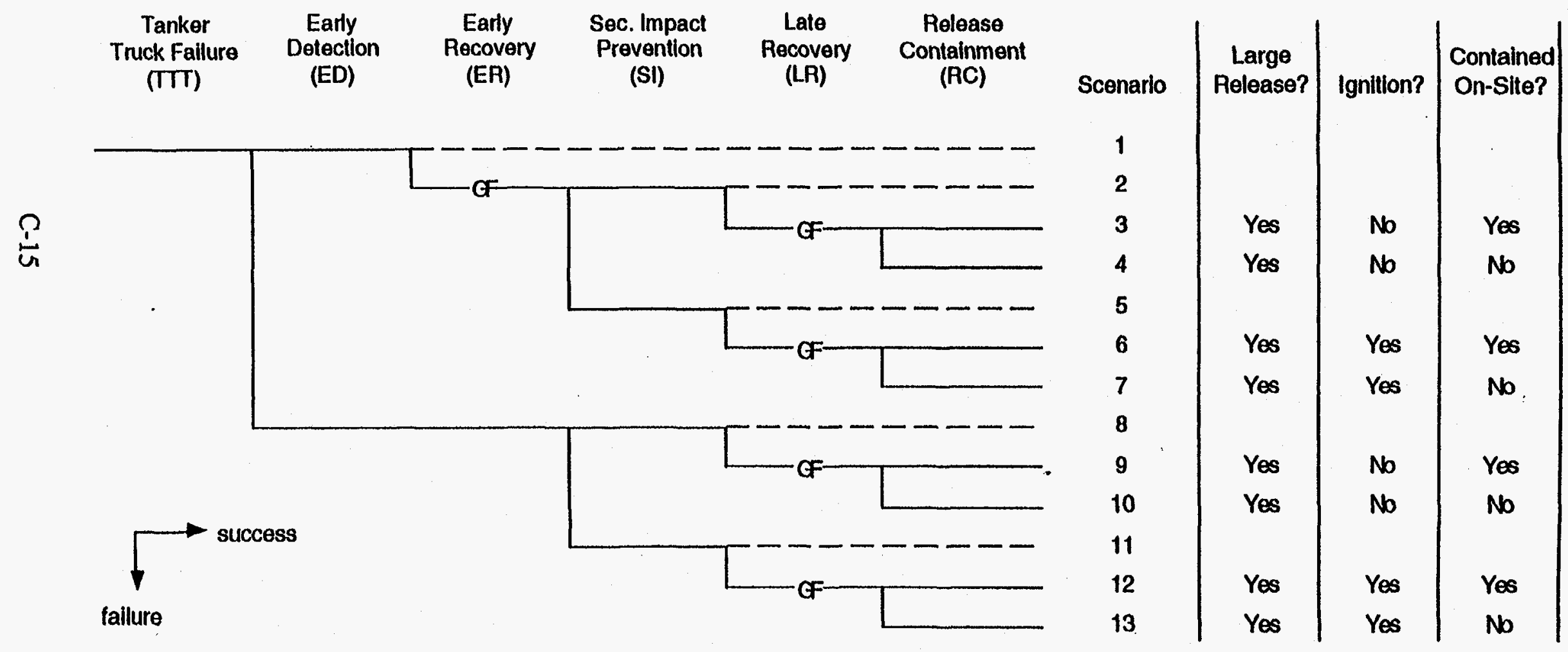




\section{Event Tree Vehicle Accident}

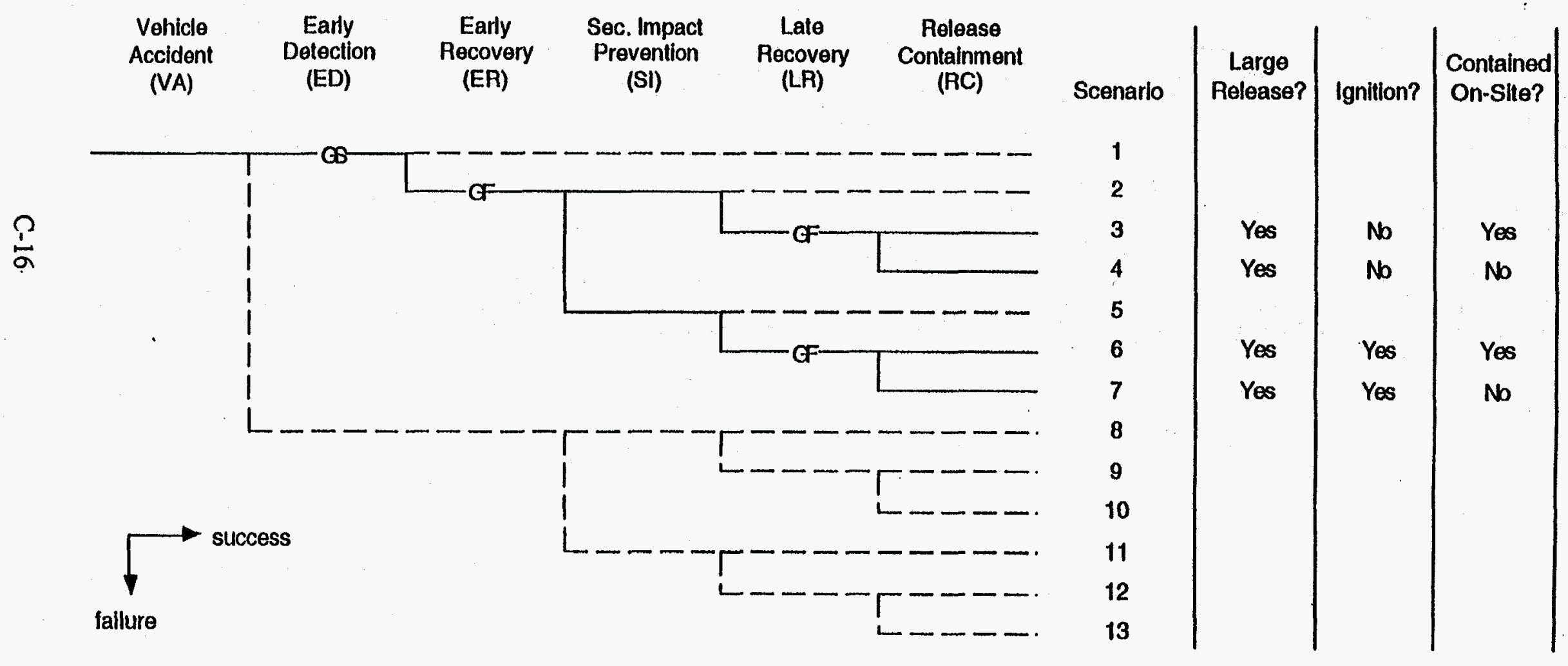




\section{Event Tree \\ Valve Failure - Isolable}

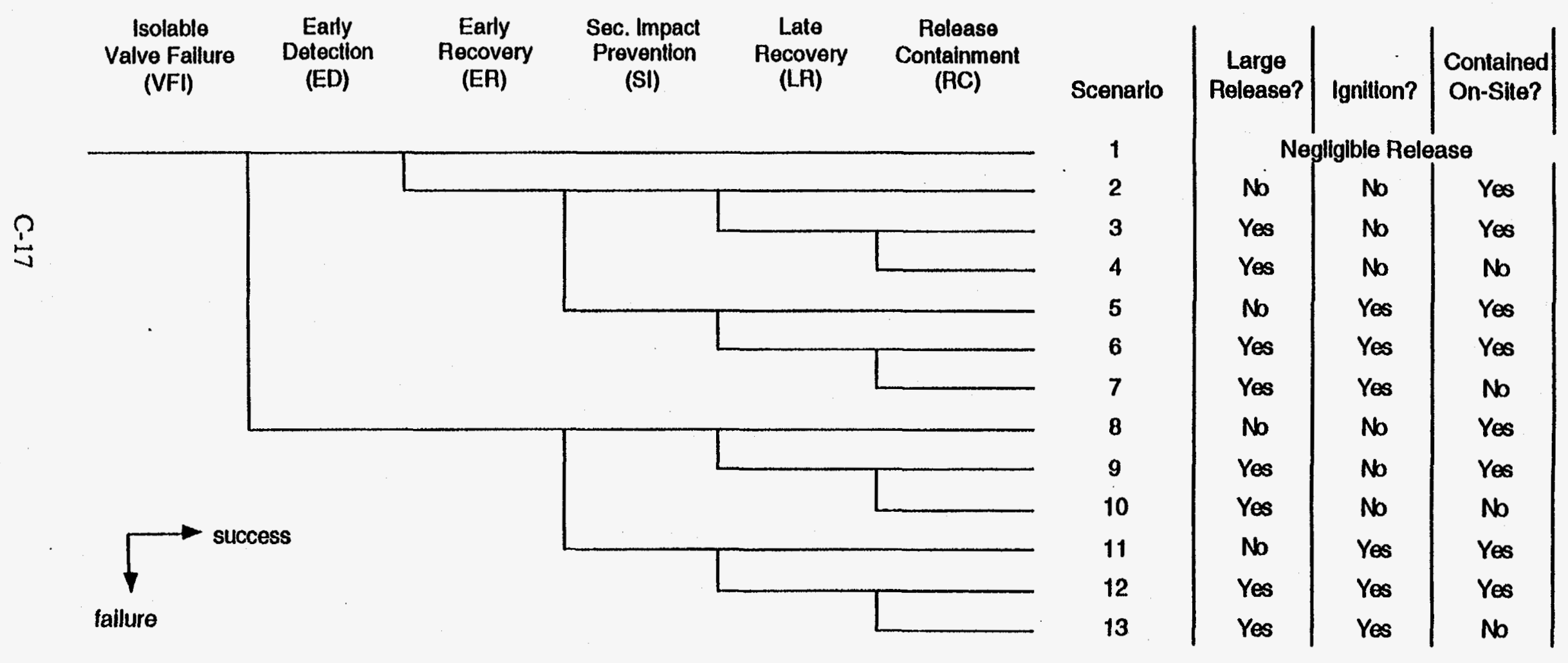




\section{Event Tree \\ Valve Failure - Unisolable}

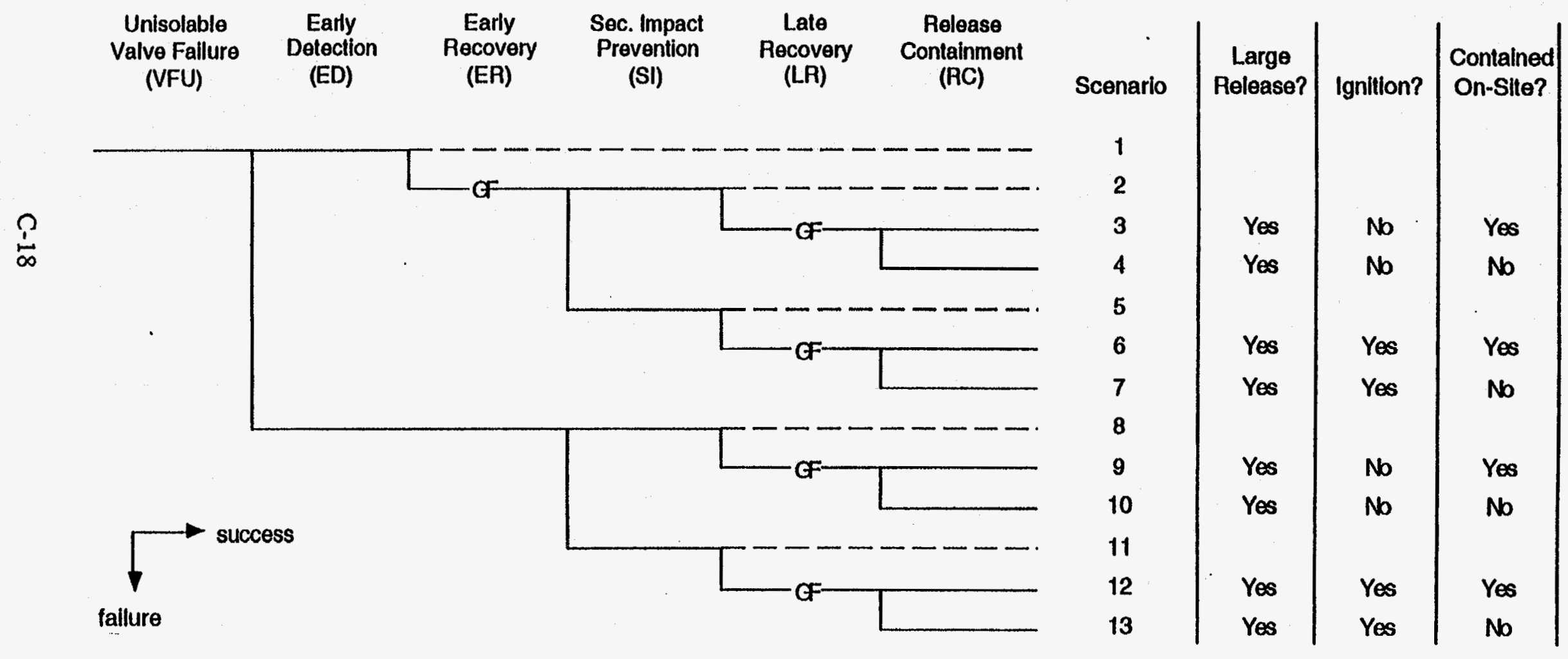




\section{Appendix D - Large Consequence Scenarios}

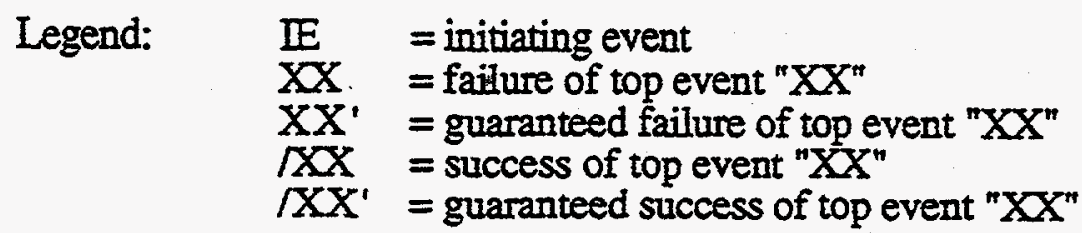

D-1 
Table D-1. Scenarios Leading to Large Releases

\begin{tabular}{|c|c|c|c|c|c|c|}
\hline IE & \multicolumn{5}{|c|}{ Top Events } & Notes \\
\hline $\mathrm{CAI}$ & /ED' & $E^{\prime}$ & ISI & LR & $\mathbf{R C}$ & Dominant CAI \\
\hline CAI & $/ \mathrm{ED}^{\prime}$ & $E R^{\prime}$ & $I S I$ & LR & RC & \\
\hline CAI & $\mathrm{ED}^{\prime}$ & $E R^{\prime}$ & SI & LR & RC & \\
\hline $\mathrm{CAI}$ & $/ \mathrm{ED}^{\prime}$ & $\mathrm{ER}^{\prime}$ & SI & LR & $\mathrm{RC}$ & \\
\hline $\mathrm{CAU}$ & EDD & $E R^{\prime}$ & ISI & IR $^{\prime}$ & IRC & Dominant CAU \\
\hline $\mathrm{CAU}$ & /ED & $E R^{\prime}$ & ISI & $\mathrm{LR}^{\prime}$ & RC & \\
\hline $\mathrm{CAU}$ & IED' & $\mathrm{ER}^{\prime}$ & $S I$ & $\mathrm{IR}^{\prime}$ & IRC & \\
\hline $\mathrm{CAU}$ & /ED & $\mathrm{ER}^{\prime}$ & SI & LR' & RC & \\
\hline EE & IED & $\mathrm{ER}^{\prime}$ & ISI & $\mathrm{LR}^{\prime}$ & RC & \\
\hline$\overline{E E}$ & IED & $E^{\prime}$ & ISI & $\mathrm{LR}^{\prime}$ & $\mathrm{RC}$ & \\
\hline $\mathrm{EE}$ & IED & $E R^{\prime}$ & $S I$ & $\mathrm{LR}^{\prime}$ & RC & \\
\hline $\mathrm{EE}$ & EDD & $\mathrm{ER}^{\prime}$ & $S I$ & $\mathrm{LR}^{\prime}$ & $\mathrm{RC}$ & \\
\hline EE & ED & $E R^{\prime}$ & ISI & $L^{\prime}$ & IRC & Dominant EE \\
\hline EE & ED & $E R^{\prime}$ & ISI & $\mathrm{LR}^{\prime}$ & $\mathrm{RC}$ & \\
\hline$\underline{E E}$ & $E D$ & $E R^{\prime}$ & SI & $\mathrm{LR}^{\prime}$ & RC & \\
\hline EE & ED & $E R^{\prime}$ & SI & IR' $^{\prime}$ & $\mathrm{RC}$ & \\
\hline HF & EDD & $E R$ & ISI & LR & $\mathbb{R C}$ & Dominant HF \\
\hline HF & EDD & ER & ISI & LR & $\mathrm{RC}$ & \\
\hline HF & IED & ER & SI & LR & RRC & \\
\hline HF & IED & $E R$ & SI & $\mathrm{LR}$ & $\mathrm{RC}$ & \\
\hline $\mathrm{HF}$ & $E D$ & $\mathrm{ER}^{\prime}$ & ISI & LR & RC & \\
\hline $\mathrm{HF}$ & $E D$ & $\mathrm{ER}^{\prime}$ & ISI & LR & $\mathrm{RC}$ & \\
\hline $\mathrm{HF}$ & $E D$ & $\mathrm{ER}^{\prime}$ & SI & LR & RC & \\
\hline $\mathrm{HF}$ & $E D$ & $\mathrm{ER}^{\prime}$ & SI & LR & $\mathrm{RC}$ & \\
\hline$O D$ & IED & ER & SI & LR & IRC & Dominant OD \\
\hline$O D$ & ED & ER & $/ S I$ & LR & $\mathrm{RC}$ & \\
\hline$O D$ & /ED & ER & SI & LR & RC & \\
\hline$O D$ & IED & ER & SI & LR & $\mathrm{RC}$ & \\
\hline OF & IED & ER & ISI & LR & $\mathrm{RC}$ & Dominant OF \\
\hline OF & IED & $\underline{E R}$ & ISI & $\mathrm{LR}$ & $\mathrm{RC}$ & \\
\hline OF & IED & ER & SI & LR & RC & \\
\hline OF & IED & $E R$ & SI & LR & $\mathrm{RC}$ & \\
\hline OF & $E D$ & $E R^{\prime}$ & $/ S I$ & LR & RC & \\
\hline OF & ED & $E R^{\prime}$ & ISI & $\underline{L R}$ & $\mathrm{RC}$ & \\
\hline OF & $E D$ & ER' & SI & $\mathrm{LR}$ & RC & \\
\hline OF & ED & ER' & SI & LR & $\mathrm{RC}$ & \\
\hline $\mathrm{OM}$ & IED & $E R$ & ISI & LR & IRC & Dominant OM \\
\hline $\mathrm{OM}$ & EDD & $E R$ & ISI & IR & $\mathrm{RC}$ & \\
\hline $\mathrm{OM}$ & $\mathrm{ED}$ & ER & SI & $\underline{L R}$ & $\mathrm{RC}$ & \\
\hline OM & /ED & ER & SI & LR & $\mathrm{RC}$ & \\
\hline $\mathrm{OM}$ & $\mathrm{ED}$ & $\mathrm{ER}^{\prime}$ & ISI & LR & RC & Dominant OM \\
\hline $\mathrm{OM}$ & $E D$ & $\mathrm{ER}^{\prime}$ & ISI & LR & $\mathrm{RC}$ & \\
\hline $\mathrm{OM}$ & $E D$ & $\mathrm{ER}^{\prime}$ & SI & LR & RC & \\
\hline $\mathrm{OM}$ & $E D$ & $\mathrm{ER}^{\prime}$ & SI & LR & $\mathrm{RC}$ & \\
\hline
\end{tabular}


Table D-1. Scenarios Leading to Large Releases (cont)

\begin{tabular}{|c|c|c|c|c|c|c|}
\hline IE & \multicolumn{5}{|c|}{ Top Events } & Notes \\
\hline PFI & IED & ER & $/ \mathrm{SI}$ & LR & IRC & Dominant PFI \\
\hline PFI & IED & ER & ISI & LR & $\mathrm{RC}$ & \\
\hline PFI & IED & ER & SI & LR & IRC & \\
\hline $\mathrm{PFI}$ & IED & ER & SI & LR & $\mathrm{RC}$ & \\
\hline PFI & $\mathrm{ED}$ & $E^{\prime}$ & ISI & LR & $\mathrm{IRC}$ & Dominant PFI \\
\hline PFI & $\mathrm{ED}$ & $E^{\prime}$ & ISI & LR & $\mathrm{RC}$ & \\
\hline PFI & $E D$ & ER' & $S I$ & LR & $\mathbb{R C}$ & \\
\hline PFI & $E D$ & $\mathrm{ER}^{\prime}$ & SI & LR & $\mathrm{RC}$ & \\
\hline PFU & IED & $\mathrm{ER}^{\prime}$ & ISI & $\mathrm{LR}^{\prime}$ & RC & Dominant PFU \\
\hline PFU & IED & ER' & ISI & $\mathrm{LR}^{\prime}$ & $\mathrm{RC}$ & \\
\hline PFU & IED & $E R^{\prime}$ & SI & $\mathrm{LR}^{\prime}$ & IRC & \\
\hline PFU & EDD & ER' & SI & $\mathbf{L R}^{\prime}$ & $\mathrm{RC}$ & \\
\hline PFU & ED & $E R^{\prime}$ & ISI & $\mathrm{LR}^{\prime}$ & IRC & \\
\hline PFU & $E D$ & $E R^{\prime}$ & ISI & $\mathrm{LR}^{\prime}$ & $\mathrm{RC}$ & \\
\hline PFU & $E D$ & $\mathrm{ER}^{\prime}$ & SI & $\mathrm{LR}^{\prime}$ & IRC & \\
\hline PFU & $E D$ & $\mathrm{ER}^{\prime}$ & SI & LR' $^{\prime}$ & $\mathrm{RC}$ & \\
\hline SFI & IED & $E R$ & ISI & $L R$ & IRC & Dominant SFI \\
\hline SFI & IED & ER & ISI & LR & $\mathrm{RC}$ & \\
\hline SFI & EDD & ER & SI & LR & $\mathrm{RC}$ & \\
\hline SFI & IED & $\mathrm{ER}$ & SI & LR & $\mathrm{RC}$ & \\
\hline SFI & ED & ER' & ISI & LR & RC & Dominant SFI \\
\hline SFI & $E D$ & $\mathrm{ER}^{\prime}$ & ISI & LR & $\mathrm{RC}$ & \\
\hline SFI & ED & $\mathrm{ER}^{\prime}$ & SI & LR & IRC & \\
\hline SFI & $\mathrm{ED}$ & $E^{\prime}$ & SI & LR & $\mathrm{RC}$ & \\
\hline SFU & IED & $\mathrm{ER}^{\prime}$ & ISI & $\mathrm{LR}^{\prime}$ & IRC & Dominant SFU \\
\hline SFU & IED & $E R^{\prime}$ & ISI & $\mathrm{LR}^{\prime}$ & $\mathrm{RC}$ & \\
\hline SFU & IED & $\mathrm{ER}^{\prime}$ & SI & $\mathrm{LR}^{\prime}$ & IRC & \\
\hline SFU & IED & $\mathrm{ER}^{\prime}$ & $S I$ & $L^{\prime}$ & $\mathrm{RC}$ & \\
\hline SFU & $E D$ & $E^{\prime}$ & ISI & $\mathrm{LR}^{\prime}$ & IRC & \\
\hline SFU & $\mathrm{ED}$ & $\mathrm{ER}^{\prime}$ & /SI & LR' $^{\prime}$ & $\mathrm{RC}$ & \\
\hline SFU & ED & $\mathbf{E R}^{\prime}$ & SI & $\mathrm{LR}^{\prime}$ & IRC & \\
\hline SFU & ED & $\mathrm{ER}^{\prime}$ & SI & $\mathrm{LR}^{\prime}$ & $\mathrm{RC}$ & \\
\hline ST & IED & $\mathrm{ER}^{\prime}$ & ISI & $\mathrm{LR}^{\prime}$ & RC & Dominant ST \\
\hline$S T$ & IED & $E^{\prime}$ & /SI & $\mathbf{L R}^{\prime}$ & $\mathrm{RC}$ & \\
\hline ST & IED & $\mathrm{ER}^{\prime}$ & $S I$ & LR' & IRC & \\
\hline ST & IED & $E R^{\prime}$ & SI & LR' $^{\prime}$ & $\mathrm{RC}$ & \\
\hline ST & $E D$ & $\mathrm{ER}^{\prime}$ & ISI & $\mathrm{LR}^{\prime}$ & IRC & \\
\hline ST & ED & $E^{\prime}$ & ISI & $L^{\prime}$ & $\mathrm{RC}$ & \\
\hline ST & $E D$ & $E R^{\prime}$ & SI & $L^{\prime}$ & IRC & \\
\hline$S T$ & $E D$ & $\mathrm{ER}^{\prime}$ & SI & $\mathrm{LR}^{\prime}$ & $\mathrm{RC}$ & \\
\hline TIF & IED & $\mathrm{ER}^{\prime}$ & ISI & $\mathrm{IR}^{\prime}$ & RC' & Dominant TIF \\
\hline TTF & EED & $\mathrm{ER}^{\prime}$ & SI & $\mathrm{LR}^{\prime}$ & $/ \mathrm{RC}^{\prime}$ & \\
\hline TTF & ED & $\mathrm{ER}^{\prime}$ & $I S I$ & $L^{\prime}$ & /RC' & \\
\hline IIF & $E D$ & $E R^{\prime}$ & $S I$ & $\mathrm{LR}^{\prime}$ & $\mathrm{RC}^{\prime}$ & \\
\hline
\end{tabular}


Table D-1. Scenarios Leading to Large Releases (cont)

\begin{tabular}{|c|c|c|c|c|c|c|}
\hline IE & \multicolumn{5}{|c|}{ Top Events } & Notes \\
\hline TTT & IED & $E R^{\prime}$ & ISI & $\mathrm{LR}^{\prime}$ & IRC & Dominant TTT \\
\hline TTT & IED & $E^{\prime}$ & /SI & $\mathrm{LR}^{\prime}$ & $\mathrm{RC}$ & \\
\hline TTT & IED & $E R^{\prime}$ & SI & $L^{\prime}$ & IRC & \\
\hline ITT & IED & $\mathrm{ER}^{\prime}$ & SI & LR' $^{\prime}$ & $\mathrm{RC}$ & \\
\hline ITT & $E D$ & $\mathrm{ER}^{\prime}$ & ISI & $\mathrm{LR}^{\prime}$ & IRC & \\
\hline TTT & $\mathrm{ED}$ & $\mathrm{ER}^{\prime}$ & /SI & $\mathrm{LR}^{\prime}$ & $\mathrm{RC}$ & \\
\hline TTT & $E D$ & $\mathrm{ER}^{\prime}$ & SI & $\mathrm{LR}^{\prime}$ & IRC & \\
\hline TTT & $E D$ & $E R^{\prime}$ & SI & $\mathrm{LR}^{\prime}$ & $\mathrm{RC}$ & \\
\hline $\mathrm{VA}$ & $/ \mathrm{ED}^{*}$ & $E^{\prime}$ & $/ S I$ & LR' $^{\prime}$ & IRC & Dominant VA \\
\hline $\mathrm{VA}$ & IED' & $E^{\prime}$ & SSI & $L^{\prime}$ & $\mathrm{RC}$ & \\
\hline VA & $\mathrm{IED}^{\prime}$ & $\mathrm{ER}^{\prime}$ & SI & LR' $^{\prime}$ & /RC & \\
\hline VA & /ED' & $\mathbf{E R}^{\prime}$ & SI & IR' & RC & \\
\hline VFI & IED & ER & ISI & LR & IRC & Dominant VFI \\
\hline VFI & EED & ER & ISI & LR & $\mathrm{RC}$ & \\
\hline VFI & /ED & ER & SI & IR & /RC & \\
\hline $\mathrm{VFI}$ & IED & ER & SI & LR & $\mathrm{RC}$ & \\
\hline VFI & $\mathrm{ED}$ & $\mathrm{ER}^{\prime}$ & ISI & LR & IRC & Dominant VFI \\
\hline VFI & $E D$ & $\mathrm{ER}^{\prime}$ & /SI & LR & $\mathrm{RC}$ & \\
\hline VFI & $\mathrm{ED}$ & $\mathrm{ER}^{\prime}$ & SI & LR & IRC & \\
\hline VFI & $\overline{E D}$ & $\mathrm{ER}^{\prime}$ & SI & IR & $\mathrm{RC}$ & \\
\hline VFU & IED & $E R^{\prime}$ & $/ S I$ & $L R^{\prime}$ & IRC & Dominant VFU \\
\hline VFU & IED & $\mathrm{ER}^{\prime}$ & ISI & $\mathbf{L R}^{\prime}$ & $\mathrm{RC}$ & \\
\hline VFU & IED & $E R^{\prime}$ & SI & $\mathrm{LR}^{\prime}$ & /RC & \\
\hline VFU & IED & $E^{\prime}$ & SI & $\mathrm{LR}^{\prime}$ & RC & \\
\hline VFU & $\overline{E D}$ & $E R^{\prime}$ & $I S I$ & $\mathrm{LR}^{\prime}$ & IRC & \\
\hline VFU & $\mathrm{ED}$ & $\mathrm{ER}^{\prime}$ & ISI & $\mathrm{LR}^{\prime}$ & RC & \\
\hline VFU & $\mathrm{ED}$ & $E R^{\prime}$ & SI & $\mathbf{L R}^{\prime}$ & /RC & \\
\hline VFU & $E D$ & $E R^{\prime}$ & $S I$ & $\mathrm{IR}^{\prime}$ & $\mathrm{RC}$ & \\
\hline
\end{tabular}


Table D-2. Scenarios Leading to Large Releases with Onsite Ignition

\begin{tabular}{|c|c|c|c|c|c|c|}
\hline $\mathbf{I E}$ & \multicolumn{5}{|c|}{ Top Events } & Notes \\
\hline $\mathrm{CAI}$ & /ED & ER' & SI & LR & /RC & Dominant CAI \\
\hline $\mathrm{CAI}$ & $/ \mathrm{ED}^{\prime}$ & $E^{\prime}$ & SI & LR & $\mathrm{RC}$ & \\
\hline $\mathrm{CAU}$ & $/ \mathrm{ED}^{\prime}$ & $\mathrm{ER}^{\prime}$ & SI & $\mathrm{LR}^{\prime}$ & IRC & Dominant CAU \\
\hline $\mathrm{CAU}$ & $\sqrt{\mathrm{ED}}$ & $\mathrm{ER}^{\prime}$ & SI & $\mathrm{LR}^{\prime}$ & $\mathrm{RC}$ & \\
\hline EE & /ED & $\mathrm{ER}^{\prime}$ & SI & $\mathrm{LR}^{\prime}$ & $\mathrm{RC}$ & \\
\hline$E$ & IED & $E R^{\prime}$ & SI & $\mathrm{LR}^{\prime}$ & $\mathrm{RC}$ & \\
\hline EE & ED & $\mathrm{ER}^{\prime}$ & SI & $\mathrm{LR}^{\prime}$ & IRC & Dominant EE \\
\hline EE & $E D$ & $\mathrm{ER}^{\prime}$ & SI & $\mathrm{LR}^{\prime}$ & $\mathrm{RC}$ & \\
\hline HF & IED & $E R$ & SI & LR & RC & Dominant HF \\
\hline HF & IED & $E R$ & SI & LR & $\mathrm{RC}$ & \\
\hline HF & ED & ER' & SI & LR & IRC & \\
\hline HF & ED & $\mathrm{ER}^{\prime}$ & SI & IR & $\mathrm{RC}$ & \\
\hline $\mathrm{OD}$ & $\mathrm{ED}$ & ER & SI & IR & RC & Dominant OD \\
\hline$O D$ & /ED' & $\mathrm{ER}$ & SI & LR & $\mathrm{RC}$ & \\
\hline OF & $\mathrm{ED}$ & $E R$ & SI & LR & $\mathrm{RC}$ & Dominant OF \\
\hline OF & EDD & ER & SI & LR & $\mathrm{RC}$ & \\
\hline OF & ED & $E^{\prime}$ & SI & $\mathrm{LR}$ & RC & \\
\hline OF & $E D$ & ER' & SI & LR & $\mathrm{RC}$ & \\
\hline $\mathrm{OM}$ & $\overline{\mathrm{EED}}$ & ER & SI & LR & /RC & Dominant OM \\
\hline $\mathrm{OM}$ & EED & ER & SI & LR & $\mathrm{RC}$ & \\
\hline $\mathrm{OM}$ & $\mathrm{ED}$ & $\mathrm{ER}^{\prime}$ & SI & $\mathrm{LR}$ & RRC & Dominant OM \\
\hline $\mathrm{OM}$ & $\mathrm{ED}$ & $E R^{\prime}$ & SI & LR & $\mathrm{RC}$ & \\
\hline PFI & IED & ER & SI & LR & IRC & Dominant PFI \\
\hline PFI & IED & ER & SI & LR & $\mathrm{RC}$ & \\
\hline PFI & $E D$ & ER' & SI & LR & IRC & Dominant PFI \\
\hline PFI & ED & $\mathrm{ER}^{\prime}$ & SI & $\mathrm{LR}$ & $\mathrm{RC}$ & \\
\hline PFU & IED & $\mathrm{ER}^{\prime}$ & SI & $\mathrm{LR}^{\prime}$ & IRC & Dominant PFU \\
\hline PFU & IED & $\mathrm{ER}^{\prime}$ & SI & $\mathrm{LR}^{\prime}$ & $\mathrm{RC}$ & \\
\hline PFU & ED & ER' & SI & $\mathrm{LR}^{\prime}$ & IRC & \\
\hline PFU & ED & $\mathrm{ER}^{\prime}$ & SI & $\mathrm{LR}^{\prime}$ & RC & \\
\hline SFI & IED & ER & SI & LR & RC & Dominaint SFI \\
\hline SFI & /ED & ER & SI & $\mathrm{LR}$ & $\mathrm{RC}$ & \\
\hline SFI & ED & ER' & SI & LR & $\mathrm{RC}$ & Dominant SFI \\
\hline SFI & $E D$ & $E R^{\prime}$ & SI & LR & $\mathrm{RC}$ & \\
\hline SFU & IED & ER: & SI & $\mathrm{LR}^{\prime}$ & IRC & Dominant SFU \\
\hline SFU & IED & $\mathrm{ER}^{\prime}$ & SI & $\mathrm{LR}^{\prime}$ & $\mathrm{RC}$ & \\
\hline SFU & ED & $\mathrm{ER}^{\prime}$ & SI & $\mathrm{LR}^{\prime}$ & RRC & \\
\hline SFU & ED & $\mathrm{ER}^{\prime}$ & SI & $\mathrm{LR}^{\prime}$ & $\mathrm{RC}$ & \\
\hline ST & IED & $\mathrm{ER}^{\prime}$ & SI & $\mathrm{LR}^{\prime}$ & $\mathrm{RC}$ & Dominant ST \\
\hline$S T$ & IED & $\mathrm{ER}^{\prime}$ & SI & $\mathrm{LR}^{\prime}$ & RC & \\
\hline ST & ED & $\mathrm{ER}^{\prime}$ & SI & $\mathrm{LR}^{\prime}$ & IRC & \\
\hline ST & ED & $E R^{\prime}$ & SI & $\mathrm{LR}^{\prime}$ & $\mathrm{RC}$ & \\
\hline TTF & IED & $E R^{\prime}$ & SI & $\mathrm{LR}^{\prime}$ & $\mathrm{RC}^{\prime}$ & Dominant TTF \\
\hline TIF & ED & $\mathrm{ER}^{\prime}$ & SI & $\mathrm{LR}^{\prime}$ & $/ \mathrm{RC}^{+}$ & \\
\hline
\end{tabular}


Table D-2. Scenarios Leading to Large Releases with Onsite Ignition (cont.)

\begin{tabular}{|c|c|c|c|c|c|c|}
\hline IE & \multicolumn{5}{|c|}{ Top Events } & Notes \\
\hline$\overline{\text { TTT }}$ & IED & $\overline{E^{\prime}}$ & SI & $\overline{\text { LR }^{\prime}}$ & RC & Dominant TTT \\
\hline TIT & IED & $\mathrm{ER}^{\prime}$ & SI & $\mathrm{LR}^{\prime}$ & $\mathrm{RC}$ & \\
\hline TTT & $E D$ & $\mathrm{ER}^{\prime}$ & SI & $\mathbf{L R}^{\prime}$ & IRC & \\
\hline TIT & ED & ER' & SI & $\mathrm{LR}^{\prime}$ & $\mathrm{RC}$ & \\
\hline $\mathrm{VA}$ & $\sqrt{\mathrm{ED}^{\prime}}$ & $\mathrm{ER}^{\prime}$ & $S I$ & $\mathrm{LR}^{\prime}$ & IRC & Dominant VA \\
\hline $\mathrm{VA}$ & ED' & ER' & SI & $\mathrm{LR}^{\prime}$ & $\mathrm{RC}$ & \\
\hline VFI & $\sqrt[E D]{ }$ & ER & SI & LR & $\mathrm{RC}$ & Dominant VFI \\
\hline VFI & /ED & ER & SI & LR & $\mathrm{RC}$ & \\
\hline VFI & $E D$ & $\mathrm{ER}^{\prime}$ & SI & LR & RC & Dominant VFI \\
\hline VFI & ED & $\mathrm{ER}^{\prime}$ & SI & LR & $\mathrm{RC}$ & \\
\hline VFU & IED & $\mathrm{ER}^{\prime}$ & SI & $\mathrm{LR}^{\prime}$ & IRC & Dominant VFU \\
\hline VFU & IED & $\mathrm{ER}^{\prime}$ & SI & $\mathrm{LR}^{\prime}$ & $\mathrm{RC}$ & \\
\hline VFU & ED & $\mathrm{ER}^{\prime}$ & SI & $\mathrm{LR}^{\prime}$ & IRC & \\
\hline VFU & ED & $\mathrm{ER}^{\prime}$ & SI & $\mathrm{LR}^{\prime}$ & $\mathrm{RC}$ & \\
\hline
\end{tabular}


Table D-3. Scenarios Leading to Large Offsite Releases

\begin{tabular}{|c|c|c|c|c|c|c|}
\hline IE & \multicolumn{5}{|c|}{ Top Events } & Notes \\
\hline $\mathrm{CAI}$ & /ED' & $\mathrm{ER}^{\prime}$ & ISI & $\mathrm{LR}$ & $\mathrm{RC}$ & Dominant CAI \\
\hline CAI & $\mathrm{ED}^{\prime}$ & $E^{\prime}$ & SI & IR & $\mathrm{RC}$ & \\
\hline $\mathrm{CAU}$ & $\sqrt{\mathrm{ED}^{+}}$ & $\mathrm{ER}^{\prime}$ & ISI & $\mathrm{LR}^{\prime}$ & $\mathrm{RC}$ & Dominant CAU \\
\hline $\mathrm{CAU}$ & $/ \mathrm{ED}^{x}$ & $\mathrm{ER}^{\prime}$ & SI & $\mathrm{LR}^{\prime}$ & $\mathrm{RC}$ & \\
\hline EE & IED & $E^{\prime}$ & ISI & $\mathrm{LR}^{\prime}$ & $\mathbf{R C}$ & \\
\hline$E E$ & IED & ER' & SI & $\mathrm{LR}^{\prime}$ & $\mathrm{RC}$ & \\
\hline$E E$ & ED & $\mathrm{ER}^{\prime}$ & ISI & $L^{\prime}$ & $\mathrm{RC}$ & Dominant EE \\
\hline $\mathrm{EE}$ & ED & $\mathrm{ER}^{\prime}$ & SI & $\mathrm{LR}^{\prime}$ & $\mathrm{RC}$ & \\
\hline HF & IED & ER & ISI & LR & RC & Dominant HF \\
\hline HF & IED & $E R$ & SI & LR & $R C$ & \\
\hline $\mathrm{HF}$ & ED & $\mathrm{ER}^{\prime}$ & ISI & LR & $\mathrm{RC}$ & \\
\hline HF & $E D$ & $\mathrm{ER}^{\prime}$ & SI & LR & $\mathrm{RC}$ & \\
\hline $\mathrm{OD}$ & EDD' & ER & ISI & LR & $\mathrm{RC}$ & Dominant OD \\
\hline $\mathrm{OD}$ & IED & $E R$ & SI & IR & $\mathrm{RC}$ & \\
\hline OF & ED & ER & ISI & LR & $\mathrm{RC}$ & Dominant OF \\
\hline OF & IED & $E R$ & $S I$ & IR & $\mathrm{RC}$ & \\
\hline OF & ED & ER' & ISI & LR & RC & \\
\hline OF & ED & $\mathrm{ER}^{\prime}$ & SI & LR & $\mathrm{RC}$ & \\
\hline $\mathrm{OM}$ & IED & ER & ISI & LR & $\mathbf{R C}$ & Dominant OM \\
\hline $\mathrm{OM}$ & IED & $E R$ & SI & LR & RC & \\
\hline $\mathrm{OM}$ & ED & $\mathrm{ER}^{\prime}$ & ISI & LR & $\mathrm{RC}$ & Dominant OM \\
\hline $\mathrm{OM}$ & $\mathrm{ED}$ & $\mathrm{ER}^{\prime}$ & SI & LR & $\mathrm{RC}$ & \\
\hline PFI & $\sqrt{\mathrm{ED}}$ & $E R$ & ISI & $\underline{L R}$ & $\mathrm{RC}$ & Dominant PFI \\
\hline PFI & IED & ER & SI & LR & RC & \\
\hline PFI & $E D$ & $E^{\prime}$ & ISI & $\underline{L R}$ & $\mathrm{RC}$ & Dominant PFI \\
\hline $\mathrm{PFI}$ & ED & $E^{\prime}$ & SI & IR & $\mathrm{RC}$ & \\
\hline PFU & EDD & $E^{\prime}$ & ISI & $\mathrm{IR}^{\prime}$ & $\underline{R C}$ & Dominant PFU \\
\hline PFU & ED & $\mathrm{ER}^{\prime}$ & SI & $\mathbf{L R}^{\prime}$ & RC & \\
\hline PFU & $E D$ & ER' & ISI & $\mathrm{LR}^{\prime}$ & $\mathrm{RC}$ & \\
\hline PFU & ED & $E R^{\prime}$ & SI & $\mathrm{LR}^{\prime}$ & $\mathrm{RC}$ & \\
\hline SFI & IED & $E R$ & $I S I$ & LR & $\mathrm{RC}$ & Dominant SFI \\
\hline SFI & EDD & ER & SI & LR & RC & \\
\hline SFI & ED & $E R^{\prime}$ & ISI & LR & $\mathrm{RC}$ & Dominant SFI \\
\hline SFI & $E D$ & $\mathrm{ER}^{\prime}$ & SI & LR & $\mathrm{RC}$ & \\
\hline SFU & IED & $\mathrm{ER}^{\prime}$ & $/ S I$ & $L^{\prime}$ & $\mathrm{RC}$ & Dominant SFU \\
\hline SFU & IED & $\mathrm{ER}^{\prime}$ & SI & $\mathrm{LR}^{\prime}$ & $\mathrm{RC}$ & \\
\hline SFU & ED & ER' & ISI & $L^{\prime} R^{\prime}$ & $\mathrm{RC}$ & \\
\hline SFU & ED & $\mathrm{ER}^{\prime}$ & SI & $I R^{\prime}$ & $\mathrm{RC}$ & \\
\hline ST & IED & $E R^{\prime}$ & ISI & $\mathrm{LR}^{\prime}$ & $\mathrm{RC}$ & Dominant ST \\
\hline$S T$ & EDD & $\mathrm{ER}^{\prime}$ & SI & $I R^{\prime}$ & $\mathrm{RC}$ & \\
\hline$S T$ & ED & $E R^{\prime}$ & $/ S I$ & $\underline{L R^{\prime}}$ & RC & \\
\hline$S T$ & ED & $\mathrm{ER}^{\prime}$ & SI & $\mathrm{LR}^{\prime}$ & $\mathrm{RC}$ & \\
\hline TTI & IED & $E^{\prime}$ & ISI & $L^{\prime}$ & $\mathrm{RC}$ & Dominant TTT \\
\hline TIT & IED & $E^{\prime}$ & SI & $\mathrm{LR}^{\prime}$ & $\underline{\mathrm{RC}}$ & \\
\hline TTT & ED & $E R^{\prime}$ & SI & $L^{\prime}$ & $\mathrm{RC}$ & \\
\hline TTI & $\mathrm{ED}$ & $\mathrm{ER}^{\prime}$ & SI & $\mathbf{L R}^{\prime}$ & $\mathrm{RC}$ & \\
\hline
\end{tabular}


Table D-3. Scenarios Leading to Large Offsite Releases (cont.)

\begin{tabular}{|c|c|c|c|c|c|c|}
\hline IE & \multicolumn{5}{|c|}{ Top Events } & Notes \\
\hline VA & $\sqrt{E^{\prime} D^{\prime}}$ & $E R^{\prime}$ & /SI & $\mathbf{L R}^{\prime}$ & $\mathrm{RC}$ & Dominant VA \\
\hline $\mathrm{VA}$ & IED' & $E R^{\prime}$ & SI & LR' $^{\prime}$ & $\underline{\mathrm{RC}}$ & \\
\hline VFI & IED & ER & ISI & LR & RC & Dominant VFI \\
\hline VFI & $\mathrm{ED}$ & ER & SI & LR & $\mathrm{RC}$ & \\
\hline VFI & ED & $E^{\prime}$ & SSI & LR & $\mathrm{RC}$ & Dominant VFI \\
\hline VFI & ED & $E R^{\prime}$ & SI & LR & $\mathrm{RC}$ & \\
\hline VFU & /ED & $E R^{\prime}$ & ISI & IR' & $\mathrm{RC}$ & Dominant VFU \\
\hline VFU & IED & ER' & SI & LR' & $\mathrm{RC}$ & \\
\hline VFU & ED & $\mathrm{ER}^{\prime}$ & ISI & $\mathrm{LR}^{\prime}$ & $\mathrm{RC}$ & \\
\hline VFU & $E D$ & ER' & SI & LR' & $\mathrm{RC}$ & \\
\hline
\end{tabular}


Appendix E - Bibliography on Liquefied Natural Gas 


\begin{tabular}{|c|c|}
\hline \multicolumn{2}{|r|}{ Appendix F Bibliography on Liquefied Natural Gas } \\
\hline reference & citation \\
\hline $96-1 F C 46$ & $\begin{array}{l}\text { LNG Facity Accident at Cove Point, Manyland, Committee Print 96-1FC 46, } \\
\text { Committee on Interstate and Foreign Commerce, U.S. House of Rep., U. S. Govt. } \\
\text { Printing Office, Washington, } 1980 .\end{array}$ \\
\hline AAR 88 & $\begin{array}{l}\text { Gasoline," in Hazardous Materials Emergency Action Gujides, Association of } \\
\text { American Railroads, Washington, DC, January } 1988 .\end{array}$ \\
\hline Abbott 94 & $\begin{array}{l}\text { Abbott, Michael L, "Investigation of Plume Buoyancy Effects During ITER } \\
\text { Cryogen Releases," ITERUS194TE/SA-13, Engineering Design File, Idaho } \\
\text { National Engineering Laboratory, July 25, 1994. }\end{array}$ \\
\hline Aboujaoude 95 & $\begin{array}{l}\text { Aboujaoude, F., Bell, S. R., Rao, A. K, and Sekar, R., Natural Gas and } \\
\text { Attemativo Fuets for Enginoers - 1995, American Society of Mechanical } \\
\text { Engineers, 1995. }\end{array}$ \\
\hline Adkins 96 & $\begin{array}{l}\text { Roy Adkins, "Pressure Point, A Fresh Approach to LNG Vehicle Refueling," } \\
\text { Natural Gas Fuels, April 1995, p. 16-17. }\end{array}$ \\
\hline ADL 91 & $\begin{array}{l}\text { The Study of Relative Risks for Flammable Liqujid Cargoes Through Tunnels, } \\
\text { prepared for. Calif. Dept of Transportation by Arthur D. Littie, Inc., Los Angeles, } \\
\text { ADL Ref \# E3776, May } 1991 .\end{array}$ \\
\hline Adorjan 83 & $\begin{array}{l}\text { Adorjan, A.S., Crawford, D. B., et al,, "Double-Walled Cryogenic Storage Tanks - } \\
\text { Effect of Perite/Fiberglass insulation on Dynamic Loads in Case of Inter Tank } \\
\text { Failure," in Cryogenic Processes and Equipment 1982, AlChE, 224, Vol. 79, } \\
\text { 1983, pp 46-50. }\end{array}$ \\
\hline Ageyev 83 & $\begin{array}{l}\text { Ageyev, A. I., Afferov, V. N., and Mulholland, G. T., "Tunnel Nitrogen Spill } \\
\text { Experiment," FNAL-TM-1207, Fermi National Accelerator Laboratory, Batavia, IL, } \\
18 \text { Aug 1983. }\end{array}$ \\
\hline AlAbdukally 87 & $\begin{array}{l}\text { Al-Abdulally, Fakah; ALShuwaib, Saad; and Gupta, B. L., "Hazard Analysis and } \\
\text { Safety Considerations in Refrigerated Ammonia Storage Tanks," PlantOperations } \\
\text { Progress, Vol. 6, No. 2, April 1987, pp. 84-88. }\end{array}$ \\
\hline Albritton 94 & $\begin{array}{l}\text { D. L. Albritton, ef al,, Trace Gas Radiative Forcing Indices," chapter } 5 \text { in Climate } \\
\text { Change 1994: Radiative Foraing of Cimate and an Evaluation of the IPCC } 1992 \\
\text { Emission Scenarios, John T. Houghton, Ed., Cambridge University Press, } 1995 .\end{array}$ \\
\hline Ale 81 & $\begin{array}{l}\text { Ale, B.J.M., Bruning, F., and Koenders, H.A.A., "The Limits of Flammability of } \\
\text { Mixtures of Ammonia, Hydrogen and Methane in Mixtures of Nitrogen and Oxygen } \\
\text { at Elevated Temperatures and Pressures," Joumal of Hazardous Materials } 4 \\
\text { (1981) 283-289. }\end{array}$ \\
\hline Alexeeff 93 & $\begin{array}{l}\text { Alexeeff, George V., Lipsett, M. J., and Kizer, K.W., "Problems Associated with } \\
\text { the Use of Immediately Dangerous to Life and Health (IDLH) Values for Estimating } \\
\text { the Hazard of Accidental Chemical Releases," Am. Ind. Hyg. Assoc. J. 50(11): } \\
598-605 \text { (1989). }\end{array}$ \\
\hline Allan 68 & $\begin{array}{l}\text { Allan, Donald S., and Athens, Peter, "Influence of Explosions on Design," Loss } \\
\text { Prevention, Vol. 2, 1968, pp. 103-109. }\end{array}$ \\
\hline Allan 74 & $\begin{array}{l}\text { Allan, D., et al., Technology and Current Practices for Processing, Transferning, } \\
\text { and Storing Liquefied Natural Gas," Arthur D. Little, Inc., Prepared for USDOT, } \\
\text { Off. of Pipeline Safety, C-76971, DOT-OS-40171, Dec. 1974. }\end{array}$ \\
\hline Allman 85 & $\begin{array}{l}\text { Allman, W. F., "Staying alive in the 20th century," Science } 4 \text { October 1985, } \\
\text { (pp.30-37). }\end{array}$ \\
\hline Alvarez 95 & $\begin{array}{l}\text { Alvarez, R. A., et al., Technology Demonstration of Dedicated Compressed } \\
\text { Natural Gas (CNG) Original Equipment Manufacturer (OEM) Vehicles at Ft. Bliss, } \\
\text { Texas," Southwest Research Institute, San Antonio, Nov. 19e5. }\end{array}$ \\
\hline Ames 88 & $\begin{array}{l}\text { Ames, S., and Crowhurst, D., "Domestic Explosion Hazards from Small LPG } \\
\text { Containers," Joumal of Hazardous Materials, } 19 \text { (1988) 183-194. }\end{array}$ \\
\hline Andrews 80 & $\begin{array}{l}\text { Assessment of the Risk of Transporting Liquid Chlorine by Ral,, Andrews, W.B., } \\
\text { Battelle Pacific Northwest Labs., Richland, WA, Mar 1980, } 189 \text { p. }\end{array}$ \\
\hline
\end{tabular}




\begin{tabular}{|c|c|}
\hline API 1003 & $\begin{array}{l}\text { Precautions Against Electrostatic Ignition During Loading of Tank Motor Vehicles, } \\
\text { API Publication 1003, Third Edition, American Petroleum institute, March } 1986 .\end{array}$ \\
\hline API 1621 & $\begin{array}{l}\text { Butk Liquid Stock Control at Retai Outlets, API Recommended Practice 1621, } 5 \text { th } \\
\text { Ed. May 1993, American Petroleum Institute, } 1220 \text { L St. NW, Washington DC, } \\
\text { 20005. }\end{array}$ \\
\hline API 1669 & $\begin{array}{l}\text { Results of a Retai Gasoline Outet And Commercial Parking Lot Storm Water } \\
\text { Runoff Study, API Publication 1669, American Petroleum institute, } 1220 \mathrm{~L} \text { Street, } \\
\text { NW, Washington, DC } 2005 \text {, December 1994. }\end{array}$ \\
\hline API 2003 & $\begin{array}{l}\text { Protection Against Ignitions Arising out of Static, Lightning, and Stray Currents, } \\
\text { API Recommended Practice 2003, Fith Edtion, American Petroleum Institute, } \\
\text { December } 1991 \text {. }\end{array}$ \\
\hline API 2510 & $\begin{array}{l}\text { Design and Construction of LPG Installations, Seventh Edition, API Standard } \\
\text { 2510, American Petroleum Institute, May } 1995 .\end{array}$ \\
\hline API 620 & $\begin{array}{l}\text { Design and Construction of Large, Welded, Low-Pressure Storage Tanks, } \\
\text { Appendx Q, Low-Pressure Storage Tanks for Liqueffed Hydrocarbon Gases, } \\
\text { API Standard 620, Ninth Edition, American Petroleum Institute, February } 1996 .\end{array}$ \\
\hline Arvidson 75 & $\begin{array}{l}\text { Arvidson, J. M., Hord, J., and Mann, D. B., "Dispersion of Hydrogen or Methane } \\
\text { Fuels Released into an Automobile Interior," in Acvances in Cryogenic } \\
\text { Engineering, Vol 21, K D. Timmerhaus and D. H. Weitzel, ed., Plenum Press, } \\
\text { New York, 1975, pp. } 387-398 .\end{array}$ \\
\hline ATA 95? & $\begin{array}{l}\text { Recommended Practices for LNG Powered Heavy Duty Trucks, ATA } \\
\text { Foundation Alternative Fuets Task force, Manufacturer's LNG Technical } \\
\text { Subcommittee, 1995? }\end{array}$ \\
\hline Atallah 90 & $\begin{array}{l}\text { S. Atallah, et.al. "Reduction of LNG Operator Error and Equipment Failure Rates," } \\
\text { Topical Report GRI-90/0008, Risk and Industrial Safety Consultants, Inc., Des } \\
\text { Plaines, It, } 20 \text { April } 1990 \text {. }\end{array}$ \\
\hline Atallah 91 & $\begin{array}{l}\text { Survey of Fire Protection Systems at LNG Facifies, GRL-91/0028, S. Atallah, } \\
\text { et.al., Risk and Industrial Safety Consultants, Inc, Des Plaines, IL, } 5 \text { Apr 91, 36 p. }\end{array}$ \\
\hline Augustynowiez 93 & $\begin{array}{l}\text { Augustynowicz, S. D., "ODH, Oxygen deficiency hazard cryogenic analysis," } \\
\text { SSCL-preprint-460, Jul 1993, }\end{array}$ \\
\hline$B-A 90$ & $\begin{array}{l}\text { Flammable Liquid Container Risk Analysis Review Survey Analysis Final Report, } \\
\text { Prepared for Athur D. Little, Inc. by Barton-Aschman Associates, inc, October 19, } \\
1990 \text {. }\end{array}$ \\
\hline Bagster 89 & $\begin{array}{l}\text { Bagster, D. F., and Pitblado, R. M., "Thermal Hazards in the Process Industry," } \\
\text { Chemical Engineering Progress, July 1989, pp. 69-75. }\end{array}$ \\
\hline Bain 76 & $\begin{array}{l}\text { Bain, J. L., "NASA Space Program Experience in Hydrogen Transportation and } \\
\text { Handing." Intemational Joumal of Hydrogen Energy, Vol. 1, pp. 173-188, } 1976 .\end{array}$ \\
\hline Baird 85 & $\begin{array}{l}\text { Baird, I. S. and Thomas, H. (1985). Toward a contingency model of strategic risk } \\
\text { taking. Acaderny of Management Review (10), (pp.230-243). }\end{array}$ \\
\hline Baker 91 & $\begin{array}{l}\text { Baker, Wilfred E., and Tang; Ming Jun, Gas, Dust and Hybrid Explosions, } \\
\text { Elsevier, Amsterdam, 1991. }\end{array}$ \\
\hline Banfield 90 & $\begin{array}{l}\text { Banfield, G. R., and Fairbaim, G. W., "Operational Experiences with LNG storage } \\
\text { tanks," Proc Insth Mech Engrs, Vol 204, (1990), 25-41. }\end{array}$ \\
\hline Bartknecht 88 & $\begin{array}{l}\text { Bartknecht, W., "Ignition Capabilities of Hot Surfaces and Mechanically Generated } \\
\text { Sparks in Flammable Gas and Dust/Air Mixtures," Plant/Operations Progress, } \\
\text { Vol. 7, No. 2, April 1988, pp. 114-121. }\end{array}$ \\
\hline Baver 92 & $\begin{array}{l}\text { Bauer, Benoit; and Havens, Jerry, "Simulation of LNG Vapor Cloud Dispersion } \\
\text { Performed with the Three Dimensional Numerical Modets, FEMBA and } \\
\text { MERCURE GL," poster 15, Tenth Int Conf on Liq Nat Gas, Kuala Lumpur, May } 25 \\
\text { 28, 1992, IGT, Chicago, 1992. }\end{array}$ \\
\hline Bazerman 86 & $\begin{array}{l}\text { Bazerman, M. (1986). Judgment in Managerial Decision Making. New York: } \\
\text { Wiley. }\end{array}$ \\
\hline
\end{tabular}




\begin{tabular}{|c|c|}
\hline $8 C C 91$ & $\begin{array}{l}\text { Cryogenics Safety Manual, a guide to good practice, Third Edfion, Safety Panel, } \\
\text { British Cryogenics Council, Butterworth-Heinemamn Ltd. Linacre House, Jordan } \\
\text { Hill, Oxford OX2 8DP, 1991. }\end{array}$ \\
\hline Beale 96 & $\begin{array}{l}\text { Beale, Jeff, "The 'One-Stop' Fueling Station," presented at the 14th National } \\
\text { Conference and Exhibition, Dalls, TX, September 15-17, 1996. }\end{array}$ \\
\hline Bechtold 97 & $\begin{array}{l}\text { Richard Bechtold, "Petroluem Use and Greenhouse Gas Emissions of Selected } \\
\text { Alternative Fuets," EA Engineering, Science and Technology, Inc. } 18 \text { April } 1997 .\end{array}$ \\
\hline Bernert 86 & $\begin{array}{l}\text { Bernert, Robert E., "Ambient Cryogenic Vaporizers: Their Limits Due to Frost } \\
\text { Formation," in Cryogenic Properties, Processes and Applications 1986, AlCHe, } \\
\text { 251, Vol 82, 1986, pp. 71-74. }\end{array}$ \\
\hline Bernert 93 & $\begin{array}{l}\text { Bemert, R. E., Jr., Everett, W., and Bemert R. E. , Sr., "Cryogenic ambient air } \\
\text { vaporizers: frost growth, wind and seismic design for safety," Cryogenics, Vol 33, } \\
\text { No. 8, pp. } 789-793,1993 \text {. }\end{array}$ \\
\hline Birk 96 & $\begin{array}{l}\text { Birk, A. M., and Cunningham, M.H., "Liquid temperature stratification and its } \\
\text { effect on BLEVEs and their hazands," Joumal of Hazardous Materials, } 48 \text { (1996) } \\
\text { 219-237. }\end{array}$ \\
\hline Black 91 & $\begin{array}{l}\text { Black, F. M., Overview of the Technical Implications of Methand and Ethand as } \\
\text { highway Motor Vehicfe Fuels, Environmental Protection Agency, Research } \\
\text { Triangle Park, NC, Atmospheric Research and Exposure Assessment Lab. 1991, } \\
32 \text { p. }\end{array}$ \\
\hline Blades 88 & $\begin{array}{l}\text { Blades, C. J., "Safe transport of cryogenic liquids by rcad," Cyyogenics, Vol 28, } \\
\text { pp 853-855, December 1988. }\end{array}$ \\
\hline $\begin{array}{l}\text { Blanken } 87 \text { (attached } \\
\text { to Al-Abdulally } 87 \text { ) }\end{array}$ & $\begin{array}{l}\text { Btanken, Jan M., "Corments on "Hazard Anahysis and Safety Consideration in } \\
\text { Refrigerated Ammonia Storage Tanks" by Falah Al-Abdulally, Saad Al-Shwaib and } \\
\text { B. L Gupta," PlantOperations Progress, Vol 6, No 4, October 1987, pp. O6-08. }\end{array}$ \\
\hline Blaylock 85 & $\begin{array}{l}\text { Blaylock, B. K. (1985). Risk perception: evidence of an interactive process. } \\
\text { Journal of Business Research (13), (pp.207-221). }\end{array}$ \\
\hline Blything 85 & $\begin{array}{l}\text { Blything, KW., and Lewis, R.C.E., "Incident Probabilities on Liquid Gas Ships, } \\
\text { SRD-R-340, UKAEA Safety and Reliability Directorate, Culcheth, Nov 1985, } 43 \text { p. }\end{array}$ \\
\hline Boesmans 92 & $\begin{array}{l}\text { Boesmans, B., and Berghmans, J., "Risk Assessment for Unconfined Vapor } \\
\text { Cloud Explosions: The influence of Unknown Initial Conditions," Safety and } \\
\text { Relabity 92, Kurt E. Petersen and Brigitte Rasmussen, ed., Elsevier, London, } \\
\text { 1992, pp. 11741185. }\end{array}$ \\
\hline Bogani 92 & $\begin{array}{l}\text { Bogani, Farid; "Initial Experience with the NWS LNG Plant," paper II-4, Tenth } \\
\text { Intermational Conference on Liquefied Natural Gas, Kuala Lumpur, May 25-28, } \\
\text { 1992, Inst. of Gas Technology, Chicago, } 1992 .\end{array}$ \\
\hline Bolan 74 & $\begin{array}{l}\text { Bolan, Robert J., "Safety and Design Priorities for LNG Terminals," Pipeline and } \\
\text { Gas Joumal, Vol. } 201 \text { June 1974, pp. 46-56. }\end{array}$ \\
\hline Bourguet 73 & $\begin{array}{l}\text { Bourguet, J.M., "Cryogenic Technology and Scaleup Problems of Very Large } \\
\text { LNG Plants," in Advances in Cryogenic Engineering, Vol 18, K D. Timmerhaus, } \\
\text { ed., Plenum Press, New York, 1973, pp. 9-26. }\end{array}$ \\
\hline Bowman 80 & $\begin{array}{l}\text { Bowman, E. H. (1980). A risk/retum paradox for strategic management. Sloan } \\
\text { Management Review Spring 1980, (pp.17-31). }\end{array}$ \\
\hline Box 69a & $\begin{array}{l}\text { Box, Paul C., "Oriveway Accident and Volume Studies, Part II - Service Stations," } \\
\text { Public Safety Systems, JuhlAug 1969, Vol. 34, No. 4, pp. 15-19, Jefferson Pub., } \\
\text { Inc., } 5811 \text { Dempster St. Morton Grove, IL 60053. }\end{array}$ \\
\hline Box 696 & $\begin{array}{l}\text { Box, Paul C., "Driveway Accident and Volume Studies, Part III -Design } \\
\text { Considerations," Public Safety Systems, SeptOct 1969, Vol. 34, No. 4, Pp. 15- } \\
\text { 19, Jefferson Pub., Inc., } 5811 \text { Dempster St. Morton Grove, Il 60053. }\end{array}$ \\
\hline Brailovshy 97 & $\begin{array}{l}\text { Brailovsky, l. and Sivashinsky, G. I., "On Stationary and Traveling Fiame Balls," } \\
\text { Combustion and Fire, 110:524-529 (1997). }\end{array}$ \\
\hline Brasie 68 & $\begin{array}{l}\text { Brasie, W. C., and Simpson, D.W., "Guidelines for Estimating Damage } \\
\text { Explosion," Loss Prevention, Vol. 2, 1968. pp. 91-102. }\end{array}$ \\
\hline Brinkley 69 & $\begin{array}{l}\text { Brinkdey, S. R., "Determination of Explosion Yields," Loss Prevention, Vol. 3, } \\
1969, \text { pp. 79-82. }\end{array}$ \\
\hline
\end{tabular}




\begin{tabular}{|c|c|}
\hline British Gas & $\begin{array}{l}\text { "Liquefied Natural Gas Research," undated brochure by British Gas Research and } \\
\text { Technology, Loughborough, Leicestershire LE11 3QU, UK. }\end{array}$ \\
\hline Brocktaus 80 & $\begin{array}{l}\text { Brocktraus. R. H. (1980). Risk-taking propensity of entrepreneurs. Acadermy of } \\
\text { Management Joumal (23), (pp. 509-520). }\end{array}$ \\
\hline Broschika 83 & $\begin{array}{l}\text { Broschka, G. L., Ginsburgh, I., Mancini, R. A., and Will, R. G., "A Study of Flame } \\
\text { Arrestors in Piping systems," PlantOPerations Progress, Vol. 2, No. 1, January } \\
1983, \text { pp. 5-12 }\end{array}$ \\
\hline Brown SS & $\begin{array}{l}\text { Brown, Samuel J. and Brown, Troy J., "Hazardous Release Protection: Code and } \\
\text { Standard Considerations for Pressure Systems," Process Safety Progress, Vol. } \\
\text { 14, No. 4, October 1995, pp. 244-256. }\end{array}$ \\
\hline Bull 76 & $\begin{array}{l}\text { Bufl, D.C., Elsworth, J. E., Hooper, G., and Quinn, C. P., "A study of spherical } \\
\text { detonation in mixtures of methane and oxygen diluted by nitrogen," J. Phys. D, } \\
\text { Vol. 9, pp. 1991-2000, } 1976 \text {. }\end{array}$ \\
\hline Bull 92 & $\begin{array}{l}\text { Bull, David C., "Review of Large-Scale Explosion Experiments," Plantroperations } \\
\text { Progress, Vol. 11, No. 1, January 1992, pp. 33-40. }\end{array}$ \\
\hline Burgbacher 91 & $\begin{array}{l}\text { Burgbacher, Guenter and Falk, Siegfried, "Safety Analysis of a Liquid Natural Gas } \\
\text { Plant," Reliabity 91, R. H. Matthews, ed., Elsevier, London, 1991, pp. 839-852 }\end{array}$ \\
\hline Burgess 61 & $\begin{array}{l}\text { Burgess, David, and Zabetalis, Michael G., "Fire and Explosion Hazards } \\
\text { Associated with Liquefied Natural Gas," Report of Investigations } 6099, \text { Bureau of } \\
\text { Mines, Dept. of the Interior, Dec. 1961. }\end{array}$ \\
\hline Burgess 77 & $\begin{array}{l}\text { Burgess, Wm. A., Diberardinis, Louis and Speizer, F. E., "Health Effects of } \\
\text { exposure to automobile exhaust - V. exposure of toll booth operators to automobile } \\
\text { exhaust," Am. Ind. Hyg. Assoc. J., (38) April 1977, pp. 184191. }\end{array}$ \\
\hline Butler 86 & $\begin{array}{l}\text { Butter, John A., Motor vehicle fires in Ireland and the UK," Fire Prevention, No. } \\
\text { 195, December 1986, pp. 22-25. }\end{array}$ \\
\hline C\&EN 78 & $\begin{array}{l}\text { OTA says LNG safety data inconclusive," Chemical and Engineering News, Vol. } \\
56, \text { No. 23, June 5, 1978, pp. 5-6. }\end{array}$ \\
\hline Cain 85 & $\begin{array}{l}\text { Cain, William S., and Turk, Amos, "Smell of Danger: An Anahysis of LP-Gas } \\
\text { Odorization," Am. Ind. Hyg. Assoc. 46(3):115-126 (1985). }\end{array}$ \\
\hline Cannon 93 & $\begin{array}{l}\text { Cannon, James Spencer, Paving the Way to Natural Gas Vohicles, INFORM, } \\
\text { inc., } 381 \text { Park Avenue South, Ny 10016-8806, 212-689-4040, 1993. }\end{array}$ \\
\hline Cashman 83 & $\begin{array}{l}\text { Cashman, J. R., "Mayday, Mayday, There's Been an Explosion in Waverty," } \\
\text { Chapter } 2 \text { in Hazardous Materials Emergencies Response and Control, } \\
\text { Technomic Pubtishing Co., Inc., Lancaster PA, 1983. }\end{array}$ \\
\hline Cassidy 93 & $\begin{array}{l}\text { Cassidy, K, "Risk assessment and the safety of large cryogenic systems and } \\
\text { plant in the UK and Europe," Cryogenics, Vol 33, No 8, pp 755-761, } 1993 .\end{array}$ \\
\hline CFMCS 89 & $\begin{array}{l}\text { Caffomia Fuel Methanol Cost Study, Executive Summary, Chevron, U.S.A., Inc., } \\
\text { San Francisco, January } 1989 .\end{array}$ \\
\hline Chan 88 & $\begin{array}{l}\text { Chan, S. T., "FEMBA: A Finite Element Model for the Simulation of Gas Transport } \\
\text { and Dispersion: User's Manual," Lawrence Livermore National Laboratory, A;pril } \\
\text { 1988. }\end{array}$ \\
\hline Chan 92 & $\begin{array}{l}\text { Chan, S.T., "Numerical Simulations of LNG Vapor Dispersion from a Fenced } \\
\text { Storage Area," Joumal of Hazardous Materials, 30, (1992), 195-224. }\end{array}$ \\
\hline Cheng 84 & $\begin{array}{l}\text { Cheng, Y. S., Yeh, H. C., Mauderty, J. L, and Molder, B. V., "Characterization of } \\
\text { Diesel Exhaust in a Chronic Inhalation Study," Am. Ind. Hyg. Assoc. J., 45(8): } 547 \\
555 \text { (1984). }\end{array}$ \\
\hline Chevron 96a & $\begin{array}{l}\text { "Filling Metal Gasoline Cans Placed on Plastic Surfaces Creates Fire Danger," } \\
\text { Chevron Technical Bulletin downbaded } 9 / 27 / 96 \text { from } \\
\text { http:/Www.chevron.com/chevron_root/prodserv/bulletin/plastic_fire.html }\end{array}$ \\
\hline Chevron S6b & $\begin{array}{l}\text { Waming from Chevron," flyer downloaded from } \\
\text { http://WwW.mint.netloshcom/explode.html }\end{array}$ \\
\hline Chiu ? & $\begin{array}{l}\text { Chiu, C., Kinard, F. E., and J. M. Geist, "Depressuring Analysis for Cryogenic } \\
\text { Plant Safety," pp. 57-60. }\end{array}$ \\
\hline
\end{tabular}




\begin{tabular}{|c|c|}
\hline Clayion 94 & $\begin{array}{l}\text { Clayton, W. Edward and Griffin, Michael, L, "Catastrophic Failure of a Liquid } \\
\text { Carbon Dioxide Storage Vessel," Process Safety Progress, Vol. 13, No. 4, } \\
\text { October 1994, pp. 202-209. }\end{array}$ \\
\hline Cleaver 92 & $\begin{array}{l}\text { Cleaver, R. P., Cooper, M. G., and Britter, R. E., "Modelling LNG Releases at } \\
\text { Storage Facities," poster 27, Tenth International Conference on Liquefied Natural } \\
\text { Gas, Kuala Lumpur, May 25-28, 1992, inst. of Gas Technology, Chicago, } 1992 .\end{array}$ \\
\hline Clfford 87 & $\begin{array}{l}\text { Clifford, P. K, etal., Evaluation of Low-Cost Gas Sensor Technology, Phase 2, } \\
\text { Final Report June-September 1986, GR1-870028, PB89-131072, Mosaic } \\
\text { industries, inc., Mountain View, CA, Jan. 87, 42 p. }\end{array}$ \\
\hline Closner 78 & $\begin{array}{l}\text { Closner, John J., "Safety of storage designs compared," The Oi and Gas } \\
\text { Joumal, Vol. 76, Feb. 13, 1978, pp. 121-125. }\end{array}$ \\
\hline Cole 887 & Cole, Lee S., A Survey of Vehiclo Firo Causes, Lee Books, ISBN 0-939818-16-7. \\
\hline Cole 92 & $\begin{array}{l}\text { Investigation of Motor Vehicie Fires, Lee S. Cole. Lee Books, P.O. Box } 906 \\
\text { Novato, CA } 94948,(415-456-4388), 1992 .\end{array}$ \\
\hline Collins 92 & $\begin{array}{l}\text { Collins, Cyril, et al., "Liquefaction Plant Design in the 1990"s," paper I1-6, Tenth } \\
\text { international Conference on Liquefied Natural Gas, Kuala Lumpur, May 25-28, } \\
\text { 1992, Inst. of Gas Technology, Chicago, } 1992 .\end{array}$ \\
\hline Collison 97 & $\begin{array}{l}\text { Colisson, Charles E., III, Richard L. Bechtold and Jerry L Gibbs, "Marytand Mass } \\
\text { Transit Administration Demonstratioin of Liquefied Natural Gas Transit Buses," } \\
\text { International Spring Fuels \& Lubricants Mtg, Dearbom, MI, May 5-8, 1997, SAE, } \\
\text { SP-1274, 97166. }\end{array}$ \\
\hline Contey 91 & $\begin{array}{l}\text { Conley, Michael J.; Angetson, Sture; and Williams, David, "Ammonia Vessel } \\
\text { Integrity Program: A Modern Approach," Plant'Operations Progress, Vol 10, No. } \\
\text { 4, October 1991, pp. 201-206. }\end{array}$ \\
\hline Conley 96 & $\begin{array}{l}\text { Conley, Christopher J., "Deadlier Than You Think," NFPA Joumal, Volume } 90 \text { pp. } \\
79-84 \text {. Sept-Oct. } 96 \text {. }\end{array}$ \\
\hline Corradini 84 & $\begin{array}{l}\text { Corradini, M. L, "Molten Fuel / Coolant Interactions: Recent Anatysis of } \\
\text { Experiments," Nuclear Science and Engineering, Vol. 86, pp. 372-387, } 1984 .\end{array}$ \\
\hline Courtay 92 & $\begin{array}{l}\text { Courtay, Roger, "Propulsion of LNG Carriers by Steam Turbines; A necessity or a } \\
\text { Tradition," paper IV-9, Tenth International Conference on Liquefied Natural Gas, } \\
\text { Kuala Lumpur, May 25-28, 1992, inst. of Gas Technology, Chicago, } 1992 .\end{array}$ \\
\hline Covello 86 & $\begin{array}{l}\text { Covello, V., Menkes, J., and Mumpower, J. (Eds.) (1986). Risk Evaluation and } \\
\text { Management. NY: Plenum Press. }\end{array}$ \\
\hline Covello 91 & $\begin{array}{l}\text { Covello, V., Sandman, P., and Slovic, P. (1991). Guidelines for communicating } \\
\text { information about chemical risks effectively and responsibly. In Mayo, D. and } \\
\text { Hollander, R., (Eds.) Acceptable Evidence (pp.66-90). NY: Oxford University } \\
\text { Press. }\end{array}$ \\
\hline Croce 82 & $\begin{array}{l}\text { Croce, Paul A., Laroque, G., Long, M.H., and Bendixen, LM., A Feasibility Study } \\
\text { of a Sealed Safety Monitor for Trucks Carying LNG and Other Hazardous } \\
\text { Materists, DOE/EV/1C502-1, Arthur D. Little, Inc., Cambridge, MA, December } \\
1982 .\end{array}$ \\
\hline Davenport 87 & $\begin{array}{l}\text { Davenport, John A., "Gas Plant and Fuel Handling Faciftites: An Insurer's View," } \\
\text { PlantOPerations Progress, Vol. 6, No. 4, October 1987, pp. 199-202. }\end{array}$ \\
\hline De Steese 96 & $\begin{array}{l}\text { De Steese, John, PNNL, "Project Bibliographies from related project areas," fax } \\
\text { to Bruce Wilding, INEL, October 21, } 1996 \text {. }\end{array}$ \\
\hline Deal 82 & $\begin{array}{l}\text { Deal, T. E., and Kennedy, A. A. (1982). Corporate Cultures: The Rites and } \\
\text { Rituals of Corporate Life. Reading, MA: Addison-Wesley. }\end{array}$ \\
\hline Dean 73 & $\begin{array}{l}\text { Dean, L. E., "Heat Transfer Problems in Liquefied Natural Gas Ptants," in } \\
\text { Advances in Cryogenic Engineering, Vol 18, K. D. Timmerhaus, ed., Plenum } \\
\text { Press, New York, 1973, pp. 27-31. }\end{array}$ \\
\hline Delboy 91 & $\begin{array}{l}\text { Delboy, W. J., Dubnansky, R. F., and Lapp, Steven, "Sensitivity of Process Risk } \\
\text { to Human Error in an Ammonia Plant," Plant/Operations Progress, Vol. 10, No. 4, } \\
\text { October 1991, pp. 207-211. }\end{array}$ \\
\hline
\end{tabular}




\begin{tabular}{|c|c|}
\hline Deshotels 95 & $\begin{array}{l}\text { Deshotels, Robert and Dejmek, Mark, "Choosing the Level of Detail for Hazard } \\
\text { lointification," Process Safoty Progress, Vol. 14, No. 3, pp. 218-225, Juty 19S5. }\end{array}$ \\
\hline Dietz 97 & $\begin{array}{l}\text { Diet, Dan, "You can Trust Your Car to the Robot who Wears the Star," } \\
\text { Inputoutput, Mechanical Engineering, Febnuary, 1997, p. 122. }\end{array}$ \\
\hline DOESPE-0100P & $\begin{array}{l}\text { Assessment of Costs and Beneits of Flexible and Aftemative Fuel Use in the U. } \\
\text { S. Transportation Sector, Technical Report Seven: Environmental, Hea/th and } \\
\text { Safety Concerms, DOE/PE-0100P, US Dept of Energy, October 1991. }\end{array}$ \\
\hline Douglas 82 & $\begin{array}{l}\text { Douglas, N., and Widavsky, A. (1982). Risk and Cuthure. Berkeley. University of } \\
\text { Calfomia Press. }\end{array}$ \\
\hline Douglas 85 & $\begin{array}{l}\text { Douglas, M. (1985). Risk Acceptability According to the Social Sciences. New } \\
\text { York Russell Sage Foundation. }\end{array}$ \\
\hline Drake 73 & $\begin{array}{l}\text { Drake, Elizabeth M, Geist, J. M., and Smith, K A., "Prevent LNG 'rollover," } \\
\text { Hydrocarbon Processing, Vol 52, March 1973, pp 87-90. }\end{array}$ \\
\hline Drake 75 & $\begin{array}{l}\text { Drake, E. M., and Putman, A. A., "Vapor Dispersion from Spills of LNG on Land, " } \\
\text { in Advances in Cryogenie Engineening. Vol 20, K D. Timmertaus, ed., Plenum } \\
\text { Press, New York, 1975, pp. 134142. }\end{array}$ \\
\hline Drakopolis 93 & $\begin{array}{l}\text { Drakopolis, A., et.al., Attemative Fuek for Buses and Other Heavy Vehictes, Final } \\
\text { Report, May } 90 \text { - Sep 93, GLCTTR-20-91/4, Great Lakes Center for Truck } \\
\text { Transportation Research, Ann Arbor, MI, Oct 93, } 247 \text { p. }\end{array}$ \\
\hline Drysctale 85 & $\begin{array}{l}\text { An introduction to Fire Dynamies, Dougal Dryscdale, John Wiley and Sons, New } \\
\text { York, } 1985 .\end{array}$ \\
\hline Duncan 72 & $\begin{array}{l}\text { Duncan, R. B. (1972). Characteristics of organizational environments and } \\
\text { perceived environmental uncertainty. Administrative Science Quarterty (17), } \\
\text { (pp.313-327). }\end{array}$ \\
\hline Dutcher 84 & $\begin{array}{l}\text { Dutcher, J. S., Sun, J. D., Lopez, J. A., Wolf, I., Wolff, R. K, and McClellan R. } \\
\text { O., "Generation and Characterization of Radiolabeled Diesel Exhaust," American } \\
\text { industrial Hygiene Association Joumal, (45) July 1979, pp. 491-498. }\end{array}$ \\
\hline Dutton 87a & $\begin{array}{l}\text { Dutton J. E., and Duncan, R. B. (1987). The creation of momentum for change } \\
\text { through the process of strategic issue diagnosis. Strategic Management Journal } \\
\text { (8) (pp.279-295). }\end{array}$ \\
\hline Dutton $87 \mathrm{~b}$ & $\begin{array}{l}\text { Dutton, F. E., and Jackson, S. E. (1987). Categorizing strategic issues: Links to } \\
\text { organizational actions. Academy of Management Review (11), (pp.76-90). }\end{array}$ \\
\hline Edeskity 71 & $\begin{array}{l}\text { Edeskuty, F. J., Reider, R., and Williamson, Jr., K D., "Safety," Chapter } 11 \text { in } \\
\text { Cryogenic Fundamentals, Haselden, GG, Academic Press, London, 1971, pp. } \\
633-672 \text {. }\end{array}$ \\
\hline Edeskuty 96 & $\begin{array}{l}\text { Safety in the Handing of Cryogenic Fuids, Frederick J. Edeskuty and Walter F. } \\
\text { Stewart, Plenum Press, New York, 1996. }\end{array}$ \\
\hline Edwards 86 & $\begin{array}{l}\text { Edwards, W., and von Winterfeldt, D. (1986). Public disputes about risky } \\
\text { technologies, stakeholders and arenas. In Covello, V., Menkes, J., and } \\
\text { Mumpower, J. (Eds.) Risk Evaluation and Management (pp. 69-92). NY: } \\
\text { Plenum Press. }\end{array}$ \\
\hline Ekstrom 92 & $\begin{array}{l}\text { Ekstrom, Thomas E, and Garrison, Phillip E., "Large Gas Turbines for LNG } \\
\text { Refrigeration Process Application," paper II-10, Tenth. International Conference on } \\
\text { Liquefied Natural Gas, Kuala Lumpur, May 25-28, 1992, Inst. of Gas Technology, } \\
\text { Chicago, } 1992 .\end{array}$ \\
\hline Elliott 46 & $\begin{array}{l}\text { Elliott, M. W., Seibel, C. W., et al, Report on the Investigation of the Fire at the } \\
\text { Liquefaction, Storage, and Regasification Plant of the East Ohio Gas Co., } \\
\text { Cleveland, Ohio, October 20, 1944, B of Mines R. 1. 3857, Feb. 1946. }\end{array}$ \\
\hline Elliott 88 & $\begin{array}{l}\text { Elliott, M. J., "Use of quantified risk assessment techniques in relation to major } \\
\text { hazard installations," Cryogenics, Vol 28, pp 835837, December } 1988 .\end{array}$ \\
\hline Emerson 82 & $\begin{array}{l}\text { Emerson, E. L., McClure, J. D., Accident-Incident History in the Transportation of } \\
L W \text { Since 1971, SAND-82-1417. Sandia National Laboratories, Albuquerque, } \\
\text { NM, August 1982, } 8 \text { p. }\end{array}$ \\
\hline
\end{tabular}




\begin{tabular}{|c|c|}
\hline Emya 86 & $\begin{array}{l}\text { Enya, Shintaro; and Morioka, Mikjo; "An Engineering Simulation of LNG Tank } \\
\text { Rollover, "in Advances in Cryogenic Engineering, Vo' 31, R. W. Fast, ed., } \\
\text { Plenum Press, New York, 1986, pp. 1151-1159. }\end{array}$ \\
\hline EPA-450 & $\begin{array}{l}\text { Guvidance on the Application of Refined Dispersion Models for Air Toxias } \\
\text { Releases, EPA-450/4-91-007, Office of Air Quality Planning and Standards, U.S. } \\
\text { Environmental Protection Agency, Research Triangle Park, NC 27711, March } \\
1991\end{array}$ \\
\hline Erwin 94 & $\begin{array}{l}\text { Erwin, J., Moulton, D. S., and Hetrick, D. L, Maintenance and operation of the } \\
\text { USDOE Akernative Fuel Center, NRELTP-425-20245, National Renewable } \\
\text { Energy Laboratory, Golden, CO, Aug } \$ 994,50 \text { p. }\end{array}$ \\
\hline Fay 73 & $\begin{array}{l}\text { Fay, James A., "Unusual Fire Hazard of LNG Tanker Spills," Combustion and } \\
\text { Fire Technology, Vol 7, pp. 47-49, } 1973 \text {. }\end{array}$ \\
\hline Fay 76 & $\begin{array}{l}\text { Fay, James A, and Lewis, David H., Jr., "Unsteady Buming of Unconfined Fuel } \\
\text { Vapor Clouds," 16th Intemational Symposium on combustion, Aug 15-20, 1976, } \\
\text { MIT, Cambridge, MA, pp 1397-1405. }\end{array}$ \\
\hline Fay 79 & $\begin{array}{l}\text { Fay, James A., Descroseilliers, Gary, J., and Lewis, David, H., "Radiation from } \\
\text { Buming Hydrocarbon Clouds," Combustion Science and Technology, Vol. 20, pp. } \\
141-151,1970 \text {. }\end{array}$ \\
\hline Fischhoff 81 & $\begin{array}{l}\text { Fischhoff, B., Lichtenstein, S., Slovic, P., Derby, S. L, and Keeney, R. L (1981). } \\
\text { Acceptable Risk. Cambridge: Cambridge University Press. }\end{array}$ \\
\hline Fomasiero 86 & $\begin{array}{l}\text { Fornasiero, Gary R., "LNG Tank Foundation Heating Parameters, "in Advances } \\
\text { in Cyogenic Engineering, Vol 31, R. W. Fast, ed., Plenum Press, New York, } \\
\text { 1986, pp. 1141-1149. }\end{array}$ \\
\hline FR 80a & $\begin{array}{l}\text { "Liquefied Natural Gas Facilities; New Federal Safety Standards (Final rule)," } \\
\text { [Design and Construction] Federal Register, Vol. 45, No. 29, pp. 91849219. }\end{array}$ \\
\hline FR 80b & $\begin{array}{l}\text { "Liquefied Natural Gas Facilities; Federal Safety Standards, (Notice of proposed } \\
\text { rulemaking)" [operations, maintenance, fire control...] Federal Register, Vol. 45, } \\
\text { No. } 29, \text { pp. } 9220-9237 \text {. }\end{array}$ \\
\hline FR 80C & $\begin{array}{l}\text { "Liquefied Natural Gas Faciities; Federal Safety Standards, (Final rule)," } \\
\text { [operations, maintenance, fire control,...], Federal Register, Vol. 45, No. 207, pp. } \\
70390-70410 \text {. }\end{array}$ \\
\hline Frangesh 75 & $\begin{array}{l}\text { Frangesh, N. E., and Randall, Jr., G. A., "Distrigas LNG Barge Operating } \\
\text { Experience," in Advances in Cryogenic Engineering, Vol 21, K D. Timmerhaus } \\
\text { and D. H. Weitzel, ed., Plenum Press, New York, 1975, pp. 337-345. }\end{array}$ \\
\hline Frayne 85 & $\begin{array}{l}\text { Frayne, Roger, "Session II: Heavy Gas Dispersion - Applied Safety, Session } \\
\text { chaiman's Introductory Remarks," Proceectings of the Heavy Gas (LNG/PG) } \\
\text { Workshop, Toronto, 29-30 June 1985, pp. 108-116. }\end{array}$ \\
\hline Freeman 92 & $\begin{array}{l}\text { Freeman, R. A., and Shaw, D. A., "The Use of Spreadsheets in Modelling } \\
\text { Accidental Releases of Toxic Chemical," Plant/Operations Progress, Vol 11, No. } \\
\text { 2, April 1992, pp. 71-76. }\end{array}$ \\
\hline Freudenberg 88 & $\begin{array}{l}\text { Freudenberg, William R., "Perceived Risk, Real Risk. Social Science and the Art } \\
\text { of Probabilistic Risk Assessment," Science, Vol. 242, } 7 \text { October 1988, pp. 44-49. }\end{array}$ \\
\hline Frondeville $\pi$ & $\begin{array}{l}\text { Frondeville, Bertrand de, "Reliability and Safety of LNG Shipping: Lessons from } \\
\text { Experience," SNAME Transactions, Vol. 85, 1977, pp. 459-480. }\end{array}$ \\
\hline Fthenalis 93 & $\begin{array}{l}\text { Fthenakis, Vasilis M., Prevention and Control of Accidental Releases of } \\
\text { Hazardous Gases, Van Nostrand Reinhold, New York, } 1993 .\end{array}$ \\
\hline Fulford 88 & $\begin{array}{l}\text { Fulford, N. J., and Slatter, M. D., "Developments in the safe design of LNG } \\
\text { tanks," Cryogenics, Vol 28, pp 810-817, December } 1988 .\end{array}$ \\
\hline GAO 78 & $\begin{array}{l}\text { Liquefied Energy Gases Safety, GAO-EMD-78-28, General Accounting Office, } \\
\text { Washington DC, July 31, } 1978 .\end{array}$ \\
\hline Gaumer 86 & $\begin{array}{l}\text { Gaumer, Lee S., "LNG Processes," in Advances in Cyogenic Engineering, Vol } \\
\text { 31, R. W. Fast, ed., Plenum Press, New York, 1986, pp. } 10051100 .\end{array}$ \\
\hline
\end{tabular}




\begin{tabular}{|c|c|}
\hline Gefien 80 & $\begin{array}{l}\text { Geffen, C. A. (Proj coord.), "An Assessment of the Risk of Transporting Propane } \\
\text { by Truck and Train," PNL-3308, Pacilic Northwest Laboratory, March } 1980 .\end{array}$ \\
\hline George 81 & $\begin{array}{l}\text { George, E. A., "Case History on Transportation," Lass Prevention, Vol. 14, (1981) } \\
\text { pp. 185-186. }\end{array}$ \\
\hline Germeles 75 & $\begin{array}{l}\text { Germeles, A. E., "A Model of LNG Tank Rollover," in Advances in Cryogenic } \\
\text { Engineering, Vol 21, K D. Timmerhaus and D. H. Weitzel, ed., Plenum Press, } \\
\text { New York, 1975, pp. 326-336. }\end{array}$ \\
\hline Gibbs 95 & $\begin{array}{l}\text { Gibbs, Jerry L, Richard L Bechtold and Charles E. Collison, III, The Effects of } \\
\text { LNG Weathering on Fuel Composition and Vehicle Management Techniques," } \\
\text { International Truck \& Bus Mtg \& Exposition, Winston-Salem, NC, Nov. 13-15, } \\
\text { 1995, SAE SP-1124 952607. }\end{array}$ \\
\hline Gideon 75 & $\begin{array}{l}\text { Gideon, D. N., Putman, A. A., and Duffy, A. R., "Safety Aspects of LNG Spills on } \\
\text { Land," in Advances in Cryogenic Engineering, Vol 21, K D. Timmerhaus and D. } \\
\text { H. Weitzel, ed., Plenum Press, New York, 1975, pp. 377 386. }\end{array}$ \\
\hline Giesbrecht 88 & $\begin{array}{l}\text { Giesbrecht, H., "Evaluation of Vapour Cloud Explosions by Damage Analysis," } \\
\text { Joumal of Hazardous Materiats } 17 \text { (1988) 247-257. }\end{array}$ \\
\hline Gillette 80 & $\begin{array}{l}\text { Gillette, Roger, H., "Comments on "Thermal Hazards from LNG Fireballs," } \\
\text { Combustion Science and Technology, Vol. 22, pp. 185-188, } 1980 .\end{array}$ \\
\hline Giordani 89 & $\begin{array}{l}\text { Giordani, Marie-Louise and Acton, Anthony, "Safety Systems at LNG Storage } \\
\text { Installations," Intermational Conterence on Liquefied Natural Gas, Nice, France, } \\
17-20 \text { October 1989, Voi. 2, Inst. of Gas Tech., Chicago, Conf-8910391, } 1989 .\end{array}$ \\
\hline Coldwire $83 a$ & $\begin{array}{l}\text { Goldwire, H. C., Jr., and Rodean, H. C., "Coyote Series Data Report Vol. I," } \\
\text { Lawrence Livermore National Laboratory, Oct. } 1983 .\end{array}$ \\
\hline Goldwire $83 \mathrm{~b}$ & $\begin{array}{l}\text { Goldwire, H. C., Jr., and Rodean, H. C., "Coyote Series Data Report LLNLNWC } \\
1981 \text { LNG Spill Tests Dispersion, Vapor Bum Vol II," Lawrence Livermore } \\
\text { National Laboratory, Oct. 1983. }\end{array}$ \\
\hline Goto 92 & $\begin{array}{l}\text { Goto, Takashi; Furuta, Akio; and Sato, Kunio; "High Efficiency Mercury Removal } \\
\text { Adsorbent for Natural Gas Liquefaction Plant; poster 17, Tenth Int Conf on } \\
\text { Liquefied Natural Gas, Kuala Lumpur, May 25-28, 1992, Inst. of Gas Technology, } \\
\text { Chicago, } 1992 .\end{array}$ \\
\hline Greenberg 1991 & $\begin{array}{l}\text { Greenberg, Harris; and Cramer, Joseph J. (editors); Risk Assessment and Risk } \\
\text { Management for the Chemical Process Industry, Van Nostrand Reinhold, New } \\
\text { York, 1991. }\end{array}$ \\
\hline GRL-89/0138 & $\begin{array}{l}\text { Brown, T. C., et al., Falcon Series Data Report, } 1987 \text { LNG Vapor Barrier } \\
\text { Verification Fiald Trials, Final Report, Gas Research Institute (Prepared by . } \\
\text { Lawrence Livermore National Laboratory) June } 1990 .\end{array}$ \\
\hline GRL-96/0180 & $\begin{array}{l}\text { Midgett, Dan E. II, Best Avalable Practices for LNG Fueling of Fleet Vehicles, } \\
\text { GRI-Sa10180, Gas Research institute (prepared by the M. W. Kellogg Company, } \\
\text { Houston, Texas), February } 1996 .\end{array}$ \\
\hline Grill 92 & $\begin{array}{l}\text { Grill, Alain, "Is a 125,000 m3 class Ship Awways an Optimum for LNG Carriers?" } \\
\text { Paper IV 3, Tenth International Conference on Liquefied Natural Gas, Kuala } \\
\text { Lumpur, May 25-28, 1992, Inst. of Gas Technology, Chicago, } 1992\end{array}$ \\
\hline Grookjans 92 & $\begin{array}{l}\text { Grootjans, H. F., "Natural Gas Drying Unit Premature Decline of Performance," } \\
\text { paper II-2, Tenth international Conference on Liquefied Natural Gas, Kuala } \\
\text { Lumpur, May 25-28, 1992, Inst. of Gas Technology, Chicago, 1992. }\end{array}$ \\
\hline Grossmann 91 & $\begin{array}{l}\text { Grossmann, Georg and Fromm, Dieter, "HAZOP-Proof Ammonia Plant: A New } \\
\text { Way of Defining a Safe and Reliable Design," PlantOOperations Progress, Vol. 10, } \\
\text { No. 4, October } 1991, \text { pp. } 223-227 \text {. }\end{array}$ \\
\hline Gugan 79 & $\begin{array}{l}\text { Gugan, Keith, Unconfined Vapor Cloud Explosions, The Institution of Chemical } \\
\text { Engineers, 1979. }\end{array}$ \\
\hline Gutin 91 & $\begin{array}{l}\text { Gutin, Joann, "At Our Peril: The False Promise of Risk Assessment," } \\
\text { Greenpeace, Mar/Apr 1991, pp. 13-18. }\end{array}$ \\
\hline
\end{tabular}




\begin{tabular}{|c|c|}
\hline Gyles 92 & $\begin{array}{l}\text { Gyles, John L, "Safety Requirements at LNG Terminals," paper N-8, Tenth } \\
\text { International Conference on Liquefied Natural Gas, Kuala Lumpur, May 25-28, } \\
\text { 1992, Inst. of Gas Technology, Chicago, } 1992 .\end{array}$ \\
\hline Halder $86 a$ & $\begin{array}{l}\text { Halder, Clive A., Van Gorp, Gail S., Hatoum, Nabil S., and Wame, Thomas M., } \\
\text { "Gasoline Vapor Exposures. Part I. Characterization of Workplace Exposures," } \\
\text { Am. Ind. Hyg. Assoc. J., } 47 \text { (3): 164-172 (1986). }\end{array}$ \\
\hline Halder $86 b$ & $\begin{array}{l}\text { Halder, Cive A., Van Gorp, Gail S., Hatoum, Nabi S., and Wame, Thomas M., } \\
\text { "Gasoline Vapor Exposures. Part II. Evaluation of the Nephrotoxicity of the Major } \\
\text { C44C5 Hydrocarbon Components," Am. Ind. Hyg. Assoc. J., } 47 \text { (3): 173-175 } \\
\text { (1986). }\end{array}$ \\
\hline Hallan 94 & $\begin{array}{l}\text { Hallan, Tom, "In-service inspection of Storage Tanks: A New Non-destructive } \\
\text { Evaluation Method," Process Safery Progress, Vol. 13, No. 2, April 1994, pp. } \\
\text { 101-104. }\end{array}$ \\
\hline Hands 88 & $\begin{array}{l}\text { Hands, B. A., "Problems due to superheating of cryogenic liquids," Cryogenics, } \\
\text { Vol 28, pp823-829, December } 1988\end{array}$ \\
\hline Harris 83 & $\begin{array}{l}\text { Harris, R. J., The Investigation and Control of Gas Explosions in Butdings and } \\
\text { Heating Plant, E \& FN Spon Ltd, } 11 \text { New Fetter Lane, London EC4P 4EE, } 1983 .\end{array}$ \\
\hline Harris 93 & $\begin{array}{l}\text { Harris, F. S. , "Safety features on LNG ships," Cryogenies, Vol 33, No 8, pp } 772 \text { - } \\
777,1993\end{array}$ \\
\hline Harvison 81 & $\begin{array}{l}\text { Harvison, C. J., "Safety and Loss Prevention in the Tank Truck Transportation of } \\
\text { Chemicals," Loss Prevention, Vol. 14, 1981, pp. 60-65. }\end{array}$ \\
\hline Hashiguchi 92 & $\begin{array}{l}\text { Hashiguchi, Hironobu; et al., "A Computerized System for Aiding Cargo } \\
\text { Operations in Future LNG Carriers," paper N-10, Tenth International Conference } \\
\text { on Liquefied Natural Gas, Kuala Lumpur, May 25-28, 1992, Inst. of Gas } \\
\text { Technology, Chicago, } 1992 \text {. }\end{array}$ \\
\hline Herbertsson 92 & $\begin{array}{l}\text { Herbertsson, Gunnar, "Some Improvements in Design of Atmospheric Ammonia } \\
\text { Storage Tanks of the Double Integrity Type," Plantoperations Progress, Vol. 11, } \\
\text { No. 2, April 1992, pp. 126-127. }\end{array}$ \\
\hline HETA $88-304-2326$ & $\begin{array}{l}\text { Hazards of MTBE, NIOSH Health Hazard Evaluation Report, Centers for Disease } \\
\text { Control and Prevention, Public Health Service, U.S. Dept. of Health and Human } \\
\text { Services, June } 1993 \text {. }\end{array}$ \\
\hline Hibl 75 & $\begin{array}{l}\text { Hibl, J. J., "Cryogenic Fuel Systems for Motor Vehicles," in Advances in } \\
\text { Cryogenic Engineering, Vol 21, K. D. Timmerhaus and D. H. Weitzel, ed., } \\
\text { Plenum Press, New York, 1975, pp. 180-186. }\end{array}$ \\
\hline Hiro-oka 82 & $\begin{array}{l}\text { Hiro-oka, T., "Latest Design Features and Operational History of LNG Inground } \\
\text { Tanks at the Negishi LNG Receiving Terminal," in Advances in Cyogenic } \\
\text { Engineering, Vol 27. Plenum Press, New York, 1982, pp. 937-944. }\end{array}$ \\
\hline Hise 83 & $\begin{array}{l}\text { Hise, Ralph E., Massey, Lester G., et al. "The CNG Process: A New Approach to } \\
\text { Physical Absorption Acid Gas Removal," in Cryogenic Processes and Equipment } \\
\text { 1982, AlChE, 224, Vol. 79, 1983, pp 51-56. }\end{array}$ \\
\hline Hjertager 88 & $\begin{array}{l}\text { Hjertager, B. H., Bjorkhaug, M. and Fuhre, K, "Explosion Propagation of Non- } \\
\text { Homogenous Methane-Air Clouds Inside an Obstructed } 50 \text { m3 Vented Vessel," } \\
\text { Joumal of Hazardous Materials } 19 \text { (1988) 139-153. }\end{array}$ \\
\hline Hord 78 & $\begin{array}{l}\text { Hord, J., "Is Hydrogen Safe?" Intemational Joumal of Hydrogen Energy, Vol. 3, } \\
\text { pp. 157-176, } 1978\end{array}$ \\
\hline Houston 97 & $\begin{array}{l}\text { "Houston Metropolitan Transit Authority Fallbrook Bus Operating Facility } \\
\text { LNG/CNG Fueling Station," fact sheet received from Bruce Whiding, April 2, } 1997 .\end{array}$ \\
\hline Hunt 96 & $\begin{array}{l}\text { Hunt, Peter, Peter Hunt Associates, 7501 Elba Road, Alexandria, VA 22305, letter } \\
\text { to Thomas Grumbly, Asst. Sec. of Energy, Oct. 15, 1996. }\end{array}$ \\
\hline ljams 75 & $\begin{array}{l}\text { Jjams, T. E., and Wolfe, B. A., "Planning for Safety," in Actvances in Cryogenic } \\
\text { Engineering, Vol 21, K D. Timmerhaus and D. H. Weitzel, ed., Plenum Press, } \\
\text { New York, 1975, pp. } 367-376 \text {. }\end{array}$ \\
\hline INEL 92 & $\begin{array}{l}\text { Unknown authors, "Identification and Ranking of Methodiogies for Anatysis of } \\
\text { Chemical Hazards at Department of Energy Facilities," Idaho National } \\
\text { Engineering, EG\&G Idaho, inc., December } 1992 \text {. }\end{array}$ \\
\hline
\end{tabular}




\begin{tabular}{|c|c|}
\hline Irving 79 & $\begin{array}{l}\text { Irving, W. S., and Grumbles, Thomas G., "Benzene exposures during gasoline } \\
\text { loading at bulk marketing terminals," Am. Ind. Hyg. Assoc. J., (40) Jine 1979, pp. } \\
468-472 \text {. }\end{array}$ \\
\hline Iversen 92 & $\begin{array}{l}\text { Wersen, Halidan H., What LNG Carrier does the Market Needr" paper IV-2, } \\
\text { Tenth International Conference on Liquefied Natural Gas, Kuala Lumpur, May 25- } \\
28,1992 \text {, Inst. of Gas Technology, Chicago, 1992. }\end{array}$ \\
\hline Jabionsik 83 & $\begin{array}{l}\text { Jablonski, J., and Lent, L, Assessment of Institutional Bamiers to the Use of } \\
\text { Natural Gas in Automotive Vehicle Floets, Jack Faucett Associates, inc., Chevy } \\
\text { Chase, MD, August } 1983,89 \mathrm{p} \text {. }\end{array}$ \\
\hline Jackson 88 & $\begin{array}{l}\text { Jackson, S. E. and Dutton, J. E. (1988). Discerning threats and opportunities. } \\
\text { Administrative Science Quarterty (33), (pp.370-387). }\end{array}$ \\
\hline Jacobs 86 & $\begin{array}{l}\text { Jacobs, W. S., and Handman S.E., "Enhanced Integrity LNG Storage Tanks," in } \\
\text { Advances in Cryogenic Engineering, Vol 31, R. W. Fast, ed., Plenum Press, New } \\
\text { York, 1986, pp. 1129-1139. }\end{array}$ \\
\hline Jacofsiny 88 & $\begin{array}{l}\text { Jacofsky, E. F., Slocum, J. W., and McQuaid, S. J. (1988). Cuthural values and } \\
\text { the CEO: Alluring companions? Acaderny of Management Excecutive }(11,1) \text {, } \\
\text { (pp.39-49). }\end{array}$ \\
\hline Janis 72 & Janis, I. L (1972). Victims of Groupthink. Boston: Houghton Mifflin. \\
\hline $\operatorname{Janis} \pi$ & Janis, 1. L, and Mann, L. (1977). Decision Making. New York Free Press. \\
\hline Jean 92 & $\begin{array}{l}\text { Jean, P., and Biaggi, J. P., "A New Step in the LNG Sea Transportation "The } \\
200,000 \mathrm{m3} \text { GT type LNG Carrier" "Tenth International Conference on Liquefied } \\
\text { Natural Gas, Kuala Lumpur, May 25-28, 1992, Inst. of Gas Technology, Chicago, } \\
1992 .\end{array}$ \\
\hline Jensen 83 & $\begin{array}{l}\text { Jensen, N. O., "On Cryogenic Liquid Pool Evaporation," Joumal of Hazardous } \\
\text { Materials } 3 \text { (1983) 157-163. }\end{array}$ \\
\hline Johnson 81 & $\begin{array}{l}\text { John, D.W., and Welkor, J. R., "Development of an Improved LNG Plank Failure } \\
\text { Rate Data Base," PB82-153503, Gas Research Institute, Sept. } 81 .\end{array}$ \\
\hline Johnson 86 & $\begin{array}{l}\text { Johnson, Paul C." "Updating LNG Plants," in Advances in Cryogenic } \\
\text { Engineering, Vol 31, R. W. Fast, ed., Plenum Press, New York, 1986, pp. 1101- } \\
1110 .\end{array}$ \\
\hline Jollivet 90 & $\begin{array}{l}\text { Jolivet, Philippe "Different Concepts for LNG Storage Tanks and impact of Safeby } \\
\text { Requirements," EUROGAS 90: European applied research conference on } \\
\text { natural gas, Trondheim, Nonway, May 28-30, 1990, pp. 641-654. }\end{array}$ \\
\hline Jones $84 b$ & $\begin{array}{l}\text { Jones, D. A., "A review of the developments in LNG storage safety as reflected by } \\
\text { risk assessment," GASTECH ' } 84 \text {, Amsterdam, Nov. 6, 1984, pp. 133-141. }\end{array}$ \\
\hline Jones 84a & $\begin{array}{l}\text { Jones, N.G.L, "A Scematic Design for a HAZOP Study on a Liquid Hydrogen } \\
\text { Filling Station," Int. J. of Hydrogen Energy, Vol. 9, No. 1/2, pp. 115-121, } 1984 .\end{array}$ \\
\hline Joyce 92 & $\begin{array}{l}\text { Joyce, Thomas, J., Willams, Ted A., and Chemoff, Harny, "Small-Scale LNG } \\
\text { Satelite Facitties," paper II-12, Tenth Intemational Conference on Liquefied } \\
\text { Natural Gas, Kuala Lumpur, May 25-28, 1992, inst. of Gas Technology, Chicago, } \\
1992 .\end{array}$ \\
\hline Kahneman 79 & $\begin{array}{l}\text { Kahneman, D., and Tversiky, A. (1979). Prospect theory. An analysis of decision } \\
\text { under risk. Econometrica (47), (pp.263-291). }\end{array}$ \\
\hline Kajinara 92 & $\begin{array}{l}\text { Kajivara, Shuzo; and Hayashi, Koichi; "Comosion Behavior of Thermal-Sprayed } \\
\text { Coating of Aluminum Alloy LNG Vaporizer," poster 22, Tenth International Conf on } \\
\text { Liquefied Natural Gas, Kuala Lumpur, May 25-28, 1992, inst. of Gas Technology, } \\
\text { Chicago, 1992. }\end{array}$ \\
\hline Kakehi 92 & $\begin{array}{l}\text { Kakehi, Katuyub, et al., "The World's Largest LNG Inground Storage Tank of } \\
\text { Kawasakis Membrane," paper III-7, Tenth international Conference on Liquefied } \\
\text { Natural Gas, Kuala Lumpur, May 25-28, 1992, Inst. of Gas Technology, Chicago, } \\
1992 .\end{array}$ \\
\hline Kamel 79 & $\begin{array}{l}\text { Kame, M. M., and Khalli, A., "Explosion Hazards of LNG and LPG Carriers During } \\
\text { Transport," Advances in Cryogenic Engineering, Vol 25, 1979, pp. 757-762. }\end{array}$ \\
\hline
\end{tabular}




\begin{tabular}{|c|c|}
\hline Kamel 80 & $\begin{array}{l}\text { Kamel, M. M., and Whall, A., "Explosion Hazards of LNG and LPG Carriers During } \\
\text { Transport," in Advances in Cryogenic Engineering, Vol 25, K D. Timmerhaus } \\
\text { and H. A. Snyder, ed., Plenum Press, New York 1980. pp. 757-752. }\end{array}$ \\
\hline Kaplan 81 & $\begin{array}{l}\text { Kaptan, Stanley; and Garrick, B. John; "On the Quantitative of Risk," Risk } \\
\text { Analysis, Vol. 1, No. 1, 1981, pp.11-27. }\end{array}$ \\
\hline Kasper 80 & $\begin{array}{l}\text { Kasper, R. (1980). Perceptions of risk and their effects on decision maling. In } \\
\text { Schwing, R., and Albers, W. (Eds.) Societal Risk Assessment, How Safe is Safe } \\
\text { Enough? (Pp 71-84). NY: Plenum Press. }\end{array}$ \\
\hline Kearney 86 & $\begin{array}{l}\text { Keamey, Christine A., and Dunham, David B., "Gasoline Vapor Exposures at a } \\
\text { High Volume Service Station," Am. Ind. Hyg. Assoc. J., 47(8): 535-539 (1986). }\end{array}$ \\
\hline Keeney 86 & $\begin{array}{l}\text { Keeney, Raiph L; and von Winterfeldt, Detiog; "Improving Risk Communication," } \\
\text { Risk Anaysis, Vol. 6, No. 4, 1986, pp.417-424. }\end{array}$ \\
\hline Kerby 89 & $\begin{array}{l}\text { Kerby, J., "Underestimation of oxygen deficiency hazard through use of finearized } \\
\text { temperature profiles," FNAL-TM-1601, Fermi National Accelerator Laboratory, } \\
\text { Batavia, IL, } 15 \text { Jun } 1989 .\end{array}$ \\
\hline Thajehnajadi 94 & $\begin{array}{l}\text { Khajehnajaf, Shahryar and Shinde, Ashok, "Prediction of Discharge Rate from } \\
\text { Pressurized Vessel Blowdown Through Sheared Pipe," Process Safety Progress, } \\
\text { Vol. 13, No. 2, April 1994, pp. 75-82. }\end{array}$ \\
\hline Wet $77 a$ & $\begin{array}{l}\text { Ketz, T. A., "Unconfined Vapor Cloud Explosions," Loss Prevention, Vol. 11, } \\
\text { 1977, pp. 50-58. }\end{array}$ \\
\hline Ketz $77 b$ & $\begin{array}{l}\text { Ketz, Trevor, "Protect pressure vessels from fire," Hydrocarbon Processing, } \\
\text { August } 1977, \text { pp. 98-102. }\end{array}$ \\
\hline Kingmueller 85 & $\begin{array}{l}\text { Kingmuelier, O., "Influence of Structural Safety on Overall Risk Analysis of LNG } \\
\text { Storage Facilities," ICOSSAR '85: 4th Int1 conf. on Structurel Safety and } \\
\text { Reliabity, Kobe, Japan, May 27, 1985, Vol 1, pp. I1-501-11-505. }\end{array}$ \\
\hline Knowtion 84 & $\begin{array}{l}\text { Knowton, R. E., "An Investigation of the Safety Aspects in the Use of Hydrogen } \\
\text { as a Ground Transportation Fuel," int. J. Hydrogen Energy, Vol. } 9 \text { No. 1/2, 1984, } \\
\text { pp. 129-136. }\end{array}$ \\
\hline Knowiton 88 & $\begin{array}{l}\text { Knowtton, R. Ellis, An Introduction to Hazard and Operabithy Studies, The Guide } \\
\text { Word Approach, Fourth Printing, February, 1988. }\end{array}$ \\
\hline Kogan 64 & $\begin{array}{l}\text { Kogan, N., and Wallach, M. A. (1964). Risk Taking: A Study in Cognition and } \\
\text { Personality. New York Hoth, Rinehart, and Winston. }\end{array}$ \\
\hline Koopman 82 & $\begin{array}{l}\text { Koopman, R. P., "Analysis of Burro Series 40-m3 LNG Spill Experiments," } \\
\text { Joumal of Hazardous Materials," Vol. 6, pp. 43-83, } 1982 .\end{array}$ \\
\hline Kosseim 92 & $\begin{array}{l}\text { Kosseim, Alex J., et al., "New Developments in Gas Purification for LNG Plants," } \\
\text { paper II-11, Tenth International Conference on Liquefied Natural Gas, Kuala } \\
\text { Lumpur, May 25-28, 1992, Inst. of Gas Technology, Chicago, 1992. }\end{array}$ \\
\hline Krein 96 & $\begin{array}{l}\text { Krein, Philip T., "Electrostatic Discharge issues in Electric Vehicles," IEEE Trans. } \\
\text { on industry Appications, Vot. 32, No. 6, Nov/Dec. 1996, pp. 1278-1284. }\end{array}$ \\
\hline Kruplca 83 & $\begin{array}{l}\text { Krupka, M. C., Peasiee, A. T. Jr., and Laquer, H. L., Aternative Gaseous Fuels } \\
\text { Safety Assessment, LA-UR-83-3028 Conf-831205-2, Sixth Miami International } \\
\text { Conference on Alternative Energy Sources, December 12-14-1983. }\end{array}$ \\
\hline Kuchta 86 & $\begin{array}{l}\text { Kuchta, J.M., "Investigation of Fire and Explosion Accidents in the Chemical, } \\
\text { Mining and Fuet-Related industries-A Manual," Bureau of Mines, Washington, } \\
\text { DC., } 1986 .\end{array}$ \\
\hline Kumar 93 & $\begin{array}{l}\text { Kumar, Ashok, Lwo, Jie; and Bennett, Gary F., "Statistical Evaluation of Lower } \\
\text { Flammability Distance (LFD) Using four Hazardous Release Models," Process } \\
\text { Safety Progress, Vol. 12, No. 1, January 1993, pp.1-11. }\end{array}$ \\
\hline LA-9829-MS & $\begin{array}{l}\text { Krupka, M.C., Peaslee, A. T., and Laquer, H. L, Gaseous Fuel Safety } \\
\text { Assessment for Light-Dury Automotive Vehickes, LA-9829-M, Nov. } 83 .\end{array}$ \\
\hline
\end{tabular}




\section{Appendix E Bibliography}

\begin{tabular}{|c|c|}
\hline Lainoff 82 & $\begin{array}{l}\text { Lainoff, S. M., "Potential for Catastrophic Rupture of Large Liquid Oxygen Storage } \\
\text { Tanks," in Advances in Cryogenic Engineering, Vol 27, Plenum Press, New } \\
\text { York, 1982, pp. 953-961. }\end{array}$ \\
\hline Lanty 92 & $\begin{array}{l}\text { Lantzy, Ronald J., Vapor Cloud Source Modeling Workshop Chairman's Report," } \\
\text { PlantCOperations Progress, Vol. 11, No. 1, January 1992, pp. 41-45. }\end{array}$ \\
\hline Lapp 95 & $\begin{array}{l}\text { Lapp, Ken and Werneburg, Hal, "Detonation Flame Arrester Qualifying Application } \\
\text { Parameter for Explosion Prevention in Vapor Handling Systems," Process Safoty } \\
\text { Progress, Vol. 14, No. 2, April 1995, pp. 139-146. }\end{array}$ \\
\hline Larson 92 & $\begin{array}{l}\text { Larson W. G., "Aluminum/Cold Temperature Tank Car Puncture Resistance } \\
\text { Tests: Data Report (Final Rept.)," DOT/FRAORD-92/29, Association of American } \\
\text { Railroads, Pueble, CO, Transportation Test Center, Aug } 92 .\end{array}$ \\
\hline Ledbetter 78 & $\begin{array}{l}\text { Ledbetter, Joe O., "Exclusion area for safety from high-pressure sour gas leaks," } \\
\text { Am. Ind. Hyg. Assoc. J., (39)7/78, pp. 586-592. }\end{array}$ \\
\hline Lee $\pi$ & $\begin{array}{l}\text { Lee, J. H., Guirao, C. M., Chiu, KM., and Bach, G. G., "Blast Effects from Vapor } \\
\text { Cloud Explosions," Loss Preventioin, Vol. 11, 1977, p. 59-70. }\end{array}$ \\
\hline Lenoir 93 & $\begin{array}{l}\text { Lenoir, Eric M. and Davenport, John A., "A Survey of Vapor Cloud Explosions: } \\
\text { Second Update," Process Safety Progress, Vol. 12, No. 1, January 1993, pp. 12- } \\
33 .\end{array}$ \\
\hline Leone 90 & $\begin{array}{l}\text { Leone, F. A., "Hazard Materials Testing at the U.S. Department of Energy's } \\
\text { Liquefied Gaseous Fuets Spill Test Facility," PlantOperations Progress, Vol. 9, } \\
\text { No. 4, October 1990, pp. 226-230. }\end{array}$ \\
\hline Leslie 91 & $\begin{array}{l}\text { Leslie, I.R.M., and Birk, A.M., "State of the Art Review of Pressure Liquefied Gas } \\
\text { Container Failure Modes and Associated Projectile Hazards," Joumal of Hazard" } \\
\text { Materials, } 28 \text { (1991) 329-365. }\end{array}$ \\
\hline Lev 81 & $\begin{array}{l}\text { A Novel Method for Controlling LNG Pool Fires," Y. Lev, Fire Technology, Vol. 17, } \\
\text { No. 4, 1981, pp. 275-284. }\end{array}$ \\
\hline Libby 7 & $\begin{array}{l}\text { Libby, R., and Fishbum, P. C. (1977). Behavioral models of risk taking in } \\
\text { business decision: A survey and evaluation. Joumal of Accounting Research (15), } \\
\text { (pp.272-292). }\end{array}$ \\
\hline Lihou 91 & $\begin{array}{l}\text { Lihou, D. A., "Failures of liquefied gas storage vessels," Proc. Insth Mech Engrs } \\
\text { Vol. } 205 \text { (1991) 27-31. }\end{array}$ \\
\hline Lindstrom 92 & $\begin{array}{l}\text { Lindstrom, Andrew B., Highsmith, V. Ross, et al., "Household Exposures to } \\
\text { Benzene From Showering with Gasoline Contaminated Ground Water," } \\
\text { EPAVO0/A-92/259. }\end{array}$ \\
\hline Lipscomb 97 & $\begin{array}{l}\text { Lipscomb, Linton T., "The basics of natural gas safety," Gas Industries, March } \\
1997, \text { pp. } 27-29 \text {. }\end{array}$ \\
\hline Liu 86 & $\begin{array}{l}\text { Liu, Chang-Keng and Hsu, Ike C., "Safety Analysis of a Supercitical Helium } \\
\text { Dewar," in Cryogenic Properties, Processes and Applications 1986, AlCHe, 251, } \\
\text { Vol 82, 1986, pp. 92-95. }\end{array}$ \\
\hline Liu 92 & $\begin{array}{l}\text { Liu, Yu-Nan, et al., "Design Considerations of Larger LNG Plants," paper II-8, } \\
\text { Tenth International Conference on Liquefied Natural Gas, Kuala Lumpur, May 25- } \\
28,1992 \text {, Inst. of Gas Technology, Chicago, } 1992 .\end{array}$ \\
\hline LNGnews 3/96 & $\begin{array}{l}\text { Bechtold, Richard L, Gibbs, Jerry L, and Collison, Charles E., "LNG } \\
\text { Weathering," in LNGnows, a supplement to Natural Gas Fuols, p. 4, March } \\
\text { 1996. }\end{array}$ \\
\hline Lounamaa 87 & $\begin{array}{l}\text { Lounamaa, P. H., and March, J. G. (1987). Adaptive coordination of a leaming } \\
\text { team. Management Science (33), (pp.107-123). }\end{array}$ \\
\hline Lovesmith 92 & $\begin{array}{l}\text { Lowesmith, B. J., Moorhouse, J, and Roberts, P." "Fire Safety Assessments for } \\
\text { LNG Storage Facilities," paper III-2, Tenth Intemational Conference on Liquefied } \\
\text { Natural Gas, Kuala Lumpur, May 25-28, 1992, Inst. of Gas Technology, Chicago, } \\
1992 .\end{array}$ \\
\hline MacCrimmon 86 & $\begin{array}{l}\text { MacCrimmon, K R., and Wehrung, D. A. (1986). Taking Risks: The } \\
\text { Management of Uncertainty. New York. Free Press. }\end{array}$ \\
\hline MacCrimmon 90 & $\begin{array}{l}\text { MacCrimmon, K R., and Wehrung, D. A. (1990). Characteristics of risk taking } \\
\text { executives. Management Science (36, 4), (pp.422-435). }\end{array}$ \\
\hline
\end{tabular}




\begin{tabular}{|c|c|}
\hline Macey 94 & Macey, Daniel, "Anatomy of a Gas Disaster," Gas Daily's NG, June/July 1994. \\
\hline Madsen 94 & $\begin{array}{l}\text { Madsen, Warren W. and Wagner, Robert C., "An Accurate Methodlogy for } \\
\text { Modeling the Characteristics of Explosion Effects," Process Safety Progress, Vol. } \\
13, \text { No. 3, Juhy 1994, pp. 171-175. }\end{array}$ \\
\hline Mancini 88 & $\begin{array}{l}\text { Mancini, R. A., The Use (and Misuse) of Bonding for Control of Static Ignition } \\
\text { Hazards," Plantroperations Progress, Vol. 7, No. 1, January 1988, pp. 23-31. }\end{array}$ \\
\hline Mancini 92 & $\begin{array}{l}\text { Mancini, R. A., "Workshop on Unconfined Vapor Cloud Explosions," } \\
\text { PlantOperations Progress, Vol. 11, No. 1, January } 1992 \text { pp. 27-32. }\end{array}$ \\
\hline March 78 & $\begin{array}{l}\text { March, J. G. (1978). Bounded rationality, ambiguity, and the engineering of } \\
\text { choice. Bell Journal of Economies (9), (pp.587-608). }\end{array}$ \\
\hline March 87 & $\begin{array}{l}\text { March, J. G., and Shapira, Z (1987). Managerial perspectives on risk and risk } \\
\text { taking. Management Science (33), (pp.1404-1418). }\end{array}$ \\
\hline Martinsen 81 & $\begin{array}{l}\text { Martinsen, W. E., et al., "LPG Land Transportation and Storage Safety. Final } \\
\text { Report," DOE/EVIOCO20-T6, Applied Technology Corp., Norman, OK, 1981, } 143 \\
\text { p. }\end{array}$ \\
\hline Martinsen 92 & $\begin{array}{l}\text { Martinsen, William E., "Notes on a Few Vapor Suppression Techniques," } \\
\text { PlantO Operations Progress, Vol 11, No. 1, January 1992, pp. 23-32. }\end{array}$ \\
\hline Mayo 91 & $\begin{array}{l}\text { Mayo, D., and Hollander, R. (Eds.) (1991). Acceptable Evidence. NY: Oxford } \\
\text { University Press. }\end{array}$ \\
\hline Mazzocchi 86 & $\begin{array}{l}\text { Mazzocchi, A., and Campana, M., "Risk Analysis of a Large Tank Farm of } \\
\text { Liquefied Petroleum Gases," Reliabithy Data Collection and Use in Risk and } \\
\text { Avalabifty Assessment, Proc of the Sth Euredata Conf, Heidelberg, Apr 9-11, } \\
\text { 1986, Springer Pp. 344356. }\end{array}$ \\
\hline MeClellan 86 & $\begin{array}{l}\text { McClellan, Roger O., "Health Effects of Diesel Exahust: A case Study in Risk } \\
\text { Assessment," } 1985 \text { Stokinger Lecture, Am. Ind. Hyg. Assoc. J., } 47(1): 1-13 \\
(1986) \text {. }\end{array}$ \\
\hline McClelland 61 & McClelland, D. C. (1961). The Acheiving Sociely. Princeton: Van Nostrand. \\
\hline McClure 81 & $\begin{array}{l}\text { McClure, J. D., Probabifty of Spent Fuel Transportation Accidents, SAND-80- } \\
1721 \text {, Sandia National Laboratories, Albuquerque, NM, July 1981, } 20 \text { p. }\end{array}$ \\
\hline McDermott 78 & $\begin{array}{l}\text { McDermott, H. J., and Kiliany, S. E., Jr, "Quest for a gasoline TLV," Am. Ind. } \\
\text { Hyg. Assoc. J., (39) Feb 1978, pp. 110-117. }\end{array}$ \\
\hline McDermott 79 & $\begin{array}{l}\text { MeDermott, H. J., and Vos G. A., "Service station attendants' exposure to benzene } \\
\text { and gasoline vapors," American industrial Hygiene Association Joumal, (40) April } \\
1979, \text { pp. 315-321. }\end{array}$ \\
\hline MicGint 87 & $\begin{array}{l}\text { McGill, R.N., Hillis, S. L, and Wantiand, J. L., Results from the First Year of } \\
\text { Operation of the Federal Methanol Fret at Lawrence Berkeley Laboratory, } \\
\text { ORNL-TM-10485, Oak Ridge National Laboratory, August 1987, } 40 \text { p. }\end{array}$ \\
\hline MicRae 82 & $\begin{array}{l}\text { McRae, T. G., "Preliminary analysis of RPT Explosions Observed in the } \\
\text { LLNLNWC LNG Spill Tests," Lawrence Livermore National Laboratory, May } \\
1982 .\end{array}$ \\
\hline McRae 84 & $\begin{array}{l}\text { McRae, T. G., Goldwire, H. C., Hogan, W. J., and Morgan, D. L., Jr., "Effects of } \\
\text { Large Scale LNGMater RPT Explosions," UCRL-90502, Lawrence Livermore } \\
\text { National Laboratory, Livermore, CA, } 27 \text { April 1984. }\end{array}$ \\
\hline Mead 84 & $\begin{array}{l}\text { Mead, H. B., and Gee, D. E., "The Analysis and Development of a Floating LNG } \\
\text { Emergency Transfer Hose," in Advances in Cryogenic Engineering, Vol 29, R. } \\
\text { W. Fast, Ed., Plenum Press, New York, 1984, pp. 847-857. }\end{array}$ \\
\hline Medard 70 & $\begin{array}{l}\text { Medard, L., "Rupture of an Ammonia Road Tanker," Ammonia Plant Safoty and } \\
\text { Related Facitios, Vol. 12, American Institute of Chemical Engineers, pp. 17-18, } \\
1970 .\end{array}$ \\
\hline Melchers 95 & $\begin{array}{l}\text { Risk Assessment for Automotive LPG Facifities, Robert E. Melchers and William } \\
\text { R. Feutril, PVP-Vol. 296/SERA-Vol. 3, Risk and Safety Assessment. Where is the } \\
\text { Balance?, Honolulu, July 23-27, ASME 1995, pp. } 457-462 .\end{array}$ \\
\hline
\end{tabular}




\begin{tabular}{|c|c|}
\hline Meratta 90 & $\begin{array}{l}\text { Meratta, Z, "Approach to a Leak on an LNG Tank Bottom," Joumal of Hazardous } \\
\text { Materials } 24 \text { (1990) 67-75. }\end{array}$ \\
\hline Merex 93 & $\begin{array}{l}\text { Merex, W. P. M., van Wingerden, C. J. M., and Pasman, H. J., "Venting of } \\
\text { Gaseous Explosions," Process Safety Progress, Vol. 12, No. 1, January 1993, } \\
\text { pp. 40-46. }\end{array}$ \\
\hline Meyer 75 & $\begin{array}{l}\text { Meyer, G. M., "Inert Gas Generating System for Liquefied Natural Gas Carriers," } \\
\text { in Advances in Cryogenic Engineering, Vol 21, K D. Timmerhaus and D. H. } \\
\text { Weitzel, ed., Plenum Press, New York, 1975, pp. 346-358. }\end{array}$ \\
\hline Meyer 92 & $\begin{array}{l}\text { Meyer, Mark, and Staible, Fred E., "Safety Management in the Design and } \\
\text { Operation of LNG Facilities," paper III-3, Tenth Intemational Conference on } \\
\text { Liquefied Natural Gas, Kuala Lumpur, May } 25-28,1992 \text {, Inst. of Gas Technology, } \\
\text { Chicago, } 1992 \text {. }\end{array}$ \\
\hline Miller 84 & $\begin{array}{l}\text { Miller, Timothy M., and Mazur, Peter O., "Oxygen Deficiency Hazards Associated } \\
\text { with Liquefied Gas Systems: Derivation of a Program of Controls," Am Ind Hyg } \\
\text { Assoc J 45(5) 293-298 (1984). }\end{array}$ \\
\hline Mintzberg 76 & $\begin{array}{l}\text { Mintzberg, H., Raisinghani, D., and Theoret, A. (1976). The structure of } \\
\text { "unstructured" decision processes. Administrative Science Quarterty (25), } \\
\text { (pp.246-275). }\end{array}$ \\
\hline Miyata 75 & $\begin{array}{l}\text { Miyata, Y., "Experience of Tokyo Gas with In-ground LNG Tanks," in Advances in } \\
\text { Cryogenic Engineering, Vol 21, K D. Timmerhaus and D. H. Weitzel, ed., } \\
\text { Plenum Press, New York, 1975, pp. } 307-314 .\end{array}$ \\
\hline Miyata 92 & $\begin{array}{l}\text { Miyata, Yoshiaki, et al., "Development of Double Tube Type Vaporizer with } \\
\text { Enhanced Economy, Easy Operation and Maintenance," poster 19, Tenth int Conf } \\
\text { on Liquefied Natural Gas, Kuala Lumpur, May 25-28, 1992, Inst. of Gas } \\
\text { Technology, Chicago, 1992. }\end{array}$ \\
\hline Monroe 76 & $\begin{array}{l}\text { Monroe, K B. (1976). The influence of price differences and brand familiarity on } \\
\text { brand preferences. Journal of Consumer Research (3), (pp.42-49). }\end{array}$ \\
\hline Moorhouse 88 & $\begin{array}{l}\text { Moorhouse, J., and Roberts, P. "Cryogenic spill protection and mitigation," } \\
\text { Cryogenics, Vol 28, pp 838-846, December 1988,. }\end{array}$ \\
\hline Morioka 86 & $\begin{array}{l}\text { Moriola, Mikjo; Obarna, Toshio; Kouda, Yasuo; Mori, Mikio; Tomura, S. and } \\
\text { Shintaro, E., "Simulation of the Geysering Phenomenon in LNG Pipes," in } \\
\text { Advances in Cryogenic Engineering, Vol 31, R. W. Fast, ed., Plenum Press, New } \\
\text { York, 1986, pp. 11111-1119. }\end{array}$ \\
\hline Moskowitz 88 & $\begin{array}{l}\text { Moskowitz, P. D., Fthenakis, V. M., and Kalb, P. D., "Preventing and Controlling } \\
\text { Accidental Gas Releases," BNL-41671, prepared for presentation at the } \\
\text { Photovoltaic Safety Conference, Solar Energy Research institute, Denver, CO, } \\
\text { Jan 19-20, } 1988 \text {. }\end{array}$ \\
\hline Mueller 82 & $\begin{array}{l}\text { Safe Handing and Testing of Altemative Fuels, Mueller Associates, Inc., } \\
\text { Baltimore, MD, Jan. } 1982,31 \text { p. }\end{array}$ \\
\hline Mulliner 74 & $\begin{array}{l}\text { Mulliner, David K, "Now - A Practical Method For Odorizing LNG," Pipeline and } \\
\text { Gas Joumal, Vol. 201, June 1974, pp. 78-84. }\end{array}$ \\
\hline Murphy 95 & $\begin{array}{l}\text { Murphy, M. J., et al., Clean Air Program: Summary Assessment of the Safety, } \\
\text { Heafth, Environmental and System Risks of Altemative..., FTA-MA-90-7007-95- } \\
\text { 1, PB95-271326, John A. Volpe Nationa Transportation System Center, } \\
\text { Cambridge, MA Aug. } 95,140 \text { p. }\end{array}$ \\
\hline MVE 96 & "LNG Vehicle Fuel Tank System," MVE spec sheet, dtd 9/96 \\
\hline MVE $97 a$ & $\begin{array}{l}\text { "Palletized LNG Fueter," spec sheet from MVE, Bloomington, MN, rec'd March } 26 \text {, } \\
1997\end{array}$ \\
\hline Neale 86 & $\begin{array}{l}\text { Neale, M. A., Bazerman, M. H., Northcraft, G. B. and Alperson, C. (1986). } \\
\text { "Choice shitt" effects in group decisions: A decision bias perspective. Internatioal } \\
\text { Joumal of Small Group Research (2), (pp.33-42). }\end{array}$ \\
\hline NFPA 30 & $\begin{array}{l}\text { Flammable and Combustible Liquids Code, NFPA 30, } 1993 \text { Edition, National Fire } \\
\text { Protection Association, } 1993 \text {. }\end{array}$ \\
\hline NFPA 30A & $\begin{array}{l}\text { Automotive and Marine Service Station Code, NFPA 30A, } 1996 \text { Edition. National } \\
\text { Fire Protection Association, } 1996 .\end{array}$ \\
\hline
\end{tabular}




\begin{tabular}{|c|c|}
\hline NFPA 52 & $\begin{array}{l}\text { Standard for Compressed Natura Gas (CNG) Vehicular Fuel Systems, } 1992 \\
\text { Edition, National Fire Protection Association, } 1992\end{array}$ \\
\hline NFPA 54 & $\begin{array}{l}\text { National Fuel Gas Code, ANSI Z223.1-1992 and NFPA-54, } 1992 \text { Edition, } \\
\text { National Fire Protection Association, 1992. }\end{array}$ \\
\hline NFPA 55 & $\begin{array}{l}\text { Standard for the Storage, Use and Handing of Compressed and Liquefied } \\
\text { Gases in Portable Cylinders, } 1993 \text { Edition, Netional Fire Protection Asscoiation, } \\
\text { 1993. }\end{array}$ \\
\hline NFPA 57 & $\begin{array}{l}\text { Standand for Liquefied Natural Gas (LNG) Vehicular Systems, } 1996 \text { Edtion, } \\
\text { National Fire Protection Association, 1996. }\end{array}$ \\
\hline NFPA 58 & $\begin{array}{l}\text { Standard for the Storage and Handing of Liquelied Petroleum Gases, } 1992 \\
\text { Edition, National Fire Protection Association, } 1992 \text { plus Amendments and Emata, } \\
\text { 1993. }\end{array}$ \\
\hline NFPA 59 & $\begin{array}{l}\text { Standard for the Storage and Handing of Liquefied Petroleum Gases at Utity } \\
\text { Gas Plents, } 1992 \text { Edition, National Fire Protection Association, } 1992 .\end{array}$ \\
\hline NFPA 59A & $\begin{array}{l}\text { Standard for the Production, Storage, and Handing of Liquefied Natural Gas } \\
\text { (LNG), } 1994 \text { Edition, National Fire Protection Association, } 1994 .\end{array}$ \\
\hline NFPA 77 & $\begin{array}{l}\text { Recommended Practice on Static Electricity, } 1993 \text { Edition, National Fire } \\
\text { Protection Association, } 1993\end{array}$ \\
\hline NFPA 385 & $\begin{array}{l}\text { Standard for Tank Vehicfes for Flammable and Combustible Liquids, } 1990 \\
\text { Edfion, National Fire Protection Association, } 1990\end{array}$ \\
\hline NFPA 512 & $\begin{array}{l}\text { Standard for Truck Fire Protoction, } 1994 \text { Edition, National Fire Protection } \\
\text { Association, 1994. }\end{array}$ \\
\hline NGF $3 / 96$ & $\begin{array}{l}\text { Nepywoda, John, "At Last, LNG an Economic Solution for Truck Fleets," Natural } \\
\text { Gas Fuels, March 1996, p. 24-25. }\end{array}$ \\
\hline NGF 496 & $\begin{array}{l}\text { "No Word on Cause of Columbia Station Blast," Natural Gas Fuels, April 1996, p. } \\
\text { 6. Also commentary "it could Have Been Much Worse..," same issue, p. 4. }\end{array}$ \\
\hline NGV S6 & $\begin{array}{l}\text { Legistation and Regulations Affecting Natural Gas Vehictes, Natural Gas Vehicle } \\
\text { Coaftion, Wilson Btvd, Attington, VA, April } 1996 .\end{array}$ \\
\hline Nimocks 95 & $\begin{array}{l}\text { Nimocks, R. (1995). LNG Vehicle Markets and infrastructure: Final Report. GRI- } \\
\text { 9510423. Chicago: Gas Research institute. }\end{array}$ \\
\hline NIOSH75 & $\begin{array}{l}\text { "Heath and Safety Guide for Service Stations," NIOSH-75/139, PB-267 384, } \\
\text { National Institute for Occupational Safety and Health, Division of Technical } \\
\text { Services, Cincinnati, OH, Feb } 75 \text {. }\end{array}$ \\
\hline Noon 95 & $\begin{array}{l}\text { Noon, Randall, Engineering Analysis of Fires and Explosions, CRC Press, Boca } \\
\text { Raton, FL, 1995. "Odorant Fade," pp. 90-91. }\end{array}$ \\
\hline Novak 82 & $\begin{array}{l}\text { Novak, J. K, Edesicuty, F. J., and Bartit, J. R., "Coot-down Flow-rate Limits } \\
\text { imposed by Thermal Stresses in LNG Pipelines," in Advances in Cryogenic } \\
\text { Engineering, Vol 27, Plenum Press, New York, 1982, pp. 963-970. }\end{array}$ \\
\hline $\begin{array}{l}\text { NRLMR } 6101-97- \\
7926\end{array}$ & $\begin{array}{l}\text { M. D. Max. R. E. Pellanbarg and B. G. Hurdle, "Methane Hydrate, A Special } \\
\text { Clathrate: Its Attributes and Potential," Naval Research Laboratory, Washington, } \\
\text { DC, February } 28,1997 \text {. }\end{array}$ \\
\hline NTSB-HZM-78-1 & $\begin{array}{l}\text { National Transportation Safety Board, "An Overview of a Bulk Gasoline Delivery } \\
\text { Fire and Explosion," Special Investigation Report NTSB-HZM-78-1, Washington } \\
\text { DC 20594, Feb. 24, 1978. }\end{array}$ \\
\hline NTSB-PAR-80-2 & $\begin{array}{l}\text { "Columbia Liquified Natural Gas Corporation Explosion and Fire, Cove Point, } \\
\text { Maryland, October 6, 1979," Pipeline Accident Report, NTSB-PAR-80-2, National } \\
\text { Transportation Safety Board, Washington, DC, 20594, adopted April 16, } 1980 .\end{array}$ \\
\hline NTSB 80 & $\begin{array}{l}\text { Analysis of Accident Data from Plastic Pipe Natural Gas Distribution Systems, } \\
\text { Special Study, National Transportation Safety Board, Washington, DC, } 19 \text { Sep } \\
1980,33 p \text {. }\end{array}$ \\
\hline Nutt 86 & $\begin{array}{l}\text { Nutt, P.C. (1986). Decision style and strategic decisions of top executives. } \\
\text { Technological Forecasting and Social Change (30), (pp.39-62). }\end{array}$ \\
\hline
\end{tabular}




\begin{tabular}{|c|c|}
\hline NVO-319 & $\begin{array}{l}\text { Report of the Investigation Board for the Unplanned Fire at the Liquetiod } \\
\text { Gaseous Fuels Spil Test Faciity on August 29, 1987, NVO-319, DE88 002214, } \\
\text { U. S. Department of Energy, October 23, 1987. }\end{array}$ \\
\hline Okumura 92 & $\begin{array}{l}\text { Okumura, Yoshita; Tanaka, Shigeyuki; Hoh, Hidetaroh and Fujitani, Takashi; } \\
\text { "Building of SPB Carriers," paper IV-4, Tenth intemational Conference on } \\
\text { Liquefied Natural Gas, Kuata Lumpur, May 25-28, 1992, Inst. of Gas Technology, } \\
\text { Chicago, } 1992 .\end{array}$ \\
\hline Oliveira 94 & $\begin{array}{l}\text { Oliveira, L.F.S., Amaral Netto, J. D., Pinto, R.A., and Lima, J.C.A., "Quantitative } \\
\text { Risk Analysis of a Butane Storage Facility," paper 048-7, PSAM-11, San Diego, } \\
\text { March 20-25, } 1994\end{array}$ \\
\hline Ong 85 & $\begin{array}{l}\text { Ong. Han, 1., "Development of LNG Facilities Safety Standards," Butrotin of the } \\
\text { Association of Engineering Geologists, Vol. XXII, No. 1, Feb. 1985, pp. 25-38. }\end{array}$ \\
\hline Opschoor 94 & $\begin{array}{l}\text { Opschoor, G., van den Berg, A.C., and Mercx, W.P.M., "Developinent and } \\
\text { Val;idation of a Vapour Cloud Explosion Blast Model," paper O37-11, PSAM-1l, } \\
\text { San Diego, March 20-25, 1994. }\end{array}$ \\
\hline Ordin 71 & $\begin{array}{l}\text { Ordin, P.M., Mishaps with Oxygen in NASA Operations, NASA TM-X-67953, } \\
\text { National Aeronautios and Space Administration, } 1971 \text {. }\end{array}$ \\
\hline Ordin 74 & $\begin{array}{l}\text { Ordin, P.M., Review of Hydrogen Accidents and Incidents in NASA } \\
\text { Operations, NASA TM-X-71565, National Aeronauties and Space Administration, } \\
\text { 1974. }\end{array}$ \\
\hline Ouchi 77 & $\begin{array}{l}\text { Ouchi, W. G. (1977). The relationship between organizational strueture and } \\
\text { organizational control. Administrative Science Quarterty (22), (pp.95-113). }\end{array}$ \\
\hline Page 89 & $\begin{array}{l}\text { Page, Norbert P., and Mehlman, Myron, "Health Effects of Gasoline Refueling } \\
\text { Vapors and Mceasured Exposures at Service Stations," Toxicology and Industrial } \\
\text { Health, Vol. 5., No. 5, 1989, pp. 869-890. }\end{array}$ \\
\hline Papazoglou 91 & $\begin{array}{l}\text { Papazoglou, I. A., Aneziris, O., Christou, M., and Nivoliantou, Z., "Probabilistic } \\
\text { Safety Analysis of an Ammonia Storage Plant," Proc. of the Inter. Conf. on } \\
\text { Prababilistic Safety Assessment and Management Feb. 47, 1991, Beverty Hills, } \\
\text { CA, pp. 233-238. }\end{array}$ \\
\hline Party 93 & $\begin{array}{l}\text { Pamy, R., Clabom, G., Haas, A., Landis, R., Page, W., and Smith, J., "A high } \\
\text { reliability oxygen monitoring system," SSCl-preprint-430, May } 1993 \text {. }\end{array}$ \\
\hline Parry 93 & $\begin{array}{l}\text { Parry, R., Clabom, G., Hass, A., Landis, R., Page, W., and Smith, J., "A High } \\
\text { Reliability Oxygen Deficiency Monitoring system, Superconducting Supercollider } \\
\text { Laboratory, Dallas, TX, May 1993, 6 p. }\end{array}$ \\
\hline Pastuhov 72 & $\begin{array}{l}\text { Pastuhov, A., The Balance Between Innovations and Risks in the LNG Industry," } \\
\text { Advances in Cryogenic Engineering, Vol. 17, K. D. Timmerhaus, ed., Plenum } \\
\text { Press, New York, 1972, pp. 69-73. }\end{array}$ \\
\hline Patty's 91 & $\begin{array}{l}\text { Patty's Industrial Hygiene and Toxicology, Fourth Edition, Vol. II, Part D, John } \\
\text { Wiley \& Sons, New York, 1991, ISBN 0-471-57947-5, pp 2588-2609. . }\end{array}$ \\
\hline Pelto 82 & $\begin{array}{l}\text { Analysis of LNG Peakshaving-Facitty Release-Prevention Systems, Pelto, P.J., } \\
\text { and E. G. Baker, Pacific Northwest Laboratory, Richland, WA, May 1982, } 144 \text { p. }\end{array}$ \\
\hline Pelto 84 & $\begin{array}{l}\text { Pelto, R. J., and Baker, E.G., "Analysis of Liquefied Natural Gas (LNG) Release } \\
\text { Prevention Systems," PNL-SA-12278, Pacific Northwest Laboratory, Richland, } \\
\text { WA, Aug 1984, } 21 \text { p. }\end{array}$ \\
\hline Pentz 95 & $\begin{array}{l}\text { Pent, Russell, "Liquified Natural Gas Experience of a Large Transit Fleet," } \\
\text { American Energy Week } 95 \text { Conference and Exhibition, Jan 31-Feb. 2, 1995, } \\
\text { Houston, TX, Book 3, Aternative Fuel Vehicies '95. }\end{array}$ \\
\hline Peschika 80 & $\begin{array}{l}\text { Peschka, W. and Carpetis, C., "Cryogenic Hydrogen Storage and Refueling for } \\
\text { Automobiles," Intemational Joumal of Hydrogen Energy, Vol 5, pp. 619-625, } \\
1980 .\end{array}$ \\
\hline Pettitt 94 & $\begin{array}{l}\text { Pettit, G. N., Harms, J. D., and Wooctward, J. L., "Post-Morten Risk Modeling of } \\
\text { the Mexico City Disaster," paper 037-17, PSAM-II, San Diego, March 20-25, 1994 }\end{array}$ \\
\hline
\end{tabular}




\begin{tabular}{|c|c|}
\hline Pfenning 82 & $\begin{array}{l}\text { Coaxial Piping System, LNG Relesse-Provention Demonstration Program, Final } \\
\text { Report Pfenning, T.E., Tatge, R. J., CV International, inc., Torrance, CA, Dec } \\
1982,169 \text { p. }\end{array}$ \\
\hline Philipson 78 & $\begin{array}{l}\text { Philipson, Lloyd L., The Operational Relability of LNG Systems," } 1541 \text { 78RMO51, } \\
\text { Proceedings } 1978 \text { Annual Reilability and Maintainabity Symposium, Los } \\
\text { Angefes, January 17-19, 1978, institute of Electrical and Electronic Engineers, } \\
\text { 1978, pp. 300-305. }\end{array}$ \\
\hline Philipson 80 & $\begin{array}{l}\text { Philipson, Lloyd L, "LNG Operations Risk Analyses: Evaluation and Comparison } \\
\text { of Techniques and Results," Synthesis and Analysis Methods for Safety and } \\
\text { Refabity Studies, G. Apostotakis, ed., Plenum Press, New York, 1980, pp. 401- } \\
\text { 407. . }\end{array}$ \\
\hline Phillips 78 & $\begin{array}{l}\text { Phillips, Carolyn F., and Jones, Robert K, "Gasoline vapor exposure during bulk } \\
\text { handling operations," An. Ind., Hyg. Assoc. J., (39) Feb 1978, pp. 118-128. }\end{array}$ \\
\hline Piattelli 91 & $\begin{array}{l}\text { Piattelli-Palmarini, Massimo; "Probability: Neither Rational nor Capricious," } \\
\text { Bostonia, March/April 1991, pp. 28-35. }\end{array}$ \\
\hline Piquette 86 & $\begin{array}{l}\text { Piquette, R., Lawson, A., Ha, K, Simmons, E.W., and Battista, V., "Safely } \\
\text { Aspects of the Use of Alcohol Fuels in Road Vehicles," Tth Inter. Symp. on } \\
\text { Alcohol Fugls, Paris, Oct. 20, 1986, pp. 415-419. }\end{array}$ \\
\hline Plaxton 95 & $\begin{array}{l}\text { Plaxton, B. G. (1995). Profile and Segmentation of Medium and Heavy Vehicle } \\
\text { Purchase Patterns and Current and Projected Poputations. GRI-95/0025. } \\
\text { Chicago: Gas Research institute. }\end{array}$ \\
\hline Pohl 95 & $\begin{array}{l}\text { Hydrogen and Other Altemative Fuels for Air and Ground Transportation, H.W. } \\
\text { Pohl, ed., John Wiley and Sons, New York, } 1995 \text {. }\end{array}$ \\
\hline Popp 97 & $\begin{array}{l}\text { Popp, } P_{\text {., and Baum, M., "Anahysis of Wall Heat Fluxes, Reaction Mechanisms, }} \\
\text { andUnbernt Hydrocarbons during the Head-on Quenching of a Laminar Methane } \\
\text { Flame," Combustion and Flame, Vol. 108, pp } 327348,1997 \text {. }\end{array}$ \\
\hline Port 96 & $\begin{array}{l}\text { Port, David, "Northem Lights, Bright Prospects for Natural Gas Vehicles in } \\
\text { Canada," Natural Gas Fuets, pp. 16-21, Narch } 1996 .\end{array}$ \\
\hline Pratt 96 & $\begin{array}{l}\text { Pratt, Thomas H., and Atharton, John G., "Some Electrostatic Considerations in } \\
\text { the Transportation of Flammable Liquids," Process Safety Progress, Vol. 15, No. } \\
\text { 3, Fall 1996, pp. } 173-177 \text {. }\end{array}$ \\
\hline Prihandoko 92 & $\begin{array}{l}\text { Prihandoko, Tursilo; and Sudadjad, Achmad Iman, "Environmental Control and } \\
\text { Safety Achievement in Arun NGL Co.," paper IV-2, Tenth International Conference } \\
\text { on Liquefied Natural Gas, Kuala Lumpur, May 25-28, 1992, Inst. of Gas } \\
\text { Technology, Chicago, 1992. }\end{array}$ \\
\hline Prugh 85 & $\begin{array}{l}\text { Prugh, Richard, "Mitigation of Vapor Cloud Hazards," PlantOperations Progress, } \\
\text { Vol 4, No. 2, April 1985, pp. 95-103. }\end{array}$ \\
\hline Prugh 86 & $\begin{array}{l}\text { Prugh, Richard, "Mitigation of Vapor Cloud Hazards," Planto perations Progress, } \\
\text { Vol 5, No. 3, July 1986, pp. } 169-174 .\end{array}$ \\
\hline Prugh 94 & $\begin{array}{l}\text { Prugh, Richard W., "Quantitative Evaluation of Fireball Hazards," Process Safety } \\
\text { Progress, Vol. 13, No. 2, April 1994, pp. 83-91. }\end{array}$ \\
\hline Puttock 82 & $\begin{array}{l}\text { Puttock, J. S., Blackmore, D. R., and Colenbrander, G.W., "Field Experiments on } \\
\text { Dense Gas Dispersion," Joumal of Hazardous Materials, } 6 \text { (1982) 13-41. }\end{array}$ \\
\hline Raj 75 & $\begin{array}{l}\text { Raj, P., and Atallah, S., "Thermal Radiation from LNG Spill Fires," in Advances in } \\
\text { Cryogenic Engineering, Vol 20, K D. Timmertaus, ed., Plenum Press, New York, } \\
\text { 1975, pp. 143-150. }\end{array}$ \\
\hline Rao 88 & $\begin{array}{l}\text { Rao, A. R., and Monroe, K. B. (1988). The moderating effect of prior knowiedge } \\
\text { on cue utilization in product evaluations. Joumal of Consumer Research (15), } \\
\text { (pp.253-264). }\end{array}$ \\
\hline Rasmussen 95 & $\begin{array}{l}\text { Rasmussen, Kirsten, "Natural events and accidents with hazardous materials," } \\
\text { Joumal of Hazardous Materials, Vol 40, pp 43-54, } 1995 .\end{array}$ \\
\hline Reece 97 & $\begin{array}{l}\text { Reece, Wendy J., "Perceptions and Acceptance of LNG," LDRD Report, Idaho } \\
\text { National Engineering Laboratory, Feb. } 1997 .\end{array}$ \\
\hline Reymolds 79 & $\begin{array}{l}\text { Reynolds, William C., Thermodynamic Properties in SI, Department of } \\
\text { Mechanical Engineering, Stanford University, Stanford, CA, } 1979\end{array}$ \\
\hline
\end{tabular}




\begin{tabular}{|c|c|}
\hline Rhoads 78 & $\begin{array}{l}\text { Rhoads, R. E. (Proj. coord.), "An Assessment of the Risk of Transporting } \\
\text { Gasoline by Truck," PNL-2133, Pacific Northwest Laboratory, Nov. } 1978 .\end{array}$ \\
\hline Rice 96 & Natura/ Gas Bus Firo, RER-02-96, letter from R. E Rice, Jan. 5, 1996, \\
\hline Rabinson 84 & $\begin{array}{l}\text { Robinson, C., and Smith, D. B., "The Auto-Ignition Temperature of Methane," } \\
\text { Joumal of Hazardous Materiats } 8 \text { (1984) 199-203. }\end{array}$ \\
\hline Rodean 84 & $\begin{array}{l}\text { Rodean, H. C. and Hogan, W. J., Vapor Bum Analysis for the Coyote Series } \\
\text { LNG Spill Experiments," Lawrence Livernore National Laboratory, April 1984. }\end{array}$ \\
\hline Roe 90 & $\begin{array}{l}\text { Roe, D. R., and Roberts, P., "Application of Hazard and Risk Assessment } \\
\text { Techniques in Demonstrating the Safety of LNG Terminats," EUROGAS "90: } \\
\text { European applied research conference on natural gas, Trondheim, Norway, May } \\
28-30,1990 \text {, pp. 623-640. }\end{array}$ \\
\hline Roll 86 & $\begin{array}{l}\text { Roll, R. (1986). The Hubris hypothesis of corporate takeovers. Joumal of } \\
\text { Business (59), (pp.197-216). }\end{array}$ \\
\hline Rowe 77 & Rowe, W. D. (1977). An Anatomy of Risk. New York. Wiley. \\
\hline SAE J1616 & $\begin{array}{l}\text { Society of Automotive Engineers, "Recommended Practice for Compressed } \\
\text { Natural Gas Vehicle Fuel," SAE J1616 Febs4. }\end{array}$ \\
\hline SAE J2343 & $\begin{array}{l}\text { Recommended Practices for LNG Powered Heavy Duty Trucks," Society of } \\
\text { Automotive Engineers, } 1997 .\end{array}$ \\
\hline SAE $\sqrt{312}$ & $\begin{array}{l}\text { "Automotive Gasolines," SAE Recommended Practice SAE J312 Jan 93, Society } \\
\text { of Automotive Engineers, Jan. } 1993 \text {. }\end{array}$ \\
\hline SAE $J 313$ & $\begin{array}{l}\text { "Diesel Fuels," SAE Recommended Practice SAE J313 Mar 92, Society of } \\
\text { Automotive Engineers, Mar. } 1992 .\end{array}$ \\
\hline SAI 75 & $\begin{array}{l}\text { LNG Teminal Risk Assessment Study for Los Angeles, Calfomia, Science } \\
\text { Applications, inc, LaJolla, CA, } 22 \text { Dec } 1975 .\end{array}$ \\
\hline Santodonato 85 & $\begin{array}{l}\text { Santodonato, J., Monograph on Human Exposure to Chemicats in the } \\
\text { Workplace: Gasoline (Final Report), SRC-TR-84-1041, Syracuse Research } \\
\text { Corp., NY, Center for Chemical Hazard Assessment, July 85, } 35 \text { p. }\end{array}$ \\
\hline Sarsten 72 & $\begin{array}{l}\text { Sarsten, J. A., "LNG Stratification and Rollover," Pipeline and Gas Joumal, } \\
\text { September 1972, pp. } 37-39 .\end{array}$ \\
\hline Schaedel 97 & $\begin{array}{l}\text { Schaedel, Scott V., Richards, Mark, and Liss, Wriliam E., "Natural Gas } \\
\text { Composition, Part IV: Higher Hydrocarbons," Natural Gas Fuels, February 1997, } \\
\text { pp. 18-19. }\end{array}$ \\
\hline Schein 85 & $\begin{array}{l}\text { Schein, E. H. (1985). Organizational Culture and Leadership. San Francisco: } \\
\text { Jossey-Bass. }\end{array}$ \\
\hline Schneider 80 & $\begin{array}{l}\text { Schneider, A. L, "Liquefied Natural Gas Safety Research," Cryogenic Processes } \\
\text { and Equipment in Energy Systems, Cryogenic Processes and Equipment } \\
\text { Conference, San Francisco, August 19-21, 1980, pp. 77-82. }\end{array}$ \\
\hline Schutz 74 & $\begin{array}{l}\text { Schutz, F. P., "Safety of an LNG Peakshaving Facility," 74WAMPID-10, ASME } \\
\text { Winter Annual Meeting, Nov. 17-22, 1974. }\end{array}$ \\
\hline Schwing 80 & $\begin{array}{l}\text { Schwing, R., and Albers, W. (Eds.) (1980). Societal Risk Assessment, How Safe } \\
\text { is Safe Enough? NY: Plenum Press. }\end{array}$ \\
\hline Seroka 70 & $\begin{array}{l}\text { Seroka, Stanley, and Bolan, Robert J., "Safety considerations in the installation of } \\
\text { an LNG tank," Cryogenios and Industrial Gases, Vol. 5, September/October } \\
\text { 1970, pp. 22-27. }\end{array}$ \\
\hline Sfinteanu 96 & $\begin{array}{l}\text { Dragos Sfinteanu, "The Efficiency Equation for Small Liquefiers," Natural Gas } \\
\text { Fuels, Apri 1996, p. 28-29. }\end{array}$ \\
\hline Shaaban 89 & $\begin{array}{l}\text { Shaaban, S. H., Zuzovsky, M., and Anigstein, R., Safoty analysis of natural gas } \\
\text { vehictes transiting highway tunnel, NYSERDA-90-2, Ebasco Services, Inc., New } \\
\text { York, 1989, } 183 \text { p. }\end{array}$ \\
\hline Shah 74 & $\begin{array}{l}\text { Shah, J. M., and Aarts, J. J., "Effect of Weathering of LNG in Storage Tanks, " in } \\
\text { Advances in Cryogenic Engineering, Vol 19, K. D. Timmerhaus, ed., Plenum } \\
\text { Press, New York, 1974, pp. 253-260. }\end{array}$ \\
\hline Shebeko 96 & $\begin{array}{l}\text { Shebeko, Yu. N.; Shevchuck, A. P.; and I. M. Smolin, "BLEVE prevention using } \\
\text { vent devices," Joumal of Hazardous Materials, Vol. 50, pp. 227-238, 1996. }\end{array}$ \\
\hline
\end{tabular}




\begin{tabular}{|c|c|}
\hline Shenlde 76 & $\begin{array}{l}\text { Shenke, Willam H., "Some pointers on choosing equipment for lnplant Gas } \\
\text { Metering," Plant Engineering, Vol. 30, June 24, 1976, pp. 103-105. }\end{array}$ \\
\hline Simmons 742 & $\begin{array}{l}\text { Simmons, J. A., Erdmann, R.C., Naft, B. N., "Risk of Catastrophic Spills of Toxic } \\
\text { Chemical," UCLA-ENG-7425, UCLA School of Engineering and Applied Science, } \\
\text { May 1974. }\end{array}$ \\
\hline Simmons $74 b$ & $\begin{array}{l}\text { Risk Assessment of Storage and Transport of Liquefied Natural Gas and LP. } \\
\text { Gas, John A. Simmons, Science Applications Inc., McLean VA, EPA } 520375 \\
\text { 015, EPA 68-01 2695, } 25 \text { Nov } 7488 \text { p. }\end{array}$ \\
\hline Singh 85 & $\begin{array}{l}\text { Singh, M. K, and Moses, D. O., "Environmental Concerns Related to Natural Gas } \\
\text { Vehicles," CONF-8504127-1, Argonne National Laboratory, IL, 1985, 26 p. }\end{array}$ \\
\hline Singh 86 & $\begin{array}{l}\text { Singh, J. (1986). Perfomance, stack, and risk taling in organizational decision } \\
\text { making. Academy of Management Joumal (29), (pp.562-585). }\end{array}$ \\
\hline Sitkin 92 & $\begin{array}{l}\text { Sithin, S. B., and Pabio A. L (1992). Reconceptualizing the Determinants of Risk } \\
\text { Behavior. Academy of Management Review }(17,1) \text {, (pp.938). }\end{array}$ \\
\hline Slade 68 & $\begin{array}{l}\text { Stade, David H., (ed), Meteorology and Atomic Energy, U.S. Atomic Energy } \\
\text { Commission, Division of Technical Information. Washington, DC, } 1968\end{array}$ \\
\hline Slater 78 & $\begin{array}{l}\text { Slater, David H., "Vapour clouds," Chemistry and industry, } 6 \text { May 1978, pp. 295- } \\
\text { 302. }\end{array}$ \\
\hline Slovic 72 & $\begin{array}{l}\text { Slovic, P. (1972). Information processing, situation speciticity, and generality of } \\
\text { risk-taking behabior. Journal of Personality and Social Psychoiogy (22), (pp.128- } \\
\text { 134). }\end{array}$ \\
\hline Slovic 80 & $\begin{array}{l}\text { Slovic, P., Fischhoff, B., and Lichtenstein, S. (1980). Facts versus fears: } \\
\text { Understanding perceived risk. in D. Kahneman, P. Slovic and A. Tversky (Eds.) } \\
\text { Judgment under uncertainty. Heuristics and biases (pp.463-4a9). Cambridge: } \\
\text { Cambridge University }\end{array}$ \\
\hline Slovic 82 & $\begin{array}{l}\text { Stovic, Paul; Fisychoff, Baruch; and Lichtenstein, Sarah; "Why StudyRisk } \\
\text { Perception," Risk Analysis, Vol. 2, No. 2, 1982, pp. 83-93. }\end{array}$ \\
\hline Smith 75 & $\begin{array}{l}\text { Smith, K A., Lewis, J. P, Randall, G. A., and Meldon, J. H., "Mixing and roll-over } \\
\text { in LNG Storage Tanks," in Advances in Cryogenic Engineening, Vol 20, K D. } \\
\text { Timmerhaus, ed., Plenum Press, New York, 1975, pP. 124133. }\end{array}$ \\
\hline Smith 77 & $\begin{array}{l}\text { Smith, C. W. (1977). Differences in Hemispheric Processing of Emotional } \\
\text { Words. Ph.D. disertation, Georgia State University. }\end{array}$ \\
\hline Soeryanto 92 & $\begin{array}{l}\text { Soeryanto, Joko; and Triyatno, A.; "Availability and Capacity Improvement of the } \\
\text { Arun LNG Plant," paper II-1, Tenth Intemational Conference on Liquefied Natural } \\
\text { Gas, Kuala Lumpur, May 25-28, 1992, Inst. of Gas Technology, Chicago, 1992. }\end{array}$ \\
\hline Springmann 86 & $\begin{array}{l}\text { Springmann, Helmut, "The Economical and Technical Aspects of Cryogenic } \\
\text { Plants," in Cryogenic Properties, Process and Applications 1986, AlCHe, 251, } \\
\text { Vol 82, 1986, pp160-165. }\end{array}$ \\
\hline Squire 91 & $\begin{array}{l}\text { Squire, R. H., "An Ammonia Storage Tank Study," Plant/Operations Progress, } \\
\text { Vol. 10, No. 4, October 1991, pp. 212-220. }\end{array}$ \\
\hline Stanek 93 & $\begin{array}{l}\text { Stanek, R., and Kimer, J., "Evolution of cryogenic safety at Fermilab," } \\
\text { Cryogenics, Vol 33, No 8, pp 809-812, } 1993 \text {. }\end{array}$ \\
\hline Staw 81 & $\begin{array}{l}\text { Staw, B. M., Sandelands, L. E., and Dutton, J. E. (1981). Threat-rigidity effects in } \\
\text { organizational behavior: A multilevel analysis. Administrative Science Quarterly } \\
\text { (26), (pp.501-524). }\end{array}$ \\
\hline Staw 87 & $\begin{array}{l}\text { Staw, B. M., and Ross, J. (1987). Behavior in escalation situations: Antecedents, } \\
\text { prototypes, and solutions. in B. M. Staw and L. L. Cummings (Eds.) Research in } \\
\text { Organizational behavior (9). (pp.39-78). Greenwich, CT: JAI Press. }\end{array}$ \\
\hline Stewart 75 & $\begin{array}{l}\text { Stewart, W. F., Edeskuty, F. J., and Wullamison, K. D., "Operating Experience } \\
\text { with a Liquid Hydrogen fueled Vehicle," in Advances in Cryogenic Engineering, } \\
\text { Vol 20, K D. Timmernaus, ed., Plenum Press, New York, 1975, pp. 82-89. }\end{array}$ \\
\hline Stewart 82 & $\begin{array}{l}\text { Stewart, W. F., Operating Experience with a Liquid Hydrogen Fueled Buick and } \\
\text { Refueling System, LA-UR-82-428, Los Alamos National Laboratory, NM, 1982, } 42 \\
\text { p. }\end{array}$ \\
\hline
\end{tabular}




\begin{tabular}{|c|c|}
\hline Stewart 84 & $\begin{array}{l}\text { Stewart, W. F, "Refueling Considerations for Liquid-Hydrogen Fueled Vehicies," } \\
\text { LA-UR-84-1490, Los almos National Laboratory, NM, 1984, 32 p. }\end{array}$ \\
\hline Stewart 90 & $\begin{array}{l}\text { Stewart, A. M., and M. Van Aerde, "An Empirical Analysis of Carnadian Gasoline } \\
\text { and LPG Truck Releases," Joumal of Hazardous Materials, } 25 \text { (1990) 205-217. }\end{array}$ \\
\hline Stinton 83 & $\begin{array}{l}\text { Stinton, H. G., "Spanish Camp Site Disaster," Joumal of Hazardous Matoriaks } 7 \\
\text { (1983) } 393-401 .\end{array}$ \\
\hline Stoner 68 & $\begin{array}{l}\text { Stoner, J. (1968). Risky and cautions shifts in group decisions. Journal of } \\
\text { Experimental and Social Psychology (4), (pp.442-459). }\end{array}$ \\
\hline Studer 88 & $\begin{array}{l}\text { Studer, D.W., Cooper, B. A., and Doelp. L. C., "Vaporization and Dispersion } \\
\text { Modeling of Contained Refirigerated Liquid Spills," Plantioperations Progress, } \\
\text { Vol. 7, No. 2, April 1988, pp. 127-135. }\end{array}$ \\
\hline Sugawara 84 & $\begin{array}{l}\text { Sugawara, Y., Kubota, A., and Murak, S., "Rollover Test in LNG Storage Tank } \\
\text { and Simulation Model," in Advances in Cyyogenic Engineering, Vol 29, R. W. } \\
\text { Fast, Ed., Plenum Press, New York, 1984, pp. 804811. }\end{array}$ \\
\hline Summertin 85 & $\begin{array}{l}\text { Summerlin, John, Jr., and Prichard, Howard M., "Radiological Health Implications } \\
\text { of Lead-210 and Polonium } 210 \text { Aceumulations in LPG Refineries," Am. Ind. Hyg. } \\
\text { Assoc. J. 46(4):2102-205 (1985). }\end{array}$ \\
\hline Taniyama 86 & $\begin{array}{l}\text { Taniyama, Yoshio and Maruyama, Takashi, "Design and Construction of a } \\
\text { 140,000 Cubic Metre LNG Inground Storage Tank," in Advances in Cryogenic } \\
\text { Engineering, Vol 31, R. W. Fast, ed., Plenum Press, New York, 1986, Pp. 1121- } \\
1128 .\end{array}$ \\
\hline Tanudjaja 92 & $\begin{array}{l}\text { Tanudjaja, R., and Lanquetin, B., "Heel Management of LNG Carriers of the New } \\
\text { Generation," paper IV-5, Tenth International Conference on Liquefied Natural Gas, } \\
\text { Kuala Lumpur, May 25-28, 1992, Inst. of Gas Technology, Chicago, } 1992 .\end{array}$ \\
\hline Tarakad 81 & $\begin{array}{l}\text { Tarakad, R. R., Durr, C. A., and Crawford, D. B., "Condensation in the Annulus of } \\
\text { a Double-walled Cryogenic Storage Tank," Advances in Cryogenic Engineering, } \\
\text { Vol. 27, R. W. Fast, ed., Plenum Press, New York, 1981, pp. 945-952. }\end{array}$ \\
\hline Theodore 89 & $\begin{array}{l}\text { Theodore, Louis; Reynolds, Joseph P.; and Taylor, Francis B., Accident \& } \\
\text { Emergency Management, John Wiley and Sons, New York, } 1989 .\end{array}$ \\
\hline Thomas 96 & $\begin{array}{l}\text { Thomas, Theodore } A \text {., INEL, private communication concerning design of INEL } \\
\text { bus maintenance facility, October } 17,1996 \text {. }\end{array}$ \\
\hline Thornson 87 & $\begin{array}{l}\text { Thomson, J. R., EngineeringSafety Assessment, An Introduction, Chapter 5, } \\
\text { Major Industrial Hazards, Longman Scientific and Technical, London, } 1987 .\end{array}$ \\
\hline Timmerhaus 77 & $\begin{array}{l}\text { Timmerhaus, K D., and Flynn, T. M., "Safety with Cryogenic Systems," } \\
\text { Advances in Cryogenic Engineering, Vol. 23, K D. Timmerhaus, ed., Plenum } \\
\text { Press, New York, 1977, pp. 721-729. }\end{array}$ \\
\hline Total 95 & $\begin{array}{l}\text { Hazard Anahysis of compressed Natgural Gas Fueling systems and Fueling } \\
\text { Procedures used at Retall Gasoline Service Stations, Final Report, GRI- } \\
\text { 95/0219, PB95-237079, Total Petroleum, Inc., Denver, CO, } 28 \text { Aug 95, 156 p. }\end{array}$ \\
\hline Total 95 & $\begin{array}{l}\text { Hazard Anatysis of Compressed Natural Gas Fueling Systems and Fueling } \\
\text { Procedures used at Retal Gasoline Service Stations, Final Report, GRI-9510219, } \\
\text { Total Petroieum, inc., Denver CO, } 28 \mathrm{Apr} \text { S5, } 156 \text { p. }\end{array}$ \\
\hline Trammell 82 & $\begin{array}{l}\text { Trammell J. H., and La Fave, I. V., "Large-Seale Cryogenic Liquid Storage," in } \\
\text { Advances in Cryogenic Engineering, Vol 27, Plenum Press, New York, 1982, pp. } \\
929-935 .\end{array}$ \\
\hline Trbojevic 89 & $\begin{array}{l}\text { Trbojevic, Vadimir M. and Slater, David H., Tank Failure Modes and Their } \\
\text { Consequences," PlantOperations Progress, Vol. 8, No. 2, April 1989, pp. 84-87. }\end{array}$ \\
\hline UL 1238 & $\begin{array}{l}\text { Control Equipment for Use with Flammable Liquid Dispensing Devices, UL 1238, } \\
\text { Underwriters Laboratories, Inc., 8/28/75 +errata } 9 / 20 / 78+\text { rev. 5/9/85 + bulletin } \\
4 / 7 / 94+\text { rev. 12/28/94. }\end{array}$ \\
\hline
\end{tabular}




\begin{tabular}{|c|c|}
\hline UL 25 & $\begin{array}{l}\text { Moters for Flammable and Combustible Liquids and LP-Gas, UL 25, Sidh } \\
\text { Edition, } 95 / 90+\text { rev. } 9 / 2490+\text { rev. 3/8/93 + buttetin } 6 / 25 / 93+\text { bulfetin } 3 / 4 / 94 \text {. }\end{array}$ \\
\hline UL 87 & $\begin{array}{l}\text { Power-Operated Dispensing Devices for Petroleum Products, UL 87, Tenth } \\
\text { Edition, Underwriters Laboratories, Inc., } 333 \text { Plingsten Road, Northbrook, IL } \\
60052 \text {, 10/2495 + Rev 3/696, 321/96, 411/96. }\end{array}$ \\
\hline UL 330 & $\begin{array}{l}\text { Gasoline Hose, UL 330, Standard for Safety, Underwiters Laboratories, Inc., } 333 \\
\text { Pfingsten Road, Northbrook, IL, 60062, 8/21/78 + Rev 2/20/84, 10/20/93. }\end{array}$ \\
\hline UL 395 & $\begin{array}{l}\text { Standard for Automotive Fuel Tanks, UL 395, Fith Edition, Underwriters } \\
\text { Laboratory, March } 29,1993 .\end{array}$ \\
\hline UL 935 & $\begin{array}{l}\text { Underwiters Laboratories, Inc., "Standard for Fluorescent-Lamp Ballasts, Ninth } \\
\text { Edition," UL 935, March 24, } 1995 \text { + Appendix A, Nov. 20, 1995.. }\end{array}$ \\
\hline USDOT 97 & $\begin{array}{l}\text { U.S. Dept of Transportation, Hazardous Materials Information System, search of } \\
\text { LNG, LPG and other gaseous hazmat incidents, 1971-1996, January 28, } 1997 \text {. }\end{array}$ \\
\hline USDOT 97 sum & $\begin{array}{l}\text { U.S. Dept of Transportation, Hazardous Materials Information Systern, search of } \\
\text { LNG, LPG and other gaseous hazmat incidents, 1971-1996, January 27, } 1997 . \\
\text { summary of incidents }\end{array}$ \\
\hline Van Meerbeke 82 & $\begin{array}{l}\text { Van Meerbeke, R. C., "Accident At the Cove Point LNG Facility, " Chemical } \\
\text { Engineering Progress, January 1982, pp. 39-45. }\end{array}$ \\
\hline Van Wingerden 95 & $\begin{array}{l}\text { Van Wingerden, Kees; Salvesen, Hans-Christen; and Perbal, Roald, "Simulation } \\
\text { of an Accidental Vapor Cloud Explosion," Process Safety Progress, Vol 14, No. } \\
\text { 3, July 1995, pp. 173-181. }\end{array}$ \\
\hline Verma 92 & $\begin{array}{l}\text { Verma, Dave K, Julian, Jim A., et. al. "Hydrocarbon Exposures at Petroleum Bulk } \\
\text { Terminals and Agencies," Am. Ind. Hyg. Assoc. J., Vol. 53, No 10, Pp. 645-656, } \\
\text { October } 1992 .\end{array}$ \\
\hline Vek 80 & $\begin{array}{l}\text { Vek, C., and Stallen, P. J. (1980). Rational and personal aspects of risk. Acta } \\
\text { Psychologica (45), (pp.273-300). }\end{array}$ \\
\hline Walker 92 & $\begin{array}{l}\text { Walker, Graham, "Gas-Fired Stirling-Stirling Natural Gas Liquefier for Automotive } \\
\text { Fuel," poster paper 14, Tenth International Conference on Liquefied Natural Gas, } \\
\text { Kuala Lumpur, May 25-28, 1992, Inst. of Gas Technology, Chicago, } 1992 .\end{array}$ \\
\hline Wang 96 & $\begin{array}{l}\text { M. Q. Wang, "GREET 1.0 - Transportation Fuel Cycles Model: Methodology and } \\
\text { Use, ANLESD-33, June 1996. }\end{array}$ \\
\hline Ward 71 & $\begin{array}{l}\text { Ward, D. E., "Liquefied Natural Gas - LNG its Uses, Production and Handling," } \\
\text { pp. } 455-491 \text { new S/9in Advancod Cryogenics, Editied by C. A. Bailey, Plenum } \\
\text { Press, London, } 1971 .\end{array}$ \\
\hline Weirick 94 & $\begin{array}{l}\text { Weirick, M. L., Farquhar, S. M., and Chismar, B. P., "Spill containment and } \\
\text { Destruction of a Reactive, Volatile Chemical," Process Safety Progress, Vol. 13, } \\
\text { No. 2, April 1994, pp. 69-71. }\end{array}$ \\
\hline Welker 79 & $\begin{array}{l}\text { Welker, J. Reed and Schorr, H. Peter, "LNG Plant Experience Data Base," } \\
\text { American Gas Association Transmission Conference, New Orleans, LA, May 21- } \\
23,1979 \text {, pp. T-263 to T-266. }\end{array}$ \\
\hline Wesson ?? & $\begin{array}{l}\text { Wesson, H. R., Welker, J. R., and Brown, L. E., "Control LNG-spill fires," Fire } \\
\text { Proection and Safety?? }\end{array}$ \\
\hline Wesson 75 & $\begin{array}{l}\text { Wesson, H. R., Welker, J. R., and Brown L.E., "Control of LNG Spill fires on } \\
\text { Land," in Advances in Cryogenic Engineering, Vol 20, K D. Timmerhaus, ed., } \\
\text { Plenum Press, New York, 1975, pp. 151-163. }\end{array}$ \\
\hline West 79 & $\begin{array}{l}\text { West, H. H., Pfenning, D. B., and Brown, L. E., "A Systems Approach to LNG Fire } \\
\text { Safety," GASTECH 79 - Meeting on Liguefied Natural Gas and Liquefied } \\
\text { Petroleum Gas (LNGAPG), Houston, Nov. 13, 1979, paper 2, sess 4, pub. } \\
\text { Gastech, Ltd, Rickmansworth, UK. }\end{array}$ \\
\hline Whitney 92 & $\begin{array}{l}\text { Whithey, M. G., Barker, D. D., and Spivey, K. H., "Ultimate Capacity of Blast } \\
\text { Loaded Structures Common to Chemical Plants," Plant Operations Progress, Vol } \\
11, \text { No. 4, October 1992, pp. 205-212. }\end{array}$ \\
\hline
\end{tabular}




\begin{tabular}{|c|c|}
\hline Wiekema $84 a$ & $\begin{array}{l}\text { Wiekema, B. J., "Vapour Cloud Explosions - An Anatysis Based on Accidents, } \\
\text { Part I," Joumal of Hazardous Materiaks, Vol. 8, pp. 295-311, } 1984 .\end{array}$ \\
\hline Wiekema 84b & $\begin{array}{l}\text { Wiekema, 8. J., "Vapour Cloud Explosions - An Analysis Based on Accidents, } \\
\text { Part II," Joumal of Hazardous Materials, Vol. 8, pp. 313-329, } 1984 .\end{array}$ \\
\hline Williams 92 & $\begin{array}{l}\text { Williams, Ted A., and Wiersma, Steve J., "PC Computer Programs for LNG } \\
\text { Safety Analysis," poster 16, Tenth international Conference on Liquefied Natural } \\
\text { Gas, Kuala Lumpur, May 25-28, 1992, Inst. of Gas Technology, Chicago, } 1992 .\end{array}$ \\
\hline Wiltamson $83 a$ & $\begin{array}{l}\text { Liguid Cyogens, Volume I, Theory and Equipment, K D. Williamson, Jr. and } \\
\text { Frederick J. Edeskaty, editors, CRC Press, Boca Raton, } 1983 \text {. }\end{array}$ \\
\hline Willamson $83 b$ & $\begin{array}{l}\text { Liquid Cryogens, Volume II, Properties and Appifications, K D. Williamson, Jr. } \\
\text { and Frederick J. Edeskuty, editors, CRC Press, Boca Raton, } 1983 .\end{array}$ \\
\hline Woodward 89 & $\begin{array}{l}\text { Woodward, Paul W. and shay, Johanna Y., "U.S. Nayy Mobility Fuets: Workdwide } \\
\text { Survey and Analysis of Both Commercial and Navy Fuets," NIPER-428, National } \\
\text { Institute for Petroleum and Energy Research, Bartlesville, OK, July } 1989 .\end{array}$ \\
\hline Worniak 77 & $\begin{array}{l}\text { Wozniak, R. S., Salmon, M. and Huang, W., "Aboveground Concrete Secondary } \\
\text { Containment for LNG," in Advances in Cryogenic Engineering, Vo/ 22, K D. } \\
\text { Timmerhaus, R. P. Reed and A. F. Clark, ed., Plenum Press, New York, 1977, pp. } \\
512-525 \text {. }\end{array}$ \\
\hline Zabetakis 67 & $\begin{array}{l}\text { Zabetakis, Michael G., Safety with Cryogenic Flujds, Plenum Press, New York, } \\
\text { 1957. }\end{array}$ \\
\hline Zuber 76 & $\begin{array}{l}\text { Kenneth Zuber, "LNG Facilities, Engineered Fire Protection Systems," Fire } \\
\text { Technology, Vol. 12, pp. 41-48, } 1976 .\end{array}$ \\
\hline
\end{tabular}

